\title{
Modest expectations : causes and effects of migration on migrant households in source countries
}

Citation for published version (APA):

Hagen-Zanker, J. S. (2010). Modest expectations : causes and effects of migration on migrant households in source countries. [Doctoral Thesis, Maastricht University]. Boekenplan. https://doi.org/10.26481/dis.20100312jh

Document status and date:

Published: 01/01/2010

DOI:

10.26481/dis.20100312jh

Document Version:

Publisher's PDF, also known as Version of record

\section{Please check the document version of this publication:}

- A submitted manuscript is the version of the article upon submission and before peer-review. There can be important differences between the submitted version and the official published version of record.

People interested in the research are advised to contact the author for the final version of the publication, or visit the DOI to the publisher's website.

- The final author version and the galley proof are versions of the publication after peer review.

- The final published version features the final layout of the paper including the volume, issue and page numbers.

Link to publication

\footnotetext{
General rights rights.

- You may freely distribute the URL identifying the publication in the public portal. please follow below link for the End User Agreement:

www.umlib.nl/taverne-license

Take down policy

If you believe that this document breaches copyright please contact us at:

repository@maastrichtuniversity.nl

providing details and we will investigate your claim.
}

Copyright and moral rights for the publications made accessible in the public portal are retained by the authors and/or other copyright owners and it is a condition of accessing publications that users recognise and abide by the legal requirements associated with these

- Users may download and print one copy of any publication from the public portal for the purpose of private study or research.

- You may not further distribute the material or use it for any profit-making activity or commercial gain

If the publication is distributed under the terms of Article $25 \mathrm{fa}$ of the Dutch Copyright Act, indicated by the "Taverne" license above, 


\section{Modest expectations \\ Causes and effects of migration on migrant households in source countries}


(C) Jessica Hagen-Zanker, 2010

All rights reserved. No part of this publication may be reproduced, stored in a retrieval system, or transmitted in any form, or by any means, electronic, mechanical, photocopying, recording or otherwise, without the prior permission in writing, from the author.

ISBN 9789086661282

Cover picture by Jessica Hagen-Zanker (Tirana, Albania)

Published by Boekenplan, Maastricht, The Netherlands 
Modest expectations

Causes and effects of migration on migrant households in source countries

\section{DISSERTATION}

to obtain the degree of Doctor at the Maastricht University, on the authority of the Rector Magnificus, Prof. dr. G.P.M.F. Mols, in accordance with the decision of the Board of Deans, to be defended in public on 12 March 2010, at 10:00 hours

by Jessica Sabine Hagen-Zanker 
Supervisor:

Co-supervisors:

Assessment Committee: Prof. Dr. Hans Heijke (chairman)

Dr. Hein de Haas, University of Oxford

Dr. Talip Kilic, World Bank

Prof. Dr. Joan Muysken

Prof. Dr. Hildegard Schneider 


\section{Acknowledgments}

The work in this thesis is based on several papers that were published or are in the process of being published as journal articles, working papers and conference papers. The table below gives an overview of the main sources for each chapter. I would like to express my gratitude to the co-authors, conference-organizers, reviewers and discussants for making these publications and this dissertation possible.

\begin{tabular}{|c|c|}
\hline Chapter & Main sources \\
\hline 2 & $\begin{array}{l}\text { Hagen-Zanker, Jessica (2008) Why do people migrate? A review of the theoretical } \\
\text { literature, MGSoG Working paper 2008/002, Maastricht }\end{array}$ \\
\hline 3 & $\begin{array}{l}\text { Hagen-Zanker, Jessica and Siegel, Melissa (2007) The determinants of remittances: A } \\
\text { review of the literature, MGSOG Working paper 2007/003 }\end{array}$ \\
\hline \multirow{2}{*}{4} & $\begin{array}{l}\text { Hagen-Zanker, Jessica and Siegel, Melissa (2007) A critical discussion of the motivations to } \\
\text { remit in Albania and Moldova, MGSoG Working paper 2007/007 }\end{array}$ \\
\hline & $\begin{array}{l}\text { Hagen-Zanker, Jessica, Siegel, Melissa and De Neubourg Chris (2009) Strings attached. The } \\
\text { impediments to migration, Southeast European and Black Sea Studies, } 9(4)\end{array}$ \\
\hline 5 & $\begin{array}{l}\text { Hagen-Zanker, Jessica and Azzarri, Carlo (2008) Are internal migrants in Albania leaving } \\
\text { for the better?, Published in conference proceedings of International Conference on } \\
\text { Environment, Forced Migration and Social Vulnerability, October 2008, Bonn, Germany } \\
\text { and upcoming in Eastern European Economics }\end{array}$ \\
\hline 6 & $\begin{array}{l}\text { Tomini, Florian and Hagen-Zanker, Jessica (2009) How has internal migration in Albania } \\
\text { affected transfers amongst kinship members?, MGSoG Working paper 2009/013 }\end{array}$ \\
\hline
\end{tabular}





\section{Preface}

Many people contributed to this thesis, directly as supervisors, co-authors and colleagues or indirectly as friends and family. I am grateful for all their support.

First of all, I would like to thank Chris de Neubourg, You created the school, together with Annemarie Rima, and most importantly the warm and inspiring atmosphere that can be found here. I felt right at home and found friends for life. Going to work every day or returning after my baby breaks was always something I looked forward to, due to the unique work environment you created. Thank you for your vision, your unconditional support and the critical discussions we had about the contents of this PhD. I would also like to thank Annemarie for her trust in my programme management and actions and for relieving me of these responsibilities at the right time.

My co-supervisors Pawel Kazymarkzyk and Carlo Azzarri both helped me greatly in many ways. Pawel's inspiring classes on migration helped me to focus my work on migration on the families of migrants. Thank you Pawel for your faith in me and for your feedback and guidance on all aspects of my work, and especially the theoretical sections. I asked Carlo Azzarri to become my supervisor after he had given me very useful comments on my first empirical Albanian paper. He agreed, without ever having met me, and we had a most fruitful cooperation ever since then. You're the only supervisor I know, who is available to chat on Skype and Messenger any time of the day and any day of the week. Thank you for your extensive and thorough comments, Carlo, that made me re-think and refine methodologies and data interpretations many times. They helped me to really improve the quality of my work and I have learnt much from you.

Thank you to the reading committee members Prof. Dr. Hans Heijke, Prof. Dr. Joan Muysken, Prof. Dr. Hildegard Schneider, Dr. Hein de Haas and Dr. Talip Kilic for reading my dissertation so enthusiastically and so quickly. Thank you for your comments that helped me to put the finishing touches on this dissertation.

At the School, I thank Mindel van de Laar and Franziska Gassmann for being very understanding and supportive during the course of my PhD. Working on the Social Protection course coordination and with the MPP students was a nice complement to the PhD work and also allowed me to cooperate more extensively with the support staff. Thank you especially Celine, Mieke, Susan, Janneke, Charlotte and Ruta for your support related to my PhD and coordination tasks, but especially for your friendship.

Four of my oldest friends, Robert, Judith Lina and Mirtha also came to the School and I am very happy we could share the PhD experience. Thank you to Lina for being in this $\mathrm{PhD}$ project with me from beginning to end, from reading each others' motivation letters, when we first applied, to motivation boosts in the end. And in between we sent each other hundreds of emails and had frequent coffee breaks together. Robert, thank you for being such a caring friend. You always made me get my priorities right and talked me through many difficult decisions. You're truly the 
most ethical economist I know. Judith, I am so glad you came back to Maastricht. Robert and I have the best and silliest laughs with you! Mirtha wrote the first paper on remittances with me and right from that first paper until her defence, she was my example on how to do a PhD. Thank you for your inspiring passion and your warm friendship.

Melissa and I quickly joined forces as the migration $\mathrm{PhD}$ students. Going to conferences will never be as much fun, as it was with you, Melissa: Chatting till late at night, "sleeping in" while you went running, going shopping, long dinners, walking everywhere... and yes, we also went to the conference sessions. Thank you, Melissa, for making my PhD more fun. You and Flo will always be very good friends.

My other co-author Florian and I got to know each other better in the muddy streets of peri-urban Tirana, where we collected our data. I am very grateful to you and Sonila for the nice times we have shared, your friendship, your humour and support in difficult times. I appreciate the hospitality of you and your families; spending time with you I also learnt so much about your country and culture.

Part of the privilege of working at the School is attending international weddings. Paty's and David's in Mexico was beautiful. Thank you for the fun and interesting chats we had, about Economics or family, at home or at the School. Zina, I still regret not being able to attend yours and Yasser's Egyptian wedding. Our joint motherhood-PhD experiences created a strong bond and friendship between us. Let's hope we become mother in laws to our oldest children one day. Thank you for always understanding me!

I also thank my friends Denisa and Victor for always being ready for a mini-break with me, for the memorable holiday in Brasov and for being my daughter's biggest fans! Thank you to my other friends at the School, Bianca, Britta, Cheng, Frieda, Hao, Henry, Keetie, Jinjing, Pascal, Maha, Metka, Michal and Renée, for their friendship and the nice dinners, movies, chats or holidays we shared. Thank you to the many colleagues at the School who have babysat my kids! I am also immensely grateful to Miriam for being a supportive friend for twenty years already, both spiritually and with never-ending supplies of gummy bears. Dear Annika, no-one can motivate me like you can!

I am also grateful to my family. I want to thank my siblings Felix, Franzisca, Jonas and Clara, who take me for who I am and always make me forget about my work when it was necessary. Thank you especially to glorified nanny Franny for lots of help with the kids over the years and for calling me almost every day. My parents, Sabine and Johannes, I want to thank for always believing in me, even when I went off to study Economics, which I knew nothing about, in the Netherlands, a country I had never been to. Your love, support, patience and interest have been immensely helpful. I also thank my parents-in-law, Bonnet and Martin, for accepting and supporting the work-focused lifestyle of Alex and me.

During the course of this PhD I went on maternity leave twice and had three children. I am grateful to my children Paola, Isabella and Calvin for the fun, relaxation and distraction at home. Coming home from work, sitting on the floor and playing Lego with you, allowed me forgot about my PhD stress for a while. At 
the same time you also made me appreciate my time at work more and forced me to make efficient use of my time.

Alex knows this thesis almost as well as I do. Thank you for your encouragement, patient advice and practical help, at any time of the day. Thanks for all the maps you made for me! With your continuous interest and difficult questions, you made sure that I delved deeply into the research and enjoyed it too. And finally and most importantly, because of your love and the happiness I have with you, I had the stamina to pull through with this PhD.

Jessica Hagen-Zanker

Cambridge, November 2009 



\section{Contents}

Acknowledgments

iii

Preface

$\mathbf{v}$

$\begin{array}{ll}\text { Contents } & \text { ix }\end{array}$

List of Figures $\quad$ xii

List of Tables $\quad$ xiii

1 Introduction 1

1.1 Motivation 1

1.2 Objectives 5

1.3 Methodology 5

$\begin{array}{lll}1.4 & \text { Outline } & 7\end{array}$

$2 \quad$ Why do people migrate? 9

2.1 Introduction 9

2.2 The level of analysis $\quad 10$

2.3 Macro-theories of migration 11

$2.4 \quad$ Micro-theories of migration 13

2.5 Family-decision making and the New Economics of Labour Migration 15

$\begin{array}{lll}2.6 & \text { Perpetuation of migration } & 18\end{array}$

2.7 A general framework of migration decision making 20

2.8 Conclusion 22

$3 \quad$ The determinants of remittances 25

$\begin{array}{lll}3.1 & \text { Introduction } & 25\end{array}$

3.2 The determinants of remittances 25

3.2.1 Theoretical determinants of remittances 25

3.2.2 Empirical determinants of remittances 29

3.3 Conclusions 33

4 The determinants of migration and remittances in Albania and $\begin{array}{ll}\text { Moldova } & 35\end{array}$

4.1 Introduction $\quad 35$

4.2 Theoretical framework 38

4.2.1 Determinants of migration 38

4.2.2 Determinants of remittances 43

4.3 Data and methodology 46

4.3.1 Data 46

4.3.2 Methodology 46

$\begin{array}{lll}4.4 & \text { Why do people migrate? } & 48\end{array}$

4.4.1 Descriptive statistics 48

4.4.2 Empirical analysis $\quad 54$ 
4.5 Why do migrants send remittances? 56

4.5.1 Descriptive statistics 56

4.5.2 Empirical analysis $\quad 59$

$\begin{array}{lll}4.6 & \text { Conclusions } & 70\end{array}$

$5 \quad$ Are internal migrants in Albania leaving for the better? 75

$\begin{array}{lll}5.1 & \text { Introduction } & 75\end{array}$

$\begin{array}{lll}5.2 & \text { Literature review } & 79\end{array}$

5.2.1 Determinants of internal migration $\quad 80$

5.2.2 Effects of internal migration $\quad 81$

$5.3 \quad$ Data and Descriptive Statistics $\quad 82$

5.3.1 Data 82

5.3.2 The Albanian households 83

5.3.3 Rural and peri-urban households 84

5.3.4 Peri-urban migrant households: is there a time effect? 91

5.4 Empirical analysis $\quad 93$

5.4.1 Methodology 93

5.4.2 Empirical results 95

5.5 Conclusions 99

6 How has internal migration in Albania affected transfers amongst $\begin{array}{ll}\text { kinship members? } & 103\end{array}$

$\begin{array}{lll}6.1 & \text { Introduction } & 103\end{array}$

$\begin{array}{ll}6.2 & \text { Literature Review } \\ 6.3 & 105\end{array}$

6.3 Data and Methodology 107

$\begin{array}{lll}6.3 .1 & \text { Data } & 107\end{array}$

6.3.2 Descriptive Statistics 109

6.3.3 Methodology 111

6.4 Empirical Results 113

6.4.1 Qualitative analysis 113

6.4.2 Econometric results 115

$\begin{array}{ll}6.5 & \text { Conclusions } \\ & 120\end{array}$

$7 \quad$ Conclusions and Discussion 123

$\begin{array}{lll}7.1 & \text { Main findings } & 123\end{array}$

7.1.1 Why do people migrate? 123

7.1.2 What are the motivations of migrants to send remittances? 126

7.1.3 What is the economic impact of migration on migrant households? 128

7.1.4 How has migration affected transfers amongst kinship members? 129

7.2 Discussion and policy recommendations 132

$\begin{array}{ll}\text { References } & 135\end{array}$

$\begin{array}{llr}\text { A } & \text { Appendix to Chapter } 3 & 147\end{array}$

B Appendix to Chapter $4 \quad 153$

B.1 Summary statistics for Section $4.4 \quad 153$

B.2 Summary statistics for Section $4.5 \quad 155$

$\begin{array}{ll}\text { C Appendix to Chapter } 5 & 157\end{array}$

C.1 The distribution of the propensity score by treatment group 157 
$\begin{array}{lll}\text { C.2 Instrumental Variable diagnostic tests } & 158\end{array}$

$\begin{array}{ll}\text { C.3 Alternative specification } & 159\end{array}$

D Appendix to Chapter $6 \quad 161$

D.1 Incidence of receipt of transfers 161

D.2 Codified results from the qualitative interviews 162

$\begin{array}{lll}\text { D.3 ZIP and ZINB models } & 163\end{array}$

D.4 Measures of fit between different count models 164

D.5 Alternative specifications 165

$\begin{array}{ll}\text { Summary } & \mathbf{1 7 0}\end{array}$

$\begin{array}{ll}\text { Samenvatting } & \mathbf{1 7 4}\end{array}$

$\begin{array}{ll}\text { Biography } & 178\end{array}$ 


\section{List of Figures}

Figure 1.1 International and internal migration flows 1990-2004 6

$\begin{array}{lr}\text { Figure 2.1 A general framework of migration decision making } & 21\end{array}$

Figure 3.1 A theoretical average remittance function in the case of loan repayment 28

Figure 3.2 Insurance motives for remitting $\quad 32$

Figure 4.1 Location of Albania and Moldova in Europe $\quad 35$

Figure 4.2 Albania emigration and remittances $\quad 36$

Figure 4.3 Moldova emigration and remittances $\quad 37$

Figure 4.4 The Welfare Pentagon $\quad 39$

Figure 4.5 The migration decision making process $\quad 43$

$\begin{array}{lr}\text { Figure 4.6 The level of remittances / consumption quartile } & 57\end{array}$

$\begin{array}{ll}\text { Figure 4.7 Years abroad } & 58\end{array}$

Figure 5.1 Internal and international migration flows 1990-2004 76

Figure 5.2 Urbanisation trends 1919-2009 77

$\begin{array}{ll}\text { Figure 5.3 Main inter-district migration flows } & 78\end{array}$

$\begin{array}{ll}\text { Figure 5.4 Poverty indicators } & 87\end{array}$

Figure 5.5 Participation in income-generating activities and income shares 88

Figure 5.6 Unemployment ratio for adults of the household $\quad 91$

Figure 5.7 Whether someone in household has a sudden illness 92

$\begin{array}{lr}\text { Figure 5.8 Wellbeing indicators } & 92\end{array}$

$\begin{array}{lr}\text { Figure 6.1 Origin districts of surveyed households } & 104\end{array}$

Figure 6.2 Predicted frequency of transfers by age, for transfers before and after migration $\quad 117$

Figure C.1 The distribution of the propensity score by treatment group 157

Figure D.1 Residuals of the tested model for frequencies of all transfers 164 


\section{List of Tables}

Table 2.1 Theories of migration defined by level of analysis $\quad 10$

Table 2.2 Theories of migration defined by initiation or perpetuation of migration $\quad 10$

Table 3.1 Theoretical effects of certain factors on remittances for different motives 26

Table 4.1 Differences between migrants and non-migrants: Control variables 49

Table 4.2 Differences between migrants and non- migrants: Family institutions 50

Table 4.3 Differences between migrants and non-migrants: Market institutions $\quad 51$

Table 4.4 Differences between migrants and non-migrants: Social network institutions 52

Table 4.5 Differences between migrants and non-migrants: Membership association institutions 53

Table 4.6 Differences between migrants and non-migrants: Public authority institutions 54

Table 4.7 Probit analysis on the probability to be a migrant $\quad 55$

$\begin{array}{lr}\text { Table 4.8 Characteristics of remitters } & 59\end{array}$

Table 4.9 Results of the Tobit regression for the combined model $\quad 62$

Table 4.10 Results of the Tobit regression for the Albania model 66

Table 4.11 Results of the Tobit regression for the Moldova model $\quad 69$

$\begin{array}{ll}\text { Table 5.1 General household characteristics } & 84\end{array}$

Table 5.2 Demographics $\quad 85$

Table 5.3 Education and employment $\quad 86$

$\begin{array}{ll}\text { Table 5.4 Wellbeing indicators } & 87\end{array}$

Table 5.5 Housing outcomes $\quad 89$

Table 5.6 Health outcome and infrastructure $\quad 89$

Table 5.7 Schooling outcomes and expectations 90

Table 5.8 Propensity Score Matching results 96

Table 5.9 Ordinary Least Squares (OLS) and Instrumental Variable (IV) results 98

Table 6.1 Household characteristics in the sampled areas $\quad 109$

Table 6.2 Transfer likelihood from different kin $\quad 110$

Table 6.3 Transfer frequency from different types of kin $r 111$

Table 6.4 Results from NBRM: Frequency of receiving transfer 116

Table 6.5 Differences in coefficients from separate NBRM (before and after migration) 119

$\begin{array}{lr}\text { Table A.1 Effects for the probability to remit } & 147\end{array}$

Table A.2 Effects for the level of remittances $\quad 149$

Table A.3 Effects for the joint solution of probability \& level of remittances (Tobit) 150

Table B.1 Summary statistics for Moldova $\quad 153$

$\begin{array}{lr}\text { Table B.2 Summary statistics for Albania } & 154\end{array}$

Table B.3 Summary statistics for Moldova $\quad 155$

$\begin{array}{lr}\text { Table B.4 Summary statistics for Albania } & 156\end{array}$

$\begin{array}{ll}\text { Table C.1 Diagnostic tests for the IV regression } & 158\end{array}$

Table C.2 Alternative specification with migration as dummy endogenous variable 159

Table D.1 Incidence of receipt of transfers before and after migration $\quad 161$

Table D.2 Question E.6 What kinds of contact do you have? 162

Table D.3 Question H4.1 How did the move to Tirana change your relations with other people (including family)?

Table D.4 Question H4.4 Can you describe the kind of support you receive from others? How is this different to the past, before you moved?

Table D.5 Sum of predicted and actual mean count of the tested models for frequencies of all transfers 164

Table D.6 Results from NBRM including income: Frequency of receiving transfers 165

Table D.7 Results from NBRM and ZINB: Frequency of receiving all combined transfers 167

Table D.8 Results from NBRM: Frequency of receiving before or after migration 



\section{Introduction}

\subsection{Motivation}

Migration is a topic everyone ranging from politicians to shopkeepers has an opinion on and that is in the news almost every day. People are interested in migration because almost everyone is affected by migration, directly or indirectly. Migration affects all areas of life - social, economic and political - which makes the analysis of migration extremely relevant as well as more complicated. Due to the recent influential immigration experiences of Europe and the USA, to many people, politicians and also researchers migration is synonymous with immigration. This dissertation looks at the opposite end of the spectrum, at migrant-sending households and migrant households in source countries.

I start with the important question of why people migrate. The simple answer to this question is: People want to be better off. If migration makes people better off, why do not more people migrate? Current news coverage of migration issues is not proportional to current migration flows. Only 3\% of today's world population has migrated internationally (Koser, 2007). So in order to understand the current migration trends, there is the need to analyse thoroughly why people do or indeed do not migrate.

While migration is as old as humanity itself, theories about migration are fairly new. Early migration models (e.g. Zipf, 1946) used the physical concept of gravity and explained migration as a function of the size of the origin and destination population and predicted migration flows to be inversely related to distance. In the 1950s migration theory moved from purely mechanical models to more sophisticated theories, in which migration occurs as a result of differences in the urban/ rural wages and employment rate (Harris \& Todaro, 1970). While the early analyses look at aggregate data and often see migration as equilibrating mechanism, further research focused on elaborate microeconomic models. These models analyse individual motivations to migrate, but also consider structural community level factors like poverty (e.g. Wolpert, 1965). More modern approaches link the micro and macro level and also include less economic concepts, for example social capital (Faist, 1997, 2000). The New Economics of Labour Migration developed in the 1980s sees migration as a household decision and includes a more complete explanation for migration flows (e.g. Stark, 1991). Few authors take advantage of the complementarities between the different theories however; this is an aspect that I will emphasize.

It is known that a considerable fraction of labour migrants goes abroad in order to send remittances to family members back home. ${ }^{1}$ Even those migrants that leave for other reasons (e.g. personal freedom, persecution), often transpire to remit as

\footnotetext{
${ }^{1}$ Remittances are private money transfers that migrants send home to family and friends.
} 
well. Remittance flows have been growing and are increasingly better measured in the past decade and have consequently received a lot of public attention. The 2005 "World Economic Prospects 2006" report by the World Bank, that also motivated my interest in this topic, is widely quoted, especially the astonishing figure that global remittances reached $\$ 216$ billion in $2004^{2}$ (World Bank, 2006). Remittances outgrew global foreign aid and also foreign direct investment in many countries. Even if the exact overall amount of remittances is disputed due to measurement problems, the order of magnitude of this figure gives a clear indication that remittances are substantial and consequential.

For many politicians in poor source countries, remittances are seen as a major solution to domestic problems. These politicians believe that channelling more remittances to their countries for the benefit of the country as a whole (see discussion on the impact of migration and remittances below), is complementary to or a substitute of domestic social policy. Such large sums of money arouse the interest of not only politicians but also of researchers. The crucial question by all is: Who sends remittances under what circumstances? This is a particularly difficult question to answer and to draw general conclusions on, as the decision to remit is private and the personal considerations made in such a decision-making process are hard to measure. Consequently, the literature on the motivations to remit is still extremely dynamic. In this thesis I contribute to the discussion and I also analyse why and under what circumstances remittances are sent.

After having reviewed why people migrate and more specifically why they send remittances back home, the question of why not more people migrate comes up again. People migrate and send remittances to improve living standards for themselves and their families. It also appears that large shares of the global population would benefit from migration, but that they do not migrate. One might infer that the costs of migration are too high for many of the world's poor, but another reason could be that the impact of migration is not as positive as one would expect. Therefore the second part of my dissertation concentrates on the impact of migration.

A vibrant discussion on pressing methodological issues accounts for a significant fraction of the literature on the impact of migration. The conclusions on the actual impact are no less disputed. The answer depends on what is measured and at who is looked at: Does one look at the impact of migration in general, or remittances in particular? Does one look at the impact on the migrant or the family left behind or the wider community? Does one look at the impact on household finances, income and expenditures, or other factors of wellbeing, like health, housing or education? Very briefly, the literature finds both negative and positive effects of migration. Sending a household member abroad, might result in labour and parenting shortages in the household, but also results in remittances that can be spent on education, health or bare survival.

Looking at the impact of migration in general on household income, poverty or inequality, there is much evidence that international migration and remittances decrease poverty (e.g. Adams \& Page, 2005). The effects on inequality are generally

\footnotetext{
2 This amount is approximately Portugal's 2007 GDP (World Bank, 2008).
} 
less positive, as the extremely poor are often not able to migrate (Chimhowu et al, 2003). The precise impact depends very much on migrant selection and correcting for the endogeneity bias. One exceptional study that tracked internal and international migrants in Tanzania before and after migration, thus avoiding a bias, finds that migration has increased the consumption level of migrants (Beegle et al, 2008).

Another way of measuring the impact of migration is looking at the use of remittances. Use of remittances studies focus heavily on whether remittances are used for investment. Firstly, it is disputable what is considered investment. Expenses on food are generally considered "consumptive", but the literature is becoming less rigorous on this issue, as people being well-fed and healthy is fundamental to being productive. The country context, for example the investment climate, is also imperative. Investment of remittances in housing are widely found (e.g. Durand et al, 1996), but since many migrant houses are not lived in for large period of times, these are generally considered non-productive investments. Furthermore, there is some evidence that return migrants are more likely to become entrepreneurs at home (e.g. Dustman \& Kirchkamp, 2002, Black et al, 2003), but this discussion is far from closed. There is some evidence that households with a migrant spend more on education or that migrant's children are less likely to leave school (Adams, 2006 and Edwards \& Ureta, 2003).

Moreover one should also take the effect of migration on household employment into account. Firstly migrants leaving the household, means there is a "lost labour effect", i.e. there are fewer people to work locally, to tend the land or to look after children. Secondly, a migrant remitting to his/her family back home without visiting frequently could potentially result in moral hazard. ${ }^{3}$ If remittances are periodically sent to cover living expenses, the family might decrease their labour force participation and opt for more leisure, as Gubert (2000) finds for Mali, Germenji \& Swinnen (2004) find for Albania and Hanson (2007) finds for Mexico.

Finally one should consider the effects on the community or country as a whole. Remittances spent by individuals will have indirect multiplier effects at the meso and macro level (especially important is Taylor's work (e.g. Adelman, Taylor \& Vogel, 1988)). These higher level effects can be positive, such as more investment leading to higher economic growth or lower unemployment, or negative such as the Dutch disease ${ }^{4}$ or the much debated brain drain. However, these effects are not the focus of my dissertation.

The literature on the impact of international migration is still growing and the conclusion on whether migration is indeed a good strategy for migrants and their families are not clear-cut yet. Nevertheless, I decided to focus on a bigger gap in the literature and to investigate the impact of internal migration more closely. Internal migration is the movement of people from one region to another in the same country and is predominantly rural-urban, but not exclusively so. Internal

\footnotetext{
${ }^{3}$ Moral hazard is the danger that people insured in some sense (e.g. regularly getting remittance payments) change their behaviour compared to being fully exposed to all risks.

${ }^{4}$ In the remittances context the Dutch disease is essentially an exchange rate appreciation resulting from a remittances boom.
} 
migration is understudied despite the fact that the global number of internal migrants, 740 million people, is considerably higher than the number of international migrants, 200 million people (Bell \& Muhidin, 2009). In the second half of my dissertation I will concentrate on the impact of internal migration, looking at the specific case of internal migration to peri-urban areas in Albania's capital Tirana, as Albania experienced significant internal migration, besides the enormous international migration flows it is known for.

For internal migration there is even less evidence whether migration has positive or negative effects on income. Yap (1977) reviews a number of papers and finds that, despite higher living expenses in urban areas and missed in-kind rural income, migrants generally experience income gains. Tunali (2000), on the other hand, shows that not everybody benefited from internal migration in Turkey in the 1960s, and that a sizeable fraction of internal migrants experienced income shortfalls. Not much research has been done on other effects of migration, but local case studies e.g. in China (see Davin, 1999) show a non-surprising picture: Migrants usually live in worse living conditions than locals, have volatile employment and poor access to the health sector. I will deal with this question rigorously and analyse the impact of migration for migrant households using a wide range of criteria.

Remittances are not limited to international migration. As anyone should know from personal experience, financial, in-kind or services transfers exchanged between close family members or within a wider kinship networks living in the same country are common. International and internal migration may change the location of network members and the nature of these networks. A number of studies in the 1950s in the USA showed that rural-urban migration affected relationships amongst kinship members considerably (see Blumberg \& Bell, 1959). While some exchange still took place, especially in the beginning, increasingly residual functions of relationships, e.g. visiting, became more important (ibid). Since then not much specific research has been done on the effects of internal migration on the relationships and transfers between kinship members. My last chapter contributes to this gap in the literature.

In academia, research on origin countries is still dwarfed by immigration research. Extensive empirical research on the causes and especially impacts of migration on the country of origin has only been really dynamic in the past ten years. This dissertation will therefore contribute to the growing literature on the causes and effects of migration for households in source countries. As argued above, this type of research is vital in understanding the links between migration and development and is therefore important not only in academic terms.

Another aspect that I emphasize in my dissertation is that I do not consider migrants as individual agents. This viewpoint is relatively new to the migration literature. Migrants are part of families and wider kinship networks that contribute to the decision to migrate and that are affected by migration. There are also families that migrate as a whole. Finally the relationships between family members might be affected by the process of migration. I will analyse these family dynamics in close detail. 


\section{$1.2 \quad$ Objectives}

This dissertation has the objective to investigate the causes and effects of migration on migrant households in source countries.

It aims to further understanding of the reasons of why people migrate and send remittances. It also intends to analyse the consequences of migration on the wellbeing of migrant households and on the relationship between family members.

In addition two broad themes are analysed throughout all chapters: The investigation of migrant households, i.e. the families of migrants or complete households that have moved, and the focus on source countries.

More specifically, I would like to gain insight into the following questions:

1. Why do individuals migrate?

2. What are the motivations of migrants to send remittances?

3. What is the economic impact of migration on migrant households?

4. How has migration affected transfers amongst kinship members?

While questions 1-2 analyse international migration, questions $3-4$ focus on internal migration.

\section{$1.3 \quad$ Methodology}

Impact analysis is tricky in any field, but especially so in migration studies. Aspiring migrants self-select themselves to be migrants (i.e. it is a more or less a free decision to migrate) and are therefore different to the people who do not migrate in a number of characteristics. Some of these differences can be measured (e.g. the education level), but others are more difficult to assess (e.g. the level of risk-taking). One can expect that these differences influence a straightforward comparison between migrants and non-migrants, so one needs to apply more advanced techniques to analyse the impact of migration. A further complication is that one can expect to find reverse causality between migration and common dependent variables, like income. Essentially it is not known whether migrant's families that stay behind are richer due to migration and remittances or whether it is the family's wealth that enabled the migrant to migrate in the first place. These issues need to be dealt with thoroughly before drawing any conclusions on the impact of migration.

Unlike in the natural sciences, experiments with a random selection of people being allowed to migrate are not feasible. ${ }^{5}$ Measuring the impact thus requires other solutions. Chapter 5 and Chapter 6 come up with two different ways of solving the problem of bias: Chapter 5 uses advanced econometric techniques (Propensity Score Matching and the Instrumental Variable Method) to correct for some of the bias. In this case migrant households can be compared to households

\footnotetext{
${ }^{5}$ Very rarely a "natural experiment" comes along that achieves almost the same result that one would expect from a natural science experiment. For example visas to New Zealand from Tonga are distributed on the basis of a lottery, which means that migrants are randomly selected and that impact analysis is made more straight-forward (see the work of McKenzie e.g. Gibson, McKenzie \& Stillman, 2009).
} 
that did not migrate. Chapter 6 compares the same household's family solidarity pattern after the move to their behaviour before the move.

Except for the theoretical chapters, all other chapters use Albania as at least one of the empirical applications. Albania is situated in South-Eastern Europe and has land borders with Greece, Montenegro, Serbia and Macedonia and a sea border with Italy. It has a population of around 3.6 million, is a lower-middle income country and thus one of the poorest countries in Europe.

Albania is an excellent case study for measuring the causes and impacts of migration. Since the fall of communism in 1990, it is virtually a "country on the move" (Carletto et. al., 2006). Considerable shares of the population are affected by migration. Almost $50 \%$ of Albanian households have had one or more household members abroad since 1990 (ibid). In addition to international migration, there are also large internal rural-urban migration flows. Two characteristics define recent Albanian migration: Its sheer intensity and the suddenness with which it took place (King, 2005).

Albania is historically a migration country, but both internal and international migration was outlawed under the communist regime of Hoxha. Since 1990 the number of internal and international migrants has risen sharply, especially during times of shocks, such as the political and economical uncertainty following the fall of Communism in 1990 and the pyramid savings scheme crisis in 1997. International migrants constitute at least one fifth of population (Carletto et. al., 2006). In terms of internal migration $5.7 \%$ of the population moved from one region to another and twice that many people moved across districts between the two Censuses in 1989 and 2001 (INSTAT, 2004). Figure 1.1 compares internal to international migration flows and shows that there are considerable differences in the timing and intensity of their flows.

Figure 1.1 International and internal migration flows 1990-2004

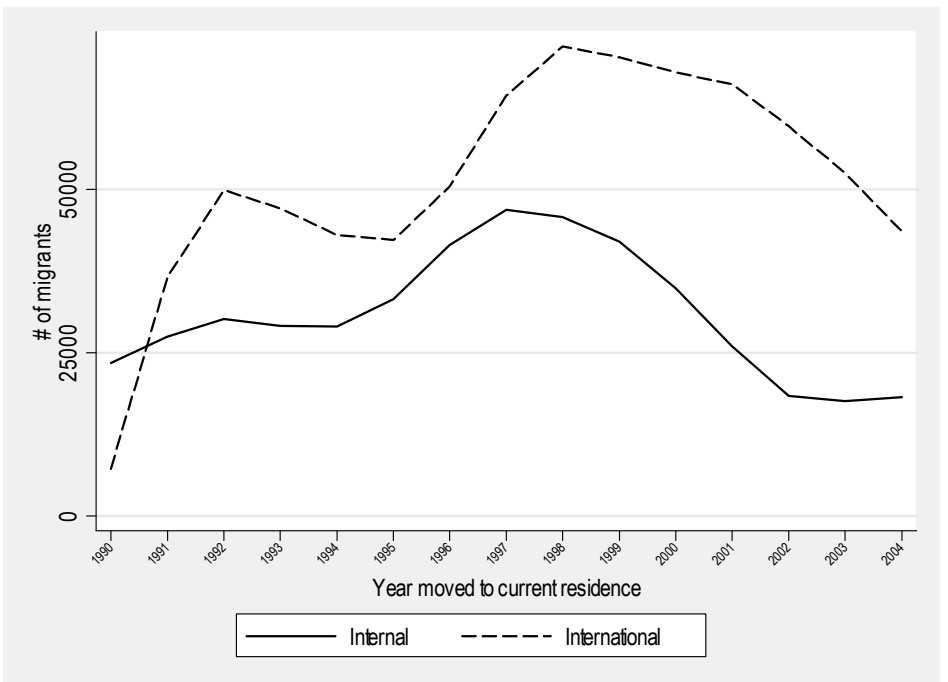

Note: Year refers to date of first move; international flows include those international migrants that have now returned to Albania 
Source: Own calculations, based on 2005 Albania ALSMS

Since migration was outlawed under Communism and increased very quickly thereafter, Albania can be thought of as a laboratory for migration. The time period where almost no migration took place is still recent, which means that the situation today can be compared to the base scenario of no migration. The Albania Living Standard Measurement surveys of the World Bank take advantage of this feature and in their very extensive questionnaires they also include questions on the household's living standards in 1990, as well as complete migration histories of individuals in households. I was able to make use of this valuable database, as well as data I collected myself during fieldwork in Albania in 2008.

\subsection{Outline}

My first step in shedding light on the question of why people migrate is by systematically reviewing the theoretical literature on the causes of migration in Chapter 2. I focus mostly on the economic literature. The literature can be divided by the level of analysis: The micro-level looks at the decision making process of individuals. The meso level studies how individuals and groups of individuals (e.g. families) are affected by their wider social setting. The macro-level, on the other hand, focuses on economy-wide opportunity differentials and differences between countries.

In Chapter 4 I link migration theories in another way by placing them in the context of the Welfare Pentagon. The Welfare Pentagon (de Neubourg, 2002) is a framework that explains how people maximise income and smooth consumption by accessing different parts of the Welfare Pentagon, namely families, markets, membership associations, social networks and public authorities. When a potential migrant has no or not significant access to some of these institutions and thus cannot make ends meet at home, the individual may decide to migrate. At the same time access to some of these institutions is also necessary in order to migrate, e.g. social networks. In Chapter 4 I also explore this framework empirically with data for Albania and Moldova and give a first indication of characteristics of people in those countries that do migrate.

I investigate the motives of remitters by reviewing the remittances literature and by looking at the specific cases of Albania and Moldova. In Chapter 3 I extensively review the empirical and theoretical literature of the determinants of remittances. According to Lucas and Stark (1985) remitting motives can be classified either as "pure altruism", "pure self-interest" or something in between, "tempered altruism or "enlightened self-interest". In reality these motives are interlinked and hard to measure separately. In Chapter 4 I systematically attempt to apply some of the determinants of remittances theories to the cases of Albania and Moldova and extensively discuss the methodological concerns specific to this literature.

In Chapter $5 \mathrm{I}$ investigate the impact of internal migration on the migrating households' finances and living standards. Internal migration in Albania mainly takes the shape of whole family relocation, from rural to urban areas. Therefore I focus on the entire household and compare them to households in rural areas that did not migrate. 
In Chapter 6 I focus more on the social impact of internal migration, in particular how relationships and transfers amongst family members are affected by migration. Here I only look at migrant households and compare their transfer mix and network before internal migration to the current situation.

Chapter 7 is my conclusion. Apart from answering my specific research questions, I reflect on the links between the papers and draw some policy considerations. 


\section{Why do people migrate?}

\section{$2.1 \quad$ Introduction}

Massey et. al.'s (1993) paper is ground-breaking in the migration literature because discusses and unifies different migration theories. However, their review and synthesis is not complete and deep enough for researchers interested in a deeper understanding of the migration theory literature. This chapter therefore aims to review the complete spectrum of economic migration theory from the 1950s until today and to show the differences and complementarities between the different approaches.

Migration is the temporary or permanent move of individuals or groups of people from one geographic location to another for various reasons ranging from better employment possibilities to persecution. While migration is as old as humanity itself, theories about migration are fairly new. One of the early writers on modern migration is Ravenstein, who in the 1880s based his "Laws of Migration" on empirical migration data. This collection of empirical regularities, for example the fact that most migrants only travel short distances, was far from a complete theory of migration. Early migration models (e.g. Zipf, 1946) used the physical concept of gravity and explained migration as a function of the size of the origin and destination population and predicted migration to be inversely related to distance.

In the 1950s migration theory moved from purely mechanical models to more sophisticated theories. Theoretical predictions of migration flows are first made in the dual-economy models of Lewis in the $1950 / 60$ s, in which migration occurs as a result of differences in the supply and demand of labour between the rural and urban sector. The Harris-Todaro models of the 1970/80s augment these models to account for some particular empirical observations and to make the models specifically about migration. Other macro-theories include the world systems theory and dual-labour market theory, which consider institutions in more detail.

While the early analyses look at aggregate data and often see migration as equilibrating mechanism, the focus since the $1980 \mathrm{~s}$ is on more elaborate microeconomic models. These models analyse individual motivations to migrate, but also consider structural community level factors. More modern approaches link the micro and macro level and also include less economic concepts, for example social capital. Another contribution of the more recent literature is the differentiation between causes and perpetuation of migration. The New Economics of Labour Migration developed in the 1980s sees migration as a household decision and includes more explanations regarding the decision to migrate. This theory will be discussed more extensively. It stands out from the classical theories of migration in that it tries to model the decision-making process more realistically by including a wide range of decision making factors.

I begin this literature review by distinguishing between the different levels of analysis. The most important theories of internal and international migration will 
be critically discussed in the next sections. While the emphasis is on economic theories, some of them are closely linked to sociological, geographical and anthropological theories. The review will focus on voluntary labour migration, thus disregarding forced migration, asylum seeking family reunion etc. The chapter will conclude by unifying the most important theories into one framework.

\section{$2.2 \quad$ The level of analysis}

Migration theories can be classified according to the level they focus on. Microlevel theories focus on individual migration decisions, whereas macro-level theories look at aggregate migration trends and explain these trends with macrolevel explanations. The meso-level is in between the micro and macro level, e.g. on the household or community level and can explain both causes and perpetuation of migration. Table 2.1 gives an overview of the theories along the level of analysis, whereas Table 2.2 gives an overview of the migration theories in terms of their classification as a cause or perpetuation of migration. As will become clear later on, some theories fit into several categories.

Table 2.1 Theories of migration defined by level of analysis

\begin{tabular}{|c|c|c|}
\hline Micro-level & Meso-level & Macro-level \\
\hline Migration cause: & Migration cause/ perpetuation: & Migration cause/ perpetuation: \\
\hline $\begin{array}{l}\text { Individual values/ desires/ } \\
\text { expectancies }\end{array}$ & Collectives/ social networks & $\begin{array}{l}\text { Macro-level opportunity } \\
\text { structure }\end{array}$ \\
\hline $\begin{array}{l}\text { e.g. improving survival, wealth } \\
\text { etc. }\end{array}$ & e.g. social ties & $\begin{array}{l}\text { e.g. economic structure (income } \\
\text { and employment opportunities } \\
\text { differentials) }\end{array}$ \\
\hline \multirow{7}{*}{$\begin{array}{l}\text { Main theories: } \\
\text { - Lee's push/ pull factors } \\
\text { - Neoclassical micro-migration } \\
\text { theory } \\
\text { - Behavioural models } \\
\text { - Theory of social systems }\end{array}$} & Main theories: & Main theories: \\
\hline & - Social capital theory & - Neoclassical macro-migration \\
\hline & - Institutional theory & theory \\
\hline & - Network theory & - Migration as a system \\
\hline & - Cumulative causation & - Dual labour market theory \\
\hline & - New Economics of Labour & • World systems theory \\
\hline & Migration & - Mobility Transition \\
\hline
\end{tabular}

Source: Faist (2000) and own elaboration

Table 2.2 Theories of migration defined by initiation or perpetuation of migration

\begin{tabular}{ll}
\hline Initiation of migration & Perpetuation of migration \\
\hline Neoclassical macro-migration theory & Migration as a system \\
$\begin{array}{l}\text { Migration as a system } \\
\text { Dual labour market theory }\end{array}$ & World systems theory \\
World systems theory & Social capital theory \\
Mobility Transition & Institutional theory \\
Lee's push/ pull factors & Network theory \\
Neoclassical micro-migration theory & Cumulative causation \\
Behavioural models & \\
Theory of Social systems & \\
New Economics of Labour Migration & \\
\hline
\end{tabular}

Source: Massey et al. (1993) and own elaboration 
This chapter will discuss the theories in rough chronological order. Therefore macro-level theories be discussed first, followed by micro and meso theories and I will finish the literature review by looking at the perpetuation of migration, which is a fairly new field.

\subsection{Macro-theories of migration}

The neoclassical macro migration theories explain migration as part of economic development. Internal migration occurs as a result of geographical differences in the supply and demand of labour, mostly between the rural traditional agricultural sector and the urban modern manufacturing sector. The basic model (Lewis, 1954 and Ranis \& Fei, 1961) that grew out of trade theory, assumes perfect markets and a labour surplus in the traditional agricultural sector that is absorbed by the modern sector. The modern sector grows through capital accumulation and by poaching labour from the traditional sector. Rural workers are attracted by the positive wage differential and migrate to the urban sector, i.e. they are pulled to migrate. In these models migration occurs until wage equalisation has taken place.

Todaro and Harris (Todaro, 1969 and Harris \& Todaro, 1970) augmented this model to account for the significant urban unemployment that was found in many less developed countries. Migration is not completely risk-free, because the migrant does not necessarily get a job upon arrival in the city. Rural-urban migration occurs, as long as the expected real income differential is positive. Expected income is a function of the rigid, institutionally determined urban wages and the urban employment rate. Migration costs can be included. The employment rate is the probability of finding a job, i.e. being selected from the pool of labour, which increases over time, for example due to wider networks of the migrants. Migration thus increases if urban wages increase or the urban employment rate increases (ceteris paribus). The authors show that it can be perfectly rational to migrate, despite urban unemployment, due to a positive expected income differential. This model has clear predictions and while the significance of income differentials is undisputable in labour migration decisions, it is probably not as excessive as Harris and Todaro describe it. Some of the model's empirical predictions e.g. wage equalisation, have not been found reality.

The dual labour market theory (Piore, 1979) explains migration as the result of a temporary pull factor, namely strong structural labour demand in developed countries. According to this not purely economic approach, there is economic dualism on the labour market of developed countries and wages also reflect status and prestige. There is a primary sector providing well-paid jobs and a secondary sector, for unskilled jobs, e.g. manufacturing. The demand for migrant labour stems from several factors. Due to structural inflation, there are constant wage rises in the primary sector. Proportional wage rises in the secondary sector are too expensive; the consequent lower pay makes the secondary sector unattractive to native workers. Traditional sources of labour in the secondary sector, women and teenagers are not available anymore due to demographic changes. Women have joined the regular labour force and there are smaller teenage cohorts. Migrants are more motivated to work in these low-status jobs, because they do not consider themselves as part of the destination society. Employment in the secondary sector 
fluctuates according to the economic cycle, making it unstable and uncertain work, again unattractive to native workers. Therefore there is a strong demand for temporary migrant labour that acts as a pull factor to migration. This model is important because it explains some of the post-war migration trends in Europe and the United States, but the focus is too narrow with only one pull factor being analysed and with no deeper analysis of migrant decision making.

The world systems theory (Wallerstein, 1974), which takes a historical structural approach, stresses the role of disruptions and dislocations in peripheral parts of the world that result from colonialism and the capitalist expansion of neoclassical governments and multinationals. It thus takes account of structural factors that other theories neglect. The capitalist expansion has had profound consequences for migration issues, as not only the capitalist mode of production, but also affecting culture and stronger transportation, communication and military links penetrate peripheries. Land consolidation, new capitalist farming methods and manufacturing plants have created a socially uprooted population with weakened attachments to their land and that are more prone to migration. A strong immigrant labour demand in global cities acts as a pull force to migration. According to this theory, migration follows the dynamics of market creation and structure of the global economy, but more individual motivations are not considered. The exact mechanisms of migration are also not clear. Recent examples of this theory are globalisation in general and the transition of Central and Eastern Europe after the fall of Communism.

Another macro-level model explaining rural-urban migration in less developed countries is Mabogunje's (1970) migration as a system model, in which he explains migration as a dynamic spatial process. Aggregate migration flows and interactions are modelled by analysing a pool of rural potential migrants that is affected by various factors in the decision to migrate. The rural control sub-system controls outflows (e.g. family or community norms) and the urban control sub-system controls inflows (e.g. through employment agencies). Feedback is channelled back to potential migrants and the background environment also affects migration flows (social \& economic conditions, government policies, transport \& communications infrastructure etc.). The environment and sub-systems are constantly changing, also as a result of migration flows, which makes the system open and dynamic. Other authors (e.g. Kritz \& Zlotnik, 1992) have also emphasised the importance of viewing international migration as an interdependent dynamic system, with own but interlinked systems for sending and receiving countries and feedback and adjustment coming from the migration process itself. It can also be linked to the world systems theory, discussed above. It is important to take note of interactions between different actors and to emphasize the dynamic nature of migration. Nevertheless the migration system models are vague and do not allow concrete prediction of migration trends.

Politics matter in migration theory, as migration laws and thus the right to cross a border legally directly influence migration flows. These laws of nation states are the result of the relative power of different interest groups. They are influenced by profits (thus linking up with Priore's dual labour market theory), national identity, considerations of national security and the extent of multiculturalism in the state. In a historical analysis it is important to point out that acquired rights, laws or 
existing institutions will always influence migration flows, irrespective of economic considerations, like the business cycle (Hollifield, 2000). Globalisation not only affects the demand for labour or facilitates migrant networks, but also leads to loss of border control. Zolberg (1981) argues that it is not just the economic factors that matter in making the structural setting of migration, for example some of the countries that would be considered peripheral in the world systems theory (the Communist countries) chose to do so due to political reasons and political motives also influence migration flows (e.g. of refugees). The political setting is thus an important structural factor in migration decisions.

Zelinsky's hypothesis of mobility transition (1971) argues that migration is part of the economic and social changes inherent in the modernisation process. It is part of the wider range of functionalist theories of social change and development, which try to link theories to past empirical trends. He argues that patterns and rates of migration can be closely linked to the stage of modernisation (e.g. industrialisation) and demographic factors (e.g. high birth rates). He emphasizes that the preference for more personal freedom is part of the modernisation process. While Zelinsky's theory broadly make sense when looking at past migration patterns in industrialised nations, it is vague, does not allow differentiation of different types of migration and it does not consider the individual migration decisions. This decision is the starting point of the microtheories of migration.

\subsection{Micro-theories of migration}

Lee (1966) was the first to formulate migration in a push-pull framework on an individual level, looking both at the supply and demand side of migration. Positive and negative factors at the origin and destination push and pull migrants towards (non) migration. They are hindered by intervening factors, e.g. migration laws and are affected by personal factors, e.g. how the migrant perceives the factors. He makes a number of predictions, for example that greater diversity among people leads to more migration and for this reason there are high rates of migration within the United States. This theory is barely a theory, it is more a grouping of factors affecting migration, without considering the exact causal mechanisms.

The human capital approach is the neoclassical micro-level migration theory. Based on the work of Sjaastad (1962) migration is treated as an individual investment decision to increase the productivity of human capital, thus again focusing on the labour market, but at the same time explaining the selectivity of heterogeneous migrants. Individuals make a rational cost-benefit calculation of the expected discounted returns of migration over future time periods, migrating only when the expected returns are positive. Equation 2.1 is one of the many variations that is used to model this approach.

$$
E R_{t=0}=\int_{0}^{n}\left[p_{D}(t) p_{E D}(t) Y_{D}(t) N R_{D}(t)-p_{E O}(t) Y_{o}(t)\right] * e^{-r t} d t-C_{t=0}
$$

The expected returns depend on the expected benefits and migration costs. Migration costs $\mathrm{C}$ consist of the monetary travel costs and non-monetary opportunity costs and psycological costs. The expected benefits consist of the 
discounted earnings (dependent on income at the destination $Y_{D}$ and origin $Y_{0}$, respective employment probabilities $\mathrm{p}_{\mathrm{ED}}$ and $\mathrm{p}_{\mathrm{EO}}$ and the deportation probability $\mathrm{p}_{\mathrm{D}}$ ) and non-monetary returns (NR), e.g. a preference for the new location. The theory emphasizes that migration might lead to occupational upgrading (i.e. investment in human capital of the migrant). Age of the migrants obviously plays a significant factor here, therefore the expected returns are discounted over the remaining lifetime. This model predicts that the young and educated migrate in the first phase. In the basic model information is freely available. The model can easily be criticised on unrealistic assumptions. Fischer, Martin \& Straubhaar (1997) therefore propose a more advanced version of the model, where the no risk and asymmetric information assumptions are dropped. The human capital approach is interesting and useful in explaining the selectivity of migrants, but it is very hard to test empirically. It also ignores more important structural factors.

Wolpert's stress-threshold model (1965) describes a behavioural model of internal migration, similar to a cost-benefit analysis, but assuming individuals that intend to be rational ex-ante, are not necessarily so ex-post. Individuals have a threshold level of utility they aspire to. They compare place utilities to this threshold in order to decide whether to migrate or not and to which place. Place utilities for the current position are based on past and future rewards, whereas place utilities for possible destinations depend on anticipated rewards. Knowledge is based on the subjective and incomplete knowledge that individuals have in their personal action spaces, so rationality is bounded. Action spaces depend on personal characteristics, the variability of the environment and life-stage of the individual. Migration flows thus occur as a consequence of these individual place utility evaluations and are not necessarily optimal according to rational and perfect information standards. This model leaves out some of the unrealistic assumptions of the human capital approach, but it is even more difficult to test. In a way Wolpert only changes the terminology of the human capital approach.

Another behavioural model, the value-expectancy model (Crawford, 1973) is a cognitive model in which migrants make a conscious decision to migrate based on more than economic considerations. The potential migrant's strength of migration intentions depends on a multiplication of the values of migration outcomes and expectations that migration will actually lead to these outcomes. Values are specific goals, e.g. wealth or autonomy. Values and expectations depend on personal and household characteristics (e.g. education level) and societal norms. These values do not necessarily need to be economic, for example security or selffulfilment can also be important to potential migrants. Migration depends on the strength of migration intentions, indirect influences of individual and societal factors and modifying effects of constraints and facilitators. It is similar to the place-utility approach of Wolpert and again it shows that migration choices are subjectively made. There are also other similar micro-based individual behavioural decision making models, e.g. work by de Jong \& Fawcett (1981) or the adjustmentto-stress approach of Ritchey (1976). The behavioural approaches also consider non-economic factors and societal influences, but are very vague and rational decision making is still assumed.

Complimentary to the dual labour market theory is Hoffmann-Novotny's approach of explaining migrations as a theory of social systems (Hoffmann-Novotny, 1981). 
According to this theory migration is a result of resolving structural tensions (power questions) and anominal tensions (prestige questions). Migrants hope to achieve their desired status in the destination country, but often tensions are transformed instead of reduced. How successful they are depends on the global distribution of different countries among "status lines". A migrant coming from a country with a low rank is unlikely to achieve a high internal rank at the destination. "Undercasting" of migrants takes place, which means that migrants take on the lowest position in society, whereas lower stratum natives experience upward mobility, at least in terms of power or income. This theory does not exclude economic push factors for migration, but instead places them in a wider context of other societal push factors and also considers what happens to migrants at their destination. The theory broadly makes sense and furthermore includes structural factors, which most micro theories neglect. It is not easy to apply and test it however.

\section{$2.5 \quad$ Family-decision making and the New Economics of Labour Migration}

The more traditional migration approaches focus either on aggregate migration movements or individuals making migration decisions. They thus assume that individuals independently make the decision to migrate. Some of the migration literature includes a seemingly wider decision-making framework, for example Harbison (1981) paper is entitled "Family Structure and Family Strategy in Migration Decision Making". However, the migration decision is still not seen as a strategic family decision; the paper only acknowledges that families can influence the individual migrant's decision, e.g. through the demographic structure. When looking at migration from a gender perspective, family structure can influence the migration decisions of women in particular. As Morokvasic (1984) points out, women migrate not only because of economic motives, but also to get married, due to social constraints, low rights and lack of protection against domestic violence.

Sandell (1977) and Mincer (1978) on the other hand view migration as a family decision. The family as a whole migrates if their net gain is positive. If only one partner finds a (better) job at the destination, the family only migrates if gains of one family member internalise the losses of the other family member. The family migration decision is thus in essence an aggregation of individual migration utilities. Bigsten (1988) also considers migration a household decision in which a family allocates labour to the urban or rural sector depending on the marginal products of combined wages.

The New Economics of Labour Migration (NELM) goes one step further. According to this approach decisions are often made by household members together and for the wellbeing of the family as a whole. ${ }^{6}$ Households also do not migrate together (as in Mincer, for example), but rather send one or more household members off as migrants. The NELM is a fundamentally different theory of migration that was developed by Oded Stark in the 1980s, in collaboration with David Bloom, Eliakim

${ }^{6}$ This does not exclude individual household members benefiting from migration. 
Katz, David Levhari, Robert Lucas, Mark Rosenzweig, and J. Edward Taylor. The NELM is the only migration theory that explicitly links the migration decision to the impacts of migration, with remittances being this link (Taylor \& Fletcher, 2001). According to the NELM a household maximises joint income, status and minimises risks. All three aspects contribute to the migration decision of the household. Each of those will now be discussed in turn.

Referring to the classical migration approaches the NELM acknowledges that potentially earning higher incomes matter to potential migrants, while adding that relative income (or accordingly relative deprivation) of the household also matters. "In real life it is likely that migration decisions are influenced by both absolute and relative income considerations" (Stark, 1991, p. 145). Relative income can be seen as social "status", assessed in comparison to the reference group of the household. The reference group can be the local community, village, town etc. Status is not only of intrinsic value, but it might also translate into monetary benefits, for example in Less Developed Countries (LDCs) money-lenders often lend money with implicit social status as the collateral.

A household then gains twofold from sending a household member abroad to a place with higher income: In terms of a higher absolute income and in terms of a higher relative income. Both factors lead to the hypothesis that a household at the lower end of the income distribution is more likely to migrate. Stark (1991) points out that this prediction might not hold for the most deprived households, since bare survival is more urgent for them and they might not be able to afford migration. He also notes that absolute and relative income effects tend to move in the same direction, so they will be difficult to separate. Comparing two villages, where one village has a more unequal income distribution, a household with a certain income might migrate in the village with the unequal income distribution, but not in the other one with a more condensed income distribution, because there the household is relatively better off. Subsequently villages with a more unequal income distribution will experience higher overall migration.

The other major contribution of NELM is the consideration of risks. These risks are mainly linked to capital market failures in the source areas, besides the labour market failures already analysed by other authors, e.g. Todaro. ${ }^{7}$ Household try to overcome market failures in their environment, for example missing or incomplete credit and insurance markets. If public social protection is also limited, the household has no means to smooth consumption in difficult times or to make investments. As will be argued below, migration is a way of overcoming these market failures. The first assumption is that households are influenced by both the mean and variability (i.e. risk) of income. The NELM can be linked to the broader risks and poverty literature (see for example Dercon, 2005), where migration is

\footnotetext{
${ }^{7}$ Capital market failures can lead to disequilibria in other markets, for example the labour market. A low capital level in rural areas can lead to a low marginal product of labour, i.e. low rural wages and high migration to urban areas. This looks like evidence for Todaro type migration model, but is actually caused by capital market failures (Morrison, 1994).
} 
one of the strategies that poor households pursue in an environment of risks and missing markets. ${ }^{8}$

The basic argument in the migration context (based on Stark \& Levhari, 1982) is as follows: An optimising, risk-averse household in a LDC wants to introduce a new technology that increases the expected return from agriculture but at the same time also increases the subjective risk. Since there are no insurance or credit markets, the household has to solve this problem internally. In order to lower the risks associated with the new technology, the households spreads the risk by diversifying its income portfolio. In rural areas of LDC non-farm activities are often not available or too closely correlated to farm activities. Therefore the household chooses another strategy, namely sending a family member to the non-correlated or negatively correlated urban labour market. ${ }^{9}$

The migration costs are shared between household members and there is household co-insurance: The migrant is supported by the family in times of need (e.g. urban unemployment) and the migrant sends remittances home to the family for their consumption smoothing and investment activities (e.g. by financing new production techniques, investing in businesses, etc.). This arrangement is possible due to a different time profile of risks: First the migrant is supported until a job has been found, then the household receives remittances to make the investment. Due to co-insurance, each party is able to participate in temporarily risky behaviour. of course it should not be forgotten that both the family back home and the migrant face uncertainty about the expected returns of their activities (Taylor, 1986). Not only rural activities are subject to uncertainty (e.g. agricultural prices, pests), but so are the activities of migrants (e.g. finding a job). That is precisely why the coinsurance and diversification of income sources is so useful.

In order for such a cooperative equilibrium to be possible, households either have to have a powerful household head that can enforce the contract, altruism has to be present in the household or cooperation is a dominant strategy of all household members. Other reasons why these contracts can be self-enforcing are: Unstable urban labour markets, strong identification of the migrant with village of origin, bequest motive, repaying education costs, tight rural insurance markets, strong dependence of investments for new technology (Stark \& Lucas, 1988), surveillance of the migrant at the destination, cultural conventions etc.

The family context is thus crucial in determining whether such a contract is successful or not. The voluntary, implicit contract between household members is based on mutual interdependence; it is a cooperative game, whose outcome

\footnotetext{
${ }^{8}$ The NELM theory is also related to the sustainable livelihoods literature, where migration is seen as one possible option of having a sustainable livelihood (improving/ avoiding deterioration of household poverty, wellbeing, capabilities, resilience and natural resource base (De Haan et al, 2002).

In the sustainable livelihoods literature the alternatives activities (besides the broad category agriculture of the NELM) are more concrete and it tries to make the interaction between the impact of migration on the other livelihood strategies clearer.

${ }^{9}$ Stark $(1982,1986)$ also shows the case of a risk-averse individual: Such an individual, having an intertemporal utility function, might migrate despite higher short-term risks, because medium-term risks are lower.
} 
depends on the bargaining power of different household members. ${ }^{10}$ Foster and Rosenzweig (2001) show that the higher the altruism between the parties and the lower the income correlation, the more likely risk-sharing is likely to occur. Transfers are also conditioned by past transfers, so transfers should flow in both directions for co-insurance to work well. The contract is designed to be selfenforcing, also including devices to deal with principal-agent and moral hazard problems. ${ }^{11}$

In conclusion, if income and or status are low and or risks are high and there are market and government failures (so no other means of social protection), the household may make the decision that one or more members of the household migrates to a labour market that is negatively or non-correlated with the local labour market. They thus co-insure each other by diversifying their labour portfolio. Both the diversification of income and the investment-enabling character of remittances matter to the migration strategy. Households cooperate to achieve income diversification and informal insurance and also benefit from intrahousehold specialisation (migrants/ non migrants). Finally, the NELM should not be seen in isolation of the other migration theories. Stark includes the income differential approach to migration. Taylor (1986) points out that migration networks can be a source of information, thus increasing the certainty about returns in potential migration destinations.

The NELM extends the migration decision to also include risk and insurance considerations, household decision making and links the migration causes to the consequences. Therefore it is a more realistic and useful theory, even though it is still quite abstract and stylised and has some strong assumptions, like rationality. Unlike the sustainable livelihoods literature it is also quite vague on the combination of different types of activities. Like most theories of migration it is also vague about how migrants choose where to go specifically.

\subsection{Perpetuation of migration}

As Massey (1990) argues the factors that influence migration to start could be very different from the conditions that make migration continue, i.e. perpetuate. After an initial phase of pioneer migration, migration becomes more common in the community, with more and more people following current migrants and being helped by them until migration becomes self-sustaining. There are different aspects for the perpetuation of migration, including social capital, social networks, migration institutions and cumulative and circular migration and they are discussed below.

Thomas Faist, a sociologist, emphasizes the meso-level of migration $(1997,2000)$. By studying the meso-level, he links the rational individual migration decision models to the structural macro migration models. Social relations and social

10 For example the household has a higher bargaining power over the migrant (i.e. gets more remittances) if there is high urban unemployment (i.e. the migrant is more dependent on the family).

11 Guilmoto \& Sandron (2001) also argue that institutionalization of migration and inter-temporal transactions occur as a result of weak and imperfect markets. Migrants develop their own institutions (rules, norms etc) that regulate exchanges in order to decrease transaction and information costs. 
capital in households, neighbourhoods, communities and more formal organisations help migrants in the migration decision and adaptation process, so they are both a resource and an integrating device. Different social relations imply different social capital, obligations and outcomes, for example exchange relationships (e.g. between migrant and migration-brokers) are based on weak social ties and usually do not imply solidarity or reciprocity between the parties involved. Social capital can be seen as a resource that is acquired as a result of different kinds of relationships (Bordieu \& Wacquant, 1992 in Massey et al., 1998) and can be converted into other types of capital (e.g. borrowing money for migration from your neighbour). Through the use of concepts like social capital the mechanism with which macro-factors shape micro-decision making is made clearer. One example of social ties and social capital in practice is the network theory, discussed below.

The role of social linkages and especially migrant networks on the micro or meso level is crucial for understanding the patterns and volume of migration, once it has set off. After a pioneer period, where migrants face many difficulties, access of their "followers" to the destination country is easier, as they are better informed through the pioneer migrants. New channels of communication are established and communities of migrants are created in the receiving country (Goss \& Lindquist 1995). New migrants will receive help from the pioneer migrants ranging from arranging the trip to finding a job, thus making migration increasingly cost and risk free. Empirical applications of networks can be found all over the world, maybe being one of the most visible aspects of migration theory.

According to Guilomoto \& Sandron (2001) migrant networks perpetuate themselves due to institutionalisation, path dependency etc., but are also affected by external factors e.g. labour market changes. The institutional part of a network refers to the rules and norms governing the network that reduce the transaction and migration costs (e.g. children sending home remittances to their parents), whereas the organisational aspects refer to the practical help given to pioneers within the network. As mentioned above, networks depend on path dependency and are not necessarily the most efficient solution; a chance event happening to a pioneer can shape the entire network. Networks can be both a chance and threat to a potential migrant. Migrant networks are held in place by these institutionalised norms, also known as social capital, but they are complimented with external migrant institutions (Goss \& Lindquist 1995). These institutions, ranging from people smugglers to recruiting agents and humanitarian NGOs, also help to perpetuate the flows of migration.

As argued above, migration networks decrease the costs and risks of migration over time and thus make migration more likely and widespread in a community, the more people have migrated. Stark and Wang (2002) argue that one reason why the more highly educated pioneers help new migrants is that having less-skilled migrants in the destination country helps to differentiate their own skills better. Other reasons could be altruism, patriotism or ownership of relevant social capital.

A final meso-level theory of migration is cumulative and circular causation (Massey, 1990), which shows how migration becomes more and more common since it has started, by sustaining itself. Past migration alters the context in which current migration decisions are made by changing the socio-economic context and 
macro environment of migrant households that then affect the migration decisions of future migrants. Networks expand, migration becomes part of local culture and this makes migration more and more accessible to all levels of the population. There is likely to be lower labour demand in the areas of origin due to new, less labour-intensive agricultural production methods brought home by migrants and land left empty by migrants. If more educated people leave, the source regions stagnate, increasing the returns from migration. Finally migration can change the local income distribution, again increasing the returns from migration. Thus, according to this theory, the more migration there is, the more migration there may be in the future. Of course migration does not continue indefinitely: At one point migration networks become saturated, labour scarcity in the source country increases and migration potential is very low with only old people or children left to migrate. At this stage migration might start to a decrease which makes the overall migration curve inverted u-shaped.

\subsection{A general framework of migration decision making}

The above review summarised the most important economic migration theories. Comparing and contrasting them makes it clear that they are not necessarily conflicting, but that they can be combined in a complimentary fashion. Individual decisions are made in specific social context that feed back into the economic and social structural environment and affect future migration choices (Massey et al., 1993). Figure 2.1 shows the links the different theories and condenses them into one complete picture. 
Figure 2.1 A general framework of migration decision making

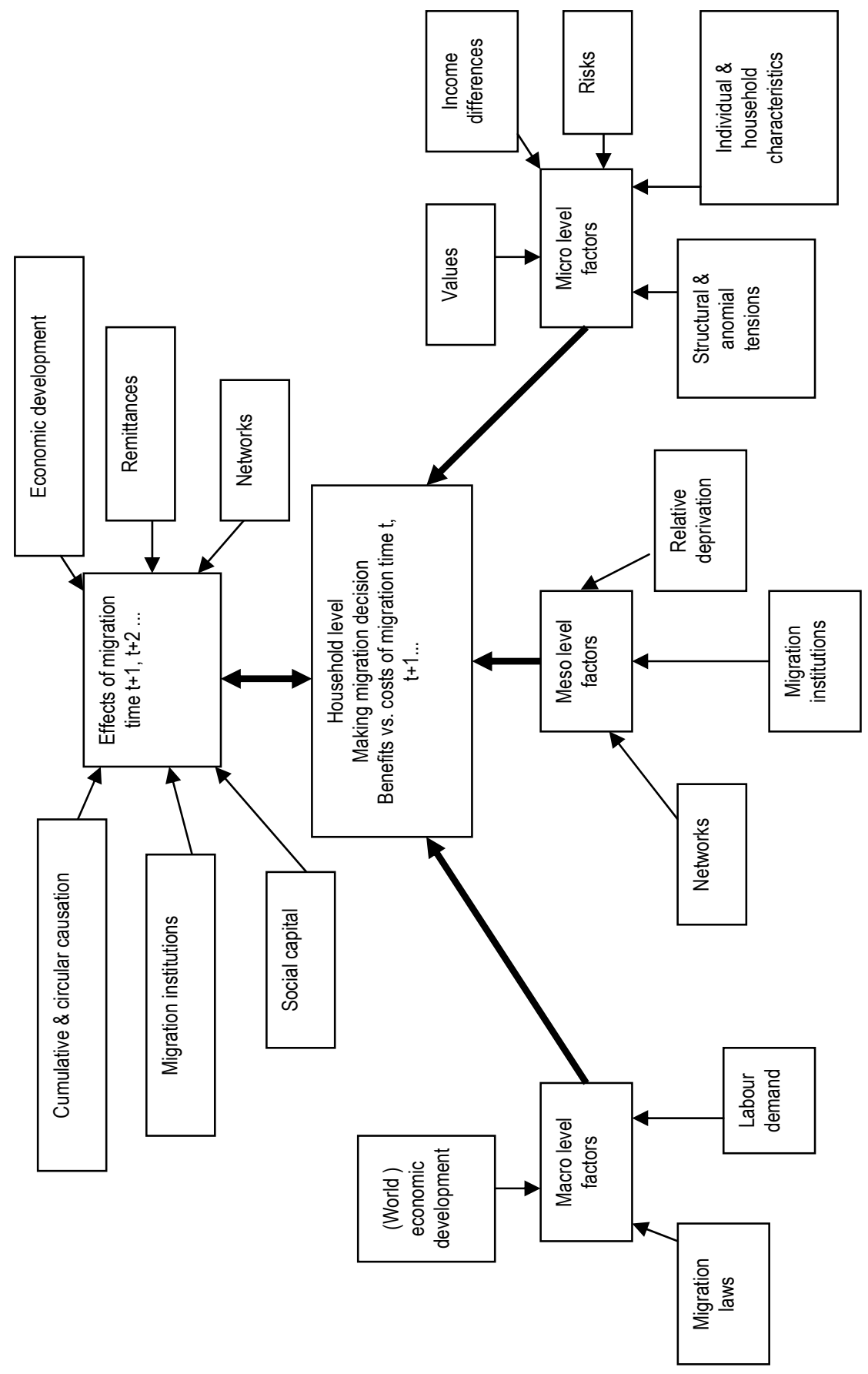


It is clear that most migrants do not take the decision to migrate in a social vacuum and that their family is likely to have some influence. Therefore the migration decision should be considered on a household level. The migration decision entails weighing up the costs versus the benefits of migration. Various factors affect the costs and benefits.

On the micro-level income differences and poverty undoubtedly push and pull potential migrants. Risks and dysfunctional credit markets in the home country could also be reasons for migration. Questions of power and prestige can also influence decision making, as well as other personal goals or values. Furthermore personal and household characteristics (e.g. marital status, education level) are very important in explaining the selectivity of migrants.

Looking at the meso level, migration is more likely to take place in a context of relative deprivation, i.e. in a community with higher levels of inequality. Migration is also more likely to take place if migration institutions have already been established or if migrant networks are available to the potential migrant.

On the macro-level the demand for labour and migration laws are crucial in influencing the decision to migrate, but especially the destination of migrants. Globalisation and world-wide economic development may affect migration flows in many ways ranging from decreasing transportation costs to changing job prospects all over the world.

Finally, migration has many effects that in turn also influence the decision-making process of future migrants. Migration affects economic development in the origin and destination country and therefore changes potential push and pull factors. For example high migration flows might make labour scarce in the origin community and therefore improves the job prospects of people left behind. These people are less likely to migrate, as impediments to migration are higher. Cumulative and circular migration refers to the fact that once migration is in place, it sustains itself. It has been shown that migrant institutions, social capital and networks that develop over time as more people migrate, reduce the costs and ease migration for future migrants. Migrants send remittances home that might finance the migration costs of future migrants.

\subsection{Conclusion}

The synthesis in the previous section showed the complementarities between the different migration theories. Very broadly, the migration decision entails weighing the costs versus the benefits of migration. The importance of wage differentials or income consideration, emphasized by the neoclassical approaches, is taken for granted by most theories and it is considered a necessary condition for people to migrate. Other more sociological factors, like the need for security, coming from the behavioural models, should also be considered. It has also been argued that coinsurance and relative deprivation affect migration decision making as well. It is also clear that a wider decision-making framework on the household level is appropriate, as very few individuals are isolated actors that take decisions in a social vacuum. 
As the system theories explain, the different actors are not isolated but often affect one another at one point in time (through social capital) and over time (e.g. cumulative causation). It is therefore important to consider the different levels of migration. Structural macro factors affect the decisions made on the micro level. Political institutions (e.g. migration laws), pull factors (like labour demand in the Dual-Labour Market theory), economic development (like in the World Systems theory, NELM or mobility of transition) all constrain the migrant's decision making progress. On a meso level social capital, institutions and networks can help or hinder migration.

Finally, migration should not be considered cross-sectionally, but historically over time. Migration flows are dynamic. The NELM makes it clear that the causes and consequences of migration are linked. As the cumulative causation theory shows, migration trends and migrant characteristics can change depending on the stage of migration. Current migrants can affect the structural environment, e.g. through influencing economic development in the origin country. Due to the dynamic nature of migration, the question of why people migrate will continue to be a lively and interesting topic in the years to come. 



\section{The determinants of remittances}

\subsection{Introduction}

The recorded flows of money sent home from the 191 million worldwide migrants working abroad, known as remittances, have now reached over $\$ 200$ billion. It is estimated that at least $50 \%$ of remittances are sent through informal channels, which are not recorded, bringing the total remittances sent to somewhere around $\$ 300$ billion (World Bank, 2006). These flows now exceed Official Development Aid (ODA) as well as Foreign Direct Investment (FDI) in many countries (World Bank, 2006). For many developing countries, remittances are a very important source of finance frequently make up anywhere between 5 and $40 \%$ of the country's GDP. These countries are often highly dependent on remittances as a source of alleviating poverty and to finance trade deficits.

It is important from a policy perspective to comprehend why people send remittances, since remittances affect and possibly improve the lives of many people around the world. In this chapter I review the current state of literature on the determinants of remittances. While the decision to remit may be clearly linked to the causes of migration, for example in the theory the New Economics of Labour Migration the causes of migration literature is taken as given I focus on the determinants of remittances. Most of the literature is based on empirical applications; hence I will focus on clearly summarising existing findings before comparing the results to my own in the next chapter. I start by giving the theoretical background of the determinants of remittances. The main theoretical determents of remittances are altruism, insurance, the bequest motive, loan repayment, and the exchange motive. I then move to a more extensive section on the empirical applications of the micro-economic determinants of remittances. I conclude with a summary of findings from the literature.

\subsection{The determinants of remittances}

\subsubsection{Theoretical determinants of remittances}

The theoretical debate about the determinants of remittances was triggered by Lucas and Stark (1985) with their ground-breaking paper "Motivations to remit: Evidence from Botswana", which is still the basis of the current discussion and extensions. Lucas and Stark studied remittances on a household level and hypothesized the main determinants to be "pure altruism", "pure self-interest" and "tempered altruism or enlightened self-interest". Any kind of contractual arrangements between the migrant and household left behind can be in the latter category, for example co-insurance, exchange-motives or loan repayment. The 
theoretical motives and their effects on remittances are summarised in Table 3.1. I give a more detailed discussion of the motives below.

Table 3.1 Theoretical effects of certain factors on remittances for different motives

\begin{tabular}{|c|c|c|c|c|c|c|c|c|}
\hline $\begin{array}{l}\text { Effect of } \\
\text { factor on } \\
\text { level of } \\
\text { remittances }\end{array}$ & $\begin{array}{l}\text { household } \\
\text { income } \\
\text { (home) }\end{array}$ & $\begin{array}{l}\text { migrant } \\
\text { income } \\
\text { (host) }\end{array}$ & $\begin{array}{c}\text { household } \\
\text { shock } \\
\text { (home) }\end{array}$ & $\begin{array}{c}\text { migrant } \\
\text { risk } \\
\text { level } \\
\text { (host) }\end{array}$ & $\begin{array}{c}\text { education } \\
\text { level of } \\
\text { migrant }\end{array}$ & $\begin{array}{l}\text { intent } \\
\text { to } \\
\text { return }\end{array}$ & $\begin{array}{l}\text { no. of } \\
\text { migrants } \\
\text { in } \mathrm{HH}\end{array}$ & time \\
\hline $\begin{array}{l}\text { Pure } \\
\text { altruism }\end{array}$ & - & + & + & & & & - & - \\
\hline $\begin{array}{l}\text { Pure self- } \\
\text { interest }\end{array}$ & + & + & & & & + & & \\
\hline Insurance & - & - & + & + & & & & \\
\hline $\begin{array}{l}\text { Loan } \\
\text { repayment }\end{array}$ & $+/-$ & + & & & + & & & $\begin{array}{l}t_{t}=0 \\
-t=1\end{array}$ \\
\hline $\begin{array}{l}\text { Exchange } \\
\text { motives }\end{array}$ & $+/-$ & + & & & + & & & \\
\hline $\begin{array}{l}\text { Strategic } \\
\text { behaviour }\end{array}$ & - & + & + & & & & & \\
\hline
\end{tabular}

It is natural to assume that remittances are sent to the family left behind due to altruistic feelings of the migrant. This can be modelled in a Becker type setting where a migrant derives positive utility from the consumption of their family. The migrant thus cares about poverty, shocks, etc. of the family and consequently sends remittances. In this case, there is a positive relationship between adverse conditions of the receiving household and remittances sent, see Table 3.1. Remittances should increase with migrant income (the migrant has more to share) and altruism and decrease with recipient income (Funkhouser, 1995). However, income does not necessarily have a linear effect. As Cox, Eser and Jimenez (1998) demonstrate, income may have a different effect at different points of the income distribution. ${ }^{12}$ Remittances may decrease over time due to weaker relationships with the family members left behind, but Poirine (2006) shows in a theoretical model that this is not necessarily so, depending on the home/ host country growth rates and the size of the Diaspora amongst other factors. Remittances may also decrease if there are other remitters in the family, as the migrant might feel less accountable if s/he knows that the family is supported by others.

In contrast to altruism, self-interest may also a motivation to remit. In this case a migrant sends remittances with the aspiration to inherit, to demonstrate laudable behaviour as an investment for the future or with the intent to return home. If a migrant intends to return home, s/he may already invest in housing, livestock etc. and could ask the family to be the agent. If a migrant wants to invest at home, the household may be a trustworthy and well-informed agent. The migrant may also send remittances to invest in his reputation at home. Inheritance may be used as a blackmailing device by the household head to receive remittances. According to to the bequest motive, remittances increase with the household's assets and income, the probability of inheriting (dependent on the age of parents, number of siblings,

12 The motive may even change at different points of the income distribution. 
etc.), the migrant's wealth and income, and decreases with risk aversion. Only in the case of the aspiration to inherit, can self-interest be distinguished from altruism in the migrant's behaviour and a larger income and or wealth of the household should lead to more remittances. Finally, in a three generation setting, remittances may be sent to parents to ensure that the remitter's own children also take care of him/ her in old age (Cox \& Stark, 1994), known as the demonstration effect. Care and transfers have to be visible to the grandchildren generation for maximum effect.

A less extreme view of the motivations to remit is tempered altruism. In this case the migrant and the family at home mutually benefit from migration, through some kind of implicit contractual arrangement. Altruism and self-interest can nevertheless play a role here, by making the contracts self-enforcing. The contractual arrangements discussed here are co-insurance, loan repayment and exchange for services.

The New Economics of Labour Migration (NELM) hypothesis states that due to market failures in the source country (for example a poorly developed social protection system), a household member migrates to a non-correlated labour market, entering a type of co-insurance agreement with the household left behind. Remittances are sent home when the household experiences shocks and to enable the household to invest in new technologies. At the same time, the household also supports the migrants, e.g. during spells of unemployment. Remittances consequently increase when the household's income decreases or a shock occurs (like for altruism), but also when the risk-level of the migrant increases. Risks at home and risks in the destination country have to be non-correlated for such a coinsurance agreement to work well. Such an agreement would reduce uncertainty for all household members. The level of development of the households' community also plays an important role here. While poor economic conditions (e.g. high unemployment) may be a cause of migration, the household's community needs to have a certain level of development in order for investment by the household to be effective. Consequently it is possible that fewer remittances are sent to underdeveloped communities.

Another type of contractual agreement between the household and family is loan repayment, for example repaying a human capital investment or the cost of migration. A household finances a potential migrant's education if the family implicit lending rate is higher than the market interest rate and the youth borrowing rate is higher than the family implicit lending rate (Poirine, 1997). During the next time period the migrant should be able to find a better-paid job in the city or abroad due to the education acquired and will send remittances to repay the family for the initial investment. At this stage the migrant might also become a lender, by financing other migrant family members, which increases overall remittances. The inverse u-shaped time profile of remittances is shown in Figure 3.1. In this case, the family contract has the aim of increasing income instead of reducing uncertainty. 
Figure 3.1 A theoretical average remittance function in the case of loan repayment

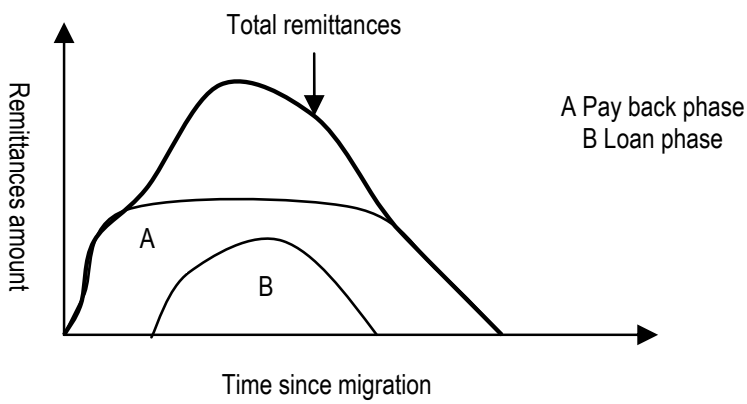

Source: Based on Poirine (1997)

In practice, only paying-back can be measured and there should be a positive link between the migrant's education level and remittances. This could also be interpreted as altruism, however, due to the high correlation between education and income.

A final contractual arrangement is the exchange motive (Cox, 1987). Here transfers are paid to the household at home for services provided (e.g. child care). The theory can also be applied to remittances, whereby remittances buy various types of services, usually by temporary migrants (Rapaport \& Docquier, 2005). If the migrant's income increases, remittances increase. If the household's income increases, thus making the services more expensive, remittances can decrease or increase depending on the migrant's elasticity of demand. If the migrant's demand for the services is elastic, fewer services will be demanded and remittances decrease. If demand is inelastic, the same services will be bought, but at higher price, which leads to more remittances, despite the higher income of the household at home. Higher unemployment in the home country should mean fewer remittances since less money is then needed to make those at home perform their service (the opposite effect is found for altruism).

The strategic model, first explained by Stark (1995) and later by Stark and Wang (2002) stems from a strategic migration decision made because of wage differentials. Since high skilled migrants usually have more to gain by migrating, they are typically the first to go and then unskilled workers follow. As individual productivity is unobservable in the rich country, migrants are paid the average productivity of the group with which they are identified. For this reason, skilled workers may have an incentive to remit money home to keep unskilled workers in their home country, since migration of these workers may mean depressed wages for the skilled migrants (Docquier \& Rapaport, 1998). In short, remittances increase with income and education of the migrant and with low income at home (Holst and Schrooten, 2006), thus again indistinguishable from altruism. 


\subsubsection{Empirical determinants of remittances}

This section discusses the literature on the microeconomic determinants of remittances, both from a receiving and sending perspective. I show how different authors tried to measure the theoretical remittance motives discussed in section 3.2.1. Some explanatory variables are repeated across many studies and these are listed Table A.1-Table A.3 in Annex A. I will extensively discuss and compare the results of these papers.

The estimations of the determinants of remittances are either based on household surveys that include remittance-receiving households, e.g. Gubert (2002), or specific surveys of the migrants themselves either in the home country, e.g. Amuedo-Dorantes \& Pozo (2006) or the destination country, e.g. Holst \& Schrooten (2006). The type of survey sometimes limits the nature of the analysis that can be done, for example, household surveys often do not have much information on the migrant. In addition some of the papers use complementary community-level data e.g. Durand et al. (1996). The countries studied most frequently are LatinAmerican and African countries and some Pacific and Asian countries. Eastern and Central Europe generally have not been studied much, though this is slowly changing.

The existing papers on the determinants of remittances have used very different methodologies. While most papers use some type of econometric analysis, they use everything from OLS to CLAD. Although earlier papers used OLS (for example Lucas \& Stark, 1985) to model the remittance decision, it is now known that using such a method leads to biased and inconsistent estimates, since a substantial fraction of the migrants does not remit. In recent papers the main methodological distinction is made between modelling the determinants of remittances as a onestage decision (Tobit) where the decision to remit and the amount of remittances are made together or as a Heckmann two-stage approach (Probit and corrected OLS), where the model separates between the decision to remit and the subsequent decision on how much to remit.

Most papers measure the altruism motive by looking at the effect of higher household or migrant income on the probability and or amount of remittances. As predicted theoretically (see Table 3.1) most papers find a positive relationship for the effect of the migrant's income on remittances ${ }^{13}$ and a negative relationship for the effect of the household's income on remittances. ${ }^{14}$ As Table 3.1 shows, all theories on the determinants of remittances predict a positive relationship between migrant income and remittances and most theories allow for a negative relationship between household income and remittances. Consequently most authors also test the effect of other variables on remittances to separate altruism from other motives.

Under pure altruism, the presence of other migrants in the households might have an effect on a migrant's behaviour. More migrants in the household means that the migrant is not solely responsible for the wellbeing of the household, so there may

\footnotetext{
13 The sole exception is Lianos \& Cavoundis (2004).

${ }^{14}$ Exceptions are Lucas \& Stark (1985) and Itzingsohn (1995).
} 
be a negative relationship between remittances and the number of migrants in the household. As tables Table A.1 to Table A.4 in Appendix A show, most papers do find this relationship ${ }^{15}$, which is some evidence for altruism. On the other hand some papers find the relationship to be insignificant, which could mean that altruism is not a determinant of remittances or not the sole determinant.

Length of stay is often related to the altruism motive. The longer a migrant has been abroad, and the less frequently the migrant has visited the home country, the weaker the ties to the home country and household are and the lower the importance of altruism is. Most papers do not find evidence for "remittance decay" 16 , which shows that generally migrants keep links to their home country.

Altruistic remitters would be more likely to send remittances and would send greater sums of remittances to larger households or households with a greater dependency ratio, as they are in greater need. This relationship generally does not hold for the probability of remittances ${ }^{17}$, but is found by most authors for the level of remittances and the simultaneous estimation of the probability and level of remittances, again some evidence for altruism. Most migrants are more likely to send remittances and send more if the household head is older, which is evidence for altruism towards the elderly. Even though in some cases women might display more altruistic behaviour (see for example de la Briere, 1997 and Vanwey, 2004 who estimates separate remittances functions for men and women), the overall empirical evidence for the gender effect is mixed.

Married migrants whose spouses are left behind in the source country should also be more likely to send remittances and send greater sums of remittances due to altruistic feelings. All papers that included the marriage variable and found a significant relationship, found a positive effect on the level of remittances and the simultaneous estimation of the probability and level of remittances. All papers find a lower probability of remittances and a drop in the amount of remittances, if the spouse has joined the migrant. This means that for certain family relationships, namely marriage, altruism does play an undisputed role.

Pure self-interest, for example the bequest motive, can be measured by looking at the effect of remittances on household wealth or the intent to return home. In theory migrants with a bequest motive should be more likely to send remittances and send greater sums of remittances if their parents are wealthy (e.g. they own land). ${ }^{18}$ Lucas \& Stark (1985) do find evidence for the bequest motive: Sons in Botswana remit more to families that have larger herds and if the household has a larger income (as predicted by the theory). However, one needs to be aware of a possible endogeneity bias: Households that can afford to send children away as migrants might have been richer in the first place. Brown (1997) finds that those

15 The following authors found positive relationships: Germenji et al (2001), Hoddinott (1994) and Pleitez-Chavez (2004).

16 The exceptions are: Banerjee (1984) and Funkhouser (1995).

17 Agarwal \& Horowitz (2002) and Osaki (2003) find a negative relationship. Banerjee (1984) and Itzigsohn (1995) find a positive relationship.

18 Some papers do find this relationship (de la Briere et al (1997), Hoddinott (1994), Pleitez-Chavez (2004), Schrieder \& Knerr (2000)), but others do not (Durand et al (1996), Germenji et al (2001), Holst \& Schrooten (2006), Lucas \& Stark (1985), Osaki (2003), Schrieder \& Knerr (2000)). 
migrants that intend to return home send more remittances, for example as investment in their assets at home. De la Briere et al (1997) find that young males in the Dominican Sierra, who have the intent to return home, do not adjust their remittance streams as a reaction to shocks their parents experience. The authors thus conclude that their remittances are more self-interested.

Whether remittances are sent as part of a co-insurance contract between migrants and households can be measured by analysing the effect of household shocks and migrant (income, employment and living) risk on remittances. According to most studies that included household shocks, shocks of the household (e.g. illness) lead to a higher probability of remittances and larger sums of remittances. ${ }^{19}$ Unfortunately, this cannot be distinguished from altruistic behaviour. The variable length of stay can also be used to measure the risk level of the migrant, as after a longer stay the migrant generally knows the destination country better, has a steadier job, etc. As mentioned before length of stay generally has a positive effect on remittances. This means that lower risk is accompanied with more remittances (so more insurance), which is some evidence against remittances as insurance. On the other hand, while few papers found a significant relationship for other measures of migrant risk level (e.g. illegal employment), almost all of those that did find risk to be significant, found a positive relationship between risk and the likelihood of remitting or the level of remittances. ${ }^{20}$ In these cases, migrants send home more remittances when they face greater risks in order to insure themselves against the loss of a job, etc.

Amuedo-Dorantes \& Pozo (2006) go further in measuring the insurance motive by distinguishing between self and family insurance and at the same time altruism. They do so by looking at what remittances are used for. Figure 3.2 outlines their hypothesis.

If remittances respond to income risks in the host economy and are used for consumption they are sent to the family as part of a co-insurance agreement. If they are used for asset accumulation instead, the family acts as an investor for the migrant, so remittances are sent for self-insurance. In essence they are like savings. The authors' findings show that those migrants with greater income risk remit more and that different types of migrants use different insurance methods. For example, young male migrants who have low levels of education and large families at home are more likely to use co-insurance (Amuedo-Dorantes \& Pozo, 2006).

19 Only Halliday (2006) finds that for an earthquake shock less remittances are sent, unlike for an agricultural shock. He attributes this to the fact that households cope with the earthquake by retaining family members at home to help with rebuilding.

20 Only Durand et al (1996) and Konica (2006) find that those migrants with stable jobs are more likely to remit. 


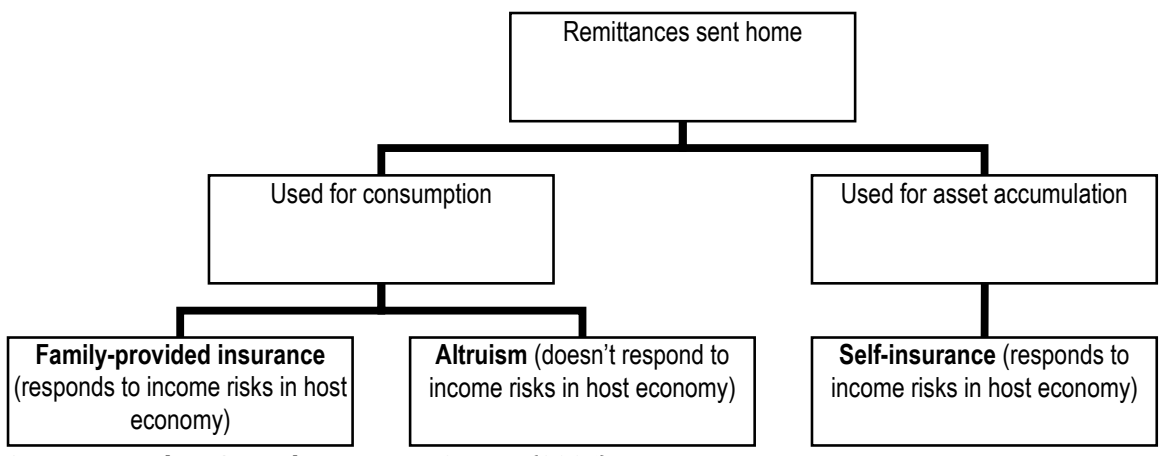

Source: Based on Amuedo-Dorantes \& Pozo (2006)

If remittances respond to income risks in the host economy and are used for consumption they are sent to the family as part of a co-insurance agreement. If they are used for asset accumulation instead, the family acts as an investor for the migrant, so remittances are sent for self-insurance. In essence they are like savings. While this may seem like self-interested remittances, both parties benefit from the informal arrangement. The authors' findings show that those migrants with greater income risk remit more and that different types of migrants use different insurance methods. For example, young male migrants who have low levels of education and large families at home are more likely to use co-insurance (AmuedoDorantes \& Pozo, 2006).

Durand et al (1996) and Sana \& Massey (2005) measure the NELM hypothesis more generally by also including community level variables into their analysis, for example the presence of banks and employment and business opportunities in the home community. Durand et al (1996) find that migrants are more likely to remit to economically dynamic and entrepreneurial communities, which suggests that remittances are sent as co-insurance under the right conditions. Sana \& Massey (2005) confirm this finding, because their results show that the community-level variables are only significant for Mexican migrants and not for Dominican migrants, for whom the family and economic structure is totally different. This also shows that cultural differences influence the remitting motives.

Loan repayment can be measured by looking at migration costs and the education level of the migrant. It is possible that those migrants that received help from their family in financing migration send more remittances as a loan repayment. This is confirmed by almost all empirical studies that find a significant relationship. ${ }^{21}$ In addition migrants with a higher education level could be sending remittances to repay the investment their parents have made in their education. That relationship is less strong however, because this variable could also measure income effects.

\footnotetext{
21 The exception is Niimi, Pham and Reilly (2008), who find a negative effect for loans with relatives and a positive effect for loans with banks.
} 
Almost all authors find a positive relationship between the migrant's education level and remittances ${ }^{22}$, providing some evidence for the loan repayment motive.

The exchange motive has not been extensively tested, probably due to data restrictions. Germenji et al. (2001) find that household heads older than fifty receive more remittances and claim that this is an exchange between the migrant and a grandparent, who could be looking after the grandchildren. However, there is no further data to prove this, so it could also be another motive, for example, altruism. Secondi (1997) looks at transfers in general in rural China and finds that recipients that are aged sixty and over and have grandchildren living with them, receive higher transfers. However this study has other problems, for example, unsatisfactory proxies for income. Therefore the evidence for the exchange motives is inconclusive.

\subsection{Conclusions}

The literature on the determinants of remittances is lively and is still growing. It links up with the general transfer literature and the determinants of migration. The main motives to remit, found in the literature, are altruism, insurance, loan repayment, bequest and exchange. While there is agreement on some determinants, e.g. altruism towards spouses, many of the results remain controversial due to a number of methodological problems. First, the decision to remit is often linked to the decision to migrate, which comes with its own methodological problems, e.g. selection bias. Most importantly it is difficult to find variables that measure one determinant only.

It is clear that different authors find different motivations to remit in different countries and at different times. Furthermore they are not exclusive of each other and remitters are likely to have more than one motive in mind. The lesson one can learn from this is that it is important to assess the remittance situation of each country on its own since there are very specific aspects to the motivations to remit in each country and for different types of migrants. Carling (2008) is a good example of explaining the determinants of remittances in the context of specific migration patterns.

The next chapter will evaluate the determinants of remittances literature more critically and will attempt to apply the theories to the cases of Albania and Moldova. I will also discuss the methodological problems in more detail.

22 Only two papers find a negative relationship between the migrant's education level and the probability of sending remittances: Durand et al (1996) and Osaki (2003). 



\section{The determinants of migration and remittances in Albania and Moldova}

\subsection{Introduction}

Albania and Moldova experienced some of the most intensive migration outflows in Europe since 1990 and are therefore ideal migration case studies. The purpose of this chapter is to test some of theoretical causes of migration and theoretical motives to remit, established in the literature, using household data for the years 2005 (Albania) and 2006 (Moldova). I am able to draw some conclusions on why people in Albania and Moldova migrate and remit, despite methodological difficulties. In the conclusion I discuss those methodological considerations extensively, besides linking the results and two strands of literature.

Albania and Moldova share a communist past and their current economic situation is similar; they are two of the poorest countries in Europe, with weak social protection systems and weak financial sectors. Figure 4.1 shows the position of both countries in Europe. Albania lies in South-Eastern Europe, bordering Greece, Macedonia, Serbia and Montenegro and lying across the Adriatic Sea from Italy. Moldova is in Eastern Europe and is landlocked between the Ukraine and Romania.

Figure 4.1 Location of Albania and Moldova in Europe

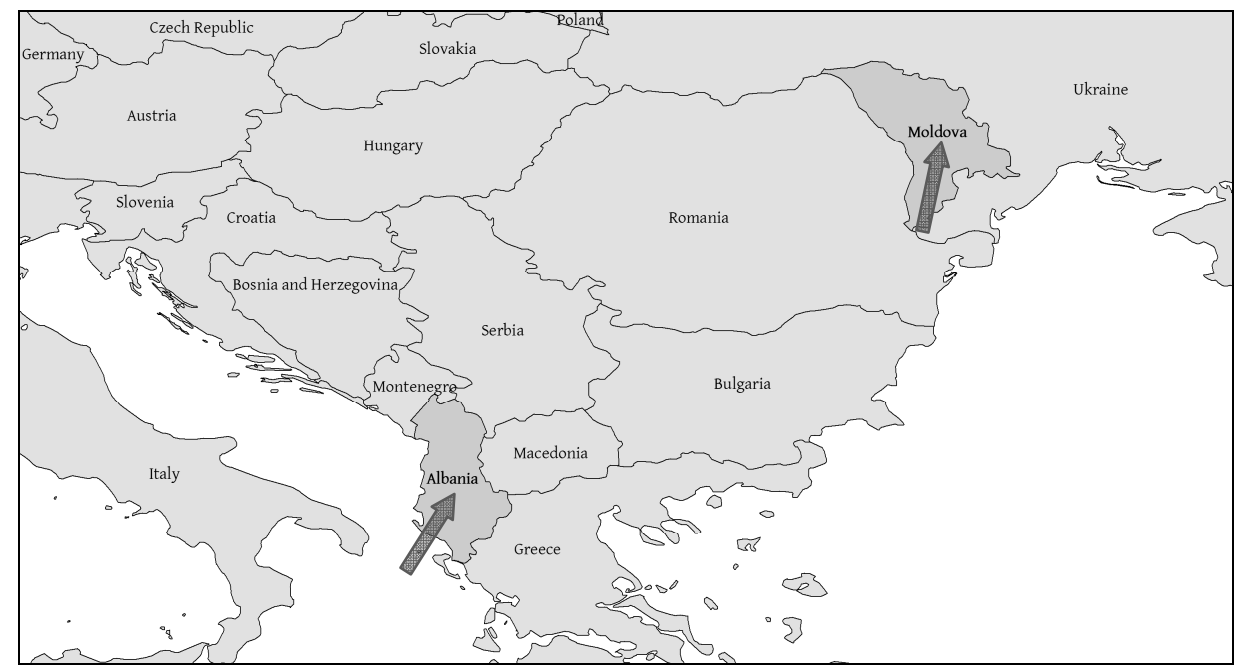

Source: DISSS (2009)

Not surprisingly, given the harsh transition experienced by Albania and Moldova, both countries have experienced high migration outflows and remittance inflows 
in recent years. Both countries are major remittance recipients, also on a global level, with remittances making up a significant fraction of GDP. Remittances have financed the growing trade deficit in both Albania and Moldova. Nevertheless both countries show different migration and remittances patterns. Therefore, it is relevant and interesting to study the determinants of migration and the motivations to remit in these countries.

Albania is a hilly and mountainous country, which contributed to its linguistic and cultural distinction. More than 95\% of the population is ethnically Albanian and $70 \%$ is of Muslim religion. Albania has experienced dramatic, sudden and intense international migration outflows since the end of the Communist era in 1990. Figure 4.2 shows the cumulative stock of emigrants since 1992. At the time of the 2001 census, 710,000 people out of a population of 3.07 million had migrated, which constitutes 23\% of the population (INSTAT, 2004). Including seasonal migration more than a million people are estimated to have migrated since 1990, mostly to Greece and Italy (Vullnetari, 2007). Political factors and the desire for personal liberation and self-expression are a motivation for emigration but the desperate economic situation was an important factor from the beginning (ibid). Seasonal and short term migration is especially common at the Albania-Greece border (Barjaba et al., 2005), where the population often has shared heritage with the Greek population and speaks Greek. In recent years, migrants often stay abroad for longer periods of time and bring their families along (de Zwager et al., 2005) and many become legalised.

Figure 4.2 Albania emigration and remittances

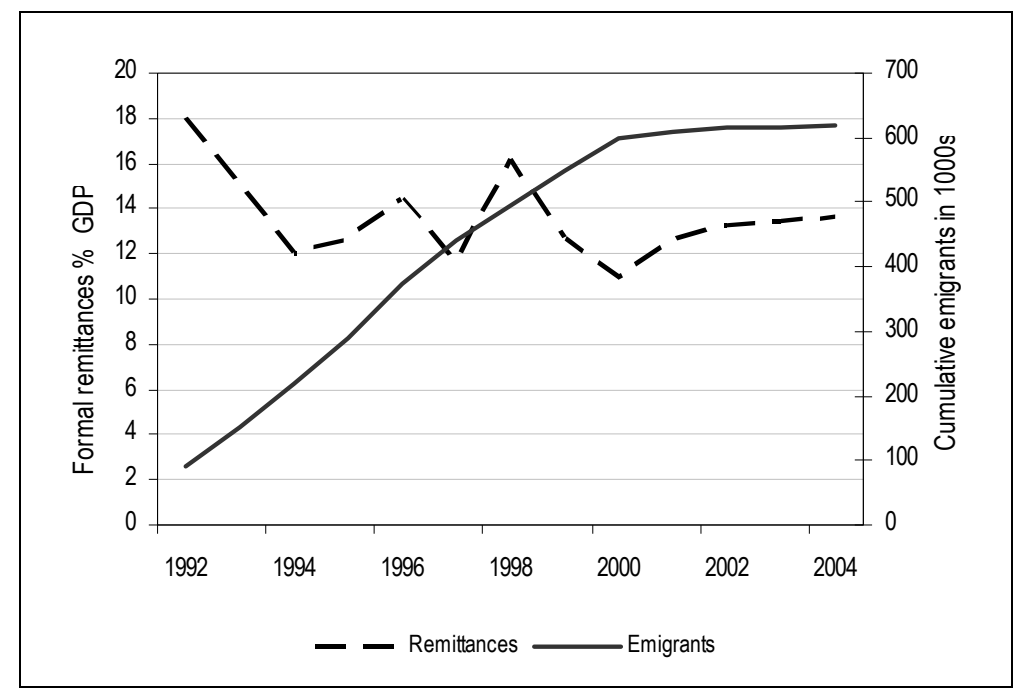

Source: IMF (2006)

Figure 4.2 also gives an overview of formal remittances as a percentage of Albanian GDP. This means that remittances/ GDP were at the highest level in 1992 when GDP was very low. Remittances have grown from \$150 million in 1992 to $\$ 1$ billion in 2004. In 2004 remittances made up 13.7\% of GDP (de Zwager et al., 2005), five times more than foreign direct investment and three times more than 
official development aid. In 2005, approximately one in five households received remittances and $68.6 \%$ of the migrants sent remittances home to their families (ibid).

Moldova also entered transition from central planning to a free market economy at the beginning of the 1990s. The Moldovan countryside is mostly low-lying fertile steppe country and having a temperate climate, agriculture remains important in the Moldovan economy. Moldova has a more diverse range of ethnic groups than Albania, with only $65 \%$ being ethnically Moldovan and other groups sharing cultural links to and languages with the Ukraine and Russia. This has affected politics and migration trends. Moldova's political history is very different to Albania's and being a part of the Soviet Union made Moldova much less isolated than Albania. Because of Moldova's dependence on Russia, the breakdown of the Russian economy in the early 1990s, threw Moldova into an extreme collapse that was worse than in other Soviet Republics. Therefore, migration in Moldova was mainly driven by poverty. Figure 4.3 shows the migration trends of labour migrants from Moldova between 1999 and 2003. There were almost 400 thousand Moldavians living abroad by 2004. By 2005 emigrants accounted for about 28\% of the working population and about $18 \%$ of the population of Moldova (Government of the Republic of Moldova, 2006). Moldovan migrants are also pulled towards their migration destinations by strong (seasonal or structural) labour demand with men mainly working in the construction sector in Russia and women working in the care sector in Western Europe. Seasonal migration is much more important in Moldova, than Albania, see Figure 4.7.

Figure 4.3 Moldova emigration and remittances

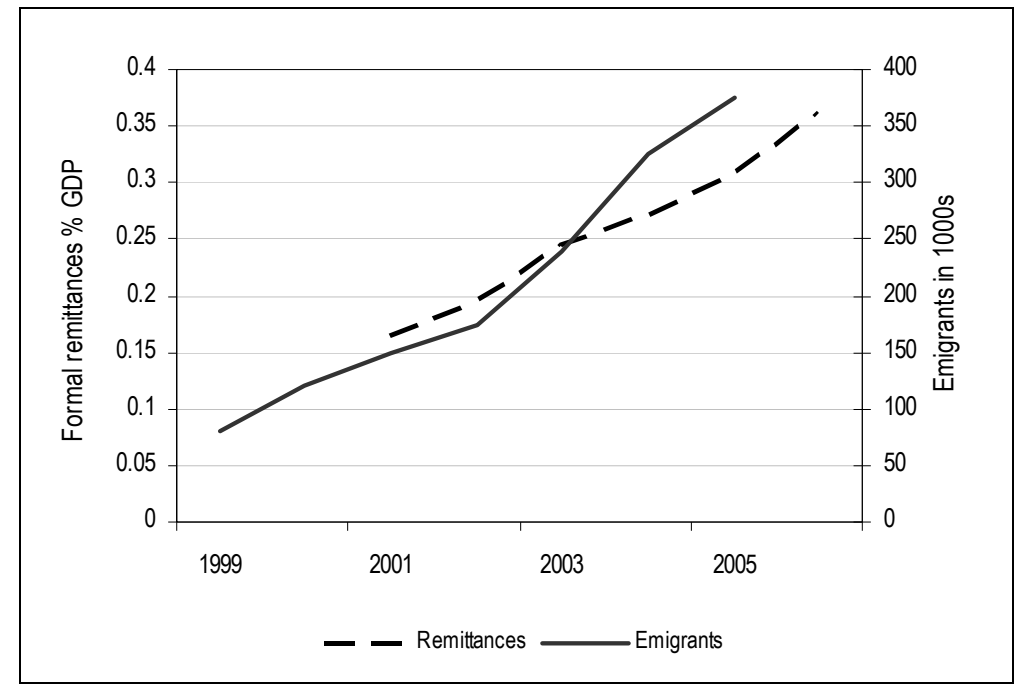

Source: World Bank (2007) and Moldova Department of Statistics and Sociology in Cuc et al. (2005)

Moldovan migrants are generally thought to keep a strong attachment to their home and remit large portions of their income. However, while in Albania family reunification in the host country is quite frequent, Moldova experiences mainly temporary migration of both men and women. The bulk of remitters are short- 
term migrants, many of whom are seasonal. In contrast to Albania, 70\% of all remittances in Moldova received are from temporary workers who stay abroad only part of the year (IMF, 2005). Remittances began to increase noticeably in 1998 during the regional crisis, which encouraged continued large-scale migration. By 2004, formal remittances had grown to $\$ 700$ million, constituting the astonishing equivalent of $27 \%$ of GDP (CBS-AXA, 2005), which is almost eight times more than foreign direct investment and seven times more than official development aid. Approximately $40 \%$ of Moldovan households receive remittances (Lücke at al, 2007).

The remainder of this chapter proceeds as follows. Section two gives the theoretical background for the determinants of migration and remittances. Section three explains the data and methodology used. Sections four and five report, analyse and discuss the results in light of the other empirical literature. Section six concludes, attempts to link the determinants of migration and remittances and discusses methodological concerns.

\subsection{Theoretical framework}

\subsubsection{Determinants of migration}

Chapter 2 extensively discusses the reasons why people migrate or why households send migrants abroad. Most of these different theories can be incorporated in some way or another in the theoretical framework in this chapter that explains why people migrate. The link between the different theories is the Welfare Pentagon. ${ }^{23}$ The theoretical framework, on which the analysis is based, links the incentives and the impediments to migration to institutional constraints and a lack of assets that may make it necessary to use migration as an income generating and consumption smoothing strategy for households and individuals.

I make use of the basic economic assumption that households maximise current income and smooth consumption over time. The Welfare Pentagon represents the five core institutions that households or individuals may use to satisfy current and future needs in a given society: family, markets, social networks, membership institutions and public authorities (Figure 4.4). ${ }^{24}$ Even though historical and geographical appearances differ, these institutions are found in all societies across time and space.

\footnotetext{
${ }^{23}$ See Hagen-Zanker, Siegel and de Neubourg (2009) for a more detailed discussion of this framework in relation to migration.

24 The Welfare Pentagon is a central and distinctive element in the 'Social Risk Management' approach as developed by de Neubourg (2002) and de Neubourg and Weigand (2000). The Social Risk Management framework is formulated to analyze the role and scope of public interventions and foremost, but not exclusively, that of public social protection policies.
} 
Figure 4.4 The Welfare Pentagon

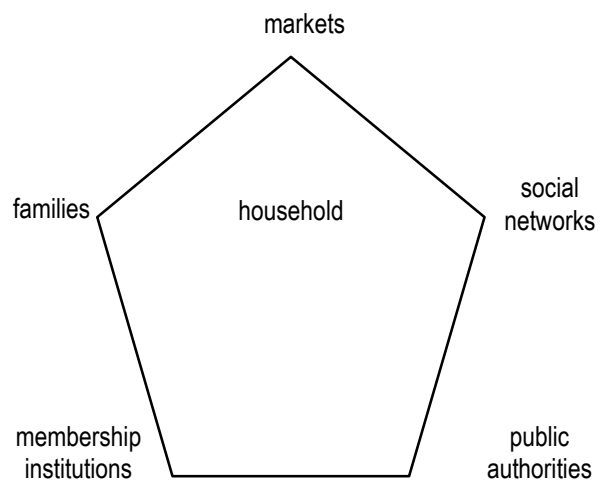

Source: de Neubourg (2002)

Households use the institutions of the Welfare Pentagon in their livelihood strategy in order to generate income but also to smooth consumption. Labour markets, product markets and capital markets allow households to trade and exchange. Families, social networks and membership institutions address the livelihood risk by means of various (and different) mechanisms of solidarity and exchange. As the fifth corner of the Welfare Pentagon, public authorities can assist households directly by means of public social protection or indirectly, for instance by providing free schooling.

In order to be able to follow a particular income generating and consumption smoothing strategy, households and individuals need access to the relevant institutions of the Welfare Pentagon, for example obtaining a (legal) wage depends on your access to the (legal) labour market. In order to have access to a particular institution, specific consumption smoothing strategies typically also require some kind of asset or capital. Assets can be financial (e.g. cash), physical (e.g. land), human (e.g. education), social (e.g. family ties,) or collective (e.g. citizenship). For instance human capital is required to enter the labour market, social capital is needed for making use of families and networks, political capital is needed to use public services, etc.

The amount of all forms of capital available to a person or a household, however, is neither fixed nor equal between individuals and households. The amount of capital available to individuals is endowed or acquired by investments. Individuals differ in their initial (capital) endowments due to two main reasons. Firstly, they are not equal in their capacity to generate wealth. Secondly and at least as important, individuals are "born in an income distribution" (allowing for endowed wealth to be passed from past generations to present ones). This means that individuals differ in their, and in their access to, income generating and consumption smoothing channels. The necessary capital to use one of the institutions (channels) of the Welfare Pentagon can, however, also be acquired. This is done by making investments and thus acquiring capital that can be used to mobilize an institution of the Welfare Pentagon to generate income or to smooth consumption. 
Households also differ in their exposure to risks (meaning that some households are plagued by more "bad luck" than others) and in their preferences regarding needs and risk aversion. As a result of the differences spelled out above (initial endowment, risk exposure, needs definition and degree of risk aversion), households adopt different income generating and consumption smoothing strategies or in other words, households differ in their livelihood portfolio strategy or in their particular place in the 5-dimensional space defined by the Welfare Pentagon.

Within this framework migration is one of the many options in the livelihood portfolio decisions of households. Households and individuals that are not able to generate sufficient income and smooth consumption over time given the institutions in their area of origin might consider moving from the place they live in to another area or country that seems to be more favourable. Whether (members of) the household actually migrate, depends on whether migration is actively considered as an option and is then implemented. This distinction is discussed extensively by Carling (2002) who introduces a theoretical model of immobility that differentiates between aspiration and ability to migrate. I focus on the ability to migrate, thereby assuming that households with a consumption shortfall will always have the aspiration to migrate. In order to adopt migration as a consumption-smoothing strategy, the institutions and assets needed to realize the strategy should be available.

The first explanation in this framework of why some people migrate and others do not is the following: People living in 'poor' households (meaning not able to generate sufficient income and not able to smooth consumption over time) have an incentive to move from the place they live in to another area or country. This explanation thus follows classic economic migration theories predicting that 'differences in net economic advantages are the main causes of migration' (Harris \& Todaro, 1970 and Mincer, 1978). However the theoretical framework used here is richer in the sense that it relates migration not only or purely to maximizing earning capacities in various geographical contexts but relates the migrationdecision to the causes of differences in earning capacities, as well as looking at a wider definition of poverty than just financial poverty. This theoretical approach also incorporates a systematic treatment of Kothari's exploration of the relationships between migration, staying put and poverty (Kothari 2003).

There is a large strand of literature specifically dealing with migrant selection, founded in the Roy (1951) tradition. Borjas's (1987) negative selection hypothesis based on the Roy model discusses the selectivity of migrants and their sorting across destinations that depends on cross-country differences in the returns to skills. Many works have followed (e.g. Borjas 1991, 1999; Chiquiar \& Hanson 2008; McKenzie \& Rapoport 2007). This chapter complements this work by approaching the phenomenon of migrant selection from a different angle (the Welfare Pentagon) as well as focusing on different migrant sending countries (Albania and Moldova). This means that the differences in migrant selectivity are not just explained in terms of education, but also other factors, such as employment possibilities, social networks etc.

Many publications in migration studies point out that there seems to be a general preference for staying "at home" (DaVanzo 1981; Faist 1997; Fischer et al. 1997). 
In the Welfare Pentagon framework presented here, this preference is explained by access to the institutions that enable a household to generate sufficient income and smooth consumption in their home location. Access to institutions are in turn explained by the investment and the sunk costs that guarantee access due to location-specific investment in economic, human and especially social capital (DaVanzo, 1981).

The argument above can also be expressed in other terms: A relatively high degree of social inclusion prevents most people from migrating. However, as argued, a minimum of social inclusion in the sending country Welfare Pentagon and ownership of relevant assets is absolutely necessary to turn migration into a viable livelihood portfolio strategy. This means that the very poor are trapped in a situation where they do not have access to a sustainable livelihood at home, but also do not have enough or relevant capital to use migration as a livelihood strategy. Those who are socially excluded are on the one hand less restrained from considering migration, but on the other hand they are too constrained in their access to channels and assets of the Welfare Pentagon to make migration work.

As argued before, migration may be triggered by a shortfall in the income generating and consumption-smoothing strategies for a household (in the sending country) leading to a negative gap between the needs that have to be fulfilled for the household and the actual potential of the household to fulfil the needs. Especially the argument that optimizing consumption-smoothing possibilities rather than only net-income differentials is consistent with the New Economics of Labor Migration, wherein risk-diversification arguments are prominent (Stark \& Bloom, 1985). The latter theory states that migration is not only aimed at maximizing income but rather at diversifying risks. This fits the income generating and consumption-smoothing hypothesis: given the households' risk aversion preferences and their endowment in smoothing channels and assets, households cover the risk of income shocks by seeking wealth creation in geographical areas wherein the shocks and the opportunities are less correlated to shocks and opportunities in their source area.

When individuals decide to migrate both institutions and assets are needed. Paying for the trip and for documents assumes that the potential migrant either has the money him/ herself (or has borrowed it from family members), or has access to the capital market where the funds can be commercially borrowed. Access to social capital in the form of membership organizations and networks that can provide information on how to arrange the documents and travel may play a role as well. The sending-country public authorities are important too since they can impede, stimulate or facilitate emigration (by providing legal documents and information). This means that households will only migrate when they have migration-efficient access to Welfare Pentagon channels that allow them to pay for the costs (formally or informally) and furthermore distribute information on where to go and how to arrive.

Access to social capital and the availability of helpful family and friends also reduces the transaction costs of migration. Assuming that access to social and financial capital and to markets (legal travel market, human smuggling market) are positively related to household endowments, it is clear why less well endowed families ('poor' households) are less likely to migrate. In order to consider 
migration as a viable livelihood option some assets and some forms of capital are indeed needed. Discrimination in the sending country can act as a incentive to leave, but at the same time it can also deprive the discriminated group of the essential pentagon channels that allow them to migrate or even to consider migration as an option.

While the (relative) position of a household in the Welfare Pentagon of the sending country is important in facilitating access to income generating and consumptionsmoothing strategies and thus providing the incentives and the means to migrate, the expected position of migrants in the Welfare Pentagon of the receiving country is also part of the decision. Household (members) will only migrate if their potential place in the Welfare Pentagon of the receiving country can at least be roughly assessed. All migrants understand that immediately after migration the need for income generating and consumption-smoothing abilities in the new society will be extreme. This means that they either need to have direct and immediate access to the labour market or access to other forms of funding provided by their own savings, by family or network members in either the sending or the receiving country.

Expectations about the consumption-smoothing options open to migrating households are positively influenced by their formal access to all the markets in the receiving country ranging from the labour market to the capital, housing, education, health and insurance markets and by the availability of family members, networks and membership organisations open to migrants (including NGOs serving migrants). The public authorities in the receiving country play an important role as well; they define the legal access of migrants to markets and public goods, and also migrants' social protection arrangements. Informal Welfare Pentagon channels are often especially important; they reduce migration risks, counteract information asymmetries and provide direct and indirect access to legal and illegal markets. There is a vast literature on the role of networks in shaping migration decisions all pointing in that direction. ${ }^{25}$

To summarize there are three main mechanisms that influence the decision to migrate:

- the household is constrained in its ability to generate sufficient income and smooth consumption to a level that it deems necessary to fulfil its needs in the sending country;

- the household has access to the Welfare Pentagon institutions and assets that allows it to consider migration and to overcome the costs related to leaving the sending country;

- the household perceives that it will have access to the Welfare Pentagon institutions and assets in the receiving country that will enable it to generate sufficient income and smooth consumption after having migrated.

${ }^{25}$ See, inter alia, Boyd (1989), Faist (1997), Fawcett (1989), Gurak and Caces (1992), Koser (1997), Massey (1990), Ritchey (1976), Wilpert (1992). 
The combination of these mechanisms can explain why some (members of) households migrate while others do not. Figure 4.5 illustrates the migration decision making process.

In this section I briefly discussed why people may migrate, using the Welfare Pentagon as a theoretical framework, and have shown how the different elements of the Welfare Pentagon relate to the existing migration literature. The main reason why people migrate is because they are "poor" in some sense; they do not have enough income today or in the future or the possibilities to generate income. I have also explained how the very poor may have too few assets to migrate. In the next section I look at why migrants remit.

Figure 4.5 The migration decision making process

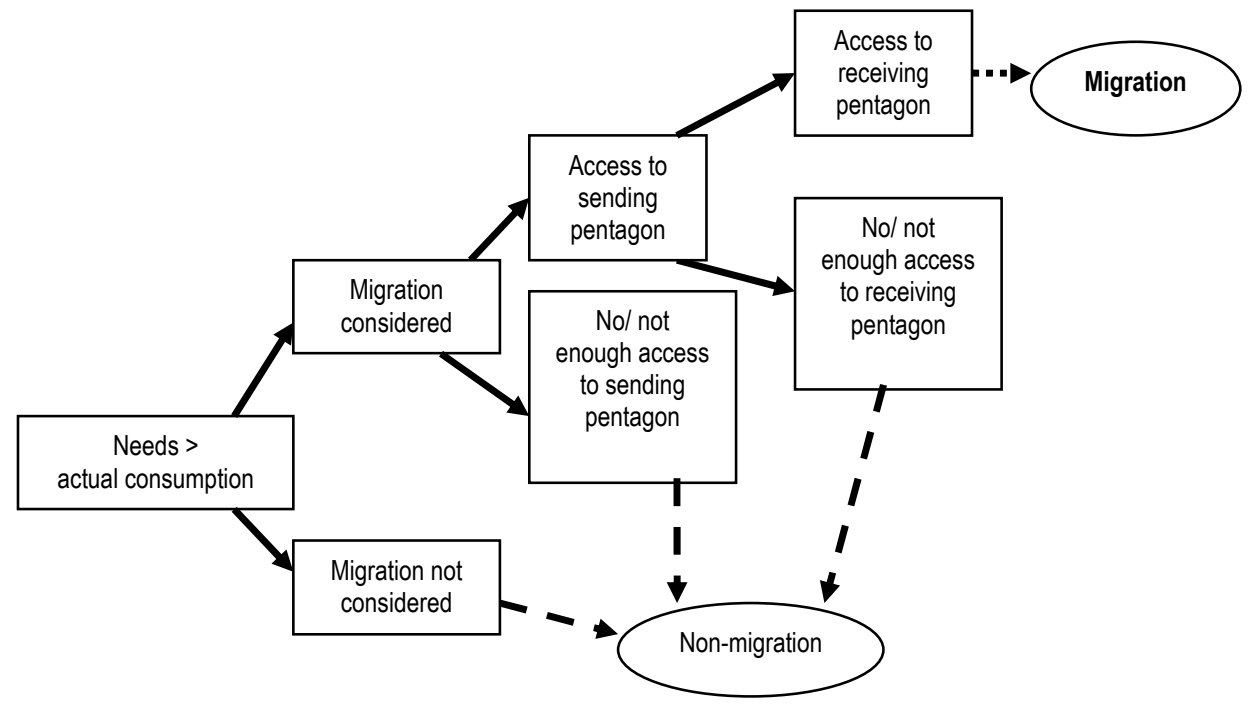

\subsubsection{Determinants of remittances}

Chapter 3 extensively discussed the theoretical and empirical determinants of remittances. Here those theories that are tested in the empirical section below are briefly reiterated.

A basic motivation of a remitting migrant may be altruistic feelings towards the family left behind. In the literature this is modelled so that the migrant derives positive utility from the consumption of the family. The migrant, thus, cares about poverty, shocks, etc. of the family and consequently sends remittances. In this case, there is a positive relationship between adverse conditions of the receiving household and remittances sent. Remittances should increase with migrant income (the migrant has more to share) and strength of altruism and decrease with recipient income (Funkhouser, 1995). There is a wide academic discussion on how to measure altruism, but most authors agree that measuring altruism by only looking at the effect of giver and receiver income is controversial. It is very 
abstract and perhaps too rational an operationalisation of decision making and, additionally, captures other effects. In general altruistic migrants are considered to send less if other family members also send remittances and to send less over time due to weakened ties and changed demographic circumstances.

The second broad remitting motive discussed in the literature is self-interest. In this case, a migrant sends remittances with the aspiration to inherit, as an investment for the future or with the intent to return home. If a migrant intends to return home, he may already invest in housing, livestock etc. and will ask the family to be the agent. If a migrant wants to invest at home, the household can be a trustworthy and well-informed agent. The migrant may also send remittances to invest in his reputation at home. Furthermore, a migrant may remit in order to be ranked highly in the (implicit) will of his family. With a bequest motive, remittances increase with the household's assets and income and the probability of inheriting (dependent on the age of parents, number of siblings, etc). In the case of a bequest motive, self-interest can be distinguished from altruism using conventional explanatory variables and larger income and or wealth of the household should lead to more remittances. Self-insurance (as developed by Amuedo-Dorantes \& Pozo, 2006) is essentially another self-interested motive in which migrants send remittances (an informal insurance premium) in order to receive transfers (i.e. reverse remittances) in times of shock (expatriation, unemployment etc).

The first contractual arrangement that may be the result of tempered altruism is co-insurance between households and migrants, as highlighted in the New Economics of Labour Migration (NELM). According to the NELM, a household member migrates to a non-correlated labour market due to market failures in the source country (for example poorly developed financial markets), entering a type of co-insurance agreement with the household left behind. These contracts are self-enforcing when mutual altruism is present or in patriarchal societies (Sana et al., 2005). Remittances are sent home when the household experiences shocks and to enable the household to invest in new technologies. ${ }^{26}$ At the same time, the household also supports the migrant, e.g. by paying for the costs of migration or during spells of unemployment. Remittances consequently increase when the household's experiences a (income) shock (like for altruism), but also when the risk-level of the migrant increases. The NELM is the only economic theory that explicitly links the motive to remit to the decision to migrate.

Another type of contractual agreement between the household and family is loan repayment, for example, repaying a human capital investment or the cost of migration. According to this theory, a household finances a potential migrant's education which enables him to find a better-paid job in urban areas or abroad (Poirine, 1997). During the next time period the migrant will send remittances to repay the family for the initial investment ("payback-phase"). At this stage the migrant might also become a lender, by financing other family member's

${ }^{26}$ The level of development of the households' community plays an important role here. While poor economic conditions (e.g. high unemployment) may be a cause of migration, the household's community needs to have a certain level of development for investment by the household to be effective. Consequently, it is possible that fewer remittances are sent to underdeveloped communities. 
education, which increases overall remittances ("loan phase"). In practice, only paying-back can be measured and there should be a positive link between the migrant's education level and remittances. However, this could also be interpreted as altruism or another remitting motive due to the close link between education and income.

A final contractual arrangement is the exchange motive (Cox, 1987). Here transfers in the wider sense are paid to the household in the origin country for services provided. The theory can also be applied to remittances, whereby remittances buy various types of services (e.g. child care), usually by temporary migrants (Rapoport et al., 2005). If the migrant's income increases, remittances increase. If the household's income increases, thus making the services more expensive, remittances can decrease or increase depending on the migrant's elasticity of demand. Higher unemployment in the home country should lead to fewer remittances since less money is needed to make the household members perform their service (the opposite effect is found for altruism).

While the economic literature focuses on strategic motivations that were freely chosen, more social motivations, like prestige and obligations are not considered. Furthermore, the economic literature neglects the fact that migrants may be willing, but not able to send remittances due to unexpected averse conditions in the host country. ${ }^{27}$ Moreover, family dynamics and the question of which family member in particular migrates, has not been discussed much in the economic literature, even though these factors are likely to influence remitting behaviour. When a migrant goes abroad or forms a new family abroad, the structure of the family left behind changes. Who migrates abroad affects the motives for remitting and, thereby, the amount remitted. For example, a husband might be altruistic and send as much as possible to his wife and children back home, while a son might feel it is a duty to remit occasional amounts. ${ }^{28}$

As was shown above, the theoretical literature is not able to clearly separate the different motives of remitting. This is a major obstacle from the start in the empirical applications and affects the strength of the conclusions that can be drawn ${ }^{29}$, but it has inspired some authors (e.g. Amuedo-Dorantes \& Pozo, 2006) to measure the remitting motives more creatively. In section 4.5 the motivations to remit in Albania and Moldova are measured in different ways and these results are compared and contrasted with other empirical applications to demonstrate the difficulty of measuring the motivations to remit, when the different theories overlap and compete. These problems are also discussed more extensively in the conclusion.

\footnotetext{
27 Al-Ali, Black \& Koser (2001) differentiate between the capacity and the desire of refugees to send remittances. This is an important nuance that should also be considered for economic migrants.

${ }^{28}$ A very interesting empirical application is Sana\& Massey. (2005), who show that sons and daughters from the Dominican Republic have very different remitting behaviour. The authors clearly make the link between changes in family dynamics and remittances.

${ }^{29}$ Liu \& Reilly (2004) is one of the few papers that explicitly discusses the difficulty of drawing clear conclusions on remittance motives from multi-interpretable results.
} 


\subsection{Data and methodology}

\subsubsection{Data}

I use data from household surveys in the migrant sending country as the basis of my empirical analysis. For Albania, the Living Standards Measurement Survey (LSMS) collected by Albania's statistical agency INSTAT in 2005, with technical assistance of the World-Bank, is used. It is representative on a national level and has a sample of 3640 households. This is a standard household survey and includes extensive modules on education, migration, consumption, labour etc. The survey asks whether the household currently has/ has had any international migrants. It also asks whether children and spouses currently living abroad send remittances and how much (these remitters may/ may not have been part of the household before migration). These two remittance-sending groups, are the most important senders of remittances (also confirmed by other studies e.g. Zwager et al., 2005). A migrant is defined as someone who has moved to another country in the past year for at least one month. I complement the household level data with information from a detailed community questionnaire, which was collected at the same time in all communities, where households were sampled. Questions were posed to community leaders or groups of persons judged to be best informed on specific sub-topics that ranged from problems in the community to community infrastructure.

For Moldova the CBSAXA 2006 survey is used. The opinion research company CBSAXA conducted this migration household survey for the International Organization for Migration in Moldova. One important purpose of the CBSAXA survey is to compare households with migrants to those without. A migrant is defined as someone who has moved to another country in the past year for at least one month (thus including seasonal migrants). Therefore, the survey was designed to be representative of Moldovan households at the national level (excluding Transnistria), for each major geographic region (North; Center; South; Chisinau), and for each major type of locality. The total number of households interviewed was close to 4,000 , resulting in a sampling error of approximately $3 \%$ for the share of households with migrants (Lücke et al, 2007). The survey collects information on international migrants and remittances received on a household level, as well as some background information on the household (demographics, education etc.).

\subsubsection{Methodology}

The methodology for the determinants of migration is straightforward. The determinants of being a migrant (a dichotomous variable taking on values of 1 for being a migrant and 0 for not being a migrant) are measured. I follow the previous literature by using a standard probit model, since I want to analyse the selection process. Equation 4.1 outlines the probability of being a migrant.

$$
p(y=1 \mid x)=G\left(\beta_{1} x_{1}+\beta_{2} x_{2}+\beta_{3} x_{3}+\beta_{4} x_{4}+\beta_{5} x_{5}+\beta_{6} x_{6}+v\right)
$$

$\mathrm{G}$ is a function taking on values between zero and one, and since this is a probit model it is a standard normal cumulative density function. $\mathrm{p}$ measures the 
probability of an individual to be a migrant, given the following characteristics. $\mathrm{x}_{1}$ are individual characteristics. The main variables of interest are regressors $\mathrm{x}_{2}$ to $\mathrm{x}_{6}$. These are characteristics that refer to the different parts of the Welfare Pentagon. $\mathrm{x}_{2}$ are family characteristics, $\mathrm{x}_{3}$ are market characteristics, $\mathrm{x}_{4}$ are membership institution characteristics, $\mathrm{x}_{5}$ are social network characteristics and $\mathrm{x}_{6}$ are public authority characteristics. $v$ is the error term referring to any unexplained differences.

Finding proxies that refer to different parts of the Welfare Pentagon is not a straightforward task. For example, how does one model whether someone has a helpful family? In this instance, I use family size (extent of possibility of help) and family wealth (extent of their helpfulness) as a proxy. In the next section I outline in detail which proxies are used for which corner of the Welfare Pentagon. Due to data limitations (especially for Moldova), the proxies used are quite rough. Nevertheless these proxies should give a basic idea about the different parts of the Welfare Pentagon.

The methodology for the determinants of remittances requires more explanation. Early papers on the motivations to remit used Ordinary Least Squares (OLS) (for example Lucas \& Stark, 1985) to model the remittance decision. It is now known that using such a method leads to biased and inconsistent estimates, since a substantial fraction of the migrants does not remit. In recent papers, the main methodological distinction is made between modelling the motivations to remit as a one-stage decision (Tobit) where the decision to remit and the amount of remittances are made together or as a Heckman two-stage approach (Probit and corrected OLS) where the model separates the decision to remit and the subsequent decision of how much to remit. The advantage of the latter approach is that it allows a regressor to differently affect the decision to remit and the level of remittances. Amuedo-Dorantes \& Pozo (2006), on the other hand, argue that using a two-part selection model leads to identification problems, i.e. it is hard to say which variables would matter for one decision and not the other.

An alternative to the two-stage approach is to assume that there is only one remittances decision in which the two stages occur simultaneously. This one-stage decision can be modelled as a single equation estimated by Tobit analysis, using both remitting and non-remitting migrants. Each regressor has the same effect on the probability of being a remitter and on the level of remittances. The convenience of this approach is that it enables the identification of a set of variables that are most significant in influencing "remittance behaviour" and thus test some of the theoretical predictions which do not differentiate between the decision to remit and how much to remit. I, therefore, assume that the remittance decision is a one-stage process and will model it using a Tobit model.

The Tobit model is specified as in equation 4.2 :

$$
R_{i}=\left\{\begin{array}{lll}
R_{i}^{*} & \text { if } & R_{i}^{*}>0 \\
0 & \text { if } & R_{i}^{*} \leq 0
\end{array}\right.
$$

where $R_{i}^{*}=\beta^{\prime} X_{i}+\varepsilon_{i}$ 
The Tobit model is used for censored data, where the dependent variable $\mathrm{R}^{*}{ }_{\mathrm{i}}$ is latent. In the following analysis $\mathrm{R}^{*}$ is observed for values that are higher than zero and it captures the i-th individual's propensity to remit. It has a normal, homoskedastic distribution with a linear conditional mean. $R_{i}$ is the actual observed value of remittances remitted by individual i. It can be either positive or zero and it is positive for those migrants that do remit. $X_{i}$ is a vector of explanatory variables that explains whether and how much someone remits. $\varepsilon$ refers to the error term that accounts for any unexplained differences.

A disadvantage associated with the Tobit model is that the assumption of normally and homoskedastic distributed errors might not hold. If households have more than one remitter, remittances of both remitters partially depend on the same unobservable household characteristics and this results in error terms that are correlated across observations. ${ }^{30}$ Since most households in the datasets only have one remitter, I assume that this problem is minimal. ${ }^{31}$

\subsection{Why do people migrate?}

This section looks at why people migrate. It uses data from standard household surveys for Albania and Moldova to explore whether something can be said about the relevance of the Welfare Pentagon institutions in explaining differences between migrants and non-migrants. It is clear that these data are not collected to test the livelihood portfolio theory. ${ }^{32}$ Many variables that would reflect the access to, endowment and investments in the institutions of the Welfare Pentagon are simply not available. This means that I roughly explore whether (not) having access to certain parts of the Welfare Pentagon explains why some migrate while others do not. Section 4.4.1 gives a first indication with descriptive statistics, followed by the econometric analysis in section 4.4.2.

\subsubsection{Descriptive statistics}

I start by showing the (possible) differences in individual characteristics of migrants and non-migrants, outlined in Table 4.1. These variables will be control variables in the regression that follows.

\footnotetext{
${ }^{30}$ For a further discussion of this problem see Gubert (2002).

${ }^{31}$ In Albania all households have 1.04 remitters on average and in Moldova 0.72 remitters/ household on average. Household members are defined as those family members related to the household head head and his/her spouse that usually live at the house, and take meals with the households and have been away for 11 months or less during the past year.

32 At the Maastricht Graduate School of Governance a large research project has been started in 2009 in collaboration with the Ministry of Foreign Affairs in the Netherlands aiming at collecting the data to analyze the mechanisms depicted in this framework.
} 
Table 4.1 Differences between migrants and non-migrants: Control variables

\begin{tabular}{|c|c|c|c|c|c|c|}
\hline \multirow[b]{2}{*}{ Is migrant } & \multicolumn{3}{|c|}{ Albania } & \multicolumn{3}{|c|}{ Moldova } \\
\hline & Yes & No & Total & Yes & No & Total \\
\hline \multicolumn{7}{|l|}{$\begin{array}{l}\text { Individual level } \\
\text { variables }\end{array}$} \\
\hline Age & $39.84^{* * *}$ & $42.71^{* * *}$ & 42.42 & $35.76^{* * *}$ & $42.49^{* * *}$ & 41.44 \\
\hline Male & $0.88^{* * *}$ & $0.42^{* * *}$ & 0.46 & $0.60^{* * *}$ & $0.44^{* * *}$ & 0.46 \\
\hline $\begin{array}{l}\text { Married } \\
\text { Household level } \\
\text { variables }\end{array}$ & $0.85^{* * *}$ & $0.67^{* * *}$ & 0.69 & $0.70^{* * *}$ & $0.63^{* * *}$ & 0.64 \\
\hline Urban & 0.48 & 0.47 & 0.47 & $0.38^{* * *}$ & $0.28^{* * *}$ & 0.36 \\
\hline Household head male & $0.95^{* * *}$ & $0.93^{* * *}$ & 0.93 & $0.80^{* * *}$ & $0.83^{* * *}$ & 0.80 \\
\hline Household head age & $50.04^{* * *}$ & $53.15^{* * *}$ & 52.84 & $47.40^{* * *}$ & $52.54^{* * *}$ & 51.75 \\
\hline $\begin{array}{l}\text { Household head } \\
\text { married }\end{array}$ & 0.92 & 0.91 & 0.91 & $0.84^{* * *}$ & $0.79^{* * *}$ & 0.80 \\
\hline $\begin{array}{l}\text { Number of children in } \\
\text { household }\end{array}$ & $1.23^{* * *}$ & $1.02^{* * *}$ & 1.04 & $0.81^{* * *}$ & $0.55^{* * *}$ & 0.59 \\
\hline No. observations & 996 & 10,748 & 11,740 & 1,798 & 9,785 & 11,583 \\
\hline
\end{tabular}

As to be expected, migrants are younger than non-migrants, but of working age on average. As hypothesized by the human-capital approach (Sjaastad, 1962) people migrate at a younger age, because then the investment "migration" is more worthwhile. In both countries migrants are more likely to be male and married than the non-migrant population. However, in Moldova the fraction of female migrants is much higher. There is a strong structural labour demand for care workers in Western Europe, a factor that may influence the migration decisions of Moldovan women, but not those of Albanian women due to cultural reasons. Only in Moldova migrants are more likely to come from an urban setting. In Albania there is no significant difference, as migrants are just as likely to come from rural areas (e.g. in Southern Albania, close to the Greek border). Coming to the household control variables, in both countries household heads of the household the migrant comes from, are younger and household have a higher number of children than non-migrant households. The latter result may be an indication of the need for migration. In Albania the fraction of male-headed household heads is higher for migrant households, while the opposite is true for Moldova. Only in Moldova household heads of migrant households are more likely to be married. These descriptive statistics indicate that there are significant demographic differences between migrants and non-migrants.

Next I investigate whether there are significant differences in access to the different parts of the Welfare Pentagon for migrants and non-migrants. First, Table 4.2 provides the results for proxies that reflect family institutions. The variables 
tell us something about family size, the extent of extended family members or about the wealth of the household in terms of the Morris index. ${ }^{33}$

Table 4.2 Differences between migrants and non- migrants: Family institutions

\begin{tabular}{l|ccc|ccc}
\hline & \multicolumn{3}{|c|}{ Albania } & \multicolumn{3}{c}{ Moldova } \\
Is migrant & Yes & No & Total & Yes & No & Total \\
\hline $\begin{array}{l}\text { Household size } \\
\begin{array}{l}\text { Number of extended } \\
\text { family members (siblings, }\end{array}\end{array}$ & $4.60^{* *}$ & $4.71^{* *}$ & 4.7 & $3.69^{* * *}$ & $4.28^{* * *}$ & 3.79 \\
$\begin{array}{l}\text { adult children) } \\
\text { Morris score index }\end{array}$ & 0.8 & 8.84 & 8.84 & & & \\
\hline No. observations & 996 & 10,748 & 11,740 & 1,803 & 9,899 & 11,702 \\
\hline
\end{tabular}

Note: All variables are household level variables

The Morris score index is a weighted asset index (see Morris et al. 1999). For Albania I refer to 1990, for Moldova to 2005 (see explanation in footnote 33 ).

Stars indicate whether the mean for each group is statistically different across groups $\left({ }^{*}\right.$ significant at $10 \%$; ${ }^{* *}$ significant at $5 \%$; ${ }^{* *}$ significant at $1 \%$ )

Source: Own calculation based on ALSMS 2005 and CBSAXA 2006

Migrants live in significantly smaller families in Albania and Moldova. Nonmigrants in Albania also have larger extended families (difference not significant). Making the assumption that family size is equivalent to helpfulness of the family, this makes sense, because one would expect that these households can rely on their extended families for consumption smoothing and so do not need to migrate. Vullnetari (2007) also confirms the importance of families for support. "Family has been one of the strongest elements of continuity over many decades in Albanian culture and society. Its importance increased as other forms of (state) support present during communism, collapsed immediately thereafter." (Vullnetari, 2007, p. 48).

It is hotly debated in the migration literature whether higher wealth or income are a cause or an effect of migration. With descriptive statistics it is not possible to draw any conclusions on causality. The household's Morris score index, which should be unaffected by migration (see footnote 33) is significantly lower for migrants. This could mean that migrants can again not rely on their families as much as non-migrants.

To explore the differences between migrants and non-migrants in their access to market institutions, I use per capita household consumption, the level of education of the migrant, employment variables and the availability of a bank in the community (Table 4.3).

33 The Morris score index is a weighted asset index that weighs each asset owned by the household by the reciprocal of the number of households that own the asset (see Morris et al. 1999). For Albania we use the index for the year 1990, which means that it is unaffected by migration. In Moldova migration occurred very rapidly, so we assume that assets are still unaffected by migration. As a precaution we exclude assets that may have been financed by remittances. 
Table 4.3 Differences between migrants and non-migrants: Market institutions

\begin{tabular}{|c|c|c|c|c|c|c|}
\hline \multirow[b]{2}{*}{ Is migrant } & \multicolumn{3}{|c|}{ Albania } & \multicolumn{3}{|c|}{ Moldova } \\
\hline & Yes & No & Total & Yes & No & Total \\
\hline \multicolumn{7}{|l|}{ Individual level variables } \\
\hline Primary education & $0.42^{* * *}$ & $0.57^{* * *}$ & 0.56 & $0.14^{* * *}$ & $0.10^{* * *}$ & 0.13 \\
\hline Secondary education & 0.22 & 0.2 & 0.2 & $0.34^{* * *}$ & $0.39 * * *$ & 0.35 \\
\hline Vocational education & $0.27^{* * *}$ & $0.14^{* * *}$ & 0.16 & $0.29^{* * *}$ & $0.32^{* * *}$ & 0.29 \\
\hline University education & 0.09 & 0.08 & 0.08 & $0.21^{* * *}$ & $0.18^{* * *}$ & 0.2 \\
\hline \multicolumn{7}{|l|}{ Household level variables } \\
\hline $\begin{array}{l}\text { Monthly per capita } \\
\text { consumption current US\$ }\end{array}$ & $76.57^{* * *}$ & $67.49^{* * *}$ & 68.38 & $98.12^{* * *}$ & $154.34^{* *}$ & 106.78 \\
\hline Household work ratio & $0.55^{* * *}$ & $0.50^{* * *}$ & 0.5 & $0.16^{* * *}$ & $0.38^{* * *}$ & 0.2 \\
\hline Household head employed & $0.73^{* * *}$ & $0.67^{* * *}$ & 0.68 & $0.17^{* * *}$ & $0.41^{* * *}$ & 0.21 \\
\hline $\begin{array}{l}\text { Whether hhh working on } \\
\text { farm }\end{array}$ & $0.34^{* *}$ & $0.38^{* *}$ & 0.38 & & & \\
\hline $\begin{array}{l}\text { Whether bank is a possible } \\
\text { source of credit in this } \\
\text { community }\end{array}$ & $0.66^{* * *}$ & $0.61^{* * *}$ & 0.61 & & & \\
\hline No. observations & 688-996 & $\begin{array}{l}6,868- \\
10,748\end{array}$ & $\begin{array}{l}7,556- \\
11,744\end{array}$ & 1,802 & 9,863 & 11,665 \\
\hline
\end{tabular}

Note: Household work ratio divides the total number of employed adults (including migrants) by the total number of adults in the household.

Community is defined as a village in rural areas and generally as an administrative unit in urban areas (defined on a case by case basis).

Stars indicate whether the mean for each group is statistically different across groups (* significant at $10 \%$; ${ }^{* *}$ significant at $5 \%$; ${ }^{* * *}$ significant at $1 \%$ )

Source: Own calculation based on ALSMS 2005 and CBSAXA 2006

In Albania household expenditures of non-migrants are lower; it could be that migrants live in richer households (thus financing the costs of migration and providing access to a larger range of resources) and that non-migrants do not have access to funds to finance migration. It may also be the case that migrant households are wealthier because they receive remittances from the migrant household member. In Moldova, on the other hand non-migrants come from families with significantly higher income, maybe because they had better access to market institutions at home and therefore did not need to migrate. However, there are several caveats that need to be pointed out. Consumption can be regarded as 'outcomes' of market processes rather than a direct indication of access to the market institution. Moreover, the direction of causality cannot be concluded from the table, as I do not account for reverse causality. For this reason I do not include it in the regression analysis.

It is not possible to draw clear conclusions on the selection patterns of migration with respect to the level of education. In Albania, individuals with secondary and vocational education are more likely to migrate and in Moldova it is people with primary and higher education. It seems that in Moldova people with higher and primary education do not seem to be well connected to the local labour market, but for Albania the message is less clear.

In Moldova non-migrants live in households with a higher employment ratio. Furthermore household heads in non-migrant households are more likely to be 
employed. This could be an indication that migrants did not have access to the domestic labour market and thus had to migrate. This is consistent with the pattern of seasonal migration that is found for Moldova: Moldovans migrate during those periods in the year when they are able to find employment abroad. It could also be the case that household members of migrants do not work due to cultural values (e.g. the wife left behind) and or due to remittances received. In Albania, however, there is an opposite picture: Households with migrants have a higher employment ratio and the household head is more likely to be employed. Nonmigrant household heads are less likely to be employed in agriculture in Albania, thus having more access to other employment options. ${ }^{34}$ Migrants are significantly more likely to live in communities with a bank, so maybe instead of allowing for more opportunities at home, banks helped to finance migration. The descriptive statistics seem to link migration in Moldova to education and employment (i.e. there is insufficient access to market institutions for individuals that then decided to migrate), while this seems less the case for Albania.

Table 4.4 considers social network institutions.

Table 4.4 Differences between migrants and non-migrants: Social network institutions

\begin{tabular}{|c|c|c|c|c|c|c|}
\hline \multirow[b]{2}{*}{ Is migrant } & \multicolumn{3}{|c|}{ Albania } & \multicolumn{3}{|c|}{ Moldova } \\
\hline & Yes & No & Total & Yes & No & Total \\
\hline $\begin{array}{l}\text { Fraction of individuals in } \\
\text { community who are } \\
\text { international migrants }\end{array}$ & $0.12^{* * *}$ & $0.11^{* * *}$ & 0.11 & $0.06^{* * *}$ & $0.08^{* * *}$ & 0.07 \\
\hline Number of friends & $2.07^{* * *}$ & $1.79^{* * *}$ & 1.81 & & & \\
\hline $\begin{array}{l}\text { Number of times joined other } \\
\text { people }\end{array}$ & $1.61^{* * *}$ & $1.29^{* * *}$ & 1.33 & & & \\
\hline $\begin{array}{l}\text { Participated in communal } \\
\text { activities }\end{array}$ & 0.1 & 0.1 & 0.1 & & & \\
\hline $\begin{array}{l}\text { Can get credit from friends etc in } \\
\text { emergency }\end{array}$ & 0.47 & 0.46 & 0.46 & & & \\
\hline No. observations & 996 & 10,748 & 11,740 & 1,803 & 9,899 & 11,702 \\
\hline
\end{tabular}

Note: All variables are household/ community level variables

Fraction of individuals in community who are international migrants is non-self constructed

Community is defined as a village in rural areas and generally as an administrative unit in urban areas (defined on a case by case basis).

Stars indicate whether the mean for each group is statistically different across groups ${ }^{*}$ significant at $10 \%$; ${ }^{* *}$ significant at $5 \%$; ${ }^{* * *}$ significant at $1 \%$ )

Source: Own calculation based on ALSMS 2005 and CBSAXA 2006

Looking at social networks, migrants seem to be better connected in many ways: they have more friends and socialize more often. However, they did not participate more frequently in communal activities and are also not more likely to get credit from a friend. The fraction of migrants in the community is significantly higher for

\footnotetext{
${ }^{34}$ This finding seemingly contradicts Miluka et al. (2007) who, also using the ALSMS dataset, find that migration of a household member has a negative impact on agricultural effort, measured by total hours spent on agriculture by all family members. However, we look at whether the household head works in agriculture and find that household heads of migrant families are more likely to be employed on a farm. This result is compatible with households as a whole working less on farms due to remittances received.
} 
migrants than non-migrants in Albania. All in all, migrants (at least in Albania) are significantly more likely to have access to migrant social networks. In Moldova non-migrants actually live in communities with more migrants. This surprising result could be the result of "migration saturation" in these communities.

So far social network institutions that measure informal connections were analysed. Next membership associations are looked at. This measures more formal networks and may have higher entry thresholds and thus be less accessible. Only the Albanian dataset has variables that may be used as indicators for the access of the households and individuals to membership institutions and to public authorities, illustrated in Table 4.5 and Table 4.6.

Table 4.5 Differences between migrants and non-migrants: Membership association institutions

\begin{tabular}{l|ccc}
\hline & \multicolumn{3}{c}{ Albania } \\
Is migrant & Yes & No & Total \\
\hline Number of groups household belongs to & $0.38^{* *}$ & $0.33^{* *}$ & 0.34 \\
Number of community organisations in community & $5.47^{* * *}$ & $4.98^{* * *}$ & 5.03 \\
\hline No. observations & 947 & 10,207 & 11,154 \\
\hline
\end{tabular}

Note: All variables are household/ community level variables

Community is defined as a village in rural areas and generally as an administrative unit in urban areas (defined on a case by case basis).

Stars indicate whether the mean for each group is statistically different across groups (* significant at $10 \%$; ${ }^{* *}$ significant at $5 \%$; ${ }^{* * *}$ significant at $1 \%$ )

Source: Own calculation based on ALSMS 2005

Table 4.5 shows that migrants live in households that belong to more membership groups, and live in communities with a higher number of membership associations. Therefore they possibly have more access to formal migration networks. The descriptive statistics so far have shown that informal and formal social networks seem more important in explaining migration flows than accessing a domestic livelihood. In other words, these social networks help potential migrants in finding employment abroad, but they are not helpful at home. As mentioned in section 4.2.1 people without any social networks are trapped in their current position, being neither able to find employment abroad, nor at home.

Table 4.6 shows differences in terms of public authority institutions. From Table 4.6 it can be seen that migrants live more often in communities with public lighting, public phones, mail, a police station. From a Welfare Pentagon perspective one would expect that migrants from non-functioning communities would be more likely to migrate, but this does not seem to be the case, at least in terms of infrastructure. In terms of receiving a public transfers, migrants are more likely to come from households that do not receive public transfers, i.e. they need to smooth income in other ways. 
Table 4.6 Differences between migrants and non-migrants: Public authority institutions

\begin{tabular}{l|ccc}
\hline & \multicolumn{3}{|c}{ Albania } \\
Is migrant & Yes & No & Total \\
\hline Household receives public transfers & $0.50^{* * *}$ & $0.59^{* * *}$ & $0.50^{* * *}$ \\
Community has... & & & \\
$\quad$ public lighting & $0.60^{* *}$ & $0.56^{* *}$ & $0.60^{* *}$ \\
$\quad$ piped water & 0.8 & 0.78 & 0.8 \\
$\quad$ sewage/ drains & 0.6 & 0.58 & 0.6 \\
$\quad$ garbage collection & 0.59 & 0.56 & 0.59 \\
$\quad$ public phones & $0.52^{* *}$ & $0.49^{* *}$ & $0.52^{* *}$ \\
mail service & $0.55^{* *}$ & $0.51^{* *}$ & $0.55^{* *}$ \\
police station & $0.45^{* *}$ & $0.41^{* *}$ & $0.45^{* *}$ \\
\hline No. observations & 994 & 10,724 & 11,718 \\
\hline
\end{tabular}

Note: All variables are household/ community level variables

Community is defined as a village in rural areas and generally as an administrative unit in urban areas (defined on a case by case basis).

Stars indicate whether the mean for each group is statistically different across groups (* significant at $10 \%$; ** significant at $5 \%$; *** significant at $1 \%$ )

Source: Own calculation based on ALSMS 2005

In the next section the combined effect of the most important variables just discussed is analysed.

\subsubsection{Empirical analysis}

A probit model on the probability to be a migrant is estimated. The variables of interest are proxies that could represent some of the corners of the Welfare Pentagon. Since the Moldovan dataset is more limited and to allow for a comparative analysis, I cannot include variables on membership associations and public authorities. Some control variables to account for demographic differences between the individuals (age, gender, marital status, household characteristics) are also included. The results are shown in Table 4.7.

The first interesting result is that signs and significance of different Welfare Pentagon explanatory variables differ somewhat between Albania and Moldova. This indicates that the migration processes in these countries are different.

In Albania there is some evidence for the family and social network part of the Welfare Pentagon. In terms of demographics, being male and married increases the propensity to migrate and a higher number of children in the household also leads to more migration. Individuals from larger households are less likely to migrate, while the Morris index is insignificant (family corner). Only migrants with vocational education are more likely to migrate, as already shown in the descriptive statistics; migrants with secondary and higher education seem to have some access to the domestic labour markets. More household members being employed also means that someone is more likely to be a migrant, whereas the probability to migrate decreases when the head is employed. This is weak evidence of people migrating if the domestic labour market fails. My empirical work does not strongly support previous findings that Albanian migration is additionally driven by dire economic circumstances, such as poverty, unemployment etc. (eg. 
Mancellari et al, 2006). The higher the share of migrants in the community, the more likely someone is to be a migrant, highlighting the importance of migrant networks. This last result is also shared by Moldova.

Table 4.7 Probit analysis on the probability to be a migrant

\begin{tabular}{|c|c|c|c|c|c|}
\hline \multirow[b]{2}{*}{$\begin{array}{c}\text { Welfare } \\
\text { Pentagon } \\
\text { corner } \\
\end{array}$} & & \multicolumn{2}{|c|}{ Albania } & \multicolumn{2}{|c|}{ Moldova } \\
\hline & & Coefficient & $\begin{array}{l}\text { Robust } \\
\text { standard } \\
\text { error }\end{array}$ & Coefficient & $\begin{array}{l}\text { Robust } \\
\text { standard } \\
\text { error }\end{array}$ \\
\hline \multirow{9}{*}{ Control } & Age & $0.12^{* * *}$ & 0.02 & $0.14^{* * *}$ & 0.02 \\
\hline & $\mathrm{Age}^{2}$ & $-0.00^{* * *}$ & 0 & $-0.00^{* * *}$ & 0.00 \\
\hline & Gender male & $1.25^{* * *}$ & 0.06 & $0.41^{* * *}$ & 0.03 \\
\hline & Married & $0.45^{* * *}$ & 0.1 & -0.05 & 0.06 \\
\hline & $\begin{array}{l}\text { HH lives in urban } \\
\text { area }\end{array}$ & -0.04 & 0.06 & $-0.12^{* * *}$ & 0.04 \\
\hline & HHH age & 0.00 & 0.00 & -0.00 & 0.00 \\
\hline & HHH male & 0.19 & 0.17 & $-0.14^{* *}$ & 0.05 \\
\hline & HHH married & $-0.29 *$ & 0.16 & $-0.09^{*}$ & 0.05 \\
\hline & \# children in $\mathrm{HH}$ & $0.05^{*}$ & 0.03 & -0.03 & 0.03 \\
\hline \multirow{3}{*}{ Family } & HH size & $-0.08^{* * *}$ & 0.03 & $0.08^{* * *}$ & 0.01 \\
\hline & Morris score index & 0.15 & 0.21 & $0.06^{* *}$ & 0.02 \\
\hline & Morris score index ${ }^{2}$ & 0.19 & 0.24 & -0.00 & 0.00 \\
\hline \multirow{5}{*}{ Market } & Secondary education & 0.04 & 0.06 & $0.11^{*}$ & 0.07 \\
\hline & Vocational education & $0.15^{* * *}$ & 0.06 & $0.21^{* * *}$ & 0.07 \\
\hline & Higher education & -0.08 & 0.09 & 0.08 & 0.08 \\
\hline & HH work ratio & $0.17^{*}$ & 0.1 & $1.41^{* * *}$ & 0.08 \\
\hline & HHH employed & $-0.17^{* *}$ & 0.07 & 0.03 & 0.05 \\
\hline \multirow{8}{*}{$\begin{array}{l}\text { Social } \\
\text { networks }\end{array}$} & $\begin{array}{l}\text { Community's migrant } \\
\text { share } 11-20 \%\end{array}$ & $0.24^{* * *}$ & 0.05 & $0.16^{* * *}$ & 0.04 \\
\hline & $\begin{array}{l}\text { Community's migrant } \\
\text { share }>21 \%\end{array}$ & $0.49^{* * *}$ & 0.08 & $0.39 * * *$ & 0.07 \\
\hline & Constant & $-4.21^{* * *}$ & 0.38 & $-4.18^{* * *}$ & 0.38 \\
\hline & $\begin{array}{l}\text { Number of } \\
\text { observations }\end{array}$ & 10393 & & 11334 & \\
\hline & Pseudo R² & 0.2391 & & 0.2000 & \\
\hline & $\begin{array}{l}\text { McKelvey \& } \\
\text { Zavoina's R² }\end{array}$ & 0.453 & & 0.536 & \\
\hline & Likelyhood ratio & 1479.86 & & 1966.45 & \\
\hline & $\begin{array}{l}\text { Likelihood } \\
\text { probability }\end{array}$ & 0.00 & & 0.00 & \\
\hline
\end{tabular}

Note: Effect measured is direct effect on odds ratio.

The Morris score index is a weighted asset index (see Morris et al. 1999). For Albania I refer to 1990, for Moldova to 2005 (see explanation in footnote 33).

Base: Migrant has primary school education; community has a migrant share $0-10 \%$

Albania: Clustered by household

* significant at $10 \%$; ${ }^{* *}$ significant at $5 \%$; ${ }^{* *}$ significant at $1 \%$ 
For Moldova people coming from larger and wealthier households are more likely to be a migrant. As discussed before, the causality for the latter result remains unclear. In Moldova people with secondary education, are more likely to become migrants than people with primary education. Moldovan labour markets are in a poor state and one can assume that migration is a human capital investment (see Sjaastad, 1962), which allows migrants to use their skills and education more effectively. If more adults in the household are employed (this can include migrants employed abroad), a person is significantly more likely to become a migrant. The head's work status is insignificant. From the descriptive statistics and empirical results on education levels, there is some evidence that Moldovans migrate for employment reasons. While the above regression does not fully confirm this, other research (e.g. Lücke et al, 2007, IOM, 2009 and Danzer \& Dietz, 2009) clearly links migration to dysfunctional labour markets in Moldova.

The next section will investigate who of these migrants remits and why.

\subsection{Why do migrants send remittances?}

In this section the empirical determinants of remittances are analysed. The aim is to test the motives of remitters going beyond previous studies on Albania and Moldova (see Germenji, Beka, \& Sarris, 2001) for Albania and for Moldova (Craciun, 2006; Görlich et al., 2007; Görlich et al., 2008). It should be noted beforehand that while there are some individual level characteristics, I mainly use household-level data to explain individual motives. The first part of this section gives some descriptive statistics followed by the empirical application.

\subsubsection{Descriptive statistics}

Some descriptive statistics are now discussed to gain a broad overview of the characteristics of senders and receivers in the Albanian and Moldovan samples. The characteristics of the households that receive remittances are looked at first and then the characteristics of the migrants that send remittances. ${ }^{35}$ Only households that have migrants are considered since households without migrants do not receive remittances.

Figure 4.6 shows the amount of remittances received by consumption quartile. The first quartile represents the poorest quarter of the sample population and the last quartile represents the richest quarter of the sample population. In Moldova poorer households receive higher remittances. On average, the amount of remittances is twice as high for households in the first income quartile as for households in the second quartile. However, since the richest two consumption quartiles also receive high remittances preliminary evidence for altruism is mixed. In Albania the differences between the quartiles are not as extreme, but the richest quartile receives significant higher amounts of remittances and the lowest quartile significantly lower amounts than the average.

35 The characteristics of migrants that do not send remittances are included in the empirical analysis. Approximately $37 \%$ of households in Albania and $50 \%$ of households in Moldova did not receive remittances even though they have a migrant. 
Figure 4.6 The level of remittances/consumption quartile

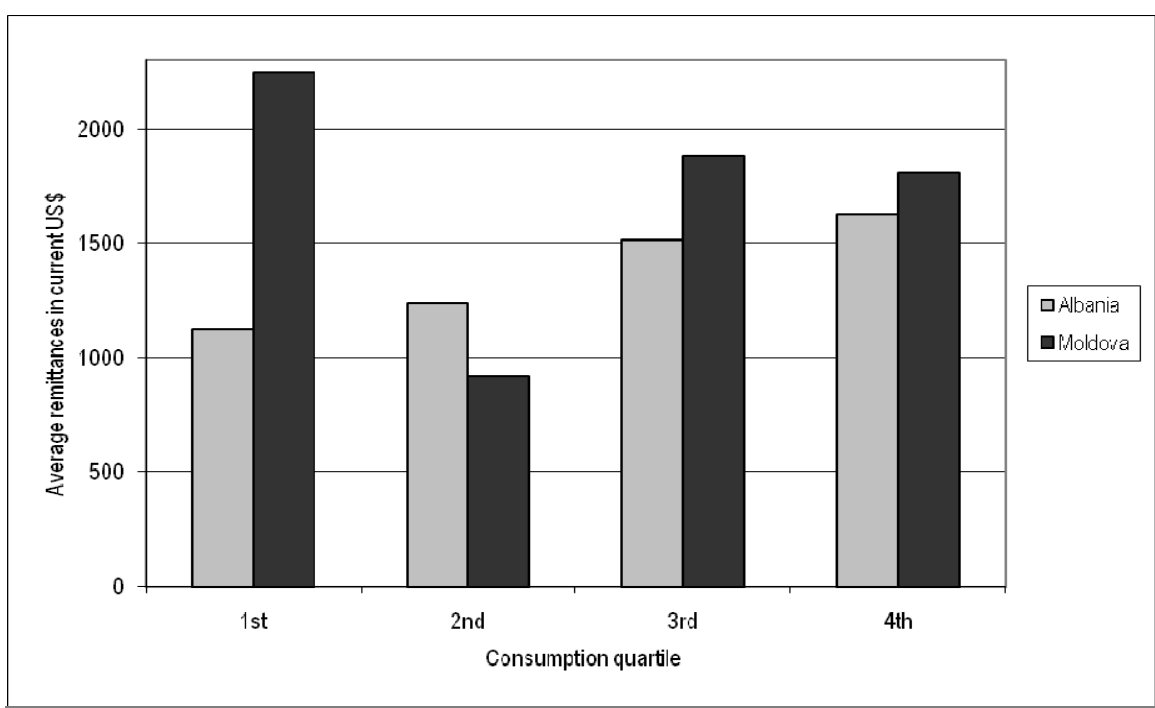

Source: Own calculation based on ALSMS 2005 and CBSAXA 2006

As discussed in the previous section, one needs to be aware of potential reverse causality. It is now clear whether rich households in Albania were rich before they had migrants. Whenever one addresses the effect of consumption (or income) on remittances we need to be aware of this potential endogeneity bias. If possible, this bias should be corrected for, for example with an IV analysis, as is done in Chapter 5.

In Figure 4.7 which shows the average number of years the remitter has been abroad, some real differences in the characteristics of remitters between the two countries emerge. In Moldova there is much short-term seasonal migration, as $20 \%$ is abroad for less than a year. These migrants generally go to Russia to work in the construction sector for a few months and return home only to leave again the next year. Albanians, on the other hand, are staying abroad for longer periods of time before returning home. 


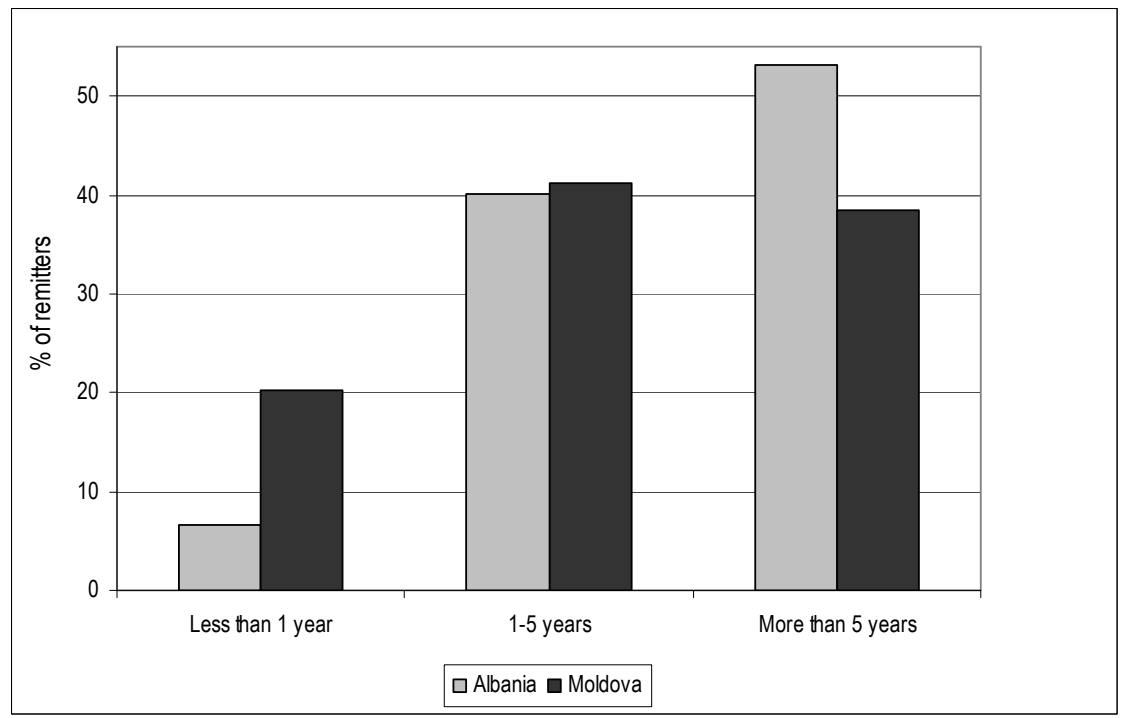

Source: Own calculation based on ALSMS 2005 and CBSAXA 2006

The individual characteristics of remitters are assessed further by looking at the link between gender, education of the remitter, the number of years abroad, their most important destination countries and the average amount of remittances sent home by remitters of each group. Table 4.8 presents the average amount of remittances sent by each group in the two countries.

$87 \%$ of the remitters in Albania and 62\% in Moldova are of working age between the ages of 25 and 45 and the majority of remitters in both countries are married (not shown in table). In both Albania (80\%) and Moldova (60\%), male migrants make up the majority of the remitting population (largely due to the fact that it is mostly males who migrate). In Albania, men also send higher amounts of remittances on average $(\$ 1059$, which is more than three times what women remit on average), while in Moldova there are no significant differences by gender. In Albania traditional gender roles mean that it is the duty of the sons to look after their parents, much more so than for their sisters, especially if the sisters are married (King et al. 2006). Married Albanian women generally remit to their husband's parents.

As shown in Table 4.8, in both countries migrants that are away for longer periods of time remit more, even though this difference is only significantly different for Albania. Both countries have two major destination countries for migration to which more than $75 \%$ of the migrating population goes. Migrants from both countries that migrate to Italy remit significantly more on average, than those going to the other important destination country, although this is much more pronounced in the case of Moldova. Moldovan migrants in Italy are mainly women, who work as household helpers which is better-paid work than the construction sector in Russia, where men mainly work. 
Table 4.8 Characteristics of remitters

\begin{tabular}{|c|c|c|c|c|c|}
\hline & & \multicolumn{2}{|c|}{ Albania } & \multicolumn{2}{|c|}{ Moldova } \\
\hline & & $\begin{array}{l}\text { Average } \\
\text { amount }\end{array}$ & $\begin{array}{c}\% \text { of } \\
\text { remitters }\end{array}$ & $\begin{array}{l}\text { Average } \\
\text { amount }\end{array}$ & $\begin{array}{c}\% \text { of } \\
\text { remitters }\end{array}$ \\
\hline \multirow{2}{*}{ Gender } & Female & $239.22^{* * *}$ & $20 \%$ & 475.24 & $40 \%$ \\
\hline & Male & $1058.85^{* * *}$ & $80 \%$ & 434.27 & $60 \%$ \\
\hline \multirow{4}{*}{$\begin{array}{l}\text { Education } \\
\text { level }\end{array}$} & Primary or less & 780.34 & $48 \%$ & $255.20^{*}$ & $7 \%$ \\
\hline & Secondary & 780.45 & $31 \%$ & 436.79 & $40 \%$ \\
\hline & Vocational & 815.17 & $13 \%$ & 457.95 & $37 \%$ \\
\hline & Higher & 631.36 & $8 \%$ & $559.90^{*}$ & $15 \%$ \\
\hline \multirow{3}{*}{$\begin{array}{l}\text { Years } \\
\text { abroad }\end{array}$} & Less than 1 year & $426.23^{* * *}$ & $7 \%$ & 371.8 & $20 \%$ \\
\hline & $1-5$ years & 832.56 & $42 \%$ & 477.09 & $41 \%$ \\
\hline & More than 5 years & 785.41 & $50 \%$ & 456.45 & $39 \%$ \\
\hline \multirow{3}{*}{ Destination } & Other & $918.19^{* *}$ & $23 \%$ & $651.85^{* * *}$ & $24 \%$ \\
\hline & $\begin{array}{l}\text { Greece (A) Russia } \\
\text { (M) }\end{array}$ & $611.18^{* * *}$ & $38 \%$ & $335.62^{* * *}$ & $62 \%$ \\
\hline & Italy & $859.07 * *$ & $39 \%$ & $732.71^{* * *}$ & $14 \%$ \\
\hline \multicolumn{2}{|c|}{ Average } & 772.35 & \multicolumn{3}{|c|}{450.5} \\
\hline \multicolumn{2}{|c|}{ Number of observations } & 1298 & \multicolumn{3}{|c|}{1607} \\
\hline
\end{tabular}

Stars indicate whether the mean for each group is statistically different across groups $\left({ }^{*}\right.$ significant at $10 \%$; ${ }^{* *}$ significant at $5 \%$; ${ }^{* * *}$ significant at $1 \%$ )

Source: Own calculation based on ALSMS 2005 and CBSAXA 2006

The amount of remittances sent by higher educated migrants in the two countries is quite different. In Moldova, the highest average amount of remittances is sent by those migrants who have completed higher education, and the low educated send significantly lower remittances. In Albania there are no significant differences between education levels.

The next section applies the theoretical motivations to remit in Albania and Moldova in order to give a more detailed picture of the motivations to remit in those countries and to demonstrate the problems associated with the literature.

\subsubsection{Empirical analysis}

As was shown in section 4.2.2 even theoretically it is difficult to distinguish between different motivations to remit. These complications are exacerbated by data limitations (only having data on either the remitter or remittance receiver) and consequently the empirical applications are often weak. Below I attempt to measure the motivations to remit in Albania and Moldova on an individual migrant level, and discuss the results in relation to other empirical papers. The starting point is a common model that has the same variables for both the Albanian and Moldovan datasets. For this model the motivations to remit with regard to altruism versus self-insurance of the migrant are measured. Due to the different nature of the two datasets, two further models for just one of the countries are specified. For Albania data on a household and community level are used to model the bequest motive, co-insurance and to explore evidence for the NELM theory. The final model tests the loan repayment motive using only Moldovan data since there are relevant variables in that dataset. 


\section{Measuring altruism and self-insurance motives in Albania and Moldova}

In each of the following models, the independent variables are grouped into migrant characteristics, household characteristics and those variables that are used to test a number of theoretical motivations to remit. The expected effects of the variables based on the theoretical motivations to remit are described based on previous papers and the specific situations in Albania and Moldova.

In the first model, I test for altruism and self-insurance of the migrant. The model is outlined in equation 4.3:

$$
R_{i}^{*}=\alpha+\beta_{1} M_{i}+\beta_{2} H_{i}+\beta_{3} R i_{i}+\varepsilon_{i}
$$

where

\begin{tabular}{ll}
\hline Variable & Expected effect \\
\hline $\begin{array}{l}\text { R= Total remittances received by household from remitter in past 12 } \\
\text { months }\end{array}$ & n.a. \\
\hline M: Migrant variables & control \\
Age of migrant & control \\
Gender of migrant & control \\
Marital status of the migrant & control \\
Education of migrant & control \\
Country of migrant destination & \\
\hline H: Household variables & + \\
Household size & - \\
Per capita income/consumption of household in splines & - \\
Other migrants in household & control \\
Household lives in urban/ rural area & \\
\hline Ri: Risk variables & + \\
Distance between Albania/ Moldova and capital of destination & - \\
Migrant stock in destination & - \\
Migrant entered legally & + \\
Unemployment rate of country of destination & - \\
Duration of migration, in categories & \\
\hline
\end{tabular}

To test the altruism motive, the following variables are looked at: per capita household consumption, number of other migrants in the household and the duration of migration. ${ }^{36}$ Income/ expenditure quintiles are used to allow remittances to have a different effect for poorer or richer households. ${ }^{37}$ For Albania there was the choice between income and consumption and I decided on income as income is more reactive and a potential altruism motive can thus be measured more clearly. The coefficient for per capita household income/ consumption should have a negative sign for altruism for low income households, indicating more remittances for households with greater need. The coefficient for

${ }^{36}$ Due to data limitations, we had to omit migrant's earnings, which would be an important variable to include.

37 See Cox et al. (2004) for more detailed arguments regarding a non-linear relationship between income and transfers. 
number of migrants in the household should have a negative sign since more migrants means more people to remit, which lowers the burden on the individual remitter. If family ties have weakened, often approximated by length of time abroad, fewer remittances should be sent ("remittance-decay"). ${ }^{38}$ A larger household at home can be an indication of need; I thus expect a positive relationship with remittances in the case of altruism. ${ }^{39}$

Instead of focusing on household risks that make it difficult to differentiate between altruism and self-insurance, I focus on migrant employment risks (see discussion in section 4.2.2). Therefore it is tested whether the migrant insures him/herself by looking at the effect of employment risk variables on the amount of remittances sent. ${ }^{40}$ The basic idea is that the migrant sends more remittances (i.e. a higher "insurance premium") when the labour market situation is more risky to ensure reverse remittances in times of need or the support of the family if the migrant has to return home due to lack of work. A direct risk variable used is whether the migrant entered the destination country legally. The indirect measures of risk used are the unemployment rate in the host country (due to nonavailability of data on migrant unemployment), the duration of migration, the distance between the migrant sending and host country and stock of Albanian/ Moldovan migrants in the host country as a measurement of networks.

A migrant that enters the country legally, has a lower risk, so is likely to send fewer remittances. If the unemployment rate in the host country is higher, then it is expected that there is a higher labour market risk. ${ }^{41}$ The shorter the duration of migration, the more money should be sent, as the migrant is less acquainted with the labour market and probably has not found stable employment yet. The greater the distance between the countries, the higher the risk for the migrant, for example, financially, as the migration costs are higher, and the more remittances should be sent. A greater migrant stock should mean less risk, as networks are used by migrants to find jobs, housing, etc. Since I cannot control for migrant income, the migrant's desire to take up insurance, but not his capacity is measured.

Table 4.9 gives the empirical results for equation 4.3 .

investment. Causality is fuzzy here, so it is hard to draw any definite conclusion.

\footnotetext{
${ }^{38}$ A linear relationship between remittances and length of stay is assumed, but one could also imagine a non-linear one.

${ }^{39}$ A higher number of household members can be an opportunity for the household if they are adults potentially earning an income or a risk if the members are children or elderly. Therefore, we tried different specifications also using the children or elderly ratio instead of household size, but these led to similar results.

${ }^{40}$ For a similar analysis see also Amuedo-Dorantes \& Pozo (2006) and Lianos \& Cavounidis (2004).

41 The most popular migration destination countries of Albanian and Moldovan migrants do not include illegal migrants in unemployment insurance schemes.
} 
Table 4.9 Results of the Tobit regression for the combined model

\begin{tabular}{|c|c|c|c|c|}
\hline & \multicolumn{2}{|c|}{ Albania } & \multicolumn{2}{|c|}{ Moldova } \\
\hline \multicolumn{5}{|c|}{$\begin{array}{l}\text { Dependent variable: Total remittances received by household from remitter in past } 12 \text { months } \\
\text { (measured in } 1 / 1000 \text { USD) }\end{array}$} \\
\hline & $\begin{array}{c}\text { Marginal } \\
\text { effects coeff. }\end{array}$ & std. error & $\begin{array}{c}\text { Marginal } \\
\text { effects coeff. }\end{array}$ & std. error \\
\hline \multicolumn{5}{|l|}{ Migrant variables } \\
\hline Age of migrant & 0.00267 & 0.00272 & $0.01039^{* * *}$ & 0.00269 \\
\hline Migrant male & $0.43988^{* * *}$ & 0.04509 & 0.03544 & 0.05789 \\
\hline Migrant married & $-0.16687^{* * *}$ & 0.04819 & -0.03638 & 0.06248 \\
\hline Migrant secondary education & $0.07827^{*}$ & 0.04374 & 0.19477 & 0.12564 \\
\hline Migrant vocational education & $0.12902^{* *}$ & 0.05844 & 0.17628 & 0.12642 \\
\hline Migrant higher education & -0.00663 & 0.07710 & $0.22983^{*}$ & 0.13382 \\
\hline Migrant in Italy (A)/ CIS (M) & -0.31761 & 0.50337 & 0.53531 & 0.76120 \\
\hline Migrant in Greece (A)/ EU (M) & -0.25700 & 0.73368 & -0.00279 & 0.14178 \\
\hline \multicolumn{5}{|l|}{ HH variables } \\
\hline HH size & $0.02874^{* *}$ & 0.01140 & 0.00026 & 0.02152 \\
\hline Consumption/ income quintile 1 & $-0.089 .66^{* *}$ & 0.02104 & $-0.12290^{* *}$ & 0.05787 \\
\hline Consumption/ income quintile 2 & $-0.08638^{* * *}$ & 0.01923 & $-0.03134^{* * *}$ & 0.01009 \\
\hline Consumption/ income quintile 3 & $-0.08186^{* * *}$ & 0.01844 & -0.004 .38 & 0.00438 \\
\hline Consumption/ income quintile 4 & $-0.07361^{* * *}$ & 0.01795 & 0.00192 & 0.00259 \\
\hline Consumption/ income quintile 5 & $-0.06012^{* * *}$ & 0.01700 & 0.00002 & 0.00080 \\
\hline Number of other migrants & -0.18668 & 0.04059 & $-0.12974^{* *}$ & 0.06411 \\
\hline HH lives in urban area & -0.06191 & 0.03986 & $-0.13544^{* *}$ & 0.06319 \\
\hline \multicolumn{5}{|l|}{ Risk variables } \\
\hline $\begin{array}{l}\text { Distance between A/ M and } \\
\text { capital of destination }\end{array}$ & -0.22362 & 0.21856 & $0.28162^{* * *}$ & 0.10560 \\
\hline Migrant stock in destination & -0.00000 & 0.00000 & -0.00000 & 0.00000 \\
\hline Migrant entered legally & -0.01237 & 0.03916 & $-0.19082^{* * *}$ & 0.06290 \\
\hline $\begin{array}{l}\text { Unemployment rate of country of } \\
\text { destination }\end{array}$ & -0.07436 & 0.07971 & 0.00286 & 0.04205 \\
\hline Migrant abroad $1-5$ years & $0.38985^{* *}$ & 0.17063 & $0.12991^{*}$ & 0.06860 \\
\hline Migrant abroad $>5$ years & $0.53299^{* * *}$ & 0.17029 & $0.13821^{*}$ & 0.07205 \\
\hline Constant & 0.0249313 & 0.0232895 & $-0.023492^{* * *}$ & 0.078622 \\
\hline Number of observations & 2032 & & 1029 & \\
\hline $\begin{array}{l}\text { Number of censored } \\
\text { observations }\end{array}$ & $734(36 \%)$ & & $535(52 \%)$ & \\
\hline Pseudo $\mathrm{R}^{2}$ & 0.11 & & 0.08 & \\
\hline McKelvey \& Zavoinas' R² & 0.16 & & 0.14 & \\
\hline Likelihood ratio & 299.88 & & 121.34 & \\
\hline Likelihood probability & 0.00 & & 0.00 & \\
\hline
\end{tabular}

Note: A=Albania, M=Moldova

Income is used for Albania and consumption is used for Moldova, both measured in current USD. Quintiles are equally spaced over the range of income/expenditures per capita, with 4 cut-off points with quintile 1 as the poorest households and quintile 5 being the richest households.

The marginal effects are conditional on being uncensored. 
Base: Migrant primary education or less; migrant location other; migrant abroad 0-1 year

*significant at $10 \%$; ${ }^{* *}$ significant at $5 \%$; ${ }^{* *}$ significant at $1 \%$

Source: Own calculation based on ALSMS 2005 and CBSAXA 2006

Most papers find some evidence for altruism, as defined in theory. As predicted theoretically (see chapter 3 ) most papers find a positive relationship for the effect of the migrant's income on remittances ${ }^{42}$ and a negative relationship for the effect of the household's income on remittances. ${ }^{43}$ Migrants' income is not known, but the education level is a common proxy, as generally more highly educated migrants have a higher earnings capacity (compared to the base group with primary education). Secondary and vocational education are significant and positive for Albanian remitters and higher education is positive and significant for Moldova, thus having the expected relationship with remittances. For both countries, and most clearly for Albania, income has a decreasing negative effect on remittances. This means that the motive altruism is most strong for remittances sent to poor households. For Moldova a reversal and a positive (but not significant) relationship at higher levels of the income distribution are found. This is similar to the picture that Cox et al. (2004) find and the different effects at different points in the income distribution can be linked to different motivations. The motive for remitting higher amounts to the poorest quintiles could be altruism, whereas for the richer households it could be another motive e.g.

Still, the results on consumption and remittances do not exclude other motives. However, another variable that is often tested is the presence of other migrants in the household. More migrants in the household means that the migrant is not solely responsible for the wellbeing of the household and most papers do find this negative relationship.44 I also find a negative coefficient for both countries (significant for Moldova). Nevertheless, the value of such a result is doubtful as it can also be interpreted completely differently, as evidence for the bequest motive, see the next analysis on Albania below.

More solid evidence for altruism is that most migrants are more likely to send remittances and send more if the household head is older. Most authors also find a positive link between the dependency ratio and the level of remittances and the simultaneous estimation of the probability and level of remittances. Germenji, Beka, \& Sarris (2001) studying Albania find a positive relationship between the level of remittances and a household head being older than 55. The dependency ratio type variables are not significant in the models but household size is positive (and significant for Albania), which indicates some evidence for altruism.

In Albania, rural households are more likely to have international migrants (see also Chapter 5), so it is not surprising that households living in urban areas receive fewer remittances (the effect is not significant, but is so in the next regression). The same effect is found for Moldova, but significant and stronger. Likewise rural households are often poorer and needier so this is additional evidence in favour of altruism. Length of stay is often used to measure (weakening) altruism. A positive

42 The sole exception is Lianos \& Cavounidis ( 2004)

${ }^{43}$ Exceptions are Lucas \& Stark (1985) and Itzigsohn (1995)

${ }^{44}$ The following authors found positive relationships: Germenji, Beka \& Sarris. (2001)., Hoddinott (1994) and Pleitez-Chavez (2004). 
and significant effect is found for Albania and Moldova. Most papers do not find evidence for remittance decay ${ }^{45}$, which shows that migrants generally keep links to their families and communities. Again, this result can be interpreted in terms of more self-interested theories, for example, as investment at home due to future plans to return.

To succeed in measuring self-insurance only, Amuedo-Dorantes \& Pozo (2006) look at the risk level of the migrant only. The first measure of the migrant's risk level used is length of stay. As already mentioned above, length of stay has a positive effect on remittances. This means that lower risk is accompanied with more remittances (so more insurance), which is some evidence against remittances as self-insurance. All other risk variables in Albania also have the opposite sign than expected and are insignificant, so self-insurance measured in this way is not a motivation. However, for Moldova the expected signs of the risk variables are correct, they are jointly significant and mostly individually significant. The only direct risk measure "Migrant entered legally" is significant and has the expected negative sign. Accordingly for Moldova there is some evidence for self-insurance. Although few papers find a significant relationship for other measures of migrant risk (e.g. legal employment), almost all of those that did, do find this positive relationship with remittances. ${ }^{46}$ This means that migrants send more remittances as insurance.

It was shown that when using the approach currently favoured in the literature, it is difficult to measure altruism as a separate motive because it overlaps with other motives and since most authors have not been able to find good operators. It is possible to distinguish self-insurance, however, if good proxies for migrant risk are found, as these variables have opposite effects to altruism. Only one direct proxy for migrant risk was available, as the remittance receiving household database has little information on the remittance senders. This is a difficulty many authors face and that aggravates the theoretical problems.

\section{Measuring the bequest and co-insurance motive in Albania}

Next data on a household and community level are used to test for the bequest motive, co-insurance and the NELM theory in Albania. The model is described in equation 4.4 .

$R_{i}^{*}=\alpha+\beta_{1} M_{i}+\beta_{2} B_{i}+\beta_{3} C_{i}+\beta_{4} N_{i}+\varepsilon_{i}$

where

45 The exceptions are: Banerjee (1984) and Funkhouser (1995).

46 Only Durand et al. (1996) and Konica (2006) find that those migrants with stable jobs are more likely to remit. 


\begin{tabular}{ll}
\hline Variable & Expected effect \\
\hline R= Total remittances received by household from remitter in past 12 & n.a. \\
months & \\
\hline M: Migrant variables & control \\
Age of migrant & control \\
Gender of migrant & control \\
Marital status of the migrant & control \\
Education of migrant & $-/+$ \\
\hline B: Bequest/ household variables & + \\
Per capita income of household in quintiles & + \\
Wealth index & + \\
Age of household head & $-/+$ \\
Household owns house & control \\
Other migrants in household & \\
Number of elderly in household & + \\
\hline C: Co-insurance & + \\
Adverse shocks experienced by household & + \\
\hline N: NELM variables & + \\
Household lives in urban/ rural area & + \\
Community infrastructure index & + \\
Credit possibility index & + \\
Lack of employment opportunities in community & + \\
\hline
\end{tabular}

To measure the bequest motive, we look at the income of the household, if there are other migrants in the household, the age of the household head, the wealth of the household and whether the house is owned by the current household. According to the theoretical literature, if the coefficient of income of the household has a positive sign this could show evidence for the bequest motive, since there is more to gain in inheriting. If remittances increase with the wealth of the household (or with the fact that the household owns the house), there is further evidence for the bequest motive. If there are other migrants in the household, then sending more remittances could be a sign of trying harder to win the bequest. If a higher age of the household head coincides with higher remittances, this could be evidence for the bequest motive, because the probability of death is higher (Brown 1997).

To test co-insurance of a household adverse shocks household experiences, namely a job, illness or property shock (e.g. house burns down) are considered. If any of the coefficients for the shocks variables have a positive sign, then there is evidence for co-insurance or altruism. The more general NELM theory discussed next, also measures co-insurance, but more indirectly.

To test the more general hypothesis of the NELM the variables community infrastructure, formal and informal credit possibilities, the population of the community, employment possibilities in the community and whether or not the household is in a rural or urban community are used, thus following the approaches of Durand et al (1996) and Sana \& Massey (2005) as much as possible. If the coefficient of community infrastructure has a positive sign, this is evidence for the NELM, since there needs to be a basic infrastructure if the household wants to invest. If it is negative, then it shows altruism because of need. If the coefficient 
of formal credit possibility has a negative sign this is evidence against coinsurance. This means there are possibilities to obtain money elsewhere, so there is less need for a co-insurance arrangement. If the coefficient of informal credit has a positive sign, then this shows an underdeveloped financial sector, i.e. there is need for co-insurance and evidence for the NELM. The sign for the coefficient for lack of employment possibilities should be positive for NELM (again due to lack of opportunities at home and therefore the need for co-insurance) and altruism. As can be seen from the above explanation, NELM variables mostly test investment possibility variables; so NELM also tests for an investment motive in some respect.

Table 4.10 gives the empirical results for equation 4.4. In theory, migrants with a bequest motive should be more likely to send remittances and send greater sums of remittances if their parents are wealthy (e.g. they own land) and have a higher income. ${ }^{47}$ Unlike Germenji et al (2001) in an earlier study on Albania, I find a positive and significant sign for wealth (the Morris score index) and a less negative relationship between remittances and income at higher income quartiles, which could be interpreted as an indication of a bequest motive. All other bequest variables have an unexpected sign and the causality between income and remittances is fuzzy, so there is no convincing evidence for the bequest motive.

Whether remittances are sent as part of a co-insurance contract between migrants and households can be measured by analysing the effect of household shocks and migrant (income, employment and living) risk on remittances. According to most studies that included household shocks, shocks of the household (e.g. illness) lead to a higher probability of remittances and larger sums of remittances. ${ }^{48}$ Unfortunately, this cannot be distinguished from altruistic behaviour. Only the illness and property shock variables seem to lead to more remittances, but the shock variables are all not significant.

Durand et al. (1996) find that migrants are more likely to remit to economically dynamic and entrepreneurial communities, which suggests that remittances are sent as co-insurance under the right conditions. Since the migration and remitting decision are highly linked, I expected the NELM to be highly significant since they also influence the migration decision. However, almost none of the NELM variables are significant, also not using different specifications, many do not have the expected signs and they are only significant at the 5\% level as a group. Households living in communities with lack of employment opportunities receive significantly more remittances, but again this could be a sign of altruism.

Table 4.10 Results of the Tobit regression for the Albania model

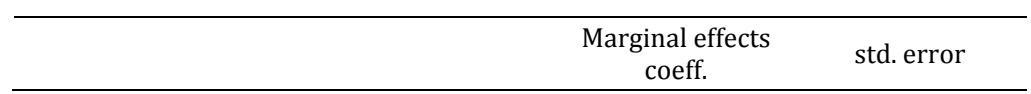

\footnotetext{
47 Some papers do find this relationship de la Briere et al. (1997), Hoddinott (1994), Lucas \& Stark (1985), Pleitez-Chavez (2004), Schrieder \& Knerr (2000) but others do not: Durand et. al. (1996), Germenji et al. (2001), Holst et al. (2006), Osaki (2003)

48 Only Halliday (2006) finds that for an earthquake shock, less remittances are sent, unlike for an agricultural shock. He attributes this to the fact that households cope with the earthquake by retaining family members at home to help with rebuilding.
} 


\begin{tabular}{|c|c|c|}
\hline \multicolumn{3}{|c|}{$\begin{array}{l}\text { Dependent variable: Total remittances received by household from remitter in } \\
\text { past } 12 \text { months; (measured in } 1 / 1000 \text { USD) }\end{array}$} \\
\hline \multicolumn{3}{|c|}{ Migrant variables } \\
\hline Age of migrant & $0.01263^{* * *}$ & 0.00309 \\
\hline Migrant male & $0.45632^{* * *}$ & 0.04512 \\
\hline Migrant married & $-0.15953^{* * *}$ & 0.04955 \\
\hline Migrant secondary education & 0.04521 & 0.04610 \\
\hline Migrant vocational education & 0.08060 & 0.06129 \\
\hline Migrant higher education & -0.02408 & 0.07625 \\
\hline \multicolumn{3}{|l|}{ HH variables } \\
\hline Income quintile 1 & $-0.07692^{* * *}$ & 0.02142 \\
\hline Income quintile 2 & $-0.07626^{* * *}$ & 0.01955 \\
\hline Income quintile 3 & $-0.07040^{* * *}$ & 0.01870 \\
\hline Income quintile 4 & $-0.06354^{* * *}$ & 0.01825 \\
\hline Income quintile 5 & $-0.05298^{* * *}$ & 0.01718 \\
\hline Morris score index & $0.14865^{* * *}$ & 0.03556 \\
\hline Age of HH head & $-0.00985^{* * *}$ & 0.00275 \\
\hline HH owns house & $-0.16917^{*}$ & 0.08821 \\
\hline Other migrants in $\mathrm{HH}$ & $-0.14662^{* * *}$ & 0.04180 \\
\hline Number of elderly in $\mathrm{HH}$ & -0.01062 & 0.03040 \\
\hline \multicolumn{3}{|l|}{ Co-insurance variables } \\
\hline HH has property shock & 0.02648 & 0.22478 \\
\hline HH has job shock & -0.07634 & 0.20129 \\
\hline HH has illness shock & 0.11081 & 0.13150 \\
\hline \multicolumn{3}{|l|}{ NELM variables } \\
\hline Household lives in urban area & $-0.10649^{*}$ & 0.06086 \\
\hline Community infrastructure index & -0.03033 & 0.10537 \\
\hline Credit possibility index & -0.02437 & 0.03051 \\
\hline $\begin{array}{l}\text { Informal credit is a source of borrowing in } \\
\text { this community }\end{array}$ & 0.02477 & 0.05886 \\
\hline $\begin{array}{l}\text { Lack of employment opportunities in } \\
\text { community }\end{array}$ & $0.11786^{* *}$ & 0.04754 \\
\hline Constant & -0.00052998 & 0.25711 \\
\hline Number of observations & 1935 & \\
\hline Number of censored observations & $708(37 \%)$ & \\
\hline Pseudo $\mathrm{R}^{2}$ & 0.12 & \\
\hline McKelvey \& Zavoinas' $\mathrm{R}^{2}$ & 0.16 & \\
\hline Likelihood ratio & 294.65 & \\
\hline Likelihood probability & 0.000 & \\
\hline
\end{tabular}

Note: The Morris score index is a weighted asset index (see Morris et al. 1999).

The marginal effects are conditional on being uncensored.

Base: Migrant primary education or less

* significant at $10 \% ;{ }^{* *}$ significant at $5 \%$; ${ }^{* * *}$ significant at $1 \%$

Source: Own calculation based on ALSMS 2005 and CBSAXA 2006

Once more most variables used to measure the different motives are too general and therefore multi-interpretable. Only the NELM accounts for the origin 
community development and more research should be done in this direction as it influences both the decision to migrate and the decision to remit, a decision that is often linked for economic migrants.

\section{Measuring loan repayment in Moldova}

In the final analysis only Moldovan data is used and I test for another theoretical motive to remit, namely loan repayment. The following model is estimated:

$$
R_{i}^{*}=\alpha+\beta_{1} M_{i}+\beta_{2} H_{i}+\beta_{3} L_{i}+\varepsilon_{i}
$$

where

Variable Expected effect

$\mathrm{R}=$ Total remittances received by household from remitter in past 12 n.a. months

\begin{tabular}{ll}
\hline M: Migrant variables & \\
Age of migrant at departure & control \\
Gender of migrant & control \\
Marital status of the migrant & control \\
Country of migrant destination & control \\
Duration of migration, in categories & control \\
\hline H: Household variables & \\
Household size & + \\
Per capita expenditures of household & - \\
Other migrants in household & - \\
Household lives in urban/ rural area & control \\
\hline L: Loan repayment variables & \\
Education of migrant & + \\
Education of household head & + \\
Cost of migration & + \\
Returned money borrowed & - \\
\hline
\end{tabular}

Loan repayment here refers to the repaying of education costs or the repayment of the financing of migration. The main variables considered when testing this motive are: Education of the household head, education of the migrant, whether debt is the motivation to remit, the cost of migration, and whether the money borrowed for migration was returned. The higher the education of the household head, the better the enforcement of loan repayment (see Hoddinott, 1992). If a migrant is highly educated, then the remittances sent by the migrant should be higher due to the greater cost of his/her education (Poirine, 1997). One of the motivations to remit can be to pay back a loan. If the money borrowed for migration has been returned already, it should have a negative effect on the level of remittances.

Table 4.11 gives the results for equation 4.5 . 
Table 4.11 Results of the Tobit regression for the Moldova model

\begin{tabular}{|c|c|c|}
\hline & $\begin{array}{c}\text { Marginal } \\
\text { effects coeff. }\end{array}$ & Std.error \\
\hline \multicolumn{3}{|c|}{$\begin{array}{l}\text { Dependent variable: Total remittances received by household from } \\
\text { remitter in past } 12 \text { months; (measured in } 1 / 1000 \text { USD) }\end{array}$} \\
\hline \multicolumn{3}{|l|}{ Migrant variables } \\
\hline Age of migrant & $0.01173^{* * *}$ & 0.00340 \\
\hline Migrant male & 0.10930 & 0.07428 \\
\hline Migrant married & -0.03544 & 0.08192 \\
\hline Migrant secondary education & -0.14846 & 0.19339 \\
\hline Migrant vocational education & -0.14281 & 0.19100 \\
\hline Migrant higher education & -0.05447 & 0.20268 \\
\hline Migrant in CIS & -0.16678 & 0.12119 \\
\hline Migrant in EU & 0.04773 & 0.13090 \\
\hline Migrant abroad $1-5$ years & 0.04736 & 0.09092 \\
\hline Migrant abroad $>5$ years & -0.10853 & 0.09621 \\
\hline \multicolumn{3}{|l|}{ Household variables } \\
\hline $\mathrm{HH}$ size & -0.01381 & 0.02712 \\
\hline Consumption quintile 1 & -0.07287 & 0.07416 \\
\hline Consumption quintile 2 & $-0.02555^{*}$ & 0.01331 \\
\hline Consumption quintile 3 & -0.00350 & 0.00585 \\
\hline Consumption quintile 4 & 0.00235 & 0.00321 \\
\hline Consumption quintile 5 & -0.00051 & 0.00101 \\
\hline Other migrants in hh & $-0.23516^{* * *}$ & 0.080 .82 \\
\hline HH lives in urban area & $-0.020205^{* *}$ & 0.07891 \\
\hline \multicolumn{3}{|l|}{ Loan repayment variables } \\
\hline Household head secondary education & $0.42512^{* * *}$ & 0.14807 \\
\hline Household head vocational education & $0.31118^{* *}$ & 0.14442 \\
\hline Household head higher education & 0.17376 & 0.17096 \\
\hline Cost of migration & $0.00009^{* * *}$ & 0.00003 \\
\hline $\begin{array}{l}\text { Return of money borrowed for } \\
\text { migration }\end{array}$ & 0.41300 & 0.84994 \\
\hline Constant & -0.22776 & 0.29477 \\
\hline Number of observations & 723 & \\
\hline Number of censored observations & $231(32 \%)$ & \\
\hline Pseudo $\mathrm{R}^{2}$ & 0.0091 & \\
\hline McKelvey \& Zavoinas' R² & 0.126 & \\
\hline Likelihood ratio & 84.797 & \\
\hline Likelihood probability & 0.000 & \\
\hline
\end{tabular}

Note: "Cost of migration" states the total amount of money spent to migrate ranging from actual travel costs to visa costs, etc.

The marginal effects are conditional on being uncensored.

Base: Migrant primary education or less; migrant location other; migrant abroad 0-1 year

* significant at $10 \%{ }^{* *}$ significant at $5 \%$; ${ }^{* * *}$ significant at $1 \%$ 
Loan repayment can be measured by looking at migration costs and the education level of the migrant. Migrants with a higher education level could be sending remittances to repay the investment their parents have made into their education. Even from a sociological perspective this motive seems justified, as the contract may be implicit and based on a feeling of duty. However, this variable could also measure income effects. Almost all authors find a positive relationship between the migrant's education level and remittances. ${ }^{49} \mathrm{~A}$ non-significant and negative relationship is found for Moldova, so there is no evidence that Moldovans are remitting to repay education costs.

It is possible that those migrants that received help from their family in financing migration send more remittances as a loan repayment. This is confirmed by all empirical studies that find a significant relationship. The loan repayment variables in the analysis are jointly significant. The household head having a higher than primary education level has a positive, very significant and large marginal effect on the amount of remittances sent. It is thought that household heads with a higher education level are better able to enforce loan repayment (Hoddinott, 1992), thus the higher remittances. Cost of migration is positive, as expected and the variable returned loan is has a different effect than expected (and not significant). Remittances are measured over the whole past year, but it is not clear at what point in time the loan was returned, so it is possible that remittances still capture the effect of repaying the loan. Overall there is mixed evidence for loan repayment.

\subsection{Conclusions}

In this chapter I set out a theoretical framework, the Welfare Pentagon, that analyses why people migrate and tested parts of it empirically. Not all theoretical predictions could be confirmed in the empirical analysis. In terms of demographics, migrants are younger on average and being male and married increases the propensity to migrate. These effects are especially strong for Albania, where a higher number of children in the household also leads to more migration. It appears that migration is very much a family-focused decision, taken in order to support the family. The existing literature on Albanian migration acknowledges the importance of the family in terms of support (see also Chapter 6) and also as an important factor in the migration decision (e.g. Vullnetari, 2007 and Barjaba \& King, 2005). It was also shown that remittances in Albania are mostly linked to the motive altruism, which corroborates the conclusion that Albanians migrate to support their families. However, my empirical work does not strongly support previous findings that Albanian migration is additionally driven by dire economic circumstances, such as poverty, unemployment etc. (e.g. Mancellari et al, 2006).

The Welfare Pentagon framework hypothesizes that individuals that are unemployed or underemployed in the local labour market, may migrate. While migrants in Albania are generally lower educated, in Moldova the more highly educated are more likely to migrate. I also show that highly educated Moldovan migrants send more remittances. My own evidence on employment is somewhat

49 Only two papers find a negative relationship between the migrant's education level and the probability of sending remittances: Durand et al (1996) and Osaki (2003). 
fuzzy, but there is some indication that in Moldova migration is linked to employment. Other research (e.g. Lücke et al, 2007 and Danzer \& Dietz, 2009) clearly links migration to dysfunctional labour markets in Moldova. This is consistent with the pattern of seasonal migration with Moldovans migrating to fill gaps in labour demand abroad. Migration in Moldova can thus be seen as a (human capital) investment (confirming Sjaastad, 1962): Moldovans migrate abroad, because they are better able to employ their skills and human capital abroad.

The Welfare Pentagon shows how access to social networks and membership institutions, helps maintaining income at home, but also to realize migration. There is strong evidence for formal and informal networks facilitating migration in both countries. Albanian migrants have more friends, than non-migrants, and meet their friends more often. Migrant households live in communities with more community groups and these households have joined more groups. In both Albania and Moldova, the higher the fraction of migrants in the community, the higher is the propensity to migrate.

The NELM emphasizes that failed or non-existing labour and credit markets in source countries may be a motivation to send one or more household members abroad. Weak public authorities should also be added to that list. Migration may be a solution for poor households, if neither markets nor the government are available to help. Previous studies have pointed out the important role the collapse of social services played in influencing Albanian migration flows (e.g. Unicef, 1998 quoted in Barjaba \& King 2005). It is also tested whether structural differences in terms of infrastructure and public transfers stimulate migration flows, but the empirical results are ambiguous. Descriptive statistics show that migrant households are less likely to receive public transfers. It is not completely clear whether migrants live in less developed communities: Migrants and remittance receivers are more likely to live in rural areas. Remittance receivers live in communities that are less developed in terms of access to credit and infrastructure but these results are not significant.

In the second part of this paper I reiterate the most important theoretical motives of remitting, before testing a number of them using data on Albania and Moldova and critically comparing the results to the previous literature. Remittances are measured from the receivers' perspective, but focus on the remitter's motives, analysing the characteristics of both the remitter and remittance receiving household. While there is evidence for some motivations, the aim to repay loans and self-insurance in Moldova and altruism in both countries, the analysis resulted in inconclusive results, very much in line with the literature.

Albania and Moldova differ in terms of migration and remitting patterns. Males are the majority of migrants in both countries and remittances are sent to all income groups. In Albania, higher amounts are sent to poorer households. Albanian men send higher amounts of remittances, probably due to cultural practice, while in Moldova there are no significant gender differences. In Moldova the more highly educated send more remittances implying that migration was an effective human capital investment in line with Sjaastad's (1962) hypothesis.

It seems that in both countries, remitters have (some) altruistic motives. The better educated (and consequently wealthier) remit more. More remittances are sent to worse off households and migrants remit less if there are other migrants in 
the household, as the migrant is not the only one responsible for the wellbeing of the family. More remittances are sent to larger and thus needier households and to households living in communities with lack of employment prospects. The altruism evidence is especially strong for Albania. This is in agreement with the idea that Albanians migrate to support their families.

In Moldova there is some evidence for self-insurance. Migrants living in more risky environments (longer distance to destination and illegal entry) send more remittances, a type of informal insurance premium. There is some evidence that remittances are being paid as loan repayment in Moldova. However, the remittances motives literature has a number of serious methodological problems that will be discussed below.

It is clear that the causes and patterns of migration in Albania and Moldova influence the remitting behaviour. It is an inter-linked decision. Geographical location, economic possibilities and family situations determine where, for long and under which circumstances a migrant can migrate and send remittances. In Albania migrants seem to leave to support their families and indeed there is some evidence for the motive altruism. In Moldova on the other hand, both the decision to migrate and remit seems to be more individualistic. Migration seems to be a human capital investment leading to a location where employment prospect, given the migrants skill level, are better. The highly educated are more likely to migrate and to remit. Remitting motives seem to be partially based on self insurance and loan repayment.

I would like to end this conclusion with a discussion of the methodological problems that I have continuously pointed out in this chapter. These problems relate both to measuring the determinants of migration and remittances and can be divided in data and measurement problems and the general complication of that I am analysing human behaviour.

he most obvious data problem is that data sets are limited and that a dataset generally never has all relevant variables. Most of the time researchers only have access to general household surveys that do not have much detail on migration or in this case, Welfare Pentagon variables. Furthermore migration datasets are often only based on one perspective, the migrant or the migrant's household. In this case this means that while there is data on the household's income, migrant's income is missing, both of which are quite essential to measure remitting motives. Especially for contractual remitting motives or joint migration decisions one should analyse both perspectives. One is often only able to measure outcomes e.g. whether somebody migrated, but not whether they aspire to migrate (migration intent surveys have their own problems) or it is known how much they earn in origin labour market but often not whether they tried to find work. Finally, data is often cross-sectional, which means that generally a household's situation before migration is not known. The ALSMS 2005 data is an exception and Chapter 5 makes uses of pre-migration data.

There are a number of measurement difficulties for both the decision to migrate and remit. First of all, migrants may have more than one (migration, remitting) motive in mind and motives may also be overlapping. Furthermore motives may have same effect on certain variables (for example in the reaction to shocks), even theoretically, which makes them almost impossible to measure empirically. The 
resulting findings are then often multi-interpretable. It is difficult to find proxies that measure human behaviour which means that operationalisation is often weak. Furthermore one needs to be aware of reverse causality between the household's income or consumption and outcome variables, for example whether someone is a migrant or how much a migrant remits. The next chapter deals with the reverse causality problem more rigorously. Finally, I am not able to account for the fact that the decision to migrate and remit may be strongly linked. Migrating and remitting are joint decisions in many cases and only looking at the motivations to remit biases the results and leaves out vital explanatory factors. At the same time one should also account for the fact that migrants may have migrated in order to remit more fully in the migration decision.

In the final paragraph I would like to bring up that the fact that migrants are social beings complicates the analysis. People are not always rational and they may not always be aware of (sub-conscious) behaviour. In reality the dichotomy altruism versus self-interest is not as sharply defined as in theory. Furthermore, a migrant might have more than one (migrating, remitting) motive in mind. economic research should therefore be improved to better include the social context and acknowledge the full complexity of a migrant's decision. ${ }^{50}$

${ }^{50}$ Carling (2008) is a good example for the determinants of remittances. 



\section{$5 \quad$ Are internal migrants in Albania leaving for the better?}

\subsection{Introduction}

While Albania is more known for its massive international migration flows, the considerable internal migration flows are less famous and very much understudied. Earlier studies on Albanian migration have shown that internal and international migration flows show distinctive patterns, both in terms of geography and poverty: Internal migrants mainly come from the mountain and North-Eastern districts, migrate to the peripheries of big urban centres, and are generally poorer than international migrants (Zezza et al., 2005). Not much is known on the impact of internal migration, both in the case of Albania and in general. This paper consequently tries to fill a gap in the migration literature by assessing the impact of internal migration on household wellbeing.

Albania was one of the most isolated and authoritarian communist countries. While international migration was officially forbidden, internal migration was allowed until the 1960s, when the Albanian government introduced a policy of rural retention and minimal urbanisation (Vullnetari, 2007). This meant that by the fall of communism in 1990, Albania was the most rural society of Europe (Cabiri, 2002). Albanians started migrating internally immediately after the fall of Communism, even though it was not legal to do so until 1993. Figure 5.1 shows internal and international migration trends between 1990 and 2004.

Internal migration in 1990 was at a higher level than international migration but dipped after the regime change in 1992, peaking again around the collapse of the pyramid savings scheme in 1996-1997.51 Internal migration reacted much quicker to the shock than international migration, presumably because it was the cheaper alternative. In recent years international migration flows have become more significant than internal flows, but all types of migration have declined and slowed down, possibly due to an improvement in economic conditions in the country (World Bank, 2007).

\footnotetext{
${ }^{51}$ From November 1996 several informal pyramid savings schemes started to fail, the losses amounting to about $50 \%$ of GDP in nominal terms. About two thirds of Albanians had invested in them and the event had immense financial and political effects. Albania was close to a civil war and many people lost all their savings and property.
} 
Figure 5.1 Internal and international migration flows 1990-2004

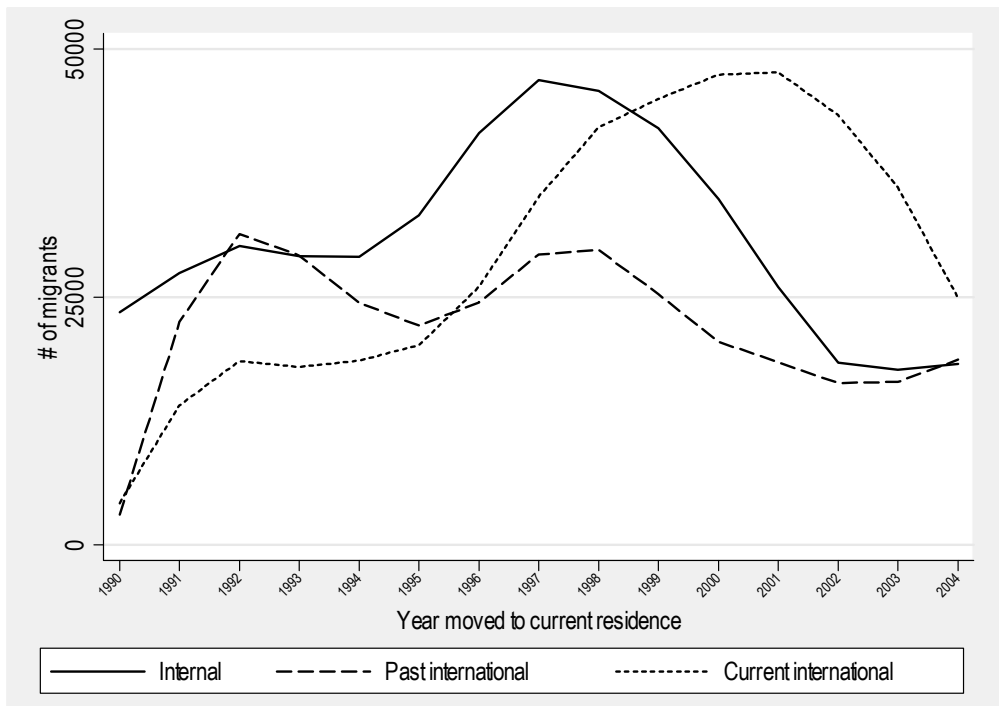

Note: Year refers to date of first move; past international migrants are those migrants that have returned to Albania

Source: Own calculations, based on 2005 Albania ALSMS

There has been little research into the links and interaction between international and internal migration, both in theory and in the Albanian case (King et al., 2008). Agorastakis et al. (2007) suggest that an initial international move (e.g. to Greece) is used as the means to finance an internal move from a rural location to an urban area. However, the calculations based on the 2005 Albania Living Standards Measurement Survey (ALSMS) show that for individuals that have migrated both internally and internationally, internal migration precedes the international move by 2 years on average. Migration in this case follows the more traditional pattern of moving to the city as a stepping stone for international migration. In any case, as Figure 5.1 and other papers (e.g., Zezza et al., 2005) show, migration flows follow unequal patterns and are motivated by different reasons.

Focusing on internal migration, between the two Censuses in 1989 and 2001 182,600 individuals (5.7\% of the population) moved from one region to another and twice that many people moved across prefectures (INSTAT, 2004). Almost one in three adults has migrated internally since birth (World Bank, 2007). Migration took different forms, but the most dramatic flows were rural to urban. A major consequence of internal migration is that urbanisation increased greatly, as Figure 5.2 shows. 
Figure 5.2 Urbanisation trends 1919-2009

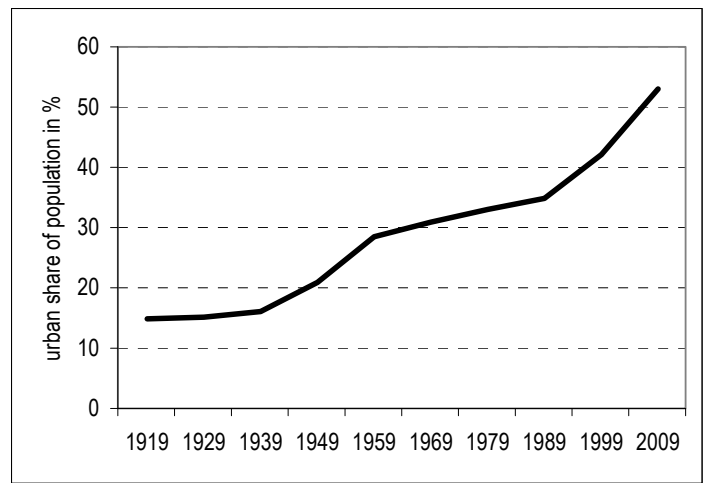

Source: Cabiri (2002); 2009 is predicted

Between 1989 and 2001 the rural population declined by 15\%, while the urban population increased by $14 \%$ (INSTAT, 2002)..$^{52}$ The share of the urban population increased from 35\% in 1980 to $45 \%$ in 2005 (Cila, 2006). In 2001, 60\% of internal migration was rural-urban, with almost half of rural-urban flows going to the Tirana municipality (INSTAT, 2004). Internal migrants mainly come from the North-Eastern remote mountain districts (such as Kukes) and move to the coastal areas and the capital Tirana. It is the most important destination in absolute and relative terms, with Durres being in second place (Carletto et al., 2004). Unlike in other areas of Eastern Europe, internal migration is permanent and not circular. Figure 5.3 depicts a map of Albania showing the major internal migration trends, with the size of the arrows being proportional to actual migration flows.

The second major consequence of internal migration is the enormous growth of Albania's capital Tirana. It is the financial, economic, cultural and educational centre of the country and has grown by more than $40 \%$ since 1989 . The population of Tirana increased from 368,000 in 1989 to at least 600,000 in 2002 (INSTAT, 2004). Unofficial estimates place the current population at around 800,000 inhabitants (de Soto et al., 2002). More than $60 \%$ of population did not live there before 1989 (Zezza et al., 2005). Tirana experienced a building boom as a result of the population increase, and 51\% of buildings have been constructed after 1990 (Agorastakis et al., 2007). Growth is focused in peri-urban areas due to cheaper housing and living costs. One of the most important peri-urban settlements is Bathore, in the Kamza municipality right next to the city. Here the number of inhabitants increased from about 7,000 in 1989 to 80,000 in 2005 (Cila, 2006). About $55 \%$ of the rural-urban internal migrants who moved to Greater Tirana in the 1990s still live in peri-urban areas (ALSMS, 2005).

52 The urban population is defined as those individuals living in towns and cities (Cabiri, 2002). 
Figure 5.3 Main inter-district migration flows

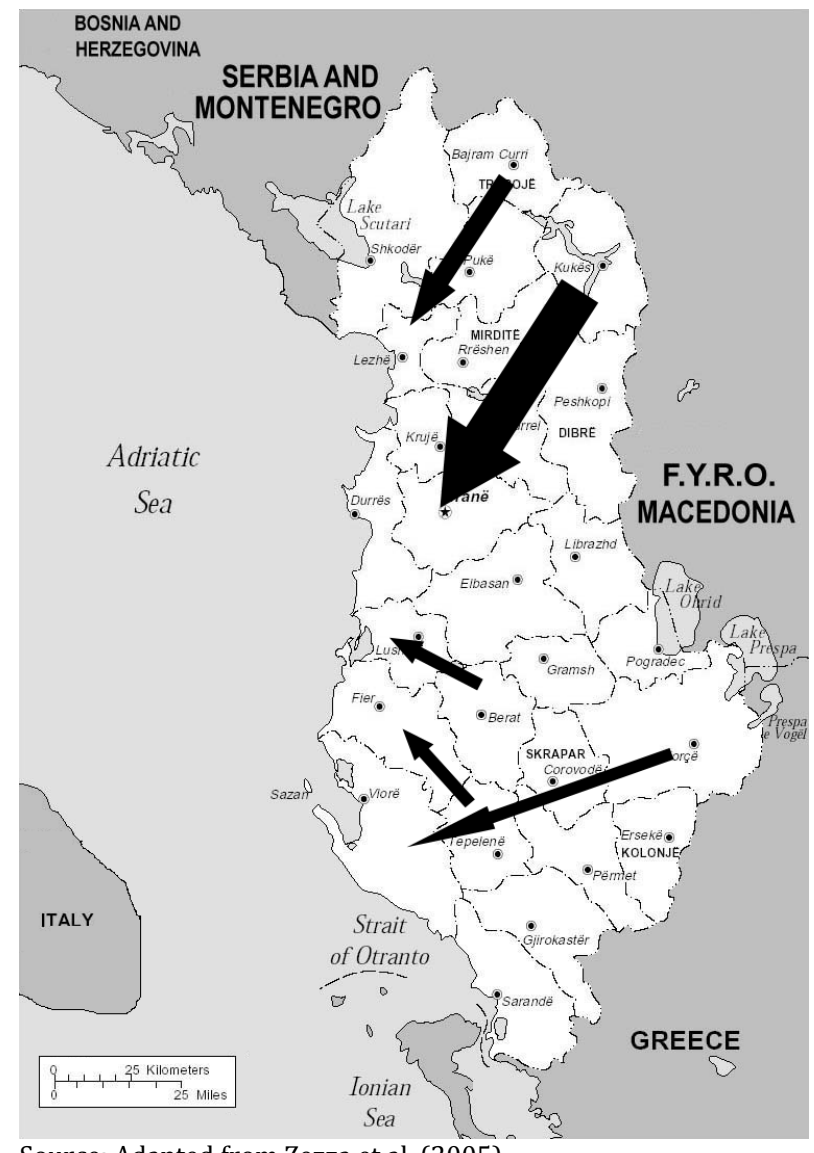

Source: Adapted from Zezza et al. (2005)

Peri-urban areas lie on the fringes of urban Tirana, often occupying former agricultural communes or abandoned public industrial areas, and not much is known on the living conditions and wellbeing of their residents. About $55 \%$ of the population in Greater Tirana lives in casual dwellings. Settlement took place illegally and informally with no urban planning. This means that most households do not have proper documentation for their houses, and often lack access to basic utilities (e.g. running water). Infrastructure was non-existent at first, though recently international organisations and NGOs have made some investments in infrastructure. There is little access to schooling: schools are far away and overcrowded. In Bathore, as an example, 2,500 children attend the only primary school, which has a capacity of 1,200 (Deda, 2006). Consequently, many schools have started holding multiple shifts of classes per day and children only attend school for a couple of hours a day (World Bank, 2003). Access to health services is also limited, as hospitals are only located in urban Tirana and health centres are running beyond capacity (ibid).

Internal migration in Albania is often characterised by whole family relocation, which means that the proportion of women migrants is also exceptionally large 
(54\% according to INSTAT, 2004). Migrants are generally of working age and highly educated (World Bank, 2007). Earlier studies indicate that internal movers come from all socio-economic backgrounds (De Soto et al., 2002, Cila, 2006), and the main motivation behind the relocation seems to be economic, i.e. work-related (Carletto et al., 2004).

This chapter will compare migrant households to rural non-migrant households using a series of wellbeing indicators, including a wide range of variables on the households' living standards in 1990, drawn from the 2005 Albania LSMS. Also, I make use of detailed information on the residence duration of internal migrants, as well as local economic and social conditions they are exposed to. The analysis will be enriched by the focus on the oversampled households in peri-urban Tirana. They represent the largest fraction and show a number of distinguishing characteristics compared to other internal migrants. ${ }^{53}$ I will assess whether, and to what extent, welfare conditions in terms of income, consumption, health, education, and housing changed after internal migration.

This paper goes beyond previous studies on the wellbeing of internal migrants in peri-urban Tirana (Cila, 2006 and Deda, 2006), by directly comparing migrant households to other groups in the population, in particular rural households, in terms of wellbeing. Appropriate econometric techniques are applied, namely the propensity-score-matching approach (PSM) and the instrumental variable (IV) method, to homogeneously compare rural migrant households in the destination communities with their similar counterpart in rural Albania who did not move, taking their pre-migration asset endowments into account. Through the PSM and IV it will shown what impact internal migration has had on migrant households, thus making a new contribution to the literature.

The paper proceeds as follows. The next section reviews the theoretical and empirical literature on internal migration, focusing on the case of Albania. Section 5.3.1 elaborates on the data characteristics, and provides a descriptive overview of peri-urban migrants. Section 5.4 discusses the methodology and shows the empirical results. The last section concludes.

\subsection{Literature review}

This paper falls in between two major strands of the literature. While there is a vast body of literature on the impact of international relocation, the impact of internal migration has not been studied much. The majority of the literature on internal migration focuses on the determinants of the move. Most works analyze the family left behind, whereas the focus here is on the internal migrant households at the new destination. Below some of the most important theories on internal migration are outlined and the outcome the theories would predict is highlighted. Where possible, the theory is illustrated with empirical applications for Albania. Finally, the literature on the impact of internal migration is discussed and the different effects are categorised.

\footnotetext{
${ }^{53}$ Most internal migrants went to urban areas. Those who moved to peri-urban areas are generally less educated, have worse housing conditions, lower income and consumption, but also a lower unemployment rate than migrants who moved to more established urban areas.
} 


\subsubsection{Determinants of internal migration}

In the theoretical literature migration is seen either as a consequence of economic and social development or as an individual response to wage differentials and employment prospects.

The neoclassical macro-economic migration theories explain migration as part of economic development. Internal migration occurs as a result of geographical differences in the supply and demand of labour, mostly between the rural traditional agricultural sector and the urban modern manufacturing sector. In the basic dual economy model (Lewis, 1954 and Ranis \& Fei, 1961) rural workers are attracted by the positive wage differential and migrate to the urban sector until wage equalisation has occurred. Cabiri et al. (2000) and INSTAT (2004) argue that internal migration in Albania takes place due to a surplus of rural labour that migrates to urban areas until equilibrium is reached.

Harris and Todaro (Todaro, 1969; Harris \& Todaro, 1970) refine the dual economy model to account for the significant urban unemployment found in many less developed countries. In the Harris-Todaro model rural-urban migration occurs as long as the expected real income differential, based on urban wages and the employment rate, is positive. Thus, migration increases as urban wages or employment rate increases (other things being equal). Extensions of this model generally represent the labour market more realistically, for example by endogenising the urban wage. Isaah et al. (2005) include urban infrastructure as an additional factor that positively affects utility of potential migrants (together with expected income). Cattaneo (2006) applies the model to Albania using household survey data, finding that migrants are more likely to move the higher wages are and the lower unemployment differentials are.

The job search approach models migration and job search as a joint decision (Harris \& Sabot, 1982; Vishwanath, 1991). In these models, a migrant's decision to move depends on the job search mechanism e.g. whether s/he is already looking for job while still in the rural area. Thus, it goes beyond the Harris-Todaro assumption that rural migrants move to the cities uninformed, and work in the informal sector while searching for a formal job. This theory has not been applied to Albania, although Banerjee (1983) finds that in India most internal migrants already have a job in mind when they move, due to the network phenomenon.

Zelinsky's functionalist hypothesis of mobility transition (1971) argues that migration is part of economic and social changes inherent in the modernisation process. He hypothesizes that patterns and rates of migration can be closely linked to the stage of modernisation (e.g. industrialisation) and demographic factors (e.g. high birth rates). He emphasizes that the preference for more personal freedom is part of the modernisation process. The theory of mobility transition is powerful when looking at past migration patterns in industrialised nations, and might be applied to the Albanian economic transition. However, it is somewhat vague and does not allow for differentiation of migration types.

The human capital approach is the neoclassical micro-level migration theory. Based on the work of Sjaastad (1962), migration is treated as an individual investment decision to increase the productivity of human capital. Individuals make a rational cost-benefit calculation, migrating only when the expected 
discounted returns of migration over future time periods are positive. This model predicts that the young and educated migrate first. While the human capital approach is interesting and useful in explaining the selectivity of migrants, it is very hard to test empirically. It has not been specifically applied to Albania, although previous studies show what while internal migrants in Albania are generally young, they are not well-educated (see section 5.3).

\subsubsection{Effects of internal migration}

The effects of internal migration can be classified into five categories. They are monetary returns of internal migration, impacts on social mobility, on poverty, on labour market success, and on health.

As already mentioned, the neoclassical migration models predict that migrants move due to an expected income gain. Most empirical papers test the income gain due to internal migration, by looking at the difference between earnings of migrants in urban areas to the ones of non migrants in rural areas. Yap (1977) reviews a number of papers and finds that, despite higher living expenses in urban and missed in-kind rural income, migrants generally experience income gains. Cila (2006) finds that the income of peri-urban migrants in Tirana increased as an effect of migration. Tunali (2000), on the other hand, shows that not everybody benefited from internal migration in Turkey in the 1960s, and that a sizeable fraction of internal migrants experienced income shortfalls.

When rural-urban migration takes place social mobility may occur. Mohaditi (1986) disputes this claim. He measures income inequality as a result of internal migration in Iran, finding that rural inequalities are reproduced in urban areas. If migrants come from a landless family, urban inequality is increased.

The effect of internal migration on poverty has not been studied much empirically. Using a unique tracking survey of individuals, Beegle et al. (2008) show that internal migration is an effective way of moving out of poverty, regardless of the destination. Migrants experience a 36\% consumption growth compared to those who stayed behind (ibid). Kundu and Sarangi (2007) show, with descriptive district statistics, that migrants in India are less poor than rural households, but poorer than urban non-migrant households. They also show that, even for casual workers, rural-urban migration has a strong and negative effect on the likelihood of being poor.

Cila (2006) uses the livelihoods framework to assess the change in wellbeing for rural migrants in Bathore. She finds that, while income tends to be higher, it is more volatile, and living expenses are also greater, but in general migrants' livelihoods have improved. Furthermore, their human capital in terms of number of years of education and knowledge has increased (though there are still gender differences). Deda (2006) finds that, despite higher incomes, peri-urban households are, nevertheless, living in poverty as they need to pay for basic public services, such as electricity, sewage and garbage disposal.

There is mixed evidence on the labour market success of internal migrants. Knight, Song and Huaibin (1999) and Meng and Zhang (2001) show that internal migrants in China are hampered by labour market segregation and they receive lower wages even when they have the same occupation and educational background as the 
natives. Davin (1999) confirms that the working conditions for migrant workers are tough and that they are granted fewer economic and social security benefits than the rest of the workers. Yamauchi (2004) also finds that the returns to schooling are lower for Thai internal migrants than natives, although the accumulation of destination experiences raises migrant's wages. Banerjee (1983) shows that mobility from the informal to the formal sector in India is low, but that within sectors the education and urban work experience of migrants and nonmigrants is valued equally. In the studies reviewed by Yap (1977), migrants have a lower unemployment rate than non-migrants, their education levels are adequately valued and they are not disproportionally more likely to work in the informal sector. Labour market outcomes for Albanian internal migrants have not been studied extensively, but descriptive statistics reveal that most of the employed workers are employed in casual, informal and low-paid work (see section 5.3).

The International Organization of Migration (2005) argues that migrants face greater health risks due to hazardous working and living conditions, peer pressure, easier access to drugs and the sex industry and because many migrants have only limited access to public health services. Shaokang et al. (2002) find that female internal migrants in Shanghai utilise antenatal care services at a much lower degree, and show worse pregnancy outcomes compared to non-migrant women, perhaps as a result of their illegal status. Davin (1999) confirms that in China temporary residents have inferior access to education and health services. Cila (2006) shows that although the health status of peri-urban migrants is fine in general, there are some health problems due to bad sanitary conditions, and the health infrastructure is insufficient (travel distances to hospital are far and underthe-table payments are often required).

\subsection{Data and Descriptive Statistics}

\subsubsection{Data}

The 2005 Albania Living Standards Measurement Survey (ALSMS) data is used; a survey carried out by the Albania National Institute of Statistics (INSTAT) with the technical assistance of the World Bank. The data was collected at the household level, as well as at the community level, including detailed information on housing, health, migration, education, labour and consumption. A nationally representative sample of 3,640 households was interviewed and supplemented with an additional 200 households oversampled in peri-urban Tirana in order to allow for a detailed analysis of peri-urban areas. A brief comparison between rural, urban and periurban households is presented in the next section.

Our study compares households by migration status of the head, as in Albania internal migration is often commenced by an initial move of the head. After s/he is settled, the rest of the family follows, or s/he sets up her/his own family at the new 
location. Households in peri-urban Tirana whose head migrated internally since 1990 are compared to rural households whose head did not move. ${ }^{54}$

Out of the 320 peri-urban households in the sample, the heads of 155 households did not move after 1990; 165 migrated after 1990 from rural areas. ${ }^{55}$ There are 1,599 rural households whose head has not migrated since 1990. The differences between the latter two groups will be explored in section 5.3.3, while the periurban migrant group will be examined in section 5.3.4. However, first show some descriptive statistics are shown for the whole sample.

\subsubsection{The Albanian households}

This section provides an overview of the differences between rural, urban and peri-urban households in Albania. Table 5.1 presents the mean values of some general characteristics.

Rural households have a greater incidence of married heads, are younger on average, larger, and with a higher number of dependent children than urban households. Peri-urban households which have migrated internally are even younger and have even more children. Rural households are more likely to have any migration exposure, as well as a higher number of migrants per household.

Table 5.1 shows that rural households have lower wellbeing in most categories. Urban households and, to a lesser extent, peri-urban households are less likely to live in a single family house, as apartment buildings are more common in urban areas. However, urban households live in better quality dwellings, which are significantly more likely to have running water than peri-urban migrants. In terms of housing the latter have even lower achievements, than rural households.

Peri-urban households (especially those which have migrated internally) are significantly more likely to have household members with a sudden illness, and while rural households are located the furthest away from the closest doctor, periurban households are not far behind. Rural residents show much lower education levels, but a significantly lower unemployment rate, as more than $90 \%$ of households in rural areas are involved in agriculture.

In terms of education levels peri-urban adults are much closer to rural adults than to urban adults. In terms of income, urban households are more affluent than rural ones, and their consumption is about 30\% higher. They get most of their income from wages and self-employment, as opposed to rural households, whose largest share is from less profitable agricultural activities. Peri-urban households have higher incomes than rural ones, but do not consume more, especially those that migrated internally. 1 out of 4 rural individuals is poor, compared to 1 out of 10 urban individuals; urban poverty is also less severe (measured by the poverty gap, see Foster, Greer and Thorbecke, 1984).

\footnotetext{
${ }^{54}$ Heads having both urban and rural origins are looked at, as this allows us to keep the sample as large and representative as possible. There is the slight possibility that a peri-urban household head was originally a family member of one of the rural households in the sample (e.g. a child). However, in a random sample of 3640 households this is very unlikely.

55 The following descriptive statistics are drawn on a slightly smaller sample, as 34 households show missing information on consumption and income.
} 
Table 5.1 General household characteristics

\begin{tabular}{|c|c|c|c|c|c|}
\hline & $\begin{array}{c}\text { Urban } \\
\text { households }\end{array}$ & $\begin{array}{c}\text { Rural } \\
\text { households }\end{array}$ & $\begin{array}{c}\text { Peri-urban } \\
\text { households } \\
\text { not migrated }\end{array}$ & $\begin{array}{c}\text { Peri-urban } \\
\text { households } \\
\text { migrated }\end{array}$ & Total \\
\hline Whether head married & $0.85^{* * *}$ & $0.91^{* * *}$ & 0.9 & 0.89 & 0.88 \\
\hline Average age of members & $34.32^{* * *}$ & $32.30^{* * *}$ & 31.23 & $27.93^{* * *}$ & 32.97 \\
\hline Number of children & $0.86^{* * *}$ & $1.20^{* * *}$ & 1.15 & $1.45^{* * *}$ & 1.05 \\
\hline Household size & $3.83^{* * *}$ & $4.46^{* * *}$ & $4.59^{* *}$ & $4.90^{* * *}$ & 4.19 \\
\hline Number of members living abroad & 0.58 & $0.67^{* * *}$ & $0.21^{* * *}$ & $0.43^{*}$ & 0.61 \\
\hline Whether Single family house & $0.49 * * *$ & $0.94^{* * *}$ & $0.84^{* * *}$ & $0.86^{* * *}$ & 0.73 \\
\hline Whether housing quality good & $0.92^{* * *}$ & $0.87^{* * *}$ & 0.87 & $0.81^{* * *}$ & 0.89 \\
\hline Whether Running water & $0.92^{* * *}$ & $0.53^{* * *}$ & $0.59 * * *$ & $0.33^{* * *}$ & 0.71 \\
\hline Whether someone has sudden illness & $0.21^{* * *}$ & $0.26^{* * *}$ & $0.34^{* *}$ & $0.36^{* * *}$ & 0.24 \\
\hline Distance to closest doctor in minutes & $13.49^{* * *}$ & $23.82^{* * *}$ & 20.14 & 18.54 & 18.77 \\
\hline Average years of education of adults & $10.14^{* * *}$ & $7.95^{* * *}$ & 8.73 & $8.17^{* * *}$ & 8.91 \\
\hline Unemployment ratio & $0.15^{* * *}$ & $0.04^{* * *}$ & 0.06 & 0.1 & 0.09 \\
\hline Monthly per capita income (Leks) ${ }^{1}$ & $11219.07^{* * *}$ & $6852.80^{* * *}$ & 9075.59 & 9224.11 & 8857.03 \\
\hline $\begin{array}{l}\text { Monthly per capita consumption } \\
\text { (Leks) }^{1}\end{array}$ & $10761.09^{* * *}$ & $7847.93^{* * *}$ & 8465.4 & $7994.92^{* *}$ & 9108.86 \\
\hline Poverty headcount & $0.11^{* * *}$ & $0.25^{* * *}$ & $0.07^{* * *}$ & 0.17 & 0.18 \\
\hline Poverty gap & $2.30^{* * *}$ & $5.67^{* * *}$ & $1.10^{* * *}$ & $2.17^{*}$ & 3.97 \\
\hline Poverty severity & $0.80^{* * *}$ & $1.89^{* * *}$ & $0.24^{* * *}$ & $0.44^{* *}$ & 1.32 \\
\hline Number of observations & 1,938 & 1,551 & 153 & 164 & 3,806 \\
\hline $\begin{array}{l}\text { Whether All children attend primary } \\
\text { school }^{2}\end{array}$ & $0.88^{* * *}$ & $0.84^{* *}$ & 0.9 & $0.70^{* * *}$ & 0.85 \\
\hline $\begin{array}{l}\text { Whether All children attend secondary } \\
\text { school }^{3}\end{array}$ & $0.62^{* * *}$ & $0.34^{* * *}$ & 0.57 & $0.34^{*}$ & 0.46 \\
\hline Time to school in minutes ${ }^{4}$ & $10.55^{* * *}$ & $16.90^{* * *}$ & 15.2 & $18.37^{* * *}$ & 13.95 \\
\hline
\end{tabular}

Note: stars indicate whether the mean for each group is statistically different from the rest (* significant at $10 \% ;{ }^{* *}$ significant at $5 \%$; ${ }^{* *}$ significant at $1 \%$ ). All figures are weighted.

${ }^{1}$ Income and consumption are corrected for regional price difference; 1 Lek $=0.01035$ US\$ (2005)

${ }^{2}$ Number of observations are 800,823, 74, 82 and 1779 respectively, as not all households have primary-school age children; ${ }^{3}$ Number of observations are 608, 605, 54, 56 and 1323 respectively, as not all households have secondary-school age children; ${ }^{4}$ Number of observations are $1114,891,96,91$ and 2195 respectively, as not all households have school age children Source: Own calculations on 2005 ALSMS, including oversample.

Rural primary school attendance is significantly lower than in urban areas, and the difference is even greater for secondary school attendance: only $34 \%$ of rural and peri-urban migrant households send all their children to secondary school. One reason might be the worse infrastructure: rural and especially peri-urban children have to travel further to school.

\subsubsection{Rural and peri-urban households}

In the following section, descriptive differences are explored between households in rural areas whose head did not migrate post 1990 (RNM) and households in peri-urban Tirana whose head has migrated post 1990 (PM). Table 5.2 shows some characteristics of their demographic composition. 
Individuals and heads in PM households are significantly younger, on average, compared to rural households. This is consistent with the human capital approach to migration. There is no significant difference in terms of marital status and gender ratio. The significantly larger family size of PM households partially confirms that whole households moved. The latter also have the highest number of children per household. RNM households show a higher international migration exposure than PM, which could be interpreted as a substitute for internal migration.

Table 5.2 Demographics

\begin{tabular}{lccc}
\hline & RNM & PM & Total \\
\hline Average age of members & $32.63^{* * *}$ & $27.93^{* * *}$ & 32.33 \\
Age of head & $52.76^{* * *}$ & $46.31^{* * *}$ & 52.38 \\
Whether head married & 0.9 & 0.89 & 0.9 \\
Ratio of males/females & 1.21 & 1.08 & 1.2 \\
Household size & $4.47^{* *}$ & $4.90^{* *}$ & 4.49 \\
Number of children & $1.17^{* *}$ & $1.45^{* *}$ & 1.19 \\
$\begin{array}{l}\text { Whether household has permanent } \\
\text { migrant }\end{array}$ & $0.37^{* *}$ & $0.26^{* *}$ & 0.36 \\
$\begin{array}{l}\text { Whether household has temporary } \\
\text { migrant }\end{array}$ & 0.1 & 0.11 & 0.1 \\
Number of members living abroad & $0.69^{* *}$ & $0.43^{* *}$ & 0.68 \\
\hline $\begin{array}{l}\text { Number of observations } \\
\text { Percentage of total households in }\end{array}$ & 1,486 & 164 & 1,650 \\
ALSMS 2005 & $39 \%$ & $4 \%$ & $43 \%$
\end{tabular}

Note: RNM = Rural household whose head did not migrate internally; PM = Peri-urban household whose head did migrate internally.

Stars indicate whether the mean is statistically different across groups $\left({ }^{*}\right.$ significant at $10 \%$; ${ }^{* *}$ significant at $5 \%$; ${ }^{* * *}$ significant at $1 \%$ ). All figures are weighted. Source: Own calculations on 2005 ALSMS, including oversample.

Table 5.3 provides some insights on education and employment for the two types of households under study. Adults and heads in PM households have a higher, but not significantly different, education level than rural households, so the two groups are very similar in terms of education level.

Individuals in peri-urban areas are more likely to be unemployed and work, on average, fewer hours per week than their rural counterparts. This can be explained by the fact that peri-urban resident are mostly employed in casual and informal employment, and their female employment rates are low. Almost all women in rural households work in agriculture, whereas migrant women are more likely to be constrained by traditional values with respect to formal employment. As a consequence, they do not seem to seek formal jobs. 
Table 5.3 Education and employment

\begin{tabular}{lccc}
\hline & RNM & PM & Total \\
\hline $\begin{array}{l}\text { Average years of education of } \\
\text { adults }\end{array}$ & 7.92 & 8.17 & 7.93 \\
$\begin{array}{l}\text { \# of education years of head } \\
\text { Whether all working age }\end{array}$ & 7.98 & 8.2 & 7.99 \\
members work & $0.26^{* * *}$ & $0.06^{* * *}$ & 0.25 \\
$\begin{array}{l}\text { Whether head unemployed } \\
\text { Unemployment ratio }\end{array}$ & $0.01^{* * *}$ & $0.06^{* * *}$ & 0.02 \\
$\begin{array}{l}\text { Average weekly hours worked by } \\
\text { adults }\end{array}$ & $0.04^{* * *}$ & $0.10^{* * *}$ & 0.04 \\
\hline $\begin{array}{l}\text { Number of observations } \\
\begin{array}{l}\text { Percentage of total households in } \\
\text { ALSMS 2005 }\end{array}\end{array}$ & 1,486 & $19.44^{* * *}$ & 24.8 \\
\hline
\end{tabular}

Note: RNM = Rural household whose head did not migrate internally; PM = Peri-urban household whose head did migrate internally.

Stars indicate whether the mean is statistically different across groups (* significant at $10 \%$; ${ }^{* *}$ significant at $5 \%$; ${ }^{* * *}$ significant at $1 \%$ ). All figures are weighted.

Source: Own calculations on 2005 ALSMS, including oversample

Table 5.4 and Figure 5.4 show different wellbeing and poverty indicators across household types, including some indicators that refer to 1990, i.e. to the premigration situation.

Peri-urban households enjoy a per-capita income significantly higher than rural households. The per capita income of the latter group is about $75 \%$ of the income of PM. This is in line with the neoclassical macro theory, and provides some evidence that migration positively affects financial wellbeing. However, if one looks at differences in consumption level, a different picture emerges. PM households show as low consumption levels as rural households, which suggests that despite a significantly higher income the latter does not fully offset the elevated living expenses of the city. Also, PM families benefit to a lesser degree from free food products from agriculture than rural counterparts.

To compare the durable asset ownership (as a proxy of wealth) the Morris score index is used (see footnote 56). PM migrants are not the least asset-deprived in 1990. By 2005 the Morris score index is similar for rural and peri-urban households, but has grown much for all groups during the 15 years period.

PM households feel, on average, more positively about their life having improved during the past three years. Looking at self-declared financial status, PM households are better off than the RNM group. Only $8 \%$ of households find that their status has worsened since 1990, and almost $70 \%$ that it is unchanged. 
Table 5.4 Wellbeing indicators

\begin{tabular}{lccc}
\hline & RNM & PM & Total \\
\hline${\text { Monthly per capita income (Leks) }{ }^{1}}$ & $6894.90^{* * *}$ & $9224.11^{* * *}$ & 7045.02 \\
Monthly per capita consumption (Leks) ${ }^{1}$ & 7865.35 & 7994.92 & 7873.7 \\
Morris score index 56 & & & 0.26 \\
1990 & $0.26^{* * *}$ & $0.38^{* * *}$ & 2.21 \\
2005 & 2.22 & 2.11 & 0.28 \\
Whether life improved over past three years & $0.27^{* * *}$ & $0.46^{* * *}$ & \\
Change in self-declared econ. status 90-05 & & & 0.14 \\
Worsened & $0.14^{*}$ & $0.08^{*}$ & 0.58 \\
Unchanged & $0.57^{* *}$ & $0.69^{* *}$ & 0.29 \\
Improved & 0.29 & 0.24 & 1,650 \\
Number of observations & 1,486 & 153 & $43 \%$ \\
Percentage of total households in ALSMS 2005 & $39 \%$ & $4 \%$ & \\
\hline
\end{tabular}

Note: RNM = Rural household whose head did not migrate internally; PM = Peri-urban household whose head did migrate internally.

Stars indicate whether the mean is statistically different across groups (* significant at $10 \%$; ${ }^{* *}$ significant at $5 \%$; ${ }^{* *}$ significant at $1 \%$ ). All figures are weighted.

1 Income and consumption are corrected for regional price difference; 1 Lek $=0.01035$ US\$ (2005)

Source: Own calculations on 2005 ALSMS, including oversample.

Figure 5.4 shows different poverty indicators.

Figure 5.4 Poverty indicators
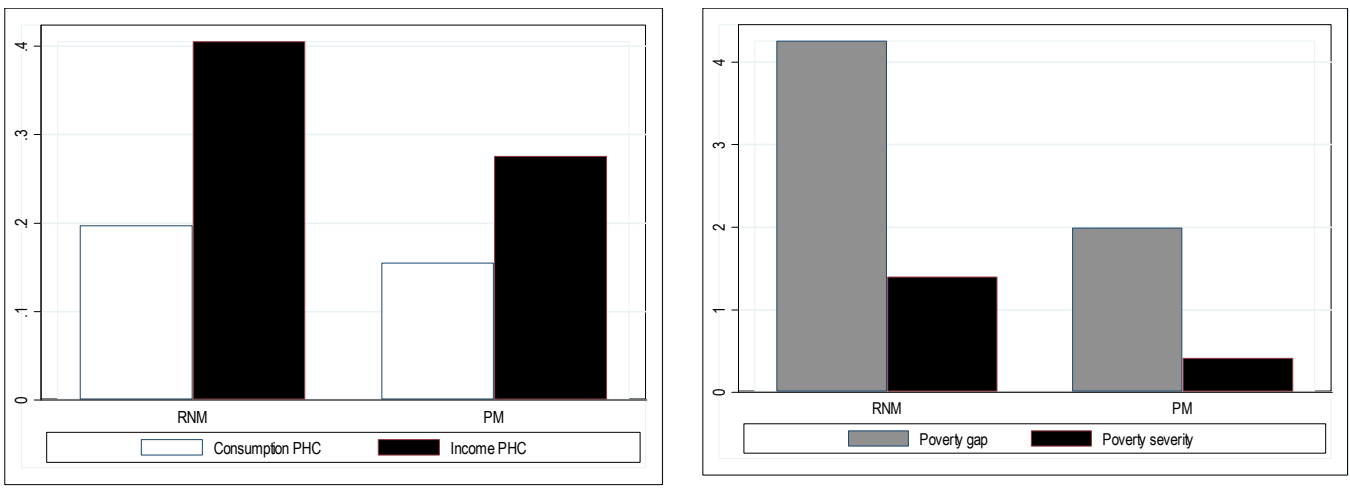

Note: RNM = Rural household whose head did not migrate internally; $\mathrm{PM}=$ Peri-urban household whose head did migrate internally.

Source: Own calculations on 2005 ALSMS, including oversample

Rural households show higher poverty rates than PM, both in terms of income and consumption-based measures. However, the difference is greater -and more significant- when using the income-based poverty headcount (PHC). Furthermore, RNM households are also significantly worse off when looking at other poverty

56 The Morris score index is a weighted asset indicator that weighs each durable asset owned by the household by the reciprocal of the number of households owning the asset, see Morris et al. (1999). 
measures, e.g., the mean poverty gap for RNM is 5.63 compared to 2.17 for PM households. This means that rural poverty is deeper than peri-urban's.

Figure 5.5 shows participation and shares of income, wage and self employment, transfers and other income generating activities for the two household groups.

Figure 5.5 Participation in income-generating activities and income shares
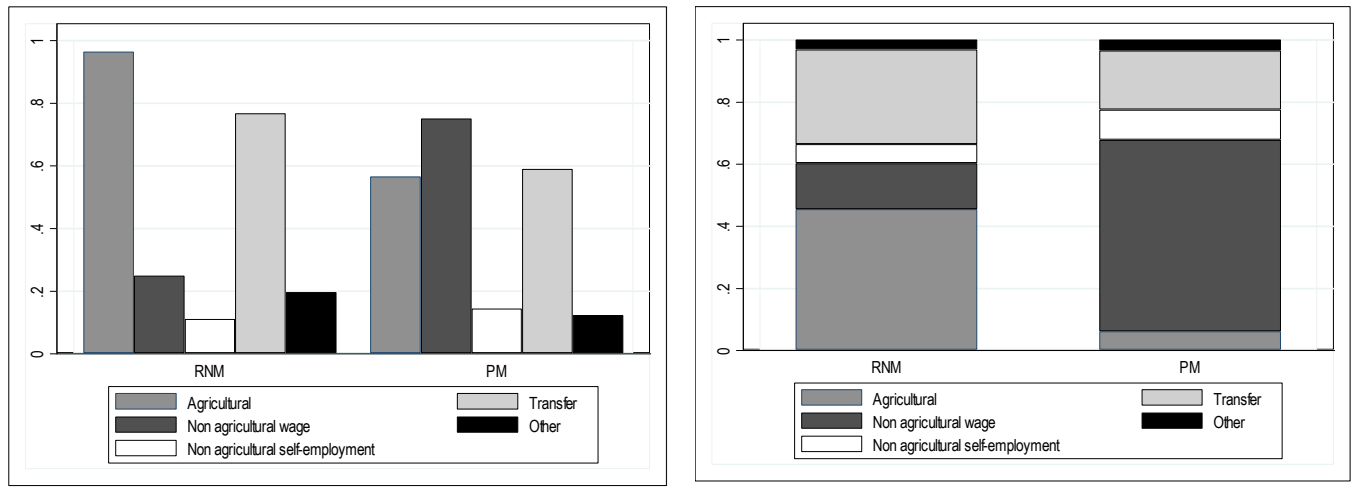

Note: RNM = Rural household whose head did not migrate internally; PM = Peri-urban household whose head did migrate internally

Source: Own calculations on 2005 ALSMS, including oversample

As expected, rural households show the highest share (96\%) of income from agricultural activities. On the other hand, wage income is the most important activity for PM households, while self-employment is also more common for PM, though the difference is not significant. The share of income from both wage and self-employment is the highest and the most significant for PM households. More than $50 \%$ of households in all categories receive some kind of transfer. RNM have the highest share of income from transfers, mostly due to public flows, the share of private being about $15 \%$ for both groups. This could be related to the fact that many PM households are illegally settled, hence less likely to be eligible for public transfers. Cila (2006) confirms that, despite the high poverty rates amongst periurban migrant households, only $10 \%$ receive state economic assistance.

Table 5.5 displays differences in housing and infrastructure for RNM and PM households. Rural households show significantly better housing conditions than peri-urban. RNM are most likely to live in a high-quality, freestanding house, and enjoy a significantly larger number of rooms per capita. In terms of house type, in 1990 RNM and PM households lived in a very similar situation, mostly residing in single family houses. PM households are now more likely to reside in apartment blocks, as they are more common in urban settings. They have a number of rooms per household member lower than for rural households, both in 1990 and now. Both groups show low incidence of availability of running water in 1990, although the situation improved for rural households only. However, PM's are now more likely to have an indoor toilet, both compared to own situation in 1990 and to rural households. Differences in access to other utilities (e.g. electricity) are not significant. Generally, in terms of housing and access to basic utilities, rural-toperi-urban migration does not seem to improve living conditions. 
Table 5.5 Housing outcomes

\begin{tabular}{|c|c|c|c|}
\hline & RNM & PM & Total \\
\hline \multicolumn{4}{|l|}{ Whether single family house } \\
\hline 1990 & 0.96 & 0.97 & 0.96 \\
\hline 2005 & $0.94^{* * *}$ & $0.86^{* * *}$ & 0.93 \\
\hline Whether good quality house in 2005 & $0.87^{*}$ & $0.81^{*}$ & 0.87 \\
\hline \multicolumn{4}{|l|}{ Number of rooms per household member } \\
\hline 1990 & $0.49^{* * *}$ & $0.39 * * *$ & 0.48 \\
\hline 2005 & $0.73^{* * *}$ & $0.49^{* * *}$ & 0.72 \\
\hline \multicolumn{4}{|l|}{ Whether running water } \\
\hline 1990 & 0.41 & 0.33 & 0.4 \\
\hline 2005 & $0.53^{* * *}$ & $0.33^{* * *}$ & 0.52 \\
\hline \multicolumn{4}{|l|}{ Whether indoor toilet } \\
\hline 1990 & $0.22^{* * *}$ & $0.39^{* * *}$ & 0.23 \\
\hline 2005 & $0.48^{* * *}$ & $0.79 * * *$ & 0.5 \\
\hline Number of observations & 1,486 & 153 & 1,650 \\
\hline Percentage of total households in ALSMS 2005 & $39 \%$ & $4 \%$ & $43 \%$ \\
\hline
\end{tabular}

Note: RNM = Rural household whose head did not migrate internally; PM = Peri-urban household whose head did migrate internally.

Stars indicate whether the mean is statistically different across groups (* significant at $10 \%$; ** significant at $5 \%$; ${ }^{* *}$ significant at $1 \%$ )

Source: Own calculations on 2005 ALSMS, including oversample

No clear pattern of health outcomes and infrastructure for the two groups emerges from Table 5.6.

Table 5.6 Health outcome and infrastructure

\begin{tabular}{lccc}
\hline & RNM & PM & Total \\
\hline $\begin{array}{l}\text { Whether someone in household } \\
\text { has sudden illness }\end{array}$ & $0.26^{* *}$ & $0.36^{* *}$ & 0.27 \\
$\begin{array}{l}\text { Whether health of household } \\
\text { members good }\end{array}$ & 0.97 & 0.99 & 0.98 \\
$\begin{array}{l}\text { Distance to closest doctor in } \\
\text { minutes }\end{array}$ & $23.87^{*}$ & $18.54^{*}$ & 23.55 \\
\hline $\begin{array}{l}\text { Number of observations } \\
\begin{array}{l}\text { Percentage of total households in } \\
\text { ALSMS 2005 }\end{array}\end{array}$ & 1,486 & 153 & 1,650 \\
\hline
\end{tabular}

Note: RNM = Rural household whose head did not migrate internally; PM = Peri-urban household whose head did migrate internally.

Stars indicate whether the mean is statistically different across groups (* significant at $10 \%$; ** significant at $5 \%$; ${ }^{* *}$ significant at $1 \%$ ). All figures are weighted.

Source: Own calculations on ALSMS 2005, including oversample

PM households show higher incidence of having a member with a sudden illness. This could be related to the fact that only $70 \%$ of PM households have access to drinking water. Cila (2006) confirms that there are health problems in peri-urban Tirana due to bad sanitary conditions. In terms of health infrastructure, Cila (2006) also finds that peri-urban households still have to travel far to secondary health 
care providers, despite the household's move to the city. Our data do not fully confirm this; rural households actually travel significantly further to the closest doctor.

Table 5.7 focuses on schooling outcomes and education expectations for the different groups, keeping in mind that the number of compulsory school age children is highest for PM households, as Table 5.2 showed. Despite the high number of school age children, primary school attendance is significantly lower for PM households. Secondary school attendance is as low as for rural households. There are several reasons why attendance could be lower for PM households: Firstly households may not be able to afford school costs and are forced to send their children to work. Teens of PM households work a number of hours per week similar to rural teens, who are expected to help the family out in agriculture. Finally, it could be that schools are not adequately sized or flexible enough. Albanian children need to be registered to attend school, and probably not all periurban parents register their children at the municipality, due to the illegal relocation. However PM's are more satisfied with the quality of education, despite the capacity problems mentioned earlier. Finally, it could be that migrant households are not fully aware of the value of education.

Table 5.7 Schooling outcomes and expectations

\begin{tabular}{|c|c|c|c|}
\hline & RNM & $\mathrm{PM}$ & Total \\
\hline $\begin{array}{l}\text { Whether all of household's children } \\
\text { attend primary school }{ }^{1}\end{array}$ & $0.84^{* *}$ & $0.70^{* *}$ & 0.83 \\
\hline $\begin{array}{l}\text { Whether all of household's children } \\
\text { attend secondary school }{ }^{2}\end{array}$ & 0.33 & 0.34 & 0.33 \\
\hline $\begin{array}{l}\text { Average weekly hours worked by } \\
\text { teens of the household }{ }^{3}\end{array}$ & 14.75 & 12.81 & 14.62 \\
\hline $\begin{array}{l}\text { Time to school in minutes by } \\
\text { members }{ }^{4}\end{array}$ & 16.7 & 18.37 & 16.8 \\
\hline $\begin{array}{l}\text { Whether members satisfied with } \\
\text { school }^{4}\end{array}$ & $0.73^{* *}$ & $0.85^{* *}$ & 0.73 \\
\hline $\begin{array}{l}\text { Whether head considers education } \\
\text { very important }{ }^{4}\end{array}$ & 0.73 & 0.79 & 0.74 \\
\hline Number of observations & 827 & 90 & 917 \\
\hline $\begin{array}{l}\text { Percentage of total households in } \\
\text { ALSMS } 2005\end{array}$ & $22 \%$ & $2 \%$ & $24 \%$ \\
\hline
\end{tabular}

Note: RNM = Rural household whose head did not migrate internally; PM = Peri-urban household whose head did migrate internally.

Stars indicate whether the mean is statistically different across groups (* significant at $10 \%$; ${ }^{* *}$ significant at $5 \%$; ${ }^{* *}$ significant at $1 \%$ ). All figures are weighted.

${ }^{1}$ Number of observations are 782, 82 and 938 respectively as not all households have primary-school age children; ${ }^{2}$ Number of observations are 586, 56 and 696 respectively as not all households have secondary-school age children; ${ }^{3}$ Number of observations are 572, 57 and 690 respectively as not all households have teenage children; ${ }^{4}$ Not all households have school age children or answered these questions.

Source: Own calculations on 2005 ALSMS, including oversample

The previous figures and tables showed that PM households are worse off, in terms of most wellbeing indicators, than rural ones, being better off only in terms of income. The next section looks at whether there are differences related to the year of arrival. 


\subsubsection{Peri-urban migrant households: is there a time effect?}

The previous section showed some puzzling and possibly contradicting results for peri-urban migrant households. They do not seem to perform well in many aspects of their livelihoods, but migration flows continue, although at a lower level, as Figure 5.1 showed. In this section PM households are analyseed in more detail in order to explain the puzzling results. More specifically, selected wellbeing indicators will be compared for three migrant cohorts according to the timing of arrival: households arriving between 1990-1994, 1995-1999, and 2000-2004. Figure 5.6 displays the unemployment ratio for the three groups.

Figure 5.6 Unemployment ratio for adults of the household

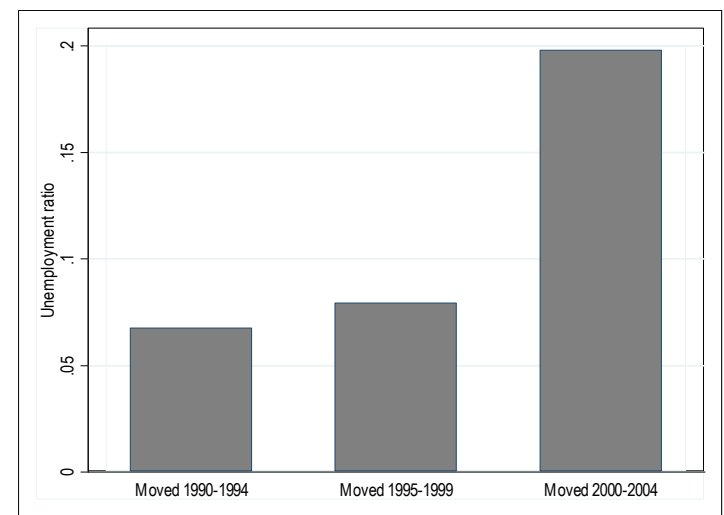

Source: Own calculations on 2005 ALSMS, including oversample

The unemployment ratio is almost three times higher for late arrivals. This might be attributed to their lower education levels -although the data show no significant difference-, or to the fact that it takes some time to find a steady fulltime job. Despite having difficulties to find a permanent job, late arrivals work, on average, approximately as many hours per week as the other groups. This means that late arrivals probably work even more than the other two groups in casual work, for example in the construction sector.

Figure 5.7 shows possible links between employment and health. The latest arrivals are twice more likely to have a sudden disease or accident than earlier ones. This is not because they have worse sanitary conditions. ${ }^{57}$ It is possible that the high rate of sudden diseases are being caused by employment in dangerous jobs, which long-term residents avoid, leaving them over to recent arrivals. This is in line with other literature on internal migration (e.g. Knight et al., 1999).

${ }^{57}$ More than $80 \%$ of late arrivals have access to drinking water, whereas only $61 \%$ of pioneers do. 
Figure 5.7 Whether someone in household has a sudden illness

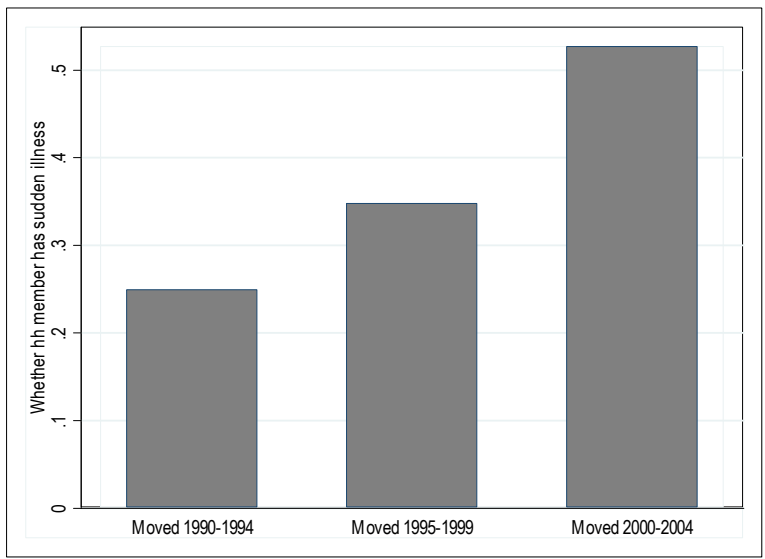

Source: Own calculations on 2005 ALSMS, including oversample

Most interesting to the purpose of this chapter are differences in income and consumption reported in Figure 5.8.

Figure 5.8 Wellbeing indicators

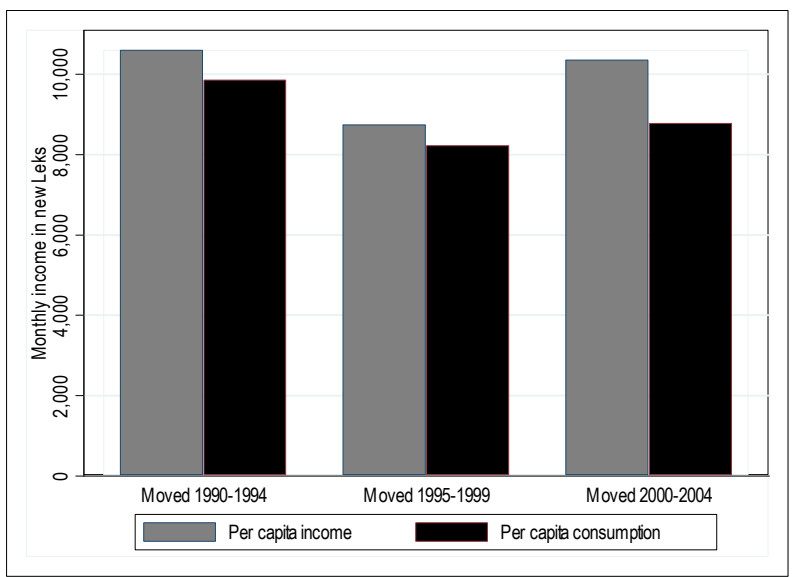

Source: Own calculations on 2005 ALSMS, including oversample

Income is the lowest for households that moved in the period 1995-1999. Our hypothesis is that internal migration was a reaction to the pyramid savings scheme shock for the middle group. Consumption is significantly higher for the pioneer group and, again, lower for the middle group. Thus, earlier arrivals are faring the best in terms of income and consumption. They have had enough time to adjust, to finish constructing their house and to find a steady job. Their relative success might have contributed to the migration desire of later migrant groups.

In the next section the time dimension is included in the impact assessment of rural-to-peri-urban migration on household wellbeing using econometric techniques. 


\subsection{Empirical analysis}

\subsubsection{Methodology}

The Propensity Score Matching approach and the Instrumental Variable method are used to assess the impact of migration on household wellbeing in peri-urban areas, while taking into account a possible self-selection bias. To estimate the impact of migration the model specified in equation 5.1 is used.

$Y_{i}=\alpha+\beta *$ migration $_{i}+\gamma * X_{i}+\varepsilon$

where $i$ represents the household, $Y$ the outcome of interest (such as income or consumption), $\alpha$ the constant term, $\beta$ the parameter of interest (having migrated), $X$ other explanatory or control factors, and finally $\varepsilon_{i}$ the error term.

However, it is likely that $\beta$ might be biased because of reverse causality and endogenous placement between migrant and non-migrant households due to observable and non observable characteristics. This means that estimating 5.1 using Ordinary Least Squares (OLS) will violate the zero conditional mean assumption (i.e. the independence of all explanatory variables) of the error term, and the selection bias needs to be corrected for. In terms of equation 5.1 a latent variable, e.g. ability, might contemporaneously affect income -on the left-hand side- and migration - on the right-hand side- (see also McKenzie \& Sasin, 2007). Since ability is unobserved, it is included in the error term, which is correlated with migration (ibid). Reverse causality also arises, making it hard to disentangle the effect of migration on income because the latter, in turn, can be an important determinant of the migration decision in the first place. ${ }^{58}$ OLS regressions, in this case, result in biased results as they do not correct for these pitfalls. On the other hand, the two methods applied partially take selection bias into account (unobservable heterogeneity can never be controlled for), bringing unbiased estimates of the impact of internal migration.

The Propensity Score Matching (PSM) approach (Rubin, 1974; Rosenbaum and Rubin, 1983) tries to eliminate the observable bias, comparing each migrant household to a very similar non-migrant counterpart based on characteristics that do not influence the outcome variable -usually pre-treatment factors-. A number of controls are used to estimate the propensity score, as shown in equation $5.2^{59}$

$$
p(Z) \equiv \operatorname{Pr}\{T=1 \mid Z\} \equiv E\{T \mid Z\}
$$

The propensity score is the conditional probability of receiving treatment $T$ given pre-treatment characteristics $Z$. In this case the treatment is whether household moved internally from a rural area to peri-urban Tirana. In PSM one looks for covariates of participation, i.e. factors having a positive effect on the migration

58 One would expect internal migration positively affecting income, but income negatively affecting migration, as more needy households migrate (internal migration does not entail the high costs of an international move). Hence, due to the negative reverse causal channel, the OLS coefficient is likely to underestimate the effect of migration on income.

59 The household subscript $i$ is omitted. 
decision. Our pre-treatment characteristics are: dwelling type in 1990, whether the household had running water or an indoor toilet in 1990, how many rooms per capita in 1990, the Morris Score index in 1990, the education level of the head's parents and household size in 1990 in different age categories. These variables are assumed to influence the probability of receiving the treatment -i.e. having migrated-, though not the outcome variables, such as income and consumption.

One crucial condition PSM needs to satisfy is the balancing property, according to which households with the same propensity score must show the same distribution of observable characteristics. Migrant households are then matched to non-migrant counterparts with a similar propensity score using various techniques, such as the nearest neighbour, radius, kernel and stratification matching. I use the "nearest neighbour" technique. Finally, the Average Treatment on the Treated (ATT) effect is calculated, which measures the average impact migration has had on the treated (i.e. migrants).

Another condition PSM requires is the "Stable Unit Treatment Value Assumption", which assumes that treatment does not affect outcome (Rubin, 1978). In this case, I am ruling out the fact that internal migration could have affected local labour market conditions, both in the place of origin and in peri-urban areas, since we measure outcome variables, like income or unemployment, that are related to labour market conditions. In general, unemployment rates in Albania increased between the 1989 -pre-migration situation- and the 2001 Censuses. However, this is clearly the result of the transition from a planned to a market economy. It is generally believed that migration took place as a reaction to unemployment rates (see also Mancellari et al., 2006), and it is unlikely that migration leads to higher unemployment rates in the areas of origin.

The second approach, the Instrumental Variable (IV) method, corrects for the correlation bias between migration and error term $\varepsilon_{i}$ in 5.1 by replacing migration with another variable, the instrument, correlated with migration but not with $\varepsilon_{i}-$ i.e. motivation, ability, risk aversion-. The instrument is assumed to affect the outcome only through migration. The impact of migration is estimated in two stages. Nakosteen and Zimmer (1980) provide the rationale for using two-stage estimation procedures, and here an additional modelling strategy is provided for the case of overdispersion and excess zeros of the endogenous variable.

In the first stage, migration is estimated using one or more instrumental variables, see equation 5.3.

$$
\hat{m}_{i}=\delta+\phi * I V_{i}+\vartheta * X_{i}+u
$$

In the second stage, the estimate of migration $\hat{m}$-predicted value of migration coming from the first stage regression- is inserted into the equation of interest, see equation 5.4.

$$
Y_{i}=\alpha+\beta * \hat{m}_{i}+\gamma * X_{i}+\varepsilon_{i}
$$

Two instrumental variables are used: a dummy of whether the household had an indoor toilet and asset ownership of the household -measured by the Morris index-, both referred to the year 1990. These characteristics reflect living conditions and wellbeing of the household before the move and can explain 
potential migration intensity. Due to the political situation in Albania, few households had moved internally before 1990, and since that year migration grew very quickly within a short time. Therefore, the 1990 housing variables are good proxies for the housing situation before the move. ${ }^{60}$ The main assumption is that it is unlikely that household asset ownership in $1990^{61}$ still affects income and consumption possibilities today, in the light of the dramatic changes that occurred in the Albanian economy during the past 15 years. Furthermore, migrants in periurban are now exposed to a totally different labour market than in the rural areas, so past assets are unlikely to influence income and consumption patterns in periurban Tirana today. I believe that the asset index is correlated with migration and that migration affects current income, so the Morris index is a suitable instrument.

\subsubsection{Empirical results}

For the PSM, households are matched using the five nearest neighbour matching technique, limiting the observations to the common support region, which makes the results more robust. ${ }^{62}$ Furthermore, the same dependent variable and data source for both control and treatment group are used, ruling out the Smith and Todd's (2005) critique. In the second specification, following Abadie and Imbens (2001), four matches and bias-corrected and heteroskedasticity-robust estimates are computed. In Figure C.1 of Appendix C.1 a histogram of the propensity score for migrant and non-migrant households (treated and un-treated) is displayed, as suggested by Heckman, Ichimura and Todd (1997) and discussed in Negri and Porto (2008). This graph shows reasonable similar propensity scores for migrant and non-migrant households in the area of common support. This provides an indication of the reliability of the estimates presented, drawn from a high number of observations with similar characteristics.

Table 5.8 displays the PSM set of results, its standard error and significance using both specifications, as described above. Bootstrapped-standard errors are not included, as bootstrapped matching estimators are not valid in the nearest neighbour matching method due to the "extreme non-smooth nature of matching estimators and the lack of evidence that the estimator is asymptotically similar" (Abadie and Imbens, 2001). A selection of results for per capita income and consumption as well as a range of other outcome measures are shown.

\footnotetext{
${ }^{60}$ A number of other housing variables as instruments -e.g. rooms per capita in 1990- were also tried, leading to similar results.

61 To avoid possible endogeneity between past asset ownership and current wellbeing, we also tried land plot size owned before the move -and current land plot owned for non-movers- as instrument. However, it turned out to be a non-valid and weak instrument variable, according to the empirical tests performed. Moreover, we excluded two assets, washing machine and sewing machine, which only welloff households might have owned in 1990.

62 Different matching specifications, including radius, kernel and stratification were also applied, results produced being qualitatively similar.
} 
Table 5.8 Propensity Score Matching results

\begin{tabular}{|c|c|c|c|c|c|}
\hline Dependent variable & $\begin{array}{c}\text { Average } \\
\text { Treatment on } \\
\text { the Treated } \\
\text { (ATT) }^{1}\end{array}$ & $\begin{array}{c}\text { Average } \\
\text { Treatment on } \\
\text { the Untreated } \\
\text { (ATU) }^{1}\end{array}$ & $\begin{array}{c}\text { Average } \\
\text { Treatment } \\
\text { Effect (ATE) }{ }^{1}\end{array}$ & $\begin{array}{c}\text { Average } \\
\text { Treatment on } \\
\text { the Treated } \\
(\text { ATT })^{2} \\
\end{array}$ & $\begin{array}{c}\text { Number of } \\
\text { observations } \\
\text { (treated, } \\
\text { untreated) }\end{array}$ \\
\hline $\begin{array}{l}\text { Per capita monthly } \\
\text { income in Lek }\end{array}$ & $\begin{array}{c}2953.69 * * * \\
(588.56) \\
\text { US\$30.84 }\end{array}$ & 2377.43 & 2434.1 & $\begin{array}{c}2281.62^{* * *} \\
(592.01) \\
\text { US\$23.82 }\end{array}$ & 155,1421 \\
\hline $\begin{array}{l}\text { Per capita monthly } \\
\text { consumption in Lek }\end{array}$ & $\begin{array}{c}740.69 \\
(50982) \\
\text { US\$ } 7.73\end{array}$ & 607.38 & 620.44 & $\begin{array}{c}356.60 \\
(526.48) \\
\text { US\$3.72 }\end{array}$ & 155,1427 \\
\hline $\begin{array}{l}\text { Whether all adult } \\
\text { hh members work }\end{array}$ & $\begin{array}{c}-0.20^{* * *} \\
(0.03)\end{array}$ & -0.16 & -0.16 & $\begin{array}{c}-0.14^{* * *} \\
(0.03)\end{array}$ & 155,1427 \\
\hline $\begin{array}{l}\text { Average weekly } \\
\text { work hours hh } \\
\text { adults }\end{array}$ & $\begin{array}{c}-5.36^{* * *} \\
(1.33)\end{array}$ & -5.14 & -5.16 & $\begin{array}{l}-3.13^{* *} \\
(1.26)\end{array}$ & 155,1427 \\
\hline $\begin{array}{l}\text { Whether household } \\
\text { poor }\end{array}$ & $\begin{array}{l}-0.07^{* *} \\
(0.03)\end{array}$ & -0.05 & -0.05 & $\begin{array}{l}-0.08^{* *} \\
(0.03)\end{array}$ & 155,1427 \\
\hline $\begin{array}{l}\text { Household poverty } \\
\text { gap }\end{array}$ & $\begin{array}{c}-2.66^{* * *} \\
(0.80)\end{array}$ & 2.01 & 2.07 & $\begin{array}{c}-2.78^{* * *} \\
(0.84)\end{array}$ & 155,1427 \\
\hline $\begin{array}{l}\text { Household poverty } \\
\text { severity }\end{array}$ & $\begin{array}{c}-1.00^{* * *} \\
(0.32)\end{array}$ & -0.73 & -0.76 & $\begin{array}{c}-0.98^{* * *} \\
(0.33)\end{array}$ & 155,1427 \\
\hline
\end{tabular}

${ }^{1}$ Using the "5 Nearest Neighbours" matching method; ${ }^{2}$ Bias-corrected and heteroskedasticity-robust adjusted estimates

Note: stars indicate significance levels: * .1 level, ${ }^{* *} .05$ level, ${ }^{* * *} .01$ level

Source: Own calculations on 2005 ALSMS, including oversample

The bias and heteroskedasticity-robust adjusted estimates show the same patterns of significance as those obtained through the five nearest neighbour matching method, although generally associated with lower coefficients. ${ }^{63}$ The PSM results are statistically significant for per capita income but not for consumption differences. As a consequence, one cannot infer that consumption for migrants in peri-urban areas is higher than that for non-migrant households in rural areas. These results confirm the descriptive statistics of section 5.3.3.

The Average Treatment effect for the Treated (ATT) is positive, meaning that migration has had a positive effect on income per capita of the moved households. More specifically, migrant households enjoy on average a monthly income 24 to 30 US\$ higher than that of the rural ones.

Adults in migrant households are less likely to be employed, and work on average 3-5 hours less per week. This also confirms previous results. Peri-urban migrant households have a 7\% lower poverty rate, less than the difference found in the descriptive statistics. The poverty gap and poverty severity are much lower for peri-urban migrant households, witnessing a similar level, but lower depth of poverty than rural households.

In Table 5.9 Instrumental Variables and OLS results are presented. The endogenous regressor to be instrumented is the number of years since migration

63 The only exception are the poverty measures (based on consumption), which are probably less biased, as people are less-likely compared to misreport consumption than income. 
to peri-urban areas, which is zero for the not-migrated households and the households that moved in 2005. The excess of "certain zeros" (non-movers) and the two processes that both arrive at a zero outcome (non-moving and moving in 2005) are the motivation for using the Zero Inflated Poisson (ZIP) model in the first stage of the two-step procedure. A dummy endogenous estimation of the first stage is provided in Appendix C.3. Annex D.2 gives more information on the ZIP model.

To be valid, IV estimates have to pass a number of empirical diagnostic tests, which are displayed in Annex C.2. Some tests are not available when the first-stage is a Zero Inflated Poisson model, in which cases they are based on the linear case. First, the variable to be instrumented has to be endogenous, justifying the use of IV. The Anderson-Rubin test of endogenous regressors performs the check, where a rejection of the null hypothesis means that the coefficient of the endogenous regressor is statistically different from zero in the structural equation. Both income and consumption coefficients show a p-value of 0.000 , a sign that migration is highly endogenous and needs to be instrumented for. This also confirms that the OLS coefficient of migration is biased.

Then, it needs to be proven that the instrumental variables are valid and strong. The Hansen J-statistic measures over-identification of the instrument, i.e. its validity. The null hypothesis is that the instruments are valid and uncorrelated with the error term, and that the tested instruments are correctly excluded from the estimated equation. This null hypothesis should not be rejected, which is the case for income ( $p$-value of 0.76 ), but not for consumption (0.01). The instruments are strong since the F-test of joint significance of the instruments is more than 10, the rule of thumb indicated in the literature (Staiger and Stock, 1997). Finally, the instruments are valid in the first stage regression, as both instruments are highly significant for income and consumption, and the instrumented variable is significant in the second stage.

Since the over-identification test fails when the dependent variable is the logarithm of total household per-capita consumption, the econometric results cannot point to a statistically reliable impact of migration on household per capita consumption. This confirms earlier results of PSM and the descriptive statistics of section 5.3.3. 
Table 5.9 Ordinary Least Squares (OLS) and Instrumental Variable (IV) results

\begin{tabular}{|c|c|c|c|c|c|c|c|c|}
\hline \multirow{3}{*}{$\begin{array}{l}\text { Model } \\
\text { dep. } \\
\text { variable }\end{array}$} & \multirow{2}{*}{\multicolumn{2}{|c|}{$\frac{\text { OLS }}{\text { log of income }}$}} & \multicolumn{4}{|c|}{ Zero Inflated Poisson } & \multirow{2}{*}{\multicolumn{2}{|c|}{$\frac{\text { IV }}{\log \text { of income }}$}} \\
\hline & & & \multicolumn{2}{|c|}{ \# of years } & \multicolumn{2}{|c|}{ inflate } & & \\
\hline & coef & $\begin{array}{l}\text { rob. } \\
\text { s.e. }\end{array}$ & coef & $\begin{array}{l}\text { rob. } \\
\text { s.e. }\end{array}$ & coef & $\begin{array}{c}\text { rob. } \\
\text { s.e. }\end{array}$ & coef & $\begin{array}{c}\text { rob. } \\
\text { s.e. }\end{array}$ \\
\hline hh size & $-0.210^{* * *}$ & 0.056 & $-0.146^{*}$ & 0.076 & 0.101 & 0.299 & $-0.204^{* * *}$ & 0.021 \\
\hline hh size ${ }^{2}$ & $0.020^{* * *}$ & 0.004 & 0.004 & 0.006 & 0.018 & 0.019 & $0.021^{* * *}$ & 0.001 \\
\hline hhh age & $0.028^{*}$ & 0.016 & -0.011 & 0.018 & 0.012 & 0.052 & $0.029^{* * *}$ & 0.006 \\
\hline hhh age ${ }^{2}$ & -0.000 & 0.000 & 0.000 & 0.000 & 0.001 & 0.001 & $-0.000^{* * *}$ & 0.000 \\
\hline $\begin{array}{l}\text { unemp. } \\
\text { ratio }\end{array}$ & $-0.233^{*}$ & 0.121 & -0.080 & 0.155 & $0.861^{*}$ & 0.515 & $-0.231^{* * *}$ & 0.046 \\
\hline hhh edu. & 0.020 & 0.022 & $0.040 *$ & 0.024 & 0.149 & 0.158 & $0.021^{* * *}$ & 0.008 \\
\hline hhh edu. ${ }^{2}$ & 0.001 & 0.001 & -0.001 & 0.001 & -0.005 & 0.009 & $0.001^{* *}$ & 0.000 \\
\hline $\begin{array}{l}\text { hhh is } \\
\text { working }\end{array}$ & $0.143^{* *}$ & 0.068 & 0.012 & 0.060 & $1.481^{* * *}$ & 0.282 & $0.174^{* * *}$ & 0.025 \\
\hline $\begin{array}{l}\text { hhh is } \\
\text { female }\end{array}$ & -0.054 & 0.092 & 0.014 & 0.084 & -0.258 & 0.566 & -0.051 & 0.034 \\
\hline $\begin{array}{l}\text { hh has } \\
\text { temp / } \\
\text { perm } \\
\text { migrant }\end{array}$ & $0.104^{*}$ & 0.055 & -0.063 & 0.058 & $0.657^{* * *}$ & 0.236 & $0.117^{* * *}$ & 0.020 \\
\hline $\begin{array}{l}\% \text { males } \\
20-39 \text { by } \\
\text { munic. }\end{array}$ & $-0.034^{* *}$ & 0.016 & 0.011 & 0.026 & 0.049 & 0.065 & $-0.034^{* * *}$ & 0.006 \\
\hline $\begin{array}{l}\text { \# property } \\
\text { shocks } \\
\text { prior to } \\
\text { move* }\end{array}$ & 0.017 & 0.028 & $-0.545^{* * *}$ & 0.082 & $1.385^{* * *}$ & 0.368 & $0.032^{* * *}$ & 0.011 \\
\hline $\begin{array}{l}\text { Morris } \\
\text { score } \\
\text { index } 1990\end{array}$ & & & -0.126 & 0.111 & $-2.838^{* * *}$ & 0.436 & & \\
\hline $\begin{array}{l}\text { indoor } \\
\text { toilet } 1990\end{array}$ & & & -0.059 & 0.050 & $-0.679^{* *}$ & 0.319 & & \\
\hline $\begin{array}{l}\text { years since } \\
\text { internal } \\
\text { move** }\end{array}$ & $0.041^{* * *}$ & 0.012 & & & & & $0.090^{* * *}$ & 0.014 \\
\hline constant & $8.723^{* * *}$ & 0.481 & $2.310^{* * *}$ & 0.473 & -1.010 & 1.716 & $8.588^{* * *}$ & 0.188 \\
\hline \# obs. & 1,623 & & 1,623 & & & & 1,623 & \\
\hline \# zero obs. & & & 1,459 & & & & & \\
\hline \# PSU & 228 & & 228 & & & & 228 & \\
\hline $\mathrm{R}^{2}$ & 0.256 & & & & & & 0.251 & \\
\hline $\mathrm{Chi}^{2}$ & 18.067 & & 41.208 & & & & 18.221 & \\
\hline $\begin{array}{l}\text { P-value of } \\
\text { Vuong test }\end{array}$ & 0.000 & & 0.000 & & & & 0.000 & \\
\hline
\end{tabular}

Note: stars indicate significance levels: * .1 level, ${ }^{* *} .05$ level, ${ }^{* * *} .01$ level. Estimates are corrected for intra-cluster correlation and sampling design; heteroskedasticity-robust and consistent standard errors are then reported.

Edu. is years of education.

*Number of property shocks are measured until now for non-movers

** Years since internal migration is zero for non-movers 
Source: Own calculations on 2005 ALSMS, including oversample

In addition to the standard tests, in the case of the first stage ZIP model some additional statistics are provided. The Vuong (1989) test of Poisson versus ZIP model is strongly rejected, providing an empirical proof of the use of ZIP estimation, thus confirming the intuition of over-dispersion of the distribution due to the excess zeros. Another LR test of a parameter $\alpha$ indicating the heterogeneity of the observations being statistically equal to zero is not rejected, favouring the ZIP over the Zero Inflated Negative Binomial (ZINB) model, which assumes unobserved heterogeneity among observations.

For the ZIP model, the "inflate" column lists the results for the non-movers (certain zeros). The "\# of years" column gives the results for the full model, which combines the certain zeros with the count model for the not-certain zeros (movers).

There is strong positive effect of the number of years since migration took place on income per capita. Evaluated at the average value, one additional year the household spends in peri-urban Tirana increases income by $9 \%{ }^{64}$, provided that the household made the decision to migrate. If the endogenous dummy regressor of whether the household migrated/ not migrated is used instead, income increases by $82 \%$ (see Appendix C.3). The comparison of the IV results to the OLS results shows the extent of the bias, as the migration effect without instrumenting is notably underestimated. Furthermore, control variables have the expected effect on income per capita: it is negative for household size and proportion of men of working age in the community and positive for age of the head, employment of head and household as a whole, education level of the head, and for any international migration exposure. Overall, the econometric analysis confirms that income of migrant households is higher than for rural non-migrant's, controlling for other crucial factors being equal. However, this has not resulted in superior living standards, as consumption levels have not necessarily increased.

\subsection{Conclusions}

This study highlights significant differences, in terms of socio-economic characteristics, between households that moved from rural areas to peri-urban Tirana and rural households that did not migrate internally. Income per capita has increased as an effect of migration, and a larger fraction of internal migrant households declare their life as having improved. Income increases by $9 \%$ a year provided that they decide to move In line with the human capital approach, individuals of internally migrated households are younger. This confirms the Harris-Todaro migration theory, providing empirical evidence of a positive financial return to migration in case of Albania.

Conversely, the results do not show statistically reliable effects of the internal move on consumption. Income has grown more than consumption with the move to peri-urban Tirana. Migrant households in peri-urban Tirana are able to earn higher wages but they are irregular, and have to cover higher living expenses, as

${ }^{64}$ It should be kept in mind that the instrumented variable measures the local average treatment effect. So, households that moved first probably had the worst living conditions -i.e. low wealth, no indoor toilet- and moving made the biggest difference for them. 
well as costs not occurring in rural areas. Water and some food products are almost free in some rural areas, but have to be bought at a high cost by migrant families. Furthermore, migrants have to finance the construction of their new house, which can often take a long time. It is also possible that households are saving to migrate internationally, but further research needs to be done. A final reason for this discrepancy between income and consumption is that migrants are financially helping their families back home. More research is needed to test these hypotheses.

Looking at housing quality and asset ownership compared to 1990, internal migration has had a negative impact. Migrant households are also significantly worse off than other groups in terms of health, and access to clean and running water. While the economic situation has improved, it seems to be accompanied by worsened living conditions.

Furthermore, access to the formal labour market seems extremely difficult for internal migrants in Greater Tirana. Working age adults in peri-urban migrant households are more likely to be unemployed, and to work fewer hours, than their counterpart in rural households. However, migrant households do show higher expectations regarding accessing higher education for their children being, in general, satisfied with the quality of education. Nevertheless, school attendance is still low for migrant children, possibly due to household poverty or infrastructure bottlenecks. Further research should look into education outcomes in more detail (e.g. looking at he the characteristics of those children going to school, in terms of sibling order, gender etc.), as providing an education to (some) children could also be a cause of migration.

Our findings highlight that the impact of internal migration of rural households to peri-urban Tirana has been less positive than one would expect. Migrant households are still vulnerable due to unfavourable living conditions and unstable employment. They do not have higher consumption levels than their rural counterparts who did not migrate.

An important question arises from this analysis: why does internal migration continue, even though its impact on overall wellbeing is unclear? Zelinsky's mobility-transition hypothesis sees migration as a natural development caused by the economic and social changes inherent in modernisation (i.e. transition in the Albanian case). He stresses that the drive for more personal freedom is an important factor and this is a relevant motive in the Albanian case. King (2005) amongst other authors stresses that the mere liberating possibility to migrate internally and internationally drove people to migrate.

Wolpert's Stress-Threshold model (1965) also comes to mind, which demonstrates that ex-ante rational behaviour may not necessarily be rational ex-post implying that the costs and benefits of migration are not always understood beforehand. One could imagine that despite general strong social networks (see Chapter 4) and strong family networks (see Chapter 6), there may still be misinformation or withheld information from migrants to potential migrants. Internal migration flows have slowed down now and it might have recently become clear to potential migrants that life is not necessarily better in Tirana than in rural areas. 
Furthermore one should consider that migration may be a long-term investment. Households expect to have more opportunities in Tirana in the shape of diversified employment opportunities, earning money to migrate internationally and having the opportunity to educate their children. Better long-term prospects are confirmed by the fact that longer-term residents and earlier migrants enjoy higher income and consumption than recent movers. However, structural changes in infrastructure and labour markets still need to take place to improve the livelihood of migrants in peri-urban Tirana. 



\section{How has internal migration in Albania affected transfers amongst kinship members?}

\subsection{Introduction}

This chapter examines the impact of internal migration on transfers received from kinship members for the specific case of internal migrant households living in periurban areas of the capital of Albania, Tirana. I analyse how internal migration has affected the frequency of receiving financial transfers, goods, and services from different members of the kinship network.

Kinship networks provide its members with continuous support both in every day life and for sudden or unforeseen events. Individuals in every society rely on such networks for getting economic, social and emotional support. They often see selfidentification with such networks as a necessary means for gaining the additional security that they can offer. But, perhaps the most distinctive feature of networks is that they are never stable. Over time the shape of such networks changes due to demographic, economic or social developments. I will be looking at the effect of one specific development, namely internal migration. As migration relocates family members, splits families and exposes migrants to new people and different cultural practices, it is likely to affect the kinship network.

Between 1945-1990 internal migration in Albania was centrally controlled during the Communist regime. In fact, permanently relocating was not legally allowed (without prior permission) until 1993, although many people started moving a few years earlier already. With the fall of totalitarian regime in late 1990, the country faced severe social and economic challenges. The mass layoffs that followed the shutdown of mines, plants, and inefficient state-owned enterprises created an immense pressure on the labour market. In many areas, especially the mountainous ones, this land was insufficient, and moreover the process was accompanied by many difficulties and irregularities (World Bank, 2004).

Being left with few other possibilities, people from former industrial towns or remote villages started migrating either internationally (mainly towards the neighbouring countries, Italy or Greece), or internally (towards the main cities in the coastal area and Tirana). Official data show that almost one in three adults has migrated internally since birth (World Bank, 2007). Internal migrants first occupied former agricultural lands in the peri-urban areas of big cities, which soon developed into major settlements.

Internal migration in Albania is often characterised by relocation of the whole household. Unlike in other former Communist countries, migration is not circular and any future migration would mostly be to an international destination. Earlier 
studies indicate that internal movers come from all socio-economic backgrounds (De Soto et al., 2002, Cila, 2006), and the main motivation behind the relocation seems to be economic, i.e. work-related (Carletto et al., 2004). Our qualitative interviews also show that often whole families and even villages relocated to the same area, for environmental, employment or education reasons.

This chapter is based on a unique household survey that was conducted in 2008 amongst internal migrant households living in peri-urban households in Tirana, covering different kinds of households (i.e. nuclear and extended families). Figure 6.1 depicts a map of Albania on which the district of origin of the surveyed households is marked. It shows that migrant households come from nearly all districts, but especially from the Northern and Central mountainous areas (the darker areas on the map).

Figure 6.1 Origin districts of surveyed households

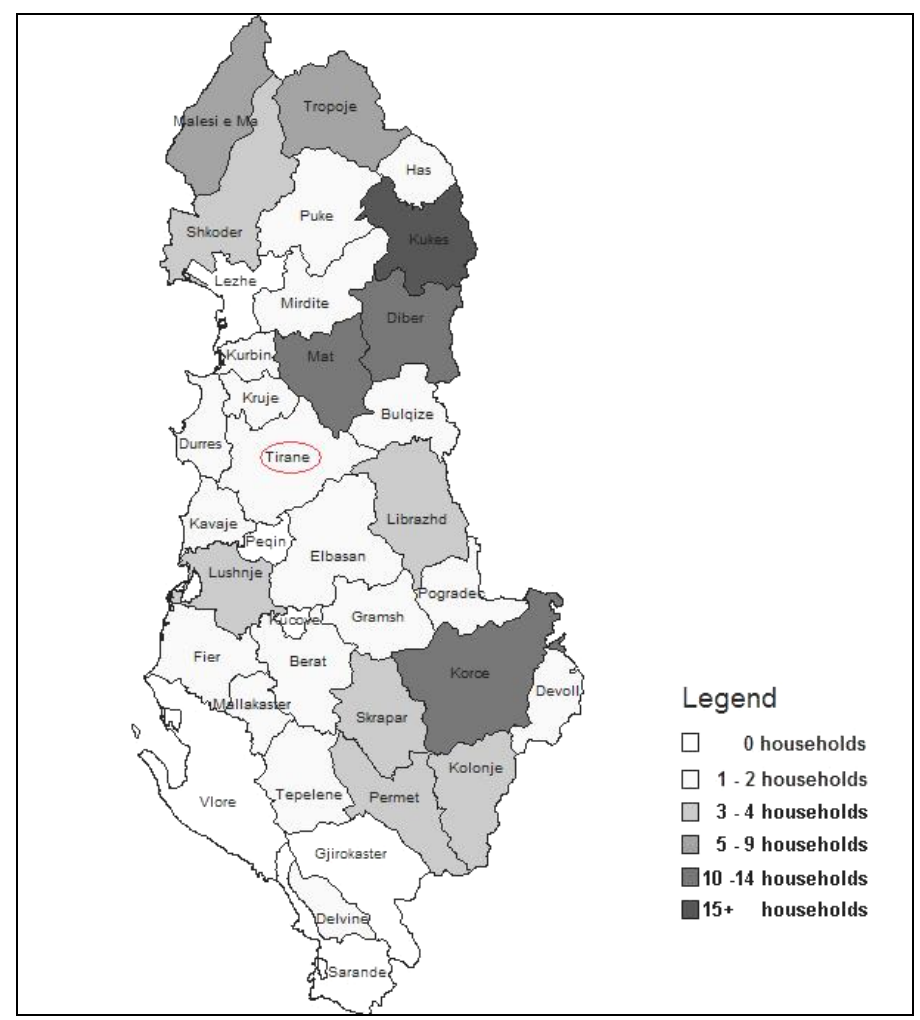

Source: Own compilation

For many of these migrant households the impact of migration has been far from successful. Previous studies (e.g. Cila, 2005 and Chapter 5) show that unemployment is very high, and while income may be higher for migrant households after migration, consumption is not (Chapter 5). This shows that households are faced with volatile circumstances and may still be very much dependent on inter-family transfers. One would expect that after migration especially financial transfers would increase. Furthermore the composition of the 
network may have changed. Households may leave family members behind due to internal migration and many also have family that migrated internationally. At the same time households are exposed to a heterogeneous group of migrants coming from all parts of Albania and living in very condensed living conditions. This could lead to more exchange and interaction with non-kin than before.

I analyse the effect internal migration and the change in location have had on the transfer network and transfer mix. I am particularly interested in the transfers received by the household. By looking at transfers received I am able to control for a wide range of characteristics for the receiving household. Based on the previous literature and Albania's particular migration dynamics, the following hypotheses will be tested: (1) After migration financial transfers became more important. (2) After migration, households supersede family members in their transfer network with non-relatives (such as friends, neighbours, etc).

This paper builds on a limited number of previous studies that study the impact of internal migration on transfers for complete family relocation. This literature focuses mainly on demographic changes in the US in the mid $20^{\text {th }}$ century. The present study analyses this issue much more thoroughly utilising both qualitative interviews and advanced econometric techniques. Furthermore I focus on a transition economy where the role of private transfers is much more important. Internal migration is high in Albania, poverty in peri-urban areas remains widespread and state support is low. This makes the investigation of private transfers and their development over time an interesting and relevant research question.

The remainder of this chapter proceeds as follows: Section 6.2 reviews the relevant literature and gives the reasoning behind the hypotheses. Section 6.3 describes the data, gives some descriptive statistics and outlines the empirical methodology. Section 6.4 analyses the results and I conclude in Section 6.5.

\subsection{Literature Review}

This paper considers the economic aspects of family solidarity. Utility of an individual (or the total household in this case) does not only depend on own consumption, but also on consumption of their family and kin members (Becker, 1974, Becker 1976). From this perspective, the degree of helping and resource sharing is a clear and measurable indicator of family solidarity, which can vary over different networks or over time. More specifically, economic relationships between kinship members may be characterized by transfers of money, goods, or services rendered. Bengtson \& Roberts (1991) argue that helping and resource sharing is one of the most important aspects of family solidarity. Changes affecting the structures of kinship networks can consequently affect the patterns of resource sharing. People's mobility through migration (and especially rural-to-urban migration) is considered to be an important factor that influences kinship ties (Blumberg \& Bell, 1959). In this paper I investigate migration's impact on the kinship network and the patterns of resource sharing (financial, goods and service transfers) among kinship members. The study is related both to the economic analysis of inter-household transfers and the impact of internal migration literature and follows in the footsteps of a few papers that combine the two research areas. 
Whether migration takes place at all is also influenced by the strength of kinship networks. The migration network literature shows how kinship networks help potential migrants to migrate and then help migrants to find employment, housing etc. at the destination (e.g. Goss \& Lindquist 1995). Choldin (1973) also emphasizes chain migration and help given to kin to also migrate. Through chain migration social networks may be reproduced in the new community. An important consequence of internal migration is that it is usually accompanied by a placement within clusters of kinship relatives coming from the same areas (see also Blumberg and Bell, 1959; Hendrix, 1975). This may lead to the preservations of certain relations and habits, and may even reinforce them. What is clear, is that the decision to migrate internally is both affected by the kinship networks and at the same time affects the relationships within the same networks.

Previous studies have shown that permanent internal migration has pervasive effects on families and kinship networks. Duke-Williams (2009) argues that mobility and migration are key drivers in changes in households. Peoples' mobility contributes to the separation of households and the creation of new households. Blumberg and Bell (1959) argue that rural to urban migration changes the structure of kinship relationships. These changes are a consequence of the "dysfunctionality of the urban setting for a kinship relationship" since urban settings are usually different from those of villages or small towns. The same authors further argue that in urban settings the importance of the family and kinship tends to decline, while residual functions (e.g. visits) may stay intact on the other hand and may become even stronger. In contrast, other studies cited by Blumberg and Bell (1959), show that a good part of rural migrants receive help from friends or relatives when they first move to urban areas.

Litwak's 1960 study in New York concludes that mobility reduced face-to-face contact, but not "extended family identification", i.e. feeling close to the extended family. He finds that over time family contacts are still as likely as before, but that long-term residents are more likely to be in contact with neighbours or belonging to a club. Jitodai (1963) finds that at arrival rural migrants in Detroit have higher rates of contact with their kin, than urban migrants, possibly because rural migrants are followed by their family. Over time contact rates for rural migrants stay more or less stable and those for urban migrants increase, becoming similar to contact rates of natives and of rural migrants. Migration thus did not hinder migrants in keeping in touch with their kin. Wellman et al (1997) also looked at social networks in Toronto in the 1970s. Kinship ties were most likely to remain ten years after the original survey, also for households that moved, while some ties with neighbours were lost for those households that moved. Ruan et al. (1997) look at the changing structure of social networks in Tiajin, China and find that between 1986 and 1993 individuals named fewer kin members as personal ties, while friends became relatively more important. The authors attribute this to changing policies in China that allowed for more residential and occupational mobility, which has some similarities with Albania's situation after 1989.

With regard to the transfer mix, there are few existing studies. Cox, Jimenez and Okrasa (1996) compare family solidarity before and after transition (1987 vs. 1992) in Poland. They find the same incidence of financial transfers in real terms, despite a worse economic situation, so family solidarity is somewhat weaker. 
Vullnetari \& King (2008) describe a growing trend of "care drain" in Albania, namely the effect migration of adult children has on their elderly parents. They depict a pattern of fewer visits (as they mainly refer to international migration) and less care, both by parents (care of the grandchildren) and children (care of their parents). Even though financial transfers from migrant children to parents rise in some instances, they do not make up for the shortfall in physical care. In short, family solidarity weakens as result of migration.

The literature on the determinants of remittances focuses on financial family transfers between the migrant and the family left behind. The literature predicts that there are financial transfers from the migrant to the household and wider family left behind due to a wide range of motives ranging from altruism to selfinterest (see Chapter 3). There could also be transfers to the migrant, as part of a co-insurance agreement, for example when the migrant is temporarily unemployed (see Stark, 1991). The remittances literature would predict that there are more financial transfers between family members after the move than before, since migrants generally migrate in order to remit. Finally the exchange motive would predict a rise in services from the household left behind to the migrants (e.g. taking care of children left behind) simultaneously with a rise in financial transfers from the migrant to the household. Even though in Albania's case generally the whole household moves (Instat, 2004), the remittances literature has some relevance. The motives for financial transfers, for example supporting needy family members, may explain changes in transfer patterns.

In conclusion, I expect that internal migration influences the kinship networks and the resource transfers within these networks. Due to longer distances between household members and greater financial means due to migration, I expect the importance of financial transfers to grow and services to decrease. Furthermore, economic theories on the causes of migration and motivations to remit hypothesize that financial transfers increase after migration (Hypothesis 1). Even if whole households moved together and they are joined by more kinship members, one can expect that the new surroundings and acquaintances lead to weakening of existing kinship networks (Hypothesis 2).

\subsection{Data and Methodology}

\subsubsection{Data}

The survey for this chapter was administered in April 2008. The sample was selected from the four main neighbourhoods that were populated after 1990 and accommodate a large migrant population. Each of those neighbourhoods has a slightly different migrant population, for example households living in Bathore are more likely to come from the Northern mountainous areas of Albania and are more likely to live in extended families. The selected households were distributed across the areas according to the size of these areas and importance of migrant inflows for these areas, which means that almost half of the sample was collected in Bathore, as this is the biggest peri-urban area and also has the largest migrant population. 
By absence of street names and accurate population registers, a random list of internal migrant households could not be selected. Therefore the sample was quasi-randomised by sub-dividing the selected areas into strata of around one $\mathrm{km}^{2}$ using satellite maps and then randomly selecting houses in selected strata. The sub-sections were then assigned to interviewers, who also marked the exact location of interviewed households on the map. If the selected households did not fit the criteria of being an internal migrant household $(11.48 \%)$, or refused to participate $(25.68 \%)$, a neighbouring house was chosen. The positive response rate is $74.32 \%$. In total 112 households were interviewed. Table 6.1 shows the number of households that were selected in each area.

Two types of questionnaires were used. The main questionnaire has 137 questions ranging from information on the main households' demographics, education, employment, income, and migration history to the key section on family solidarity. A total of 26 households were also interviewed in semi-structured interviews using additional qualitative questions. ${ }^{65}$

In the main section on family solidarity, households are questioned in great detail about transfers between the main household and a random selection of extended family members and neighbours, who the main household is in regular contact with, both before and after the move. Households were first asked to list all relatives and friends with whom they were in contact with on a regular basis and then the interviewer randomly selected two relatives in each of five broad categories of relatives (i.e. parents, children, siblings, other relatives and friends) by choosing the first two relatives whose first name comes earlier in the alphabet. Then some basic demographic questions were asked on all family and friends. Further questions on the socio-economic characteristics of the relative/ friend and on family solidarity were only asked about the selected relatives.

Households were questioned on the financial transfers, goods and services exchanged both in the last twelve months and before the move. In the latter case, households were divided broadly in those coming before 1997 and those coming after this year. ${ }^{66}$ In order to get a similar basis of comparison, migrants moving before 1997 were asked about the transfers during the last 12 months before 1991, and those moving after 1997 about transfers during the last 12 months before 1997.67 Detailed questions were asked on the type/ amount of the transfer and the frequency for both before and after the move. In this chapter I only make use of the data on the receipt of transfers because this allows us to have more control variables based on household information.

\footnotetext{
${ }^{65}$ All households questioned by them were asked whether they would be willing to also participate in an open-ended interview that was to be recorded, but not all households agreed. The qualitative interviews were thus based on a sub-section of the main sample.

661997 was chosen both as a chronological milestone and because the turmoil that followed the collapse of the financial pyramids led to an increase in numbers of especially poor migrants to periurban areas of large cities.

${ }^{67}$ Recalling transfers in the past is tricky at best. Therefore to enable recall, were asked households to give transfer patterns for a memorable year in the past, either 1990 if the household moved before 1997 or 1997 if the household moved after 1997. 1997 is memorable because of the pyramid savings scheme crisis and 1991 is memorable because it is the year that the Communist system collapsed.
} 


\subsubsection{Descriptive Statistics}

I first give a short description on the socio-economic characteristics of the sample by the neighbourhood the household lives in. Around $96 \%$ of the household heads sampled are male and about $90 \%$ are married and there are no significant differences per area. Table 6.1 outlines further characteristics.

Table 6.1 Household characteristics in the sampled areas

\begin{tabular}{lccccc}
\hline Area's name & 5 Maji & Bathore & Selite & Senatorium & Total \\
\hline Age hhh & 53.53 & 49.6 & 50 & 52.75 & 50.93 \\
Education hhh & 11.37 & 10.4 & 10.93 & 11.65 & 10.92 \\
Hhh Muslim & $0.74^{*}$ & 0.89 & 0.89 & 0.90 & 0.87 \\
Hhh Coastal origin & 0.05 & $0.02^{*}$ & $0.25^{* * *}$ & 0.00 & 0.08 \\
Hhh Central origin & $0.63^{* *}$ & $0.09^{* * *}$ & $0.61^{* * *}$ & 0.45 & 0.38 \\
Hhh North Central origin & 0.11 & $0.22^{* *}$ & $0.04^{*}$ & 0.10 & 0.13 \\
Hhh Mountain origin & $0.21^{*}$ & $0.67^{* * *}$ & $0.11^{* * *}$ & 0.45 & 0.41 \\
Hh is extended family & 0.21 & $0.33^{* *}$ & $0.11^{*}$ & 0.15 & 0.22 \\
Hh arrived < 1997 & 0.37 & 0.49 & 0.32 & 0.45 & 0.42 \\
Number of hh members & 4.74 & $5.87^{* * *}$ & $4.32^{* *}$ & 4.35 & 5.02 \\
\hline Number of observations & 19 & 45 & 28 & 20 & 112 \\
\hline Income/ capita & 16872.81 & $8049.93^{* * *}$ & $20053.09^{* * *}$ & 14325 & 13764.94 \\
\hline Number of observations & 19 & 42 & 27 & 20 & 108 \\
\hline Stars indicate whether the mean is significantly different across groups (* significant at 10\%; \\
significant at 5\%; ${ }^{* * *}$ significant at 1\%)
\end{tabular}

Household heads are on average 51 years old and have almost 11 years of education (not quite having finishing high school); however there are no significant differences between areas. Most household heads are Muslim, but significantly fewer in the area 5 Maji, a more recent peri-urban area. Household heads from Coastal origins are significantly strongly represented in Selite, and Central household heads in the areas $5 \mathrm{Maji}$ and Selite. Both are underrepresented in Bathore, where household heads are significantly more likely to come from North Central and especially the mountain areas. Most households interviewed are nuclear families, but households in Bathore are significantly more likely to live in extended families. Consequently they also have significantly more family members per household. Households in Bathore have the significantly lowest income per capita and households in Selite are significantly richer. More households arrived before 1997 in Bathore and Senatorium (these were the areas that were first settled), but the difference is not significant.

Next level of individual kin the household exchanges with, is analysed further. These kin members are classed into broad categories and it is compared whether the household has received transfers from these kin. Not all kin the household named and that were selected exchanged transfers with the household, as can be seen in Table D.1 in Annex D. ${ }^{68}$ The question on the receipt of transfers was asked

${ }^{68}$ Furthermore these questions were not always completed, even for selected relatives. 
for the past 12 months and for the situation before migration took place. Three types of transfers are analysed: Financial transfers, goods and services.

Table 6.2 compares transfers by the likelihood of receiving transfers from different kinds of kin.

Table 6.2 Transfer likelihood from different kin

\begin{tabular}{lcccccc}
\hline $\begin{array}{l}\text { Type of kin the hh } \\
\text { receives transfers } \\
\text { from }\end{array}$ & $\begin{array}{c}\text { Parents \& } \\
\text { parents in } \\
\text { law }\end{array}$ & Children & Siblings & Relatives & Friends & Total \\
\hline $\begin{array}{l}\text { Hh received financial } \\
\text { transfer before } \\
\text { migration }\end{array}$ & 0.09 & $0.19^{* *}$ & 0.11 & 0.11 & 0.13 & 0.11 \\
$\begin{array}{l}\text { Hh received financial } \\
\text { transfer in past 12 } \\
\text { months }\end{array}$ & 0.19 & $0.07^{* * *}$ & 0.18 & 0.16 & 0.19 & 0.17 \\
$\begin{array}{l}\text { Hh received goods } \\
\text { before migration }\end{array}$ & 0.21 & 0.26 & 0.21 & 0.21 & $0.33^{* *}$ & 0.22 \\
$\begin{array}{l}\text { Hh received goods in } \\
\text { past 12 months }\end{array}$ & 0.33 & 0.25 & 0.27 & 0.28 & 0.26 & 0.28 \\
$\begin{array}{l}\text { Hh received services } \\
\text { before migration }\end{array}$ & 0.3 & $0.44^{* *}$ & 0.31 & 0.29 & 0.4 & 0.31 \\
$\begin{array}{l}\text { Hh received services } \\
\text { in past 12 months }\end{array}$ & 0.31 & $0.19^{*}$ & 0.28 & 0.25 & 0.27 & 0.27 \\
\hline $\begin{array}{l}\text { Number of } \\
\text { observations }\end{array}$ & $71-86$ & $22-34$ & $196-216$ & $107-126$ & $24-106$ & 1064 \\
\hline
\end{tabular}

Stars indicate whether the mean is significantly different across groups ( ${ }^{*}$ significant at $10 \%$; ${ }^{* *}$ significant at $5 \%$; ${ }^{* * *}$ significant at $1 \%$ )

Before migration households were significantly more likely to receive money from their children, while households are significantly less likely to have received money from children in the past 12 months. This can not only be due to children growing up, since households were also significantly more likely to receive money from their children before the move and since quite a varied age range of household heads was sampled. Households are also significantly more likely to have received services from their children before the move, whereas there is the opposite pattern in the past 12 months. In the past households were significantly more likely to receive goods from friends and after migration households seem to receive more financial transfers from friends, compared to other relatives (not significant). So far, the descriptive statistics do not show a clear network change or change in the transfer mix.

Table 6.3 shows the transfer frequency from different types of kin 
Table 6.3 Transfer frequency from different types of kin

\begin{tabular}{|c|c|c|c|c|c|c|}
\hline $\begin{array}{l}\text { Type of kin the hh receives } \\
\text { transfers from }\end{array}$ & $\begin{array}{l}\text { Parents } \\
\text { \& } \\
\text { parents } \\
\text { in law }\end{array}$ & Children & Siblings & Relatives & Friends & Total \\
\hline $\begin{array}{l}\text { Frequency financial } \\
\text { transfer before migration }\end{array}$ & 0.29 & 0 & 0.25 & 0.66 & 0.04 & 0.34 \\
\hline $\begin{array}{l}\text { Frequency financial } \\
\text { transfer in past } 12 \text { months }\end{array}$ & 0.5 & 0.17 & 0.68 & 0.42 & 0.92 & 0.6 \\
\hline $\begin{array}{l}\text { Frequency goods transfer } \\
\text { before migration }\end{array}$ & 3.26 & 0.7 & 3.5 & 2.18 & 2.36 & 2.89 \\
\hline $\begin{array}{l}\text { Frequency goods transfer in } \\
\text { past } 12 \text { months }\end{array}$ & 3.16 & 2.56 & 2.39 & 1.62 & 1.26 & 2.18 \\
\hline $\begin{array}{l}\text { Frequency services transfer } \\
\text { from before migration }\end{array}$ & 11.26 & 14.38 & $10.88^{*}$ & $4.79 * * *$ & 7.93 & 9.11 \\
\hline $\begin{array}{l}\text { Frequency services transfer } \\
\text { in past } 12 \text { months }\end{array}$ & $8.81^{*}$ & $12.89^{* * *}$ & 7.08 & $3.35^{* * *}$ & 6.73 & 6.65 \\
\hline Number of observations & $61-151$ & $18-54$ & $182-407$ & $110-235$ & $25-132$ & 397-987 \\
\hline
\end{tabular}

Stars indicate whether the mean is significantly different across groups $\left({ }^{*}\right.$ significant at $10 \%$; ${ }^{* *}$ significant at $5 \%$; ${ }^{* * *}$ significant at $1 \%$ )

There are no significant differences in the absolute frequency of financial transfers received from different types of kin before and after migration. It is noteworthy however that the average number of financial transfers has increased from 0.34 to 0.6 transfers received per relative. There are also no significant differences for good transfers. However, it is interesting that the average good transfer received from children after migration (2.56 goods per child) is much higher than before (0.7).

For services both before and after migration other relatives are the least important givers of services. Before migration households received significantly more services from siblings and after migration households received significantly more services from parents and children. While services remain by far the most frequent transfer received, a lower average number of services are exchanged after migration (6.65 down from 9.11 services per relative).

\subsubsection{Methodology}

In this chapter the determinants of inter-household transfers are tested and the impact of migration on transfer patterns is analysed. The variable of interest is the frequency of receiving monetary, goods, and service transfers before migration and in the last 12 months before the survey was administered.

The data from before and after migration is pooled, accounting for when the transfer takes place with a migration dummy. To achieve this the same variables are used for before and after migration. When applicable, the variable is adjusted to the period before migration (e.g. age, number of children etc.).

As the transfers occur within a defined limit of time, and the probabilities of consecutive transfers are not dependent on each other, then it can be assumed that the distribution of transfers' frequencies follows the Poisson distribution. Consequently, the count rate would be calculated as: 


$$
\mu_{i}=E\left(y_{i}\right)=\exp \left(x_{i} \beta\right)
$$

where, $\mu_{\mathrm{i}}$ is the expected value of the model dependent on a vectors of covariates, $\beta$ is a vector of estimated coefficients, and $x_{i}$ includes characteristics of receiving household and sending relative. The probability of observing a specific count is:

$$
\operatorname{Pr}\left(Y_{i}=y_{i}\right)=\frac{e^{-\mu_{i}} \mu_{i}^{y_{i}}}{y_{i} !}, y=1,2,3, . . n
$$

where, for the $\mathrm{i}^{\text {th }}$ count, $\mathrm{y}_{\mathrm{i}}$ is the count.

However, the data show some particularities that do not satisfy this distribution. Over-dispersion (variance is greater than mean) is found, and I also suspect an excess of "zero" values. I suspect that this excess is a result of two main reasons:

1. Random heterogeneity in frequencies of received transfers. In other words, households 'face' the same probability of receiving zero or any other frequency of transfers, but some households receive more zero or 'low count' transfers, and others receive more 'high count' transfers due to idiosyncratic factors or a random bias.

2. Some households are systematically not receiving transfers because of their characteristics. For example, respondents may have had limited contact with their relatives in the last 12 months before the move.

The standard Poisson model therefore does not satisfy the features of the data. In order to investigate what drives the over-dispersion in the data, different count models are extensively compared. The "negative binomial regression model" (NBRM) is compared to the "zero inflated Poisson" (ZIP) and "zero inflated negative binomial regression" (ZINBR) which use a two stage approach. In the first stage zero and non-zero outcomes are modelled, and in the second stage the remaining counts are modelled according to the standard Poisson (ZIP) or to the negative binomial (ZINBR). Technical details of both these models are discussed in Appendix D.2.

The predicted values of NBRM, ZIP and ZINBR models are calculated and compared in Appendix D.4. Further tests, partially reproduced in Appendix D.4, confirm that a simple Poisson model is inappropriate in this context, having far less accurate predictions than the other models discussed. For all types of transfers, the ZIP model performs better than the standard Poisson, but the predictions are less accurate than NBRM and ZINB. This indicates that transfers "suffer" mostly from an idiosyncratic and random bias rather than inflated zeros. In fact, NBRM and ZINB perform similarly in predicting the probability of counts, providing less evidence on the 'inflated zero' distortion. Therefore the results of NBRM are discussed as the model that explains the hidden heterogeneity in the transfers' counts best. For comparative purposes, the results for all combined transfers using NBRM and ZINB are reproduced in Table D.7 in Appendix D.5. In fact the results from ZINB regressions for separate transfers are very close to the NBRM results.

The NBRM accounts for heterogeneity among count outcomes. The predicted count probability is: 


$$
\operatorname{Pr}\left(Y=y_{i}\right)=\frac{\Gamma\left(y_{i}+\phi\right)}{\Gamma(\phi) y_{i} !}\left(\frac{\phi}{\mu_{i}+\phi}\right)^{\phi}\left(\frac{\mu}{\mu_{i}+\phi}\right)^{y_{i}}, y=1,2,3, . . n
$$

where, the variance in the predicted counts is increased through a parameter $\varphi^{-1}$ accounting for the suspected (over)dispersion (see also Freese and Long, 2001).

In order to check how the support from different members of the network has changed before and after migration, the NBRM models are estimated separately for before and after migration. Differences between coefficients are then checked for significance using seemingly unrelated estimation (see also Weesie, 2000).

While there is quite a varied range of control variables, the survey does not provide us with information on household income or wealth in the past. I am aware that these kind of economic indicators are important in explaining differences in transfer patterns, therefore I have controlled for it in one regression using present income as a proxy for past incomes. The results are given in Appendix D.5.

\subsection{Empirical Results}

Two types of analyses are used in order to answer whether transfer patterns between extended family members have changed as a result of the move. First the open-ended qualitative interviews are analysed and first conclusions from the respondents' opinions are drawn. Then the quantitative data is utilised using an econometric analysis comparing the results to the hypotheses and conclusions from the qualitative analysis.

\subsubsection{Qualitative analysis}

The open-ended questions are first coded into groups with similar responses for the 19 open-ended questions that were asked. A count is taken of how often respondents answered in a similar way and draw conclusions here based on the frequency of certain answers. Appendix D.2 gives an overview of the questions asked, coding and number of observations for each type of response.

Even if families are separated by physical distance, many claim that their relationship was not negatively affected by this. Many of the interviewed households expressed that they meet their families more frequently than before ( 8 households). Half of the interviewed households (13) also claimed that their relationship to other family members did not change, with about the same number of households citing an improvement or a worsening of their relationships. While some families talked about relationships and lives having become more distant and separate, other respondent explain how the separation itself has made them closer:

"My father often goes to visit them. He has a lot of nostalgia."

"Yes my relationship with them didn't change. The distance can't change the affection we have for each other."

Many households also feel much closer to their families because they shared the experience of moving. Most families moved together with their nuclear, extended 
family or even the whole village (10 households say this explicitly). This means that their whole solidarity network is replicated in the city. For example one household head explained:

"All our neighbours are blood-related; it's the same big family... All our neighbours here were neighbours there."

Another household told a similar story:

"The village of K., around 16 houses, has moved together to this place. The entire block belongs to the S. family.... The strongest relations we keep with our neighbourhood, the $S$. families. We are all brothers or cousins up to the fourth degree. We have very good relations."

There are about an equal number of households that claim that they have more/ fewer friends or contacts with neighbours. Many households are thus still exchanging with the same people.

While family relationships thus often remained close, the type of transfers exchanged between household members changed. Despite high unemployment that almost all respondents name as their greatest problem, in general households benefited financially from the move (see also Chapter 5). Financial transfers are becoming more important. This allows them to give and receive more financial transfers ( 3 out of 5 households say they receive more financial transfers). At the same time less help is needed, than in an agricultural setting (4 out of 5 households say that they receive less services). Many respondents pointed out this shift from services to financial transfers:

"To be realistic, if I would have to help everyone I would have to give up my day of work, so the help is more limited to monetary terms and not physical anymore."

"At that time you needed some help to work the land. Now you need more financial help."

"Yes with money now and in the past with work."

One respondent even declared that financial solidarity replaces social solidarity to some extent:

"Economic relations are better now. Affective relationships are less good. When you get a bit richer you grow apart a bit."

The exchange of goods remains in between financial and service transfers. Certain kinds of good transfers, i.e. food products, have become less important. This is because households now grow and collect less food than in rural areas and are therefore less able to give food products, as these respondents explain:

"Here we buy all things in shops. There is no reason to ask your neighbour for something because the shop is there. Before it was different, we exchanged more goods."

"We help each other less because now we don't own agricultural land, so we have fewer products to help each other."

"Yes, there [referring to village of origin] the people can help more than here because they have cows, grow vegetables etc."

Even though migration seem to have some small effects on the relatives that households choose to exchange transfer with, a preferences for known relatives 
remain mostly unchallenged. Furthermore financial transfers are now more important than in the past.

\subsubsection{Econometric results}

Table 6.4 gives the results from the NBRM for financial, goods and services received. Table D.7 in Annex D.5 gives the regression results for all transfers combined. The data from before and after migration is pooled, accounting for when the transfer takes place with the migration dummy. To achieve this the same variables for before and after migration are used.

The tests at the bottom of Table 6.4, and in Annex D.4 measure whether the NBRM model is the appropriate model to use in this context. The results in Annex D.4 show what the actual and predicted mean count for all transfers is for each of the models and the difference (how much the prediction diverges from the actual count). The Pearson test is a chi-squared test of independence and also indicates how close the predicted count is to the actual count. Generally the NBRM model is one of the models that predicts the best. In Table 6.4, the likelihood ratio Chibar squared statistic allows us to see if the NBRM should be used instead of a standard Poisson model. The very low values of the probability suggest over-dispersion, and therefore the use of NBRM is appropriate.

Our variable of interest "transfer after migration", which is a dummy variable that is one for the observations after migration, is highly significant for all transfers combined (see Table D.7) and the separate transfers. The different types of transfers are discussed below.

For financial transfers, the variable of interest "transfer after migration" has a strong significant effect, indicating that financial transfers have become more frequent after migration and confirming the qualitative analysis and Hypothesis 1. This means that for a given transfer partner and all other parameters being equal, financial transfers are received 0.3 more frequently by an average household after migration. ${ }^{69}$ Figure 6.2a shows the predicted frequencies of financial transfers by age, for those transfers before and for those transfers after migration. The figure confirms that financial transfers are more frequent after migration, at all ages. The difference is especially large for younger household heads, who seem to be getting more frequent financial transfers on average.

${ }^{69}$ Marginal effects are not reproduced here. 
Table 6.4 Results from NBRM: Frequency of receiving transfer

\begin{tabular}{|c|c|c|c|c|c|c|}
\hline & \multicolumn{2}{|c|}{ Financial transfers } & \multicolumn{2}{|c|}{ Good transfers } & \multicolumn{2}{|c|}{ Service transfers } \\
\hline & Coef. & s.e. & Coef. & s.e. & Coef. & s.e. \\
\hline Main regression & & & & & & \\
\hline Transfer after migration & $1.01^{* * *}$ & 0.32 & $-1.08^{* * *}$ & 0.26 & $-1.00^{* * *}$ & 0.28 \\
\hline Relative parent & 0.05 & 0.61 & $1.28^{* *}$ & 0.54 & $-1.09 *$ & 0.6 \\
\hline Relative child & -0.51 & 0.86 & $2.10^{* * *}$ & 0.64 & 0.48 & 0.67 \\
\hline Relative sibling & 0.25 & 0.41 & $0.73^{*}$ & 0.37 & $-0.81^{*}$ & 0.42 \\
\hline Relative other & -0.26 & 0.47 & 0.02 & 0.38 & $-1.83^{* * *}$ & 0.45 \\
\hline $\begin{array}{l}\text { Age hhh (now/ before } \\
\text { migration) }\end{array}$ & $-0.03^{* *}$ & 0.01 & $-0.02^{*}$ & 0.01 & -0.01 & 0.01 \\
\hline Gender hh head & $1.35^{* *}$ & 0.64 & -0.91 & 0.64 & -0.27 & 0.82 \\
\hline Education years hhh & -0.04 & 0.06 & $0.08^{* *}$ & 0.03 & $0.08^{*}$ & 0.05 \\
\hline Hhh's religion Muslim & $1.00^{*}$ & 0.52 & $0.99 * *$ & 0.43 & 0.28 & 0.48 \\
\hline Hhh's origin Central & -0.65 & 0.54 & 0.5 & 0.44 & $0.91^{*}$ & 0.5 \\
\hline Hhh's origin North-Central & -0.24 & 0.61 & 0.32 & 0.53 & 0.57 & 0.58 \\
\hline Hhh's origin Mountain & -0.73 & 0.54 & -0.5 & 0.47 & 0.25 & 0.51 \\
\hline $\begin{array}{l}\text { Hh extended family (now/ } \\
\text { before migration) }\end{array}$ & 0.37 & 0.29 & $-0.60^{* *}$ & 0.27 & $-0.61^{* *}$ & 0.28 \\
\hline $\begin{array}{l}\text { Number of children hh } \\
\text { (now/ before migration) }\end{array}$ & -0.15 & 0.15 & -0.06 & 0.12 & $0.35^{* * *}$ & 0.13 \\
\hline Years since migration & $-0.06^{*}$ & 0.04 & $0.05^{* *}$ & 0.02 & 0.01 & 0.03 \\
\hline $\begin{array}{l}\text { Age relative/ friend (now/ } \\
\text { before migration) }\end{array}$ & 0.02 & 0.01 & 0 & 0.01 & -0.01 & 0.01 \\
\hline Gender relative/ friend & $-1.30^{* * *}$ & 0.29 & -0.06 & 0.26 & 0.34 & 0.27 \\
\hline $\begin{array}{l}\text { Education years relative/ } \\
\text { friend }\end{array}$ & 0.07 & 0.05 & 0 & 0.04 & $-0.09 * *$ & 0.04 \\
\hline $\begin{array}{l}\text { Hh \& relative/ friend same } \\
\text { religion }\end{array}$ & -0.58 & 0.58 & 0.13 & 0.52 & -0.37 & 0.65 \\
\hline $\begin{array}{l}\text { Hh \& relative/ friend live } \\
\text { in same district (now/ } \\
\text { before migration) }\end{array}$ & $1.15^{* * *}$ & 0.32 & 0.26 & 0.29 & $1.17^{* * *}$ & 0.29 \\
\hline Constant & -2.19 & 1.66 & 0.25 & 1.33 & $2.84^{*}$ & 1.51 \\
\hline Ln alpha & $2.18^{* * *}$ & 0.13 & $2.16^{* * *}$ & 0.08 & $2.36^{* * *}$ & 0.07 \\
\hline Number of observations & 882 & & 880 & & 877 & \\
\hline Log pseudo likelihood & -613.47 & & -1564.72 & & -1128.67 & \\
\hline P- value Chi2 & 0.00 & & 0.00 & & 0.00 & \\
\hline Pseudo R² & 0.0628 & & 0.0198 & & 0.0323 & \\
\hline LR Chibar2 & 1276.72 & & $1.5 e+04$ & & 6017.65 & \\
\hline P-value Chibar2 & 0.00 & & 0.00 & & 0.00 & \\
\hline
\end{tabular}

Note: Frequency of transfers refers to the number of times the transfer has been received in the past 12 months/ before migration

"Transfer after migration" is a dummy variable that is one for the observations for the period after migration

Base for relatives (friends), type of transfers (services), religion (catholic, orthodox and atheist), household origin (Coast)

${ }^{*}$ significant at $10 \%{ }^{* *}$ significant at $5 \%$; ${ }^{* * *}$ significant at $1 \%$ 
Figure 6.2 Predicted frequency of transfers by age, for transfers before and after migration

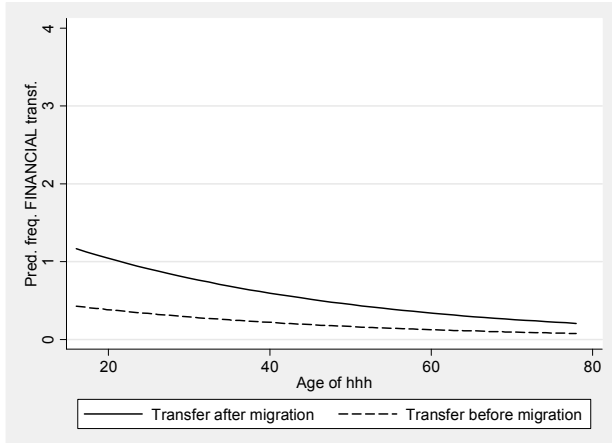

6.2a Financial transfers

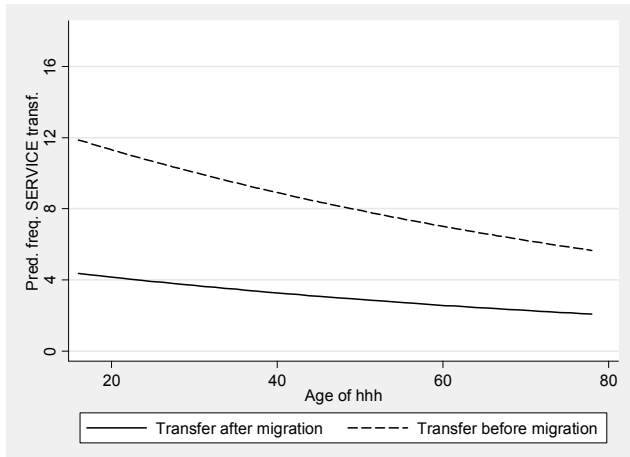

6.2c Service transfers

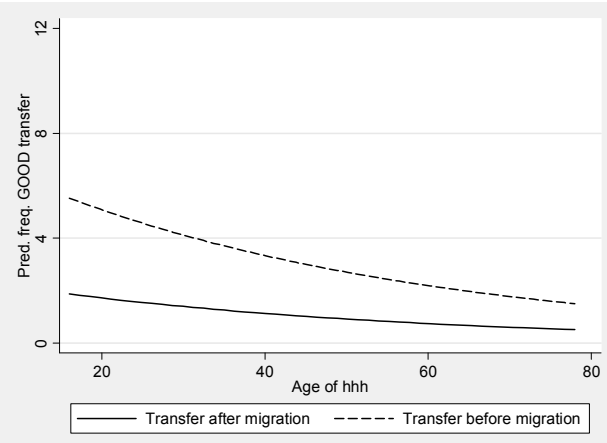

6.2b Good transfers

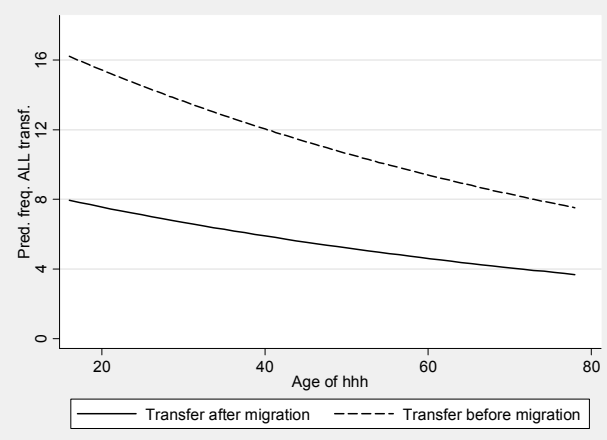

6.2d All transfers

Source: Own compilation

The "relative" variables show that friends transfer financial transfers more frequently than parents, children, or other relatives, but less frequently than siblings. However, this effect is not significant for any of the relatives.

The dummy variable, "gender of household head", has a positive effect on the transfers received (female headed households receive more frequently) and "gender of relative" has a negative effect (women relatives gives less frequently). This does not necessarily show that women tend to give less frequently, but rather that transfers may be explained by the particular situation of the households. Most of the female headed households happen to be in financial difficulties either because of the loss of the main breadwinner (i.e. widow headed households) or are in vulnerable situation due to the informal and unstable labour market. ${ }^{70}$ Households that moved before 1997 seem to receive monetary transfers less frequently than others. This can be explained by the "relative success" that these households have in financial terms due to more stable and better paid jobs (see Chapter 5). Most other control variables are significant and the coefficients have the expected signs. 
Coming to goods, the variable of interest "transfer after migration" is highly significant and negative. More specifically, for a given transfer partner and all other parameters being equal, an average household after migration receives 1.9 less frequent good transfers. Based on the informal interviews it appears that this pattern is driven by changes in the nature of goods that are exchanged. Before migration, the goods that were exchanged consisted mainly of food and agricultural products, which are exchanged repeatedly. After migration, food is exchanged less frequently as people grow less of it in peri-urban areas. However, people now exchange gifts on special occasions, like birthdays, maybe due to changing cultural practices and more financial wealth from migration. These kinds of transfers take place non-frequently. Figure $6.2 \mathrm{~b}$ shows the predicted frequency of good transfers by age, for those transfers before and for those transfers after migration. The figure shows very clearly that good transfers are lower at all ages after migration. Interestingly, the difference in the predicted frequency between before and after migration is lower for older household heads.

Looking at the relatives that give goods to the household, family relatives are generally more important givers of goods than friends (not significant for "Relative other"). The variable "Education years of household head" has a positive and significant effect showing that the most educated (and therefore those with higher chance of success in the labour market) receive goods from their kin members more frequently. Extended family households receive goods less frequently since they have stronger links with persons within their own household (the survey only measures inter-households transfers).

Finally, for service transfers, the main variable of interest "transfer after migration" is strongly significant and negative. This means that for a given transfer partner and all other parameters being equal, there are 5.2 fewer service transfers received by a given household after migration. The results that less goods and services and more financial transfers are received by households confirm Hypothesis 1 . These results are not surprising given the qualitative interviews: Relatives that are often also internal or international migrants are now much more able to give financially due to better-paid employment and having less time to spend on other transfers (such as services) due to increased distances and a different employment structure.

Figure 6.2c shows the predicted frequency of service transfers by age, for those transfers before and for those transfers after migration. It shows clearly that service transfers were higher before migration, at all ages. There is a slight decrease in the difference between "transfers before migration" and "transfer after migration" at higher ages, but to a much lesser extent than for financial transfers and goods. This might be explained by the fact that service transfers are probably much less affected by behavioural changes and that living close by (which is controlled for in the regression) affects the transfer of services much more.

Coming to relatives, again all relatives (except children) are significantly less important than friends in terms of frequency of service transfers. I suspect this to be a consequence of migration and I confirm this by running models separately for before and after migration (see discussion below). Education of the household head again has a positive effect on frequency of services (confirming the same trend as for goods). The number of children also has a positive effect suggesting 
that most of services exchanged are related to child minding activities. As expected, living in the same district has a strong positive effect. The other variables have the expected signs and are generally significant.

Of course transfers are not mutually exclusive; therefore a NBRM regression that measures the probability of having a certain frequency of all transfers ${ }^{71}$ is also estimated. The results are included in Table D.7 and strongly confirm the previous findings. The increased monetary transfers after migration have been superseded by the decrease in goods and services, therefore the overall effect of migration is the decline in the combination of transfers (Figure 6.2d). This is an interesting result. Apart from the above arguments explaining the decline of both goods and services, this can also be attributed to the increasing value placed on individuality and independence after migration, a comment that was often brought up by respondents in the qualitative interview stage.

Friends transfer more frequently than parents, siblings (not significant) or other relatives, but less than children. It seems that migration has played a role in this (see Hypothesis 2), and therefore it is investigated further.

Table 6.5 gives differences in coefficients for relatives (as compared to friends) estimated in separate NBRMs for before and after migration and measures whether this difference is significant. ${ }^{72}$ The control variables used are the same as in Table 6.4.

Table 6.5 Differences in coefficients from separate NBRM (before and after migration)

\begin{tabular}{lllll}
\hline & Financial & Goods & Services & All transfers \\
\hline Relative Parent & -1.26 & -1.08 & $-2.25^{* *}$ & -1.43 \\
Relative Child & $14.55^{* * *}$ & $2.59^{*}$ & -0.12 & -0.01 \\
Relative Sibling & $-2.77^{* * *}$ & -0.9 & $-1.9^{* * *}$ & $-1.57^{* * *}$ \\
Relative Other & $-3.43^{* * *}$ & 0.25 & $-1.57^{* *}$ & -1.03 \\
\hline
\end{tabular}

Note: The difference in coefficient is calculated as after migration less before migration ${ }^{*}$ significant at $10 \%$; ${ }^{* *}$ significant at $5 \%$; ${ }^{* *}$ significant at $1 \%$

For financial transfers after migration siblings and other relatives have become relatively less important (negative and significant difference in coefficients) compared to friends. The same holds for parents (though difference is not significant). However, transfers from children have not declined in frequency, even though this result has to be treated with caution, as children have a low number of non-zero observations (see Annex D.1).

The results are further confirmed for good transfers, where the positive and significant difference of coefficients for children shows that they are becoming increasingly more important after migration. On the other hand, the role of other members of kinship is superseded by friends (however, results are not significant).

The same trend is also confirmed for service transfers where most of are significant while the signs do not change. The effects are stronger for these

\footnotetext{
${ }^{71}$ The frequency of separate transfers (financial, goods and services) are summed to calculate the total number of transfers received.

72 Extended results from NBRM models are displayed in Table D.8. The results are estimated using "seemingly unrelated estimation" procedure (Weesie, 2000).
} 
transfers given their particular characteristics (physical distance is essential in delivering frequent services to relatives).

Generally, all the above results confirm that migration has partially shifted transfers more towards particular members of kinship. Children and friends become increasingly important after migration, especially for services, and the effects are not always significant but consistent. The findings indicate that some change in the network takes place after migration, thus confirming Hypothesis 2 .

An additional explanatory variable that is likely to affect transfers received is income or wealth of the household. As explained above, this variable is not controlled for, as the household's income before internal migration is not known. However, to measure the effect of income and to safeguard that the results are not strongly affected by this omission, wealth is controlled for by using current per capita income (see Table D.6 in Annex D.5). Firstly, the signs, statistical significance and size of the noteworthy regressors are not affected much by controlling for income. This strengthens previous results. Secondly, income has the expected negative effect on good and financial, good and service transfers received (but not significant), which shows that richer households receive fewer transfers.

\subsection{Conclusions}

This paper is based on a unique survey amongst internal migrant households in peri-urban Tirana, Albania conducted in April 2008. The informality of the settlements complicated sampling design and a random sample selection, which may affect the strength of these conclusions. Internal migration to peri-urban areas of major cities is a wide-spread phenomenon in the country. This movement is often characterized by whole family relocation. Of particular interest is how the change of location through internal migration has affected the reliance on family and non-family members of kinship and the patterns of transfers. For this three main transfers (financial, goods, and services) are looked at and the changes in receiving patterns both at the current moment and before migration are investigated. By exploiting both a quantitative survey and additional qualitative interviews, it is shown that migration has affected the mix between the transfers that households receive, towards more frequent financial transfers (Hypothesis 1) and has also had some effect on the composition of the family network on which they rely upon (Hypothesis 2).

The first hypothesis relates to the effect of migration on the mix of transfers, looking at the intensity of receiving a certain transfer. Migration seems to have a positive effect on the receipt of financial transfers, indicating that households receive more frequent financial transfers after migration. While the effect is positive and significant, its marginal effect is small: On average, households receive 0.3 financial transfers more from a given relative (ceteris paribus). The shift towards financial transfers seems logical: After migration households are much more in the need of financial transfers than before. From previous studies (e.g. Chapter 5 and Cila, 2006) it is known that unemployment is high amongst internal migrant households and that living costs have increased compared to living in rural areas (e.g. having to pay for water). The higher vulnerability of the sampled 
households after migration may explain why more frequent financial transfers are received.

Migration's impact on good transfers is interesting. Migration decreased the frequency of receiving goods and households receive 1.9 goods less on average from a given relative (ceteris paribus). This is a big drop in goods received and based on the qualitative interviews it appears that this pattern is driven by changes in the nature of goods that are exchanged. Before migration, goods exchanged were mainly food and agricultural products that are exchanged repeatedly. After migration, food is exchanged less frequently as people grow less of it in peri-urban areas. However, they exchange gifts on special occasions, like birthdays, more often, maybe due to changing cultural practices and more financial wealth from migration. These kinds of transfers take place non-frequently.

Finally, the results show that households receive service transfers less often after migration. On average a household received a service 5.1 times fewer from a given relative (ceteris paribus). This is logical, as services require proximity of transaction partners and migration is likely to have split some of the family networks. This is reinforced by the result that service transfers are more likely and frequent, if the household and kinship member live in the same district. Furthermore households and kinship members that have also migrated internally are probably less able to give services due to lack of time, brought about by volatile employment and more time spent on job search.

The second hypothesis focuses on the network the household receives transfers from. When examining all transfers combined, internal migration has changed the household's network and, with the exception of children, friends are becoming more important than relatives in giving transfers to the surveyed households. This is somewhat surprising given the qualitative analysis, which revealed that whole extended family networks and even villages moved together and which also showed that households have a very conservative attitude towards strangers. Friends rise in importance compared to parents, siblings and other relatives, but the effect is not always significant. The results show that in particular friends supersede siblings for financial transfers, and siblings and other relatives for services. This may be related to the nature of such transfers. Financial transfers are less personal, which may explain the rising importance of friends giving these transfers, despite the conservative nature of internal migrant households. On the other hand, distance is an essential condition determining the frequency of service transfers. In conclusion, there are some changes in the family network households rely on, but no complete transformation.

The above conclusions are drawn on a small-scale household survey in a very specific context. Whether the results on the continuing reliance on family members are generally applicable is debatable. In the Albanian case, whole families and even villages relocated permanently. Due to the specific nature of Albanian internal migration and the conservative nature of the migrants, transfer networks stayed closely integrated. This is very different in other internal migration contexts, e.g. China, where only one family members moves. Different patterns of migration are likely to affect the continuation and strength of pre-migration networks.

The other main conclusion, the switch to financial transfers after migration is probably even more pronounced in other migration contexts. Migration makes 
family members more physically distant, and thus less able to exchange goods and services. Furthermore migration towards (better) paid employment allows people to exchange more financial transfers. Finally, as extensively discussed in Chapter 4, many people migrate in order to remit.

The continuing and high levels of private support to migrant households are valuable in a transition context, where poverty is wide-spread and state support is low. The findings suggest that in absence of such public mechanisms, migrant households resort to private transfers for financial resources. However, it is questionable whether these financial resources are an adequate and sustainable source. Moreover, the findings have shown that services and goods transfers received by households decrease after migration. The government should have a stronger role in replacing family support, for example by providing child care opportunities for female headed households. 


\section{Conclusions and Discussion}

In this section the main findings of this dissertation are reiterated and discussed in a broader context. I will first address the specific research questions outlined in section 1.2. Section 7.2 analyses the more general objective of this dissertation, draws links between the different chapters and discusses some policy recommendations.

\subsection{Main findings}

\subsubsection{Why do people migrate?}

To answer the question on why people migrate I first reviewed the theoretical migration literature and linked the theories in a general framework. This was followed by an econometric analysis of some aspects of these theories. So why do people migrate? They migrate because their assets, investments and opportunities in the source country are limited. They migrate because they are not able to support their families or use their skills efficiently. They migrate because they do not have access to public transfers. They migrate because they see others in their social network migrate and they realise that migration is another option to make a living. I will now discuss the reasoning behind these conclusions in more detail.

The macro-level is the level of analysis of classic neoclassical migration theories. Lewis (1954), Ranis \& Fei (1961) and Harris \& Todaro (1970) all contributed to the classic macro migration model that explain migration as a result of geographical differences in the supply and demand of labour, mostly between the rural agricultural sector and the urban manufacturing sector. Migrants are attracted to cities by higher wages, where labour is scarcer and migration continues until wages are equalized. The related dual-labour market theory (Piore, 1979) also emphasizes the strong, often temporary, labour demand in Western economies as a pull factor of international migration. Other theories place migration in a broader framework: For example, Zelinsky's hypothesis of Mobility Transition (1971) argues that migration is part of the demographic transition any country undergoes when modernizing.

Another more mainstream economic theory is focused on the micro-level, the Human Capital Approach (Sjaastad, 1962). According to this theory potential migrants make a rational decision to decide whether to migrate, weighing the costs (e.g. transportation costs, missing family) versus the benefits (e.g. higher probability of employment, higher income). Related migration models are behavioural models that also include non-economic considerations. Wolpert's Stress-Threshold model (1965) describes a behavioural model of internal migration, similar to a cost-benefit analysis, but assuming that while individuals intend to be rational ex-ante, they are not necessarily so ex-post. This kind of model explains why people migrate even if they are not better off afterwards. 
Potential migrants are not individuals in a social vacuum; the decision of one or more family members to migrate is often made jointly and is also influenced by the wider community. This is stressed by meso-level theories. Mincer (1978) amongst others regards the migration decision as a cost-benefit analysis of the whole family, which may or may not result in the migration of the family as a whole. The New Economics of Labor Migration (NELM) literature (e.g. Stark, 1991) considers the decision to migrate as truly a family decision, in which a household maximises joint income, status and minimises risks. Due to failing labour and credit markets at home a household may send one or more household members abroad.

Migration networks and institutions in the origin and destination countries help to perpetuate migration (e.g. Goss \& Lindquist, 1995). These may be both informal (e.g. former neighbours helping you find a job) and formal (e.g. the IOM advising migrants on their rights). Another meso-level theory, Cumulative and Circular Causation (Massey, 1990) shows how migration becomes more and more prevalent since it has started, by sustaining itself. One should be aware that informal migrant networks may influence migration flows both by being a means to migration (i.e. facilitating migration) and an actual cause (making individuals aware of the option migration).

In the conclusion to Chapter 2, I show how most of these theories can be linked and that they should best be treated in a complementary fashion. The different actors are not isolated but often affect one another at one point in time (through social capital) and over time (e.g. cumulative causation). It is therefore important to consider the different levels of migration. Structural macro factors affect the decisions made on the micro level and vice versa. Looking at the union of migration theories in another way, one could say that macro-level factors like unemployment in the source country or structural labour demand in the destination country create migration potential, while micro level factors (like income maximisation) create actual migration streams.

In Chapter 4 the migration theories are linked in another way by placing them in the context of the Welfare Pentagon. The Welfare Pentagon (de Neubourg, 2002) is a general framework that explains how people maximise income and smooth consumption by accessing different parts of the Welfare Pentagon, namely families, markets, membership associations, social networks and public authorities. When an individual has no or not significant access to some of these institutions and has insufficient assets and thus cannot make ends meet at home, the individual may decide to migrate. At the same time relevant assets and access to some of these institutions are also necessary in order to migrate, e.g. social networks.

In Chapter 4 this framework is explored empirically with data for Albania and Moldova and I give a first indication of characteristics of Albanians and Moldovans that do migrate internationally. In terms of demographics, migrants are younger on average and being male and married increases the propensity to migrate. These effects are especially strong for Albania, where a higher number of children in the household also leads to more migration. It appears that migration is very much a family-focused decision, taken in order to support the family. The existing literature on Albanian migration acknowledges the importance of the family in terms of support (see also Chapter 6) and also as an important factor in the migration decision (e.g. Vullnetari, 2007 and Barjaba \& King, 2005). In section 4.5 
of Chapter 4 it was shown that remittances in Albania are mostly linked to the motive altruism, which corroborates the conclusion that Albanians migrate to support their families. However, my empirical work does not strongly support previous findings that Albanian migration is additionally driven by dire economic circumstances, such as poverty, unemployment etc. (e.g. Mancellari et al, 2006).

The Welfare Pentagon framework hypothesizes that individuals that are unemployed or underemployed in the local labour market, may migrate. While migrants in Albania are generally less educated, in Moldova the more highly educated are more likely to migrate. In section 4.5 .2 of Chapter 4, I also show that more highly educated Moldovan migrants send more remittances. My own evidence on employment is fuzzy, but there is some indication that in Moldova migration is linked to employment. Other research (e.g. Lücke et al, 2007 and Danzer \& Dietz, 2009) clearly links migration to dysfunctional labour markets in Moldova. According to the human capital approach (Sjaastad, 1962) and the Welfare Pentagon perspective, migration in Moldova can thus be seen as a (human capital) investment: Moldovans migrate abroad, because they are better able to employ their skills and human capital abroad.

As spelled out above, migration theories on the perpetuation of migration emphasize social networks in explaining migration flows. The Welfare Pentagon also shows how access to social networks and membership institutions helps maintaining income at home, but also to realize migration. There is strong evidence for formal and informal networks facilitating migration in both countries. Albanian migrants have more friends, than non-migrants, and meet their friends more often. Migrant households live in communities with more community groups and these households have joined more groups. In both Albania and Moldova, the higher the fraction of migrants in the community, the higher is the propensity to migrate.

The NELM emphasizes that failed or non-existing labour and credit markets in source countries may be a motivation to send one or more household members abroad. The Welfare Pentagon framework also adds weak public authorities to that list. Migration may be a solution for poor households, if neither markets nor the government are available to help. Previous studies have pointed out the important role the collapse of social services played in influencing Albanian migration flows (e.g. Unicef, 1998 quoted in Barjaba \& King 2005). In Chapter 4 it is also tested whether structural differences in terms of infrastructure and public transfers stimulate migration flows, but the empirical results are ambiguous. Descriptive statistics show that migrant households are less likely to receive public transfers. It is not completely clear whether migrants live in less developed communities: Migrants and remittance receivers are more likely to live in rural areas. Remittance receivers live in communities that are less developed in terms of access to credit and infrastructure but these results are not significant.

I have argued that it is more valuable to consider migration theories in conjunction. Moreover, not all migration theories are applicable in all country contexts. I have investigated two countries that seem similar on the surface: They are in transition from a central to market economy, very poor and European countries bordering the European Union. Nevertheless the motivations behind migration in these two countries and amongst different groups of migrants seem to 
diverge. Therefore it is impossible and undesirable to give a general answer to why people migrate and it is of utmost importance to consider the specific migration motives in different countries or amongst distinct groups of migrants.

\subsubsection{What are the motivations of migrants to send remittances?}

The motivations of migrants to send remittances are explored by reviewing the literature and by looking at the specific cases of Albania and Moldova. While I am able to find "evidence" for some motivations, the aim to repay loans, self-insurance in Moldova and altruism in both countries, the analysis resulted in inconclusive results, very much in line with the literature. It is not possible to give a satisfying answer to this question on a general level, as the migration context, e.g. type of migration flows, the causes of migration, the family setting and specific norms and values, influences whether and how much remittances are sent (see also Carling, 2008).

In Chapter 3 I extensively review the empirical and theoretical literature of the determinants of remittances. The remittances literature is defined by Lucas and Stark (1985), who argue that remitting motives can be classified either as "pure altruism", "pure self-interest" or something in between, "tempered altruism or enlightened self-interest". Indeed, a central motivation of a remitting migrant may be altruistic feelings towards the family left behind. An altruistic migrant reacts to poverty and shocks of the family by sending remittances. In this case, there is a positive relationship between adverse conditions of the receiving household and remittances sent.

The second broad remitting motive discussed in the literature is self-interest. Selfinterested migrants may send remittances for a number of reasons: In order to inherit their parent's wealth, as an investment (with family acting as a cheap and reliable financial agent) or to invest in housing, livestock, reputation etc. as a preparation for returning home.

The motivations in between self-interest and altruism, are implicit contractual arrangements that benefit both the sender and receiver of remittances. The first contractual arrangement, an implicit co-insurance contract between the migrant and family, is highlighted in the New Economics of Labor Migration theory (NELM). Remittances are sent home when the household experiences shocks and to enable the household to invest in new technologies. At the same time, the household also supports the migrant, e.g. during spells of unemployment.

Another type of contractual agreement between the household and family is loan repayment, for example, repaying human capital investment or the cost of migration. A final contractual arrangement is the exchange motive (Cox, 1987). Here remittances are paid to the household at home for services provided, e.g. looking after the migrant's children.

The most pressing problem in the remittance literature is that the theoretical literature is explicit and blunt, while the real motivations of remitters are fuzzy and implicit. Most likely it will only be a subconscious thought of migrants that building a grand house in their village of origin is an investment into their reputation. Furthermore, a migrant seldom only has one motivation in mind. The 
vague, implicit and interlinked nature of motivations to remit and the contradictory qualities of theory versus migrant behaviour makes the motives very difficult to measure.

In Chapter 3 I also review the empirical literature of the determinants to remit. I show how different authors have tried to measure the different motives to remit by quantifying the effect of specific variables on the probability of remitting and on the amount of remittances sent. For example if remittances increase with wealth of the receiving household, the motive of the migrant is postulated to be the desire to inherit the household's wealth. I compare the effects of these specific variables on remittances in different (country) studies.

Two main conclusions can be drawn from this review: Firstly, as already stated, it is very difficult to measure "a motive". The motives often overlap in practice and different migrant or household characteristics that affect remittances can be interpreted in many different ways and thus linked to different motives. Operationalisation of motives is highly problematic. Secondly, only few variables have the same effect in each study and these are mainly unsurprising revelations, for example a migrant having a higher income leads to more remittances. This means that the country and individual migrant context is still vital in explaining why people remit.

In Chapter $4 \mathrm{I}$ attempt to apply some of the determinants of remittances theories to the cases of Albania and Moldova. Albania and Moldova differ in terms of migration and remitting patterns. Males are the majority of migrants in both countries and remittances are sent to all income groups. In Albania, higher amounts are sent to poorer households. Albanian men send higher amounts of remittances, probably due to cultural practice, while in Moldova there are no significant gender differences. In Moldova the more highly educated send more remittances implying that migration was an effective human capital investment in line with Sjaastad's (1962) hypothesis.

To investigate the different theoretical motives to remit more closely, I applied three different econometric models, following the theoretical and empirical literature on the motivations to remit. In both countries, remitters have (some) altruistic motives. The better educated (and consequently wealthier) remit more. More remittances are sent to worse off households and migrants remit less if there are other migrants in the household, as the migrant is not the only one responsible for the wellbeing of the family. More remittances are sent to larger and thus needier households and to households living in communities with lack of employment prospects. The altruism evidence is especially strong for Albania. This is in agreement with the finding that Albanians migrate to support their families.

In Moldova there is some evidence for self-insurance. Migrants living in more risky environments (longer distance to destination, illegal entry, and higher unemployment rate in destination) send more remittances, a type of informal insurance premium. For some remittances seem to be paid as loan repayment in Moldova. However, all the above caveats also apply to these results and they should be taken with a grain of salt.

Testing the motivations to remit remains an intricate area of research with much room for improvement. I show that the current methodology employed in the 
economic literature of testing several theories using multi-purpose household surveys does not lead to strong and meaningful results. Further research should focus on finding more innovative ways of measuring motives, but most importantly move towards measuring specific determinants and combining quantitative research with qualitative data to get a better impression of the motives of remitters.

\subsubsection{What is the economic impact of migration on migrant households?}

The question on the economic impact of internal migration on migrant households is rather unique in the literature. It has not been analysed comprehensively and most of the previous research is in the form of descriptive case studies. In Chapter 5 , I answer this question in a detailed econometric study on internal migration to Albania's capital Tirana. I show that while income increases, living conditions do not improve and the impact of internal migration is not as positive as one would expect.

This study highlights significant differences, in terms of socio-economic characteristics, between households that moved from rural areas to peri-urban Tirana and rural households that did not migrate internally. Income per capita has increased as an effect of migration, and a larger fraction of internal migrant households declare their life as having improved. Income increases by $9 \%$ a year for migration households. This confirms the Harris-Todaro migration theory, providing empirical evidence of a positive financial return to internal migration in the case of Albania.

Conversely, the results do not show statistically reliable effects of the internal move on actual consumption of households. Income has grown more than consumption with the move to peri-urban Tirana. Migrant households are able to earn higher wages but these are irregular, and have to cover higher living expenses, as well as costs not occurring in rural areas. Water and some food products are almost for free in rural areas, but have to be bought at a high cost by migrant families in peri-urban areas. Furthermore, migrants have to finance the construction of their new house, which can often take a long time. It is also possible that households are saving to migrate internationally. A final reason for this discrepancy between income and consumption is that migrants are financially helping their families back home. More research is needed to test these hypotheses.

Looking at housing quality and asset ownership compared to 1990, internal migration has had a negative impact. Migrant households are also significantly worse off than other groups in terms of health, and access to clean and running water. While the economic situation has improved, it seems to be accompanied by worsened living conditions.

Furthermore, access to the formal labour market seems to be extremely difficult for internal migrants in Greater Tirana. Working age adults in peri-urban migrant households are more likely to be unemployed, and work fewer hours, than their rural counterparts. However, migrant households do show higher expectations regarding accessing higher education for their children being, in general, satisfied 
with the quality of education. Nevertheless, school attendance is still low for migrant children, possibly due to household poverty or infrastructure bottlenecks. Further research should look into education outcomes in more detail, as this could also be a cause of migration.

An important question arises from the analysis: Why does internal migration continue, even though its impact on poverty is unclear? Zelinsky's mobilitytransition hypothesis sees migration as a natural development caused by the economic and social changes inherent in modernisation (i.e. transition in the Albanian case). He stresses that the drive for more personal freedom is an important factor and this is a relevant motive in the Albanian case. King (2005) amongst other authors stresses that the mere liberating possibility to migrate internally and internationally drove people to migrate.

Wolpert's Stress-Threshold model (1965) also comes to mind, which demonstrates that ex-ante rational behaviour may not necessarily be rational ex-post implying that the costs and benefits of migration are not always understood beforehand and that migrants display bounded rationality (see also Hammar et al., 1997). Despite general strong social networks (see Chapter 4) and strong family networks (see Chapter 6), there may still be misinformation or withheld information from migrants to potential migrants. Internal migration flows have slowed down now and it might have recently become clear to potential migrants that life is not necessarily better in Tirana than in rural areas.

Furthermore one should consider that migration may be a long-term investment. Households expect to have more opportunities in Tirana in the shape of diversified employment opportunities, earning money to migrate internationally and having the opportunity to educate their children. My fieldwork in Tirana reveals that migrants expect improved conditions in the medium-term. Better long-term prospects are confirmed by the fact that longer-term residents and earlier migrants enjoy higher income and consumption than recent movers. However, structural changes in infrastructure and labour markets still need to take place to improve the livelihood of migrants in peri-urban Tirana.

This study looked at the specific case of migrant households living in peri-urban Tirana. However, this is not an isolated example. The International Organization for Migration (IOM, 2005) for example describes a whole range of similar instances in Asia. More academic research is needed on the impact of internal migration in order to better understand the motives of internal migrants and to suggest appropriate policies to mitigate some of the negative effects. I will discuss possible policy responses in section 7.2 below.

\subsubsection{How has migration affected transfers amongst kinship members?}

Chapter 6 is based on a survey amongst internal migrant households in peri-urban Tirana. Chapter 5 showed that Albanian internal migration is often characterized by whole family relocation and that the impact of migration has been far from positive. It is also known that state support is low. This makes the investigation of private transfers and their development over time an interesting and relevant research question. In Chapter 6 I investigate how migration and the change of 
location have affected the reliance on family and non-family members of kinship for support and on the patterns of transfers; a unique study in the literature. It is shown that migration has affected the mix between the transfers that households receive, towards more frequent financial transfers, but has also changed the composition of the family network to some extent with friends gaining importance compared to blood relatives.

The effect of internal migration on family networks and their transfers is worth studying because migration potentially has an immense effect on kinship networks. Migration relocates family members, splits families and exposes migrants to new people and different cultural practices. Intuitively one would expect that migration has made family members less close and that (new) friends become more important transaction partners, but the present analysis shows that while this is true, family members remain important givers of transfers. Furthermore economic theories on the causes of migration and motivations to remit, outlined in sections 7.1.1 and 7.1.2 above, hypothesize that financial transfers increase after migration and this study allows us to test these hypotheses in practice.

To answer the research question, I look at three groups of transfers (financial, goods, and services) and five groups of transaction partners (parents, children, siblings, other relatives and friends) and investigate the changes in the receipt of transfers by households before internal migration and in the 12 months preceding the survey. The present study consists of an econometric analysis based on a quantitative survey and careful interpretation of additional qualitative interviews.

The first part of the analysis focuses on the network the household receives transfers from. When examining all transfers combined, internal migration changed the household's network to some extent. With the exception of children, friends are becoming more important (keeping in mind that most transfers received are still from family members). The evidence for enduring networks is reinforced by the qualitative analysis, which revealed that whole extended family networks and even villages moved together.

For specific transfers, friends rise in importance compared to parents, siblings and other relatives, but the effect is not always significant. The results show that in particular friends supersede siblings for financial transfers, and siblings and other relatives for services. This may be related to the nature of such transfers. Financial transfers are less personal, which may explain the rising importance of friends giving these transfers, despite the conservative nature of internal migrant households. On the other hand, distance is an essential condition determining the frequency of service transfers. In conclusion, there are some changes in the family network households rely on, but no complete transformation.

Next I studied the effect of migration on the mix of transfers. Migration seems to have a positive effect on the frequency of financial transfers, indicating that households are more likely to receive financial transfers after migration. The shift towards financial transfers makes sense: After migration households are much more vulnerable and in the need of financial transfers than before (e.g. to pay for food, water, see also Chapter 5) and kinship that also migrated are also much more able to transfer money due to having access to paid employment in Tirana. 
Migration's impact on good transfers is interesting. Migration decreased the frequency of receiving goods. Based on the qualitative interviews it appears that this pattern is driven by changes in the nature of goods that are exchanged. Before migration, goods exchanged were mainly food and agricultural products, which are exchanged repeatedly. After migration, food is exchanged less frequently as people grow less food in peri-urban areas. However, people exchange gifts on special occasions, like birthdays, more often, maybe due to changing cultural practices and more financial wealth from migration. These kinds of transfers take place nonfrequently.

Finally, there are some indications that households receive service transfers less often after migration. This is logical, as services require proximity of transaction partners and migration is likely to have split some of the family networks. This is reinforced by the result that service transfers are more likely and frequent, if the household and kinship member live in the same district. Furthermore households and kinship members that have also migrated internally are probably less able to give services due to lack of time, brought about by volatile employment and time spent on job search.

I have shown that, as to be expected, the transfer mix switches towards more frequent financial transfers. It is not possible to compare the monetary value of the different transfers and even if it was so, financial transfers versus goods and services are never really comparable. However, one should keep in mind that money is fungible, so financial transfers can be invested into education, health, housing etc.

The continuing and high levels of private support to migrant households are valuable in a transition context, where poverty is wide-spread and state support is low. The findings suggest that in absence of such public mechanisms, migrant households resort to private transfers for financial resources. However, it is questionable whether these financial resources are an adequate and sustainable source. Moreover, the findings have shown that services and goods transfers received by households decrease after migration. The government can play a better role in replacing family support, for example by providing child care opportunities for female headed households.

The above conclusions are drawn on a small-scale household survey in a very specific context. Whether the results on the continuing reliance on family members are generally applicable is debatable. In the Albanian case, whole families and even villages relocated permanently. Due to the specific nature of Albanian internal migration and the conservative nature of the migrants, transfer networks stayed closely integrated. This is very different in other internal migration contexts, e.g. China, where only one family member moves. Different patterns of migration are likely to affect the continuation and strength of pre-migration networks.

The other main conclusion, the switch to financial transfers after migration is probably even more pronounced in other migration contexts. Migration makes family members more physically distant, and thus less able to exchange goods and services. Furthermore migration into (better) paid employment allows people to exchange more financial transfers. Finally, as discussed in section 7.1.2, many people migrate in order to remit. 


\subsection{Discussion and policy recommendations}

This dissertation analyses the causes and effects of migration for a diverse range of migrant households, for example households receiving remittances from a migrant abroad or households that migrated together, with an exclusive focus on households living in source countries. Two broad conclusions can be drawn from all chapters. 1) Families influence the behaviour of migrants and continue being important. 2) Migration is a long-term investment that does not necessarily pay off right away.

Coming to the first conclusion, a (potential) migrant's family situation and needs influence the decision to migrate, and for those that did migrate, the decision to remit. Once people have migrated, families remain consequential and social networks remain strong. New relationships with non-family members develop over time, but in the case of Albania very slowly and without replacing family ties completely. Families are so important that families or even entire clans may migrate together. The strength of family and wider kinship ties is highly beneficial in poor countries like Albania. Migrants (and also non-migrants of course) often live in poor circumstances, have high poverty rates and receive minimal support from a weak public sector. Financial and in-kind support from kin members that takes place instead is a kind of private social protection strategy.

The second broad conclusion is that migration is an investment for the future. It seems that migrants have modest expectations concerning the short-term. It takes time and money for households to finish building a house and to be solidly integrated into the labour market. Many migrant households that I interviewed even indicated that they migrated for the benefit of the next generation, their children. They want their children to have a good education and thus better future. Once again, it is valuable that family support is strong, because it helps households through the difficult investment period.

In this dissertation I have focused on two particular country case studies: Albania and Moldova. The fact that both countries underwent a transition from a planned economy to a market economy most definitely influenced the migration and remittance flows in these countries. Transition in these two countries resulted in particular socio-economic conditions, such as market failures and rising inequality that have affected migration propensities. One can imagine that the manner in which transition takes place affects the socio-economic environment- in which individuals make livelihood decisions- more or less harshly. It therefore broadens or narrows the range of institutions people have access to and thus the range of livelihood decisions people can take. In both my case studies transition has resulted in high inequality and unemployment and lack of infrastructure and thus rising migration flows. Below I argue for public investments in source areas of migration, which would expand the range of livelihood strategies people can draw on.

Focusing on a somewhat broader perspective than transition, a policy maker in a developing country would be interested in the relationship between development and migration and vice versa. Development's impact on migration was discussed in this dissertation (see above), whereas the effect of migration on development was not considered extensively. Briefly coming to internal migration's impact on 
development, I found that, on a household level, migration has a positive impact on income in the short term and possibly positive and broader impact in the medium term. Individual improvement is beneficial to development. Continuous family transfers facilitate and make migration as an investment possible. Therefore interfamily transfers (i.e. internal and international remittances) should be facilitated. Strong family relationships should thus be encouraged (e.g. by allowing kin of already settled migrant families to join them). The more negative effects of migration were discussed in great detail, but it is not clear whether these would hinder development. In any case, improving the living conditions of internal migrants would be to the benefit of the wider population (see below).

An obvious, but crucial policy lesson that can be drawn from this dissertation is that if governments want to influence migration flows or the effects of migration (for example channelling remittances towards certain kinds of investments) they first have to understand the motives of migrants and remitters. I have shown that the considerations to migrate and to possibly remit are highly personal and depend on an individual's specific family and community environment. Therefore it is of utmost importance to understand the decision making process of different migrant groups in a country to make policies work.

Furthermore I advocate the improvement of institutions in source areas of migrants. These general policies targeted at the whole population are to the benefit of non-migrants, migrants and potential migrants. I have explained how failing labour and credit markets and public institutions entails individuals not being able to support their family or use their skills adequately. I also show that migrants respond to these policy gaps and failures through migration and family transfers. I certainly do not want to make a judgement on whether migration can or should be stopped, but the potential role for policy interventions in improving local and national institutions and thus creating more opportunities for varied livelihoods at home is great. Many potential policies come to mind, none easy to implement, like more employment possibilities, access to credit and social transfers. Such policy interventions do not exclude migration as a household strategy. However, the more options households can draw on, the better positioned they are to fight poverty.

My final policy recommendation, targeted particularly at migrant households, is based on improving living conditions of internal migrants. I have shown how the impact of internal migration can be rather negative. Inequality and mutual distrust is high between old residents and newly settled migrants and therefore not just migrants would benefit from improved circumstances for migrants. The policy recommendations here are evident: Create more local infrastructure (roads, more schools, access to health) and improve employment conditions (e.g. by clarifying legal status of migrants). Having better access to health, education, employment and living in better living conditions can make migration a better investment and at an earlier stage. 



\section{References}

Abadie, A., \& Imbens, G. W. (2006). On the Failure of the Bootstrap for Matching Estimators. NBER Working Paper (T0325).

Adams Jr, R. H. (2006). International remittances and the household: analysis and review of global evidence. Journal of African Economies, 15 (Supplement 2), 396.

Adams Jr, R. H., \& Page, J. (2005). Do international migration and remittances reduce poverty in developing countries? World Development, 33(10), 1645-1669.

Adelman, I., Taylor, J. E., \& Vogel, S. (1988). Life in a Mexican village: A SAM perspective. Journal of Development Studies, 25(1).

Agarwal, R., \& Horowitz, A. W. (2002). Are international remittances altruism or insurance? Evidence from Guyana using multiple-migrant households. World Development, 30(11), 2033-2044.

Agorastakis, M., \& Sidiropoulos, G. (2007). Population Change due to Geographic Mobility in Albania, 1989-2001, and the Repercussions of Internal Migration for the Enlargement of Tirana. Population, Space and Place, 13(6), 471- 481.

Al-Ali, N., Black, R., \& Koser, K. (2001). Refugees and transnationalism: the experience of Bosnians and Eritreans in Europe. Journal of Ethnic and Migration Studies, 27(4), 615-634.

Amuedo-Dorantes, C., \& Pozo, S. (2006). Remittances as insurance: evidence from Mexican immigrants. Journal of Population Economics, 19(2), 227-254.

Banerjee, B. (1983). The Role of the Informal Sector in the Migration Process: A Test of Probabilistic Migration Models and Labour Market Segmentation for India. Oxford Economic Papers, 35(3), 399-422.

Banerjee, B. (1984). Information flow, expectations and job search : Rural-to-urban migration process in India. Journal of Development Economics, 15(1-3), 239-257.

Barjaba, K., \& King, R. (2005). Introducing and theorising Albanian migration. In R. King, N. Mai \& S. Schwandner (Eds.), New Albania Migrantion: Brighton: Sussex Academic Press.

Becker, G. S. (1974). A theory of social interactions. Journal of Political Economy 82(6), 1063.

Becker, G. S. (1976). Altruism, Egoism, and Genetic Fitness: Economics and Sociobiology. Journal of Economic Literature 14(3), 817-826.

Becker, G. S. (1991). A Treatise on the Family. Cambridge, Mass.: Harvard University Press.

Beegle, K., Weerdt, J. d., \& Dercon, S. (2008). Migration and Economic Mobility in Tanzania: Evidence from a Tracking Survey. World Bank Policy Research Working Paper 4798.

Bell, M., \& Muhidin, S. (2009). Cross-National Comparison of Internal Migration. United Nations Development Programme Human Development Reports Research Paper 2009/ 30. 
Bengtson, V. L., \& Roberts, R. E. L. (1991). Intergenerational solidarity in aging families: An example of formal theory construction. Journal of Marriage and the Family, 53(November), 856-870.

Bigsten, A. (1988). A Note on the Modelling of Circular Smallholder Migration. Economics Letters, 28, 87-91.

Black, R., King, R., \& Tiemoko, R. (2003). Migration, return and small enterprise development in Ghana: a route out of poverty? Sussex Migration Working Paper no. 9.

Blumberg, L., \& Bell, R. R. (1959). Urban migration and kinship ties. Social Problems, 328-333.

Borjas, G. J. (1987). Self-selection and the earnings of immigrants. The American Economic Review, 531-553.

Borjas, G. J. (1991). Immigration and Self-Selection. In J. M. Abowd \& R. B. Freeman (Eds.), Immigration, trade, and the labor market (pp. 29). Chicago: Chicago University Press.

Borjas, G. J. (1999). The economic analysis of immigration. In O. Ashenfelter \& D. Card (Eds.), Handbook of labor economics (Vol. 3, pp. 1697-1760). Amsterdam: Elsevier.

Boyd, M. (1989). Family and Personal Networks in International Migration: Recent Developments and New Agendas. International Migration Review, 23(3), 638-670.

de la Briere, B., Janvry, A. d., Lambert, S., \& Sadoulet, E. (1997). Why do migrants remit? An analysis for the Dominican Sierra. FCND Discussion Paper 37.

Brown, R. P. C. (1997). Estimating remittance functions for Pacific Island migrants. World Development, 25(4), 613-627.

Cabiri, Y. (2002). Human Development Report Albania 2002. Albania: Human Development Promotion Centre.

Caldwell, J. C. (1976) Toward a restatement of demographic transition theory. Population and Development Review 2(3), 321-366.

Carletto, C., Davis, B., Stampini, M., Trento, S., \& Zezza, A. (2004). Internal Mobility and International MIgration in Albania. ESA Working Paper 04(13).

Carling, J. (2002). Migration in the age of involuntary immobility: theoretical reflections and Cape Verdean experiences. Journal of Ethnic and Migration Studies, 28(1), 5-42.

Carling, J. (2008). The determinants of migrant remittances. Oxford Review of Economic Policy, 24(3), 582.

Cattaneo, C. (2006). The Determinants of Actual Migration and the Role of Wages and Unemployment in Albania: an Empirical Analysis. LIUC Working Paper 196.

CBS-AXA, C. (2005). Migration and Remittances in Moldova. Chisinau.

Chimhowu, A., Piesse, J., \& Pinder, C. (2005). The socioeconomic impact of remittances on poverty reduction. Remittances: Development impact and future prospects, 83-102. 
Chiquiar, D., \& Hanson, G. H. (2005). International migration, self-selection, and the distribution of wages: Evidence from Mexico and the United States. Journal of Political Economy, 113(2), 239-281.

Choldin, H. M. (1973). Kinship networks in the migration process. International Migration Review, 7(2), 163-175.

Cila, J. (2006). Making a Livelihood A study of rural migrants in Bathore, Tirana: Erasmus University Rotterdam.

Cox, D. (1987). Motives for private income transfers. The Journal of Political Economy, 508-546.

Cox, D., Eser, Z., \& Jimenez, E. (1998). Motives for private transfers over the life cycle: An analytical framework and evidence for Peru. Journal of Development Economics, 55(February), 57-80.

Cox, D., \& Fafchamps, M. (2007) Extended family and kinship networks: Economic insights and evolutionary directions. Handbook of Development Economics 4, 37113784.

Cox, D., Hansen, B. E., \& Jimenez, E. (2004). How responsive are private transfers to income? Evidence from a laissez-faire economy. Journal of Public Economics, 88(910), 2193-2219.

Cox, D., Jimenez, E., \& Okrasa, W. (1997). Family safety nets and economic transition: A study of worker households in Poland. Review of Income and Wealth, 43(2), 191-209.

Cox, D., \& Stark, O. (1994). Intergenerational transfers and the demonstration effect. Boston College Working Papers in Economics 329.

Craciun, C. (2006). Migration and Remittances in the Republic of Moldova: Empirical Evidence at Micro Level. National University "Kyiv-Mohyla Academy".

Crawford, T. (1973). Beliefs About Birth Control: A Consistency Theory Analysis. Representative Research in Social Psychology, 4, 53-65.

Cuc, M., Lundbäck, E., \& Ruggiero, E. (2005). Migration and Remittance in Moldova. Washington, D.C.: International Monetary Fund.

Danzer, A. M., \& Dietz, B. A. (2009). Temporary Labour Migration and Welfare at the New European Fringe: A Comparison of Five Eastern European Countries. IZA Discussion Paper No. 4142.

DaVanzo, J. (1981). Repeat migration, information costs, and location-specific capital. Population \& Environment, 4(1), 45-73.

Davin, D. (1999). Internal Migration in Contemporary China: Palgrave MacMillan.

Deda, L., \& Tsenkova, S. (2006). Poverty and inequality in Greater Tirana: The reality of peri-urban areas. In S. Tsenkova \& Z. Nedovic-Budic (Eds.), The Urban Mosaic of Post-Socialist Europe (pp. 151-170). Heidelberg: Physica Verlag Dercon, S. (2005). Insurance Against Poverty. Oxford: Oxford University Press. DISSS. (2009). Europe Shapefiles. Case Definitions for Infectious Diseases. Web Site. Docquier, F., \& Rapoport, H. (1998). Are migration minorities strategically selfselcted? Population Economics, 11, 579-588. 
Duke-Williams, O. (2009). Internal migration and inter-household relationships. In J. Stillwell, E. Coast \& D. Kneale (Eds.), Fertility, Living Arrangements, Care and Mobility, Understanding Population Trends and Processes Heidelberg: Springer Science+Business Media

Durand, J., Kandel, W., Parrado, E. A., \& Massey, D. S. (1996). International migration and development in Mexican communities. Demography, 33(2), 249-264.

Dustman, C., \& Kirchkamp, O. (2002). The optimal migration duration and activity choice after re-migration. Journal of Development Economics, 67, 663-674.

Edwards, A. C., \& Ureta, M. (2003). International migration, remittances, and schooling: evidence from El Salvador. NBER Working Paper 9766.

Faist, T. (1997). The Crucial Meso-Level. In T. Hammer, G. Brochmann, K. Tamas \& T. Faist (Eds.), International Migration, Immobility and Development. Oxford: Berg Publishers

Faist, T. (2000). The Volume and Dynamics of International Migration and Transnational Social Spaces. Oxford: Clarendon Press.

Fawcett, J. T. (1989). Networks, Linkages, and Migration Systems. International Migration Review, 23(3), 671-680.

Fischer, P. A., Martin, R., \& Straubhaar, T. (1997). Should I Stay or Should I Go? In T. Hammer, G. Brochmann, K. Tamas \& T. Faist (Eds.), International Migration, Immobility and Development. Oxford: Berg Publishers

Foster, A. D., \& Rosenzweig, M. R. (2001). Imperfect Commitment, Altruism, and the Family: Evidence from Transfer Behaviour in Low-Income Rural Areas. The Review of Economics and Statistics, 83(3), 389-407.

Foster, J., Greer, J., \& Thorbecke, E. (1984). A class of decomposable poverty measures. Econometrica, 52, 761-766.

Funkhouser, E. (1995). Remittances from International Migration: A Comparison of El Salvador and Nicaragua. The Review of Economics and Statistics, 77(1), 137.

Germenji, E., Beka, I., \& Sarris, A. (2001). Estimating remittance functions for ruralbased Albanian emigrants. Working paper, ACE research project, P97-8158-R.

Germenji, E., \& Swinnen, J. F. M. (2004). Impact of Remittances on HouseholdBased Farms in Rural Albania: Katholieke Universiteit Leuven.

Gibson, J., McKenzie, D., \& Stillman, S. (2009). The Impacts of International Migration on Remaining Household Members: Omnibus Results from a Migration Lottery Program. World Bank Policy Research Working Paper No. 4956

Görlich, D., Mahmoud, T. O., \& Trebesch, C. (2007). Explaining Labour Market Inactivity in Migrant-Sending Families: Housework, Hammock, or Higher Education: Kiel Working Paper 1391 (Kiel: Kiel Institute for the World Economy).

Görlich, D., \& Trebesch, C. (2008). Mass Migration and Seasonality Evidence on Moldova's Labour Exodus. Review of World Economics, 144(1), 107-133.

Goss, J., \& Lindquist, B. (1995). Conceptualizing International Labour Migration: A Structuration Perspective. International Migration Review, 29(2), 317-351.

Government of the Republic of Moldova. (2006). Annual Evaluation Report on the Implementation of the Economic Growth and Poverty reduction Strategy, 2005. Chisinau: Government of the Republic of Moldova. 
Gubert, F. (2000). Migration, Remittances and Moral Hazard. Evidence from the Kayes Area (Western Mali). CERDI Working Papers 2000/17.

Gubert, F. (2002). Do migrants insure those who stay behind? Evidence from the Kayes area (Western Mali). Oxford Development Studies, 30(3), 267-287.

Guilmoto, C. Z., \& Sandron, F. (2001). The Internal Dynamics of Migration Networks in Developing Countries. Population: An English Selection, 13(2), 135-164.

Gurak, D. T., \& Caces, F. (1992). Migration Networks and the Shaping of Migration Systems. International Migration Systems: A Global Approach, 150-176.

Haan, A. d., Brock, K., \& Coulibaly, N. (2002). Migration, livelihoods and institutions: contrasting patterns of migration in Mali. Labour Mobility and Rural Society Labour Mobility and Rural Society, 38(5), 37-58.

Hagen-Zanker, J., Siegel, M., \& de Neubourg, C. (2009). Strings attached: The impediments to migration in Albania and Moldova. The Journal of Southeast European and Black Sea Studies, 9(4).

Halliday, T. (2006). Migration, Risk and Liquidity Constraints in El Salvador. University of Hawaii at Manoa, Department of Economics Working Paper 05-11.

Hammar, T., Brochman, G., Tamas, K., \& Faist, T. (1997). International migration, immobility and development: multidisciplinary perspectives. New York: Berg Publishers.

Hanson, G. H. (2007). Emigration, Remittances, and Labor Force Participation in Mexico. Integration and Trade Journal, 27, 73-103.

Harbison, S. F. (1981). Family Structure and Family Strategy in Migration Decision Making. In G. d. Jong \& R. Gardner (Eds.), Migration Decision Making. New York: Pergamon Press.

Harris, J., \& Todaro, M. (1970). Migration, Unemployment and Development: A Two-Sector Analysis. The American Economic Review, 60, 126-142.

Harris, J. R., \& Sabot, R. (1982). Urban unemployment in LDCs: towards a more general search model. In R. Sabot (Ed.), Migration and Labor Market in Developing Countries. Boulder, Colorado: Westview Press.

Haug, S. (2000). Klassischere und neuere Theorien der Migration (Classical and newer theories of migration). Arbeitspapiere- Mannheimer Zentrum fuer Europaeische Sozialforschung(30).

Hendrix, L. (1975). Kinship and economic-rational migration: a comparison of micro-and macro-level analyses. Sociological Quarterly, 16(4), 534-543.

Hoddinott, J. (1992). Modelling remittance flows in Kenya. Journal of African Economies, 1(2), 206-232.

Hoddinott, J. (1994). A Model of Migration and Remittances Applied to Western Kenya. Oxford Economic Papers, 46(3), 459-476.

Hoffmann-Nowotny, H.-J. (1981). A Sociological Approach Toward a General Theory of Migration. In M. Kritz, L. L. Lim \& H. Zlotnik (Eds.), Global Trends in Migration. New York: Centre for Migration Studies.

Hollifield, J. F. (2000). The Politics of International Migration. In C. B. Brettell \& J. F. Hollifield (Eds.), Migration Theory Talking Across Disciplines. New York: Routledge. 
Holst, E., \& Schrooten, M. (2006). Migration and money- What determines remittances? Evidence from Germany. Institute of Economic Research, Hitotsubashi University, Discussion Paper Series, 477.

IMF (2005). Republic of Moldova: Selected Issues. Washington, DC: International Monetary Fund.

IMF (2006). Albania: Selected Issues. Washington, D.C.: International Monetary Fund.

INSTAT (2002). The Population of Albania in 2001: Main Results of the Population and Housing Census. Tirana: INSTAT.

INSTAT (2004). Migration in Albania- Population and Housing Census 2001. Tirana: INSTAT.

IOM (2005). Migration, Development and Poverty Reduction in Asia. Geneva: International Organization for Migration.

IOM (2009). Migration in Moldova: A Country Profile 2008. Geneva: International Organization for Migration.

Issah, I., Khan, T. Y., \& Sasaki, K. (2005). Do Migrants React to Infrastructure Difference Between Urban and Rural Areas? Development of an Extended HarrisTodaro Model. RURDS, 17(1).

Itzigsohn, J. (1995). Migrant Remittances, Labor Markets, and Household Strategies: A Comparative Analysis of Low-Income Household Strategies in the Caribbean Basin. Social Forces, Vol. 72(No. 2).

Jitodai, T. T. (1963). Migration and kinship contacts. Pacific Sociological Review, $6(2), 49-55$.

Jong, G. D., \& Fawcett, J. (1981). Motivations for Migration: An Assessment and a Value-Expectancy Model. In G. D. Jong \& R. Gardner (Eds.), Migration Decision Making. New York: Pergamon Press.

Katz, E., \& Stark, O. (1986). Labor migration and risk aversion in less developed countries. Journal of Labor Economics, 134-149.

King, R. (2005). Albania as a laboratory for the study of migration and development. Journal of Southern Europe and the Balkans, 7(2).

King, R., Dalipaj, M., \& Mai, N. (2006). Gendering Migration and Remittances: Evidence from London and Northern Albania. Population, Space and Place, 12, 409434.

King, R., Skeldon, R., \& Vullnetari, J. (2008). Internal and International Migration: Bridging the Theoretical Divide. Paper presented at the IMISCOE Theories of Migration and Social Change Conference, Oxford.

Knight, J., \& Song, L. (1999). Chinese Rural Migrants in Urban Enterprises: Three Perspectives. Journal of Development Studies, 35(3), 73.

Konica, N. (2006). The Emigration Experience and its Impact on the Albania Economy in Early Transition Period. In D. Bezemer (Ed.), On Eagle's Wings: The Albanian Economy in Transition. New York: Nova Science Publishers.

Koser, K. (1997). Social networks and the asylum cycle: the case of Iranians in the Netherlands. International Migration Review, 591-611. 
Koser, K. (2007). International migration: a very short introduction. Oxford: Oxford University Press.

Kothari, U. (2003). Staying put and staying poor? Journal of International Development, 15(5), 645-657.

Kritz, M. M., \& Zlotnik, H. (1992). Global Interactions: Migration Systems, Processes, and Policies. In M. Kritz, L. L. Lim \& H. Zlotnik (Eds.), International Migration Systems A Global Approach. Oxford: Clarendon Press.

Kundu, A., \& Sarangi, N. (2007). Migration, Employment Status and Poverty An Analysis across Urban Centres. Economic and Political Weekly, 42(4), 299-306.

Lee, E. (1966). A Theory of Migration. Demography, 3(1), 47-57.

Lewis, W. A. (1954). Economic Development with Unlimited Supply of Labour. The Manchester School, 22(2), 139-191.

Lianos, T. P., \& Cavounidis, J. (2004). Immigrant remittances, stability of employment and relative deprivation. Paper presented at the New Perspectives on Albanian Migration and Development, Korçë, Albania.

Litwak, E. (1960). Geographic mobility and extended family cohesion. American Sociological Review, 25(3), 385-394.

Liu, Q., \& Reilly, B. (2004). Income transfers of Chinese rural migrants: some empirical evidence from Jinan. Applied Economics, 36(12), 1295-1313.

Long, J. S., \& Freese, J. (2001) Regression models for categorical dependent variables using Stata: Stata press College Station, TX.

Lucas, R. E. B., \& Stark, O. (1985). Motivations to Remit: Evidence from Botswana. The Journal of Political Economy, 93(5), 901-918.

Lücke, M., Mahmoud, T. O., \& Pinger, P. (2007). Patterns and Trends of Migration and Remittances in Moldova. Chisinau: International Organization for Migration.

Mabogunje, A. L. (1970). Systems Approach to a Theory of Rural-Urban Migration. Geographical Analysis, 2, 1-18.

Mancellari, A., Kule, D., Qirici, S., \& Sanfey, P. (2006). Labour Markets and Emigration in Albania. In D. Bezemer (Ed.), On Eagle's Wings: the Albanian Economy in Transition. New York: Nova Science Publishers.

Massey, D., Arango, J., Graeme Hugo, Kouaouci, A., Pellegrino, A., \& Taylor, E. (1993). Theories of International Migration: A Review and Appraisal. Population and Development Review, 19(3).

Massey, D. S. (1990). Social Structure, Household Strategies, and the Cumulative Causation of Migration. Population Index, 56(1), 3-26.

Massey, D. S., Arango, J., Hugo, G., Kouauci, A., Pellegrinp, A., \& Taylor, J. E. (1998). Worlds in Motion. Oxford: Clarendon Press.

McKenzie, D., \& Rapoport, H. (2007). Self-selection patterns in Mexico-US migration: the role of migrant networks. World Bank Policy Research Working Paper 4118.

McKenzie, D., \& Sasin, M. J. (2007). Migration, remittances, poverty, and human capital: conceptual and empirical challenges: The World Bank, Policy Research Working Paper Series: 4272. 
Meng, X., \& Zhang, J. (2001). The Two-Tier Labor Market in Urban China: Occupational Segregation and Wage Differentials between Urban Residents and Rural Migrants in Shanghai. Journal of Comparative Economics, 29(3), 485-504.

Miluka, J., Carletto, C., Davis, B., \& Zezza, A. (2007). The vanishing farms. The impact of international migration on Albanian family farming. World Bank Policy Research Working Paper 4367.

Mincer, J. (1978). Family Migration Decisions. Journal of Political Economy, 86(5), 749-773.

Mohtadi, H. (1986). Rural stratification, rural to urban migration, and urban inequality: Evidence from Iran. World Development, 14(6), 713-725.

Morokvasic, M. (1984). Birds of Passage are also Women. International Migration Review, 18(4), 886-907.

Morris, S., Carletto, C., Hoddinott, J., \& Christiaensen, L. J. M. (1999). Validity of Rapid Estimates of Household Wealth and Income for Health Surveys in Rural Africa. Food and Consumption Division Discussion Paper No. 72.

Morrison, A. R. (1994). Capital Market Imperfections, Labor Market Disequilbrium and Migration: A Theoretical and Empirical Analysis. Economic Inquiry, 32(2), 290302.

Nakosteen, R. A., \& Zimmer, M. (1980). Migration and income: the question of selfselection. Southern Economic Journal, 46(3), 840-851.

Negri, M., \& Porto, G. G. (2008). Burley Tobacco Clubs in Malawi: Nonmarket Institutions for Exports. World Bank Policy Research Working Paper, 2008(4561).

de Neubourg, C., \& Weigand, C. (2000). Social Policy as Social Risk Management. Innovation: The European Journal of Social Sciences, 13(4), 401-412.

de Neubourg, C. (2002). The Welfare Pentagon and the Social Management of Risks. In R. Sigg \& C. Behrendt (Eds.), Social security in the global village. New Brunswick, New Jersey: Transaction Publishers.

Niimi, Y., Pham, T. H., \& Reilly, B. (2008). Determinants of Remittances: Recent Evidence Using Data on Internal Migrants in Vietnam. World Bank Policy Research Working Paper, 4586.

Osaki, K. (2003). Migrant remittances in Thailand: Economic necessity or social norm. Journal of Population Research, 20(2), 203-222.

Piore, M. J. (1979). Birds of passage: migrant labor and industrial societies: Cambridge University Press.

Pleitez Chavez, R. A. (2004). Remittances as a Strategy to Cope With Systemic Risk: Panel Results from Rural Households in El Salvador. Unpublished PhD, Ohio State University, Columbus.

Poirine, B. (1997). A theory of remittances as an implicit family loan arrangement. World Development, 25(4), 589-611.

Poirine, B. (2006). Remittances sent by a growing altruistic diaspora: How do they grow over time? Asia Pacific Viewpoint, 47(1), 93-108.

Ranis, G., \& Fei, J. C. H. (1961). A Theory of Economic Development. The American Economic Review, 51(4), 533-565. 
Rapoport, H., \& Docquier, F. (2005). The Economics of Migrants' Remittances. IZA Discussion Paper Series No.1531.

Ravenstein, E. G. (1885). The Laws of Migration. Journal of the Statistical Society of London, 48(2), 167-235.

Ritchey, P. N. (1976). Explanations of Migration. Annual Review of Sociology, 2, 363404.

Rosenbaum, P. R., \& Rubin, D. B. (1983). The central role of the propensity score in observational studies for causal effects. Biometrika, 70(1), 41-55.

Rosenzweig, M. R. (1988). Risk, Implicit Contracts and the Family in Rural Areas of Low-Income Countries. The Economic Journal, 98(December 1988), 1148-1170.

Roy, A. D. (1951). Some Thoughts on the Distribution of Earnings. Oxford Economic Papers, 3(2), 135-146.

Ruan, D., Freeman, L. C., Dai, X., Pan, Y., \& Zhang, W. (1997). On the changing structure of social networks in urban China. Social Networks, 19(1), 75-89.

Rubin, D. B. (1974). Estimating Causal Effects of Treatments in Randomized and Nonrandomized Studies. Journal of Educational Psychology, 66(5), 688-701.

Rubin, D. B. (1978). Bayesian inference for causal effects: The role of randomization. Annals of Statistics, 6(1), 34-58.

Sana, M., \& Massey, D. S. (2005). Household Composition, Family Migration, and Community Context: Migrant Remittances in Four Countries. Social Science Quarterly, 86(2), 509-528.

Sandell, P. (editor). (2007) Geographica World Atlas \& Encyclopedia. Koenigswinter: Tandem Verlag.

Sandell, S. H. (1977). Women and the Economics of Family Migration. The Review of Economics and Statistics, 59(4), 406-414.

Schrieder, G., \& Knerr, B. (2000). Labour Migration as a Social Security Mechanism for Smallholder Households in Sub-Saharan Africa: The Case of Cameroon. Oxford Development Studies, 28(2), 223-236.

Secondi, G. (1997). Private Monetary Transfers in Rural China: Are Families Altruistic? Journal of Development Studies, 33(4), 487-511.

Shaokang, Z., Zhenwei, S., \& Blas, E. (2002). Economic transition and maternal health care for internal migrants in Shanghai, China. Health Policy and Planning, 17(90001), 47-55.

Sjaastad, L. (1962). The Costs and Returns of Human Migration. Journal of Political Economy, 70(5), 80-93.

Smith, A. J., \& Todd, E. P. (2005). Does matching overcome LaLonde's critique of nonexperimental estimators? Journal of Econometrics, 125(1-2), 305-353.

de Soto, H., Gordon, P., Gedeshi, I., \& Sinoimeri, Z. (2002). Poverty in Albania. A Qualitative Assessment. Washington: World Bank.

Staiger, D., \& Stock, J., H. (1997). Instrumental Variables Regression with Weak Instruments. Econometrica, 65(3), 557-586. 
Stark, O. (1995). Altruism and beyond: An economic anaysis of transfers and exchanges within families and groups. Cambridge, MA: Cambridge University Press.

Stark, O., \& Bloom, D. E. (1985). The New Economics of Labour Migration. American Economic Review, 75, 173-178.

Stark, O., \& Levhari, D. (1982). On Migration and Risk in LDCs. Economic Development and Cultural Change, 31(1), 191-196.

Stark, O., \& Lucas, R. E. B. (1988). Migration, Remittances, and the Family. Economic Development and Cultural Change, 36(3), 465-481.

Stark, 0., \& Wang, W. Q. (2002). Migration dynamics. Economics Letters, 76, 159164.

Taylor, J. E. (1986). Differential migration, networks, information and risk. In 0. Stark (Ed.), Research in human capital and development (Vol. 4, pp. 147-171). Greenwich, Connecticut: JAI Press.

Taylor, J. E. (1999). The New Economics of Labour Migration and the Role of Remittances in the Migration Process. International Migration, 37(1).

Taylor, J. E., \& Fletcher, P. L. (2001). Remittances and Development in Mexico: The New Labour Economics of Migration: a Critical Review. Rural Mexico Research Project, 2.

Todaro, M. (1969). A Model of Labor Migration and Urban Unemployment in Less Developed Countries. The American Economic Review, 59(March 1969), 138-148.

Tunali, I. (2000). Rationality of Migration. International Economic Review, 41(4), 893-920.

Vanwey, L. K. (2004). Altruistic and contractual remittances between male and female migrants and households in rural Thailand. Demography, 739-756.

Vishwanath, T. (1991). Information flow, job search, and migration. Journal of development economics, 36(2), 313-336.

Vullnetari, J. (2007). Albanian migration and development: state of the art review. IMISCOE Working Paper 18.

Vullnetari, J., \& King, R. (2008). 'Does your granny eat grass?' On mass migration, care drain and the fate of older people in rural Albania. Global Networks, 8(2), 139171.

Vuong, Q. H. (1989) Likelihood ratio tests for model selection and non-nested hypotheses. Econometrica 57(2), 307-333.

Wallerstein, I. (1974). The Modern World-system: Academic Press New York.

Weesie, J. (1999) Seemingly unrelated estimation and the cluster-adjusted sandwich estimator. Stata Technical Bulletin 52, 34-47.

Wellman, B., Wong, R. Y., Tindall, D., \& Nazer, N. (1997). A decade of network change: Turnover, persistence and stability in personal communities. Social Networks, 19(1), 27-50.

Wilpert, C. (1992). The use of social networks in Turkish migration to Germany. In M. M. Kritz, L. L. Lim \& H. Zlotnik (Eds.), International migration systems: a global approach (pp. 177-189). Oxford: Clarendon Press. 
Wolpert, J. (1965). Behavioural Aspects of the Decision to Migrate. Papers of the Regional Science Association, 15, 159-169.

Wooldridge, J. M. (2002) Introductory Econometrics. Mason, OH Thomson Learning. World Bank (2003). Albania: Poverty Assessment. Tirana: World Bank Human Development Sector Unit Europe and Central Asia Region.

World Bank (2004) Albania sustaining growth beyond transition. Washington: World Bank.

World Bank (2006). Global Economic Prospects: Economic Implications of Remittances and Migration: 2006: Washington, D.C.: World Bank.

World Bank (2007). Albania Urban Growth, Migration and Poverty Reduction (No. 40071-AL). Washington: World Bank.

World Bank (2008). Gross domestic product 2007. Retrieved June 2009, from website

Yamauchi, F., \& Tanabe, S. (2006). Nonmarket networks among migrants: evidence from metropolitan Bangkok, Thailand. Journal of Population Economics, 1-16.

Yap, L. (1977). The Attraction of Cities: A Review of the Migration Literature. Journal of Development Economics, 4(3), 239-264.

Zelinsky, W. (1971). The Hypothesis of the Mobility Transition. Geographical Review, 61(2), 219-249.

Zezza, A., Carletto, G., \& Davis, B. (2005). Moving away from poverty: a spatial analysis of poverty and migration in Albania. Journal of Southern Europe and the Balkans, 7(2).

Zipf, G. (1946). The PP/D hypothesis: on the Intercity Movement of Persons. American Sociological Review, 11, 677-686.

Zolberg, A. (1981). International Migration in Political Perspective. In M. Kritz, L. L. Lim \& H. Zlotnik (Eds.), Global Trends in Migration. New York: Centre for Migration Studies.

Zwager, N. d., Gedeshi, I., Germenji, E., \& Nikas, C. (2005). Competing For Remittances: International Organisation for Migration Tirana. 



\section{A Appendix to \\ Chapter 3}

Table A.1 Effects for the probability to remit

\begin{tabular}{|c|c|c|c|c|c|c|c|c|c|c|c|c|c|c|c|c|}
\hline $\begin{array}{l}\text { Effect of ... on } \\
\text { probability of } \\
\text { remittances }\end{array}$ & 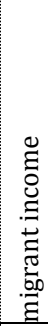 & 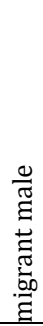 & 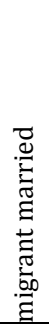 & 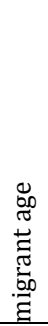 & 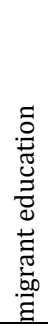 & 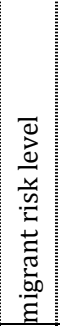 & 宽 & 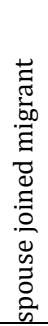 & 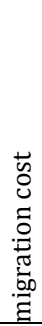 & 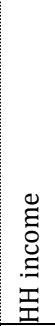 & 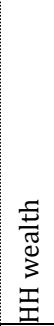 & 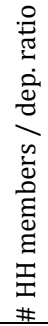 & 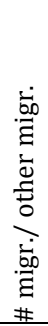 & 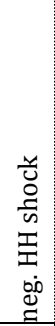 & 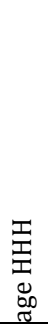 & 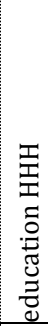 \\
\hline $\begin{array}{l}\text { Agarwal \& Horowitz } \\
\text { (2002) } \\
\text { Guyana }\end{array}$ & & $x$ & & & + & $x$ & +1 & & & 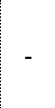 & - & - & - & & $x$ & $x$ \\
\hline $\begin{array}{l}\text { Banerjee (1984) } \\
\text { India }\end{array}$ & + & & & & $\mathrm{x}$ & & + & - & & & & + & & & & \\
\hline $\begin{array}{l}\text { Cai (2003) } \\
\text { China* }^{*}\end{array}$ & + & - & & $x$ & $x$ & + & + & & $+^{2}$ & & $x$ & $x$ & & & & \\
\hline $\begin{array}{l}\text { Crăciun (2006) } \\
\text { Moldova }\end{array}$ & & $\mathrm{x}$ & $\mathrm{x}$ & $\mathrm{x}$ & $\mathrm{x}$ & & $+/-$ & & & & & & & $t^{3}$ & & \\
\hline $\begin{array}{l}\text { Durand et al (1996) } \\
\text { Mexico, [Remittances \& } \\
\text { savings] }\end{array}$ & $\mathrm{x}$ & & + & + & - & $\mathrm{x}^{4}$ & $\mathrm{x}$ & - & + & & -5 & $x$ & & & & \\
\hline $\begin{array}{l}\text { Funkhouser(1995) } \\
\text { El Salvador \& Nicaragua }\end{array}$ & $x^{6}$ & $\mathrm{x}$ & & $\mathrm{x}$ & $x$ & & $x$ & $x$ & & & & & $\mathrm{x}$ & & & \\
\hline $\begin{array}{l}\text { Germenji et al (2001) } \\
\text { Albania }\end{array}$ & $\mathrm{x}$ & $x$ & & & & & & & $\mathrm{x}$ & - & $\mathrm{x}$ & $\mathrm{x}$ & + & & $\mathrm{x}$ & $x$ \\
\hline $\begin{array}{l}\text { Hoddinott (1994) } \\
\text { Western Kenya }\end{array}$ & & & & & + & & & & & & + & $x$ & & & & + \\
\hline $\begin{array}{l}\text { Holst \& Schrooten } \\
(2006) \\
\text { Migrants in Germany }\end{array}$ & $\begin{array}{r}+7 / \\
x^{8}\end{array}$ & + & + & + & + & & & & & & -9 & $\mathrm{x}$ & & & & \\
\hline $\begin{array}{l}\text { Itzigsohn (1995) } \\
\text { Jamaica, Haiti, } \\
\text { Dominican Republic \& } \\
\text { Guatemala }\end{array}$ & & & $\mathrm{x}$ & & & & & & & $\begin{array}{l}1+/ \\
x^{10}\end{array}$ & & + & & & $\mathrm{x}$ & $+/$ \\
\hline Konica (2006) & & + & & $\mathrm{x}$ & & - & + & - & & & & & - & & & \\
\hline Albania & & & & & & & & & & & & & & & & \\
\hline $\begin{array}{l}\text { Liu Reilly (2004) } \\
\text { China* }\end{array}$ & + & & $\mathrm{x}$ & $\mathrm{x}$ & & + & - & - & + & & & $\mathrm{x}$ & & & & \\
\hline
\end{tabular}




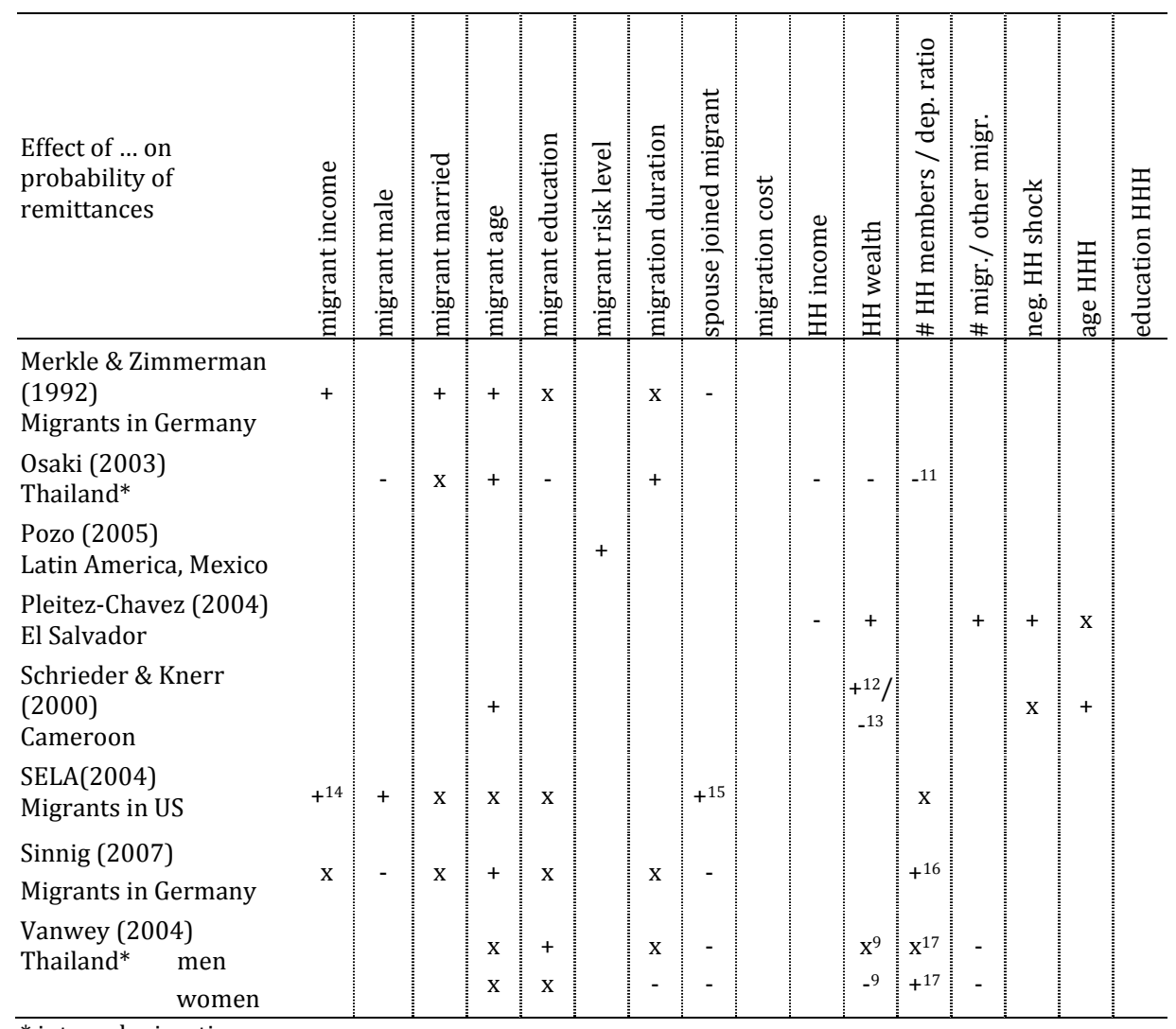

* internal migration

+ positive effect; - negative effect; $\mathrm{x}$ included in regression but not significant

$1>1$ year

2 brought money when migrated

${ }^{3}$ unemployment

4 taxes withheld

5 business owned

${ }^{6}$ employment

${ }^{7}$ migrants in Germany

8 income

${ }^{9}$ real estate owned

${ }^{10}$ depends on country

11 no. children

12 property

13 other wealth variables

14 employment

${ }^{15}$ home visits $>=1$

16 no. children

${ }^{17}$ no. elderly 


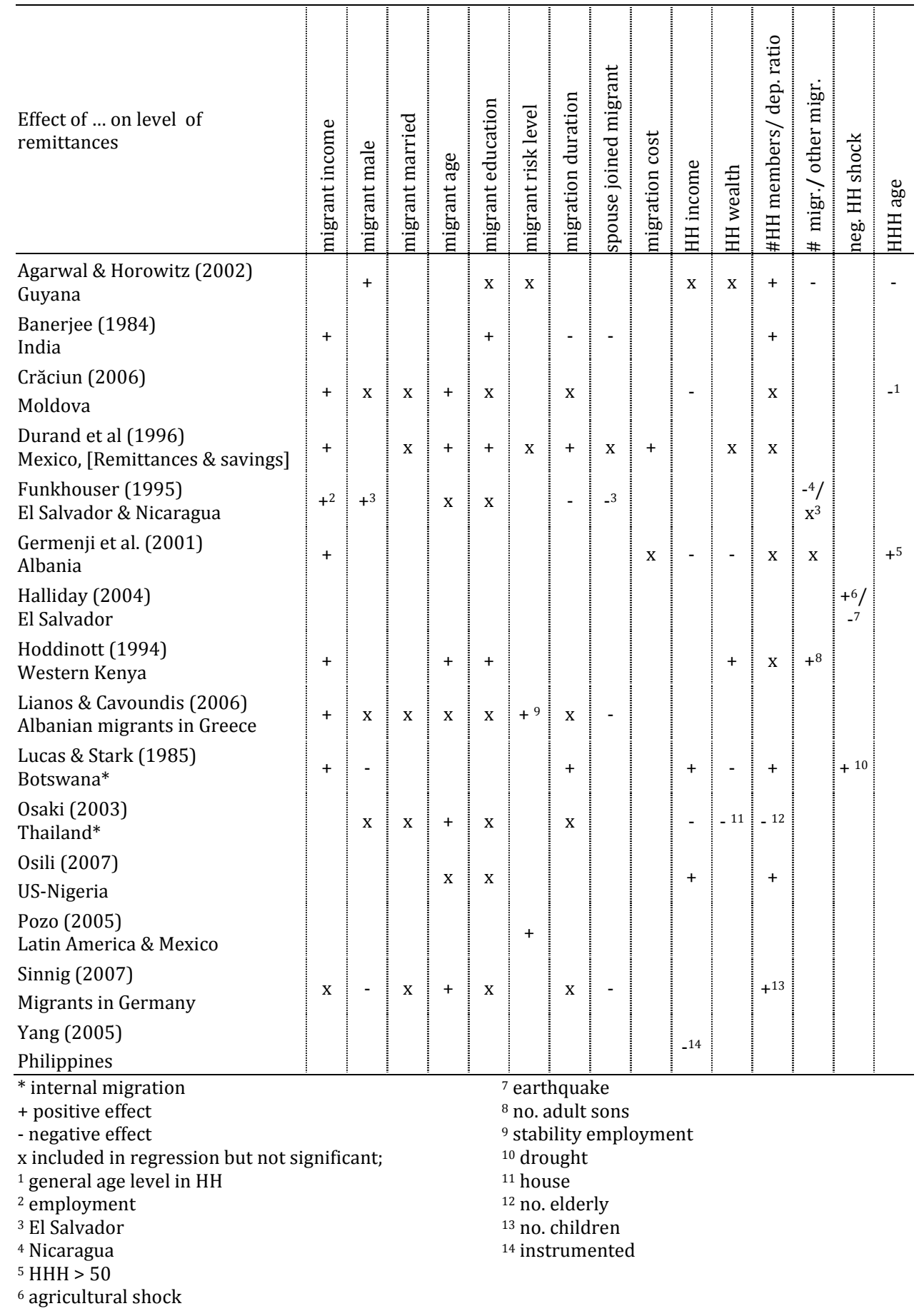


Table A.3 Effects for the joint solution of probability \& level of remittances (Tobit)

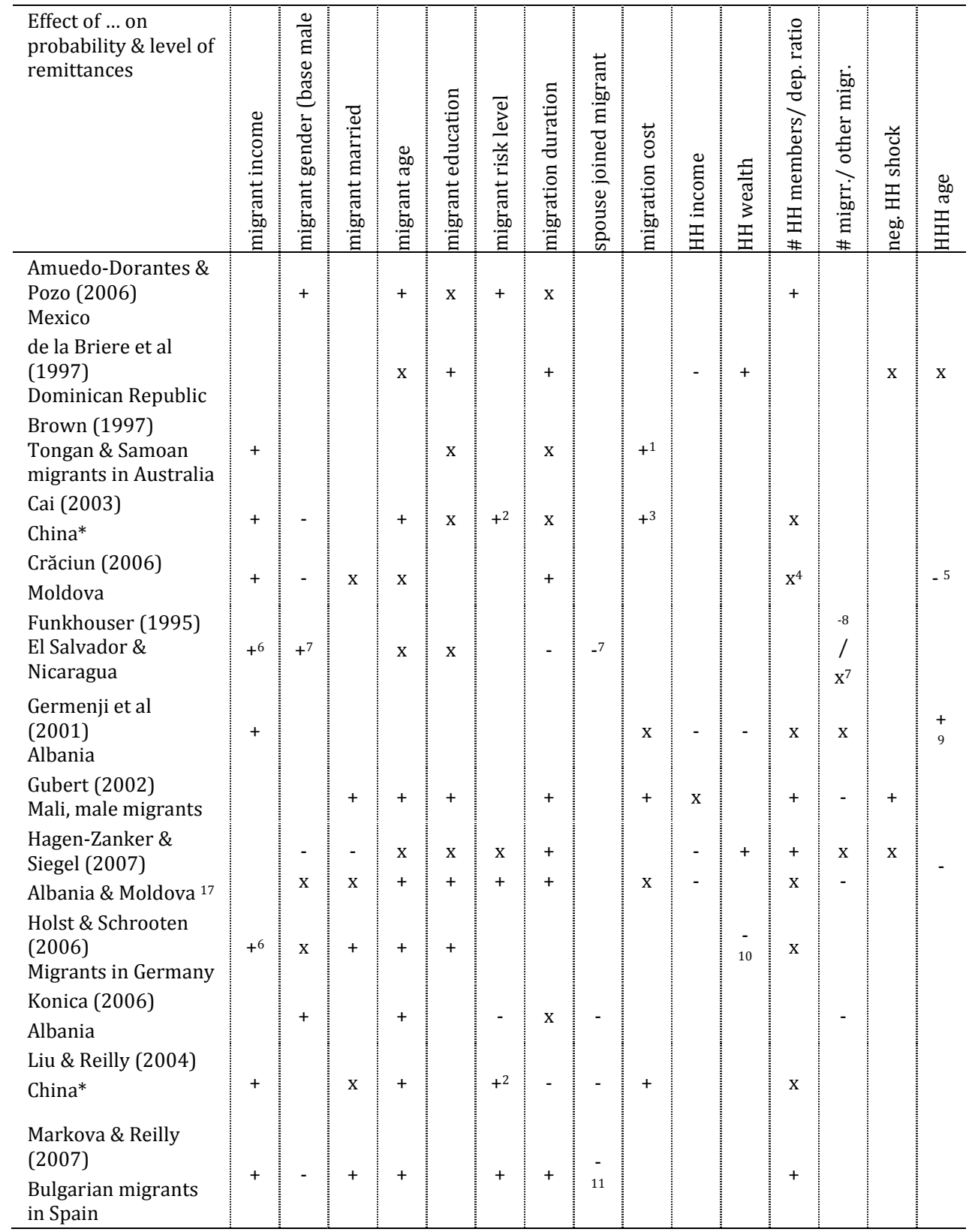




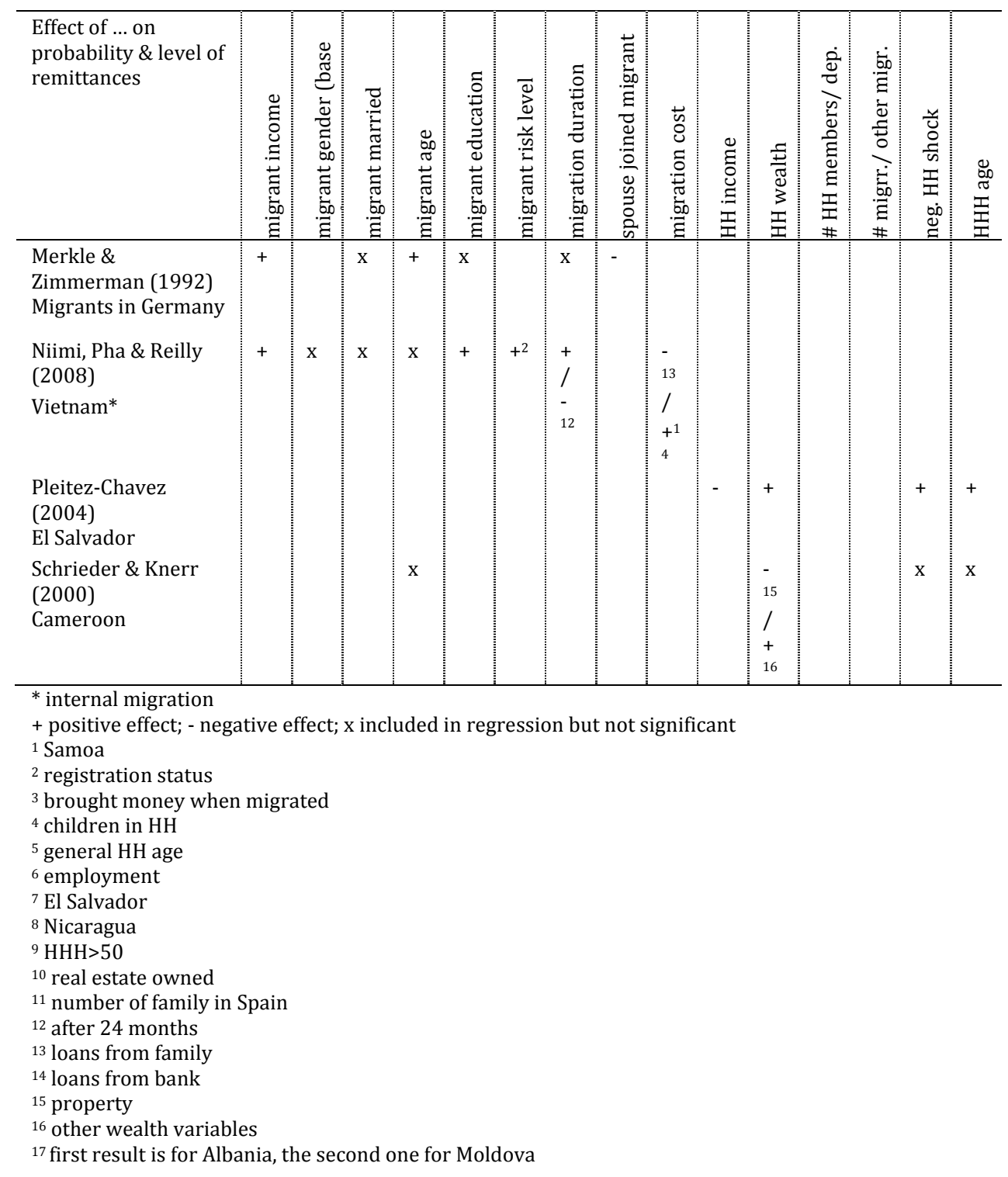



Appendix to
Chapter 4

B.1 Summary statistics for Section 4.4

Table B.1 Summary statistics for Moldova

\begin{tabular}{|c|c|c|c|c|c|}
\hline Variable & Obs & Mean & Std. Dev & Min & Max \\
\hline Migrant & 11702 & 0.15 & 0.36 & 0 & 1 \\
\hline Age & 11583 & 41.00 & 18.00 & 16 & 100 \\
\hline Male & 11671 & 0.46 & 0.50 & 0 & 1 \\
\hline Married & 11663 & 0.64 & 0.48 & 0 & 1 \\
\hline Household head male & 11702 & 0.80 & 0.40 & 0 & 1 \\
\hline Household head age & 11702 & 51.74 & 13.65 & 16 & 100 \\
\hline Household head married & 11700 & 0.80 & 0.40 & 0 & 1 \\
\hline \# Children in household & 11702 & 0.59 & 0.87 & 0 & 8 \\
\hline Primary & 11457 & 0.14 & 0.34 & 0 & 1 \\
\hline Secondary & 11457 & 0.35 & 0.48 & 0 & 1 \\
\hline Vocational & 11457 & 0.30 & 0.46 & 0 & 1 \\
\hline University & 11457 & 0.21 & 0.41 & 0 & 1 \\
\hline Urban & 11702 & 0.36 & 0.48 & 0 & 1 \\
\hline HH size & 11702 & 3.79 & 1.57 & 1 & 13 \\
\hline Morris index & 11702 & 0.68 & 1.17 & 0 & 13.27 \\
\hline $\begin{array}{l}\text { Adults employed in the } \\
\text { hh ratio }\end{array}$ & 11702 & 0.20 & 0.26 & 0 & 1 \\
\hline $\begin{array}{l}\text { Household head } \\
\text { employed }\end{array}$ & 11665 & 0.21 & 0.40 & 0 & 1 \\
\hline $\begin{array}{l}\text { Community's migrant } \\
\text { share }\end{array}$ & 11702 & 0.07 & 0.05 & 0 & 0.27 \\
\hline
\end{tabular}


Table B.2 Summary statistics for Albania

\begin{tabular}{|c|c|c|c|c|c|}
\hline & Obs & Mean & Std. dev. & Min & $\operatorname{Max}$ \\
\hline Migrant & 11744 & 0.09 & 0.28 & 0 & 1 \\
\hline Age & 11744 & 41.01 & 18.29 & 15 & 105 \\
\hline Gender male & 11744 & 0.46 & 0.50 & 0 & 1 \\
\hline Married & 11744 & 0.65 & 0.48 & 0 & 1 \\
\hline $\mathrm{HH}$ lives in urban area & 11744 & 0.55 & 0.50 & 0 & 1 \\
\hline HHH age & 11744 & 52.52 & 12.50 & 16 & 96 \\
\hline HHH male & 11744 & 0.93 & 0.26 & 0 & 1 \\
\hline HHH married & 11744 & 0.91 & 0.29 & 0 & 1 \\
\hline \# Children in $\mathrm{HH}$ & 11744 & 1.10 & 1.18 & 0 & 7 \\
\hline HH size & 11740 & 4.83 & 1.86 & 1 & 16 \\
\hline $\begin{array}{l}\text { Number of extended } \\
\text { family members }\end{array}$ & 11744 & 8.78 & 3.59 & 0 & 22 \\
\hline Morris score index & 11744 & 0.38 & 0.30 & 0 & 1.34 \\
\hline Primary education & 11744 & 0.51 & 0.49 & 0 & 1 \\
\hline Secondary education & 11744 & 0.21 & 0.41 & 0 & 1 \\
\hline Vocational education & 11744 & 0.15 & 0.36 & 0 & 1 \\
\hline Higher education & 11147 & 0.09 & 0.29 & 0 & 1 \\
\hline HH work ratio & 11744 & 0.47 & 0.29 & 0 & 1 \\
\hline HHH employed & 11648 & 0.65 & 0.48 & 0 & 1 \\
\hline $\begin{array}{l}\text { Whether bank is a } \\
\text { possible source of credit } \\
\text { in this community }\end{array}$ & 11121 & 0.63 & 0.48 & 0 & 1 \\
\hline Number of friends & 11744 & 1.90 & 1.78 & 0 & 40 \\
\hline $\begin{array}{l}\text { Number of times joined } \\
\text { other people }\end{array}$ & 11744 & 1.381 & 3.00 & 0 & 31 \\
\hline $\begin{array}{l}\text { Community's migrant } \\
\text { share }\end{array}$ & 11744 & 0.10 & 0.06 & 0 & 0.51 \\
\hline $\begin{array}{l}\text { Participated in communal } \\
\text { activities }\end{array}$ & 11744 & 0.10 & 0.31 & 0 & 1 \\
\hline $\begin{array}{l}\text { Can get credit from } \\
\text { friends etc in emergency }\end{array}$ & 11744 & 0.44 & 0.50 & 0 & 1 \\
\hline $\begin{array}{l}\text { Number of groups } \\
\text { household belongs to }\end{array}$ & 11744 & 0.24 & 0.70 & 0 & 6 \\
\hline $\begin{array}{l}\text { Number of community } \\
\text { organisations in } \\
\text { community }\end{array}$ & 11154 & 5.40 & 3.43 & 0 & 13 \\
\hline $\begin{array}{l}\text { Household receives } \\
\text { public transfers }\end{array}$ & 11718 & 0.60 & 0.49 & 0 & 1 \\
\hline $\begin{array}{l}\text { Community has public } \\
\text { lighting }\end{array}$ & 11744 & 0.61 & 0.49 & 0 & 1 \\
\hline Community has phone & 11744 & 0.55 & 0.50 & 0 & 1 \\
\hline Community has mail & 11744 & 0.56 & 0.50 & 0 & 1 \\
\hline $\begin{array}{l}\text { Community has police } \\
\text { station }\end{array}$ & 11744 & 0.48 & 0.50 & 0 & 1 \\
\hline
\end{tabular}




\section{B.2 Summary statistics for Section 4.5}

Table B.3 Summary statistics for Moldova

\begin{tabular}{|c|c|c|c|c|c|}
\hline Variable & Obs & Mean & Std. Dev. & Min & Max \\
\hline Migrant remittances USD & 1843 & 450 & 1274 & 0 & 75348 \\
\hline Age of migrant & 1843 & 36.00 & 11.00 & 6 & 99 \\
\hline Male & 1843 & 0.60 & 0.49 & 0 & 1 \\
\hline Married & 1842 & 0.69 & 0.46 & 0 & 1 \\
\hline Secondary migrant & 1820 & 0.38 & 0.49 & 0 & 1 \\
\hline Vocational migrant & 1820 & 0.37 & 0.48 & 0 & 1 \\
\hline University migrant & 1820 & 0.18 & 0.39 & 0 & 1 \\
\hline CIS & 1843 & 0.63 & 0.48 & 0 & 1 \\
\hline EU & 1843 & 0.23 & 0.42 & 0 & 1 \\
\hline Household size & 1843 & 4.29 & 1.49 & 1 & 12 \\
\hline $\begin{array}{l}\text { Expenditure per cap USD } \\
\text { (Spline 1) }\end{array}$ & 1843 & 31.99 & 41.26 & 0.78 & 277.81 \\
\hline $\begin{array}{l}\text { Expenditure per cap USD } \\
\text { (Spline 2) }\end{array}$ & 1843 & 0.37 & 8.14 & 0 & 277.09 \\
\hline $\begin{array}{l}\text { Expenditure per cap USD } \\
\text { (Spline } 3 \text { ) }\end{array}$ & 1843 & 0.02 & 0.79 & 0 & 34.05 \\
\hline Other migrants in the hh & 1843 & 0.25 & 0.43 & 0 & 1 \\
\hline Urban & 1843 & 0.28 & 0.45 & 0 & 1 \\
\hline Between 1 and 5 years abroad & 1607 & 0.41 & 0.49 & 0 & 1 \\
\hline More than 5 years abroad & 1481 & 0.42 & 0.49 & 0 & 1 \\
\hline Migration cost & 1327 & 728.08 & 1331.38 & 7 & 7800 \\
\hline Repayed loan & 1022 & 0.00 & 0.03 & 0 & 1 \\
\hline Secondary hhh & 1822 & 0.36 & 0.48 & 0 & 1 \\
\hline Vocational hhh & 1822 & 0.38 & 0.48 & 0 & 1 \\
\hline University hhh & 1822 & 0.14 & 0.34 & 0 & 1 \\
\hline Distance log & 1770 & 7.06 & 0.38 & 5.88 & 8.07 \\
\hline Migrant stock at destination & 1770 & 181,884 & 127,273 & 266 & 277,53 \\
\hline Migrant entered legally & 1282 & 0.77 & 0.42 & 0 & 1 \\
\hline $\begin{array}{l}\text { Unemployment rate of country } \\
\text { of destination }\end{array}$ & 1770 & 7.59 & 0.89 & 4.60 & 11.10 \\
\hline
\end{tabular}


Table B.4 Summary statistics for Albania

\begin{tabular}{|c|c|c|c|c|c|}
\hline & Obs & Mean & Std. dev. & Min & Max \\
\hline $\begin{array}{l}\text { Migrant remittances in } \\
\text { USD }\end{array}$ & 2034 & 772.35 & 1525.60 & 0 & 24907.8 \\
\hline Age of migrant & 2034 & 31.12 & 8.34 & 16 & 69 \\
\hline Gender of migrant & 2034 & 0.65 & 0.48 & 0 & 1 \\
\hline $\begin{array}{l}\text { Marital status of the } \\
\text { migrant }\end{array}$ & 2034 & 0.66 & 0.47 & 0 & 1 \\
\hline $\begin{array}{l}\text { Migrant secondary } \\
\text { education }\end{array}$ & 2034 & 0.31 & 0.46 & 0 & 1 \\
\hline $\begin{array}{l}\text { Migrant vocational } \\
\text { education }\end{array}$ & 2034 & 0.13 & 0.34 & 0 & 1 \\
\hline Migrant higher education & 2034 & 0.08 & 0.28 & 0 & 1 \\
\hline Migrant in Italy & 2034 & 0.39 & 0.49 & 0 & 1 \\
\hline Migrant in Greece & 2034 & 0.40 & 0.49 & 0 & 1 \\
\hline Expenditure spline 1 & 2032 & 4.16 & 0.12 & 3.36 & 4.20 \\
\hline Expenditure spline 2 & 2032 & 0.50 & 0.40 & 0 & 1.39 \\
\hline Expenditure spline 3 & 2032 & 0.00 & 0.04 & 0 & 0.90 \\
\hline Morris score index & 2034 & 2.60 & 0.59 & 0.04 & 3.48 \\
\hline Age of HH head & 2034 & 61.46 & 9.83 & 22 & 96 \\
\hline HH owns house & 2034 & 0.95 & 0.21 & 0 & 1 \\
\hline Other migrants in $\mathrm{HH}$ & 2034 & 0.71 & 0.45 & 0 & 1 \\
\hline Number of elderly in $\mathrm{HH}$ & 2034 & 2.39 & 1.44 & 0 & 10 \\
\hline HH has property shock & 2034 & 0.01 & 0.08 & 0 & 1 \\
\hline HH has job shock & 2034 & 0.01 & 0.09 & 0 & 1 \\
\hline HH has illness shock & 2034 & 0.02 & 0.14 & 0 & 1 \\
\hline $\begin{array}{l}\text { Household lives in urban/ } \\
\text { rural area }\end{array}$ & 2034 & 0.53 & 0.50 & 0 & 1 \\
\hline $\begin{array}{l}\text { Community } \\
\text { infrastructure index }\end{array}$ & 1937 & 0.69 & 0.30 & 0 & 1 \\
\hline Credit possibility index & 1937 & 0.76 & 0.63 & 0 & 2 \\
\hline $\begin{array}{l}\text { Informal credit is a } \\
\text { source of borrowing in } \\
\text { this community }\end{array}$ & 1935 & 0.88 & 0.32 & 0 & 1 \\
\hline $\begin{array}{l}\text { Lack of employment } \\
\text { opportunities in } \\
\text { community }\end{array}$ & 1935 & 0.78 & 0.42 & 0 & 1 \\
\hline $\begin{array}{l}\text { Distance between A/ M } \\
\text { and capital of destination }\end{array}$ & 2034 & 6.63 & 0.71 & 3.21 & 8.91 \\
\hline $\begin{array}{l}\text { Migrant stock in } \\
\text { destination }\end{array}$ & 2034 & $233,726.2$ & $148,239.2$ & 6281 & 403,856 \\
\hline Migrant entered legally & 2034 & 0.55 & 0.50 & 0 & 1 \\
\hline $\begin{array}{l}\text { Unemployment rate of } \\
\text { country of destination }\end{array}$ & 2034 & 8.55 & 1.24 & 5.1 & 11.1 \\
\hline Migrant abroad 1-5 years & 2034 & 0.38 & 0.49 & 0 & 1 \\
\hline Migrant abroad $>5$ years & 2034 & 0.61 & 0.49 & 0 & 1 \\
\hline
\end{tabular}




\section{Appendix to \\ Chapter 5}

\section{C.1 The distribution of the propensity score by treatment group}

Figure C.1 The distribution of the propensity score by treatment group

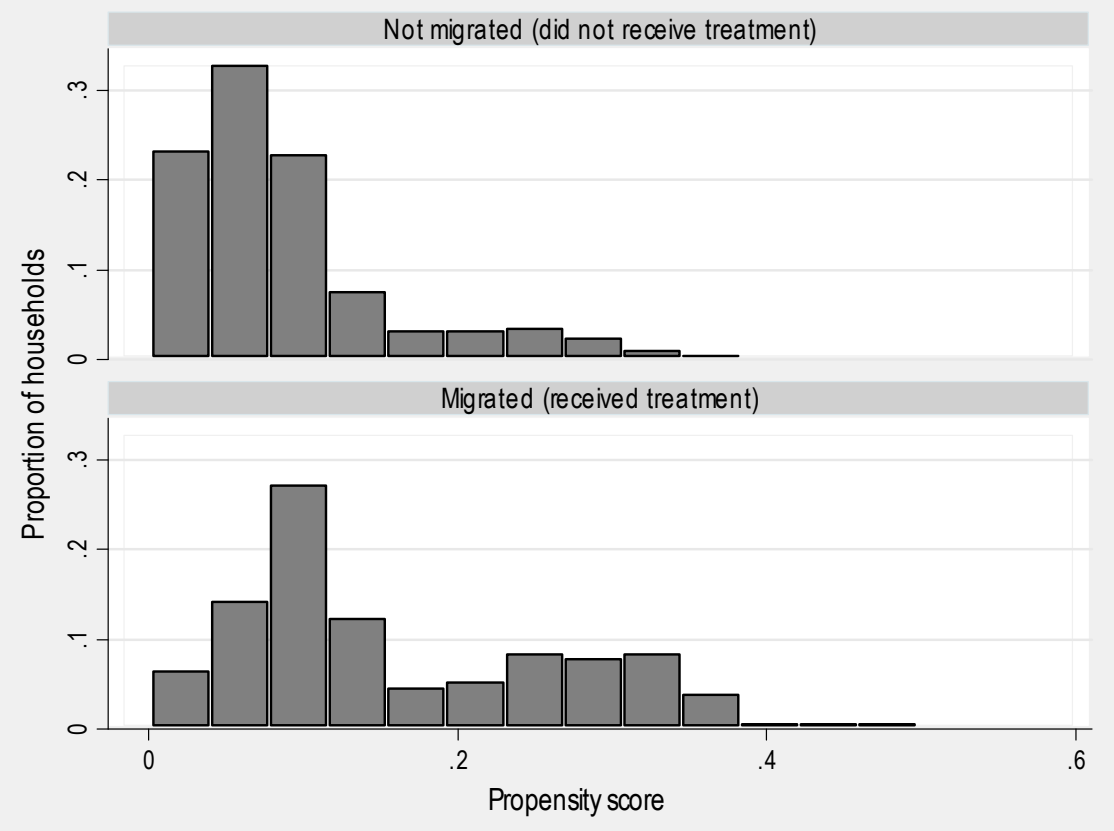

Source: Own calculations on 2005 ALSMS, including oversample 


\section{C.2 Instrumental Variable diagnostic tests}

Table C.1 Diagnostic tests for the IV regression

\begin{tabular}{|c|c|c|c|c|}
\hline Dependent variable & \multicolumn{2}{|c|}{ Per capita monthly income } & \multicolumn{2}{|c|}{$\begin{array}{l}\text { Per capita monthly } \\
\text { consumption }\end{array}$} \\
\hline $\begin{array}{l}\text { 1) Endogeneity of migration variable } \\
\text { (Anderson-Rubin test p-value) }\end{array}$ & 0.0000 & Passed & 0.000 & Passed \\
\hline $\begin{array}{l}\text { 2) Validity of instruments } \\
\text { (Hansen-J statistic p-value) }\end{array}$ & 0.7572 & Passed & 0.0099 & Failed \\
\hline $\begin{array}{l}\text { 3) Strength of instruments (F-Test in first } \\
\text { stage) }\end{array}$ & 15.936 & Passed & 16.123 & Passed \\
\hline $\begin{array}{l}\text { 4) Instruments have to be significant in } 1 \text { st } \\
\text { stage and instrumented variables have to be } \\
\text { significant in } 2 \text { nd stage }\end{array}$ & see Table 5.9 & Passed & see Table 5.9 & Passed \\
\hline
\end{tabular}

Note: Based on the linear regression.

Source: Own calculations on 2005 ALSMS, including oversample 


\section{C.3 Alternative specification}

Table C.2 Alternative specification with migration as dummy endogenous variable

\begin{tabular}{|c|c|c|c|c|c|c|}
\hline Model & \multicolumn{2}{|c|}{ OLS } & \multicolumn{2}{|c|}{ Probit } & \multicolumn{2}{|c|}{ IV } \\
\hline \multirow[t]{2}{*}{ dependent variable } & \multicolumn{2}{|c|}{ log of income } & \multicolumn{2}{|c|}{ whether head mig } & \multicolumn{2}{|c|}{ log of income } \\
\hline & coef & rob.se & coef & rob. se & coef & rob.se \\
\hline hh size & $-0.211^{* * *}$ & 0.056 & -0.084 & 0.147 & $\begin{array}{c}- \\
0.208^{* * *}\end{array}$ & 0.021 \\
\hline hh size ${ }^{2}$ & $0.020^{* * *}$ & 0.004 & -0.007 & 0.010 & $0.021^{* * *}$ & 0.001 \\
\hline hhh age & $0.028^{*}$ & 0.016 & -0.009 & 0.028 & $0.029^{* * *}$ & 0.006 \\
\hline hhh age ${ }^{2}$ & -0.000 & 0.000 & -0.000 & 0.000 & $\overline{-}^{-}$ & 0.000 \\
\hline unemployment ratio & $-0.240^{* *}$ & 0.121 & -0.328 & 0.257 & $0.243^{* * *}$ & 0.046 \\
\hline hhh education & 0.021 & 0.022 & -0.075 & 0.078 & $0.023^{* * *}$ & 0.008 \\
\hline hhh education ${ }^{2}$ & 0.001 & 0.001 & 0.003 & 0.004 & $0.001^{* *}$ & 0.000 \\
\hline hhh is working & $0.150^{* *}$ & 0.067 & $-0.759 * * *$ & 0.141 & $0.185^{* * *}$ & 0.026 \\
\hline hhh is female & -0.054 & 0.092 & 0.129 & 0.255 & $-0.057^{*}$ & 0.034 \\
\hline \# of children $<=5$ yrs & $-0.158^{* * *}$ & 0.060 & 0.156 & 0.128 & $0.164^{* * *}$ & 0.023 \\
\hline \# of children 6-10 yrs & $-0.188^{* * *}$ & 0.059 & -0.047 & 0.113 & $0.182^{* * *}$ & 0.022 \\
\hline \# of boys $11-14$ yrs & $-0.230^{* * *}$ & 0.062 & 0.009 & 0.157 & $\overline{-}^{-}$ & 0.023 \\
\hline \# of girls $11-14$ yrs & $-0.256^{* * *}$ & 0.062 & $0.445^{* *}$ & 0.224 & $0.276^{* * *}$ & 0.025 \\
\hline \# of males $15-19$ yrs & $-0.189 * * *$ & 0.058 & 0.246 & 0.152 & $\overline{-}^{-}$ & 0.023 \\
\hline \# of females 15-19 yrs & $-0.170^{* * *}$ & 0.053 & 0.239 & 0.166 & $\overline{-}^{-}$ & 0.020 \\
\hline \# of males $20-34$ yrs & $-0.106^{*}$ & 0.054 & 0.197 & 0.149 & $0.112^{* * *}$ & 0.021 \\
\hline \# of females 20-34 yrs & $-0.154^{* * *}$ & 0.049 & $0.426^{* * *}$ & 0.154 & $\overline{-}^{-}$ & 0.019 \\
\hline \# of males 35-59 yrs & -0.007 & 0.069 & 0.009 & 0.167 & -0.009 & 0.026 \\
\hline \# of females 35-59 yrs & 0.028 & 0.069 & 0.291 & 0.181 & 0.020 & 0.026 \\
\hline hh Social Capital Index & -0.022 & 0.028 & 0.000 & 0.083 & $-0.021^{* *}$ & 0.010 \\
\hline $\begin{array}{l}\text { hh has either temp or } \\
\text { perm mig }\end{array}$ & $0.104^{*}$ & 0.055 & $-0.328^{* * *}$ & 0.116 & $0.115^{* * *}$ & 0.020 \\
\hline $\begin{array}{l}\% \text { of males } 20-39 \text { by } \\
\text { municipality }\end{array}$ & $-0.034^{* *}$ & 0.016 & -0.022 & 0.032 & $\overline{-}^{-}$ & 0.006 \\
\hline $\begin{array}{l}\text { \# of property-loss } \\
\text { related shocks prior to } \\
\text { move (until now if } \\
\text { non-mover) }\end{array}$ & 0.018 & 0.028 & $-0.651^{* * *}$ & 0.136 & $0.030^{* * *}$ & 0.011 \\
\hline $\begin{array}{l}\text { Morris score index } \\
1990\end{array}$ & & & $1.381^{* * *}$ & 0.223 & & \\
\hline whether indoor toilet & & & $0.386^{* *}$ & 0.161 & & \\
\hline
\end{tabular}




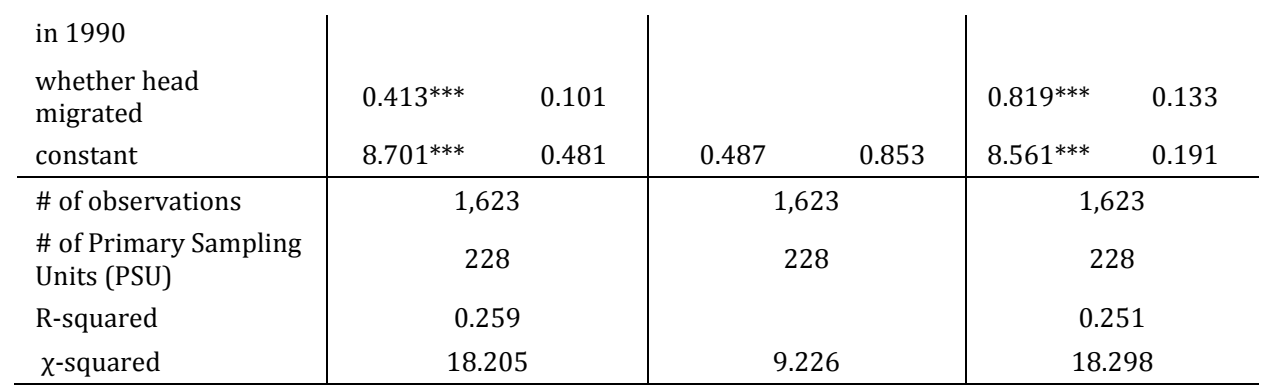

Note: stars indicate significance levels: ${ }^{*} .1$ level, ${ }^{* *} .05$ level, ${ }^{* * *} .01$ level. Estimates are corrected for intra-cluster correlation and sampling design; heteroskedasticity-robust and consistent standard errors are then reported.

Source: Own calculations on 2005 ALSMS, including oversample 


\section{Appendix to \\ Chapter 6}

\section{D.1 Incidence of receipt of transfers}

Table D.1 Incidence of receipt of transfers before and after migration

\begin{tabular}{|c|c|c|c|c|c|c|}
\hline & \multicolumn{3}{|c|}{$\begin{array}{l}\text { Before migration (last } 12 \text { months in } \\
1991 \text { or } 1997 \text { ) }\end{array}$} & \multicolumn{3}{|c|}{ Last 12 months } \\
\hline \multicolumn{7}{|c|}{ Financial transfers } \\
\hline & No & Yes & $\begin{array}{l}\% \text { yes } / \\
\text { total }\end{array}$ & No & Yes & $\begin{array}{l}\text { \% yes/ } \\
\text { total }\end{array}$ \\
\hline $\begin{array}{l}\text { Parents \& parents in } \\
\text { law }\end{array}$ & 46 & 5 & $9.80 \%$ & 70 & 15 & $17.65 \%$ \\
\hline Children & 10 & 0 & $0.00 \%$ & 30 & 4 & $11.76 \%$ \\
\hline Siblings & 130 & 33 & $20.25 \%$ & 170 & 45 & $20.93 \%$ \\
\hline Relatives & 99 & 9 & $8.33 \%$ & 110 & 14 & $11.29 \%$ \\
\hline Friends & 26 & 1 & $3.70 \%$ & 84 & 20 & $19.23 \%$ \\
\hline Total & 311 & 48 & 359 & 464 & 98 & 562 \\
\hline \multicolumn{7}{|c|}{ Good transfers } \\
\hline & No & Yes & $\begin{array}{l}\text { \% yes/ } \\
\text { total }\end{array}$ & No & Yes & $\begin{array}{l}\% \text { yes/ } \\
\text { total }\end{array}$ \\
\hline $\begin{array}{l}\text { Parents \& parents in } \\
\text { law }\end{array}$ & 37 & 15 & $28.85 \%$ & 52 & 33 & $38.82 \%$ \\
\hline Children & 7 & 3 & $30.00 \%$ & 20 & 14 & $41.18 \%$ \\
\hline Siblings & 117 & 49 & $29.52 \%$ & 150 & 61 & $28.91 \%$ \\
\hline Relatives & 92 & 17 & $15.60 \%$ & 104 & 20 & $16.13 \%$ \\
\hline Friends & 17 & 8 & $32.00 \%$ & 79 & 25 & $24.04 \%$ \\
\hline Total & 270 & 92 & 362 & 405 & 153 & 558 \\
\hline \multicolumn{7}{|c|}{ Service transfers } \\
\hline & No & Yes & $\begin{array}{c}\text { \% yes/ } \\
\text { total }\end{array}$ & No & Yes & $\begin{array}{c}\text { \% yes/ } \\
\text { total }\end{array}$ \\
\hline $\begin{array}{l}\text { Parents \& parents in } \\
\text { law }\end{array}$ & 33 & 20 & $37.74 \%$ & 54 & 30 & $35.71 \%$ \\
\hline Children & 4 & 6 & $60.00 \%$ & 21 & 13 & $38.24 \%$ \\
\hline Siblings & 98 & 66 & $40.24 \%$ & 156 & 58 & $27.10 \%$ \\
\hline Relatives & 86 & 23 & $21.10 \%$ & 109 & 15 & $12.10 \%$ \\
\hline Friends & 17 & 10 & $37.04 \%$ & 69 & 35 & $33.65 \%$ \\
\hline Total & 238 & 125 & 363 & 409 & 151 & 560 \\
\hline
\end{tabular}




\section{D.2 Codified results from the qualitative interviews}

Table D.2 Question E.6 What kinds of contact do you have?

\begin{tabular}{ll}
\hline Approximate response & $\begin{array}{l}\text { Number of } \\
\text { observations }\end{array}$ \\
\hline More frequent & 8 \\
Less frequent & 6 \\
\hline
\end{tabular}

Table D.3 Question H4.1 How did the move to Tirana change your relations with other people (including family)?

\begin{tabular}{ll}
\hline Approximate response & $\begin{array}{l}\text { Number of } \\
\text { observations }\end{array}$ \\
\hline Feel closer & 7 \\
Feel same & 13 \\
More distant & 6 \\
$\begin{array}{l}\text { Family moved as well } \\
\text { (physically closer) }\end{array}$ & 10 \\
\hline & \\
\hline Approximate response & Number of \\
observations
\end{tabular}

Table D.4 Question H4.4 Can you describe the kind of support you receive from others? How is this different to the past, before you moved?

\begin{tabular}{ll}
\hline Approximate response & $\begin{array}{l}\text { Number of } \\
\text { observations }\end{array}$ \\
\hline Receive more support & 6 \\
Receive same support & 5 \\
Receive less support & 5 \\
\hline & \\
\hline Approximate response & Number of \\
\hline More financial support & 3 \\
Same financial support & 0 \\
Less financial support & 2 \\
\hline
\end{tabular}

\begin{tabular}{ll}
\hline Approximate response & $\begin{array}{l}\text { Number of } \\
\text { observations }\end{array}$ \\
\hline More goods & 0 \\
Same goods & 1 \\
Less goods & 6 \\
\hline & \\
\hline Approximate response & Number of \\
\hline More services & 0 \\
Same services & 1 \\
Less services & 4 \\
\hline
\end{tabular}




\section{D.3 ZIP and ZINB models}

The first stage of both the ZIP and ZINB model determines whether the count is zero/non-zero, and the second stage is used to model the actual magnitude of the count. The final outcome therefore is determined by two separate probabilities as below:

$\operatorname{Pr}\left(Y_{i}=y_{i}\right)=\pi_{i} f_{1}\left(y_{i}\right)+\left(1-\pi_{i}\right) f_{2}\left(y_{i}\right), i=1,2,3, \ldots n$

where, $\pi_{\mathrm{i}}$ is the probability of a zero count in the transfer/non-transfer model $f_{1}\left(y_{i}\right)=I_{\{0\}}\left(y_{i}\right)$, and $f_{2}\left(y_{i}\right)$ is the probability density function of the Poisson distribution (as in equation 6.2). Given this, the probability of observing a certain count using a zero inflated model would be:

ZIP

$\operatorname{Pr}\left(Y_{i}=y_{i}\right)=\left\{\begin{array}{ccc}\pi_{i}+\left(1-\pi_{i}\right)\left(\exp \left(-\mu_{i}\right)\right. & \text { for } & y_{i}=0 \\ \left(1-\pi_{i}\right) \frac{\exp \left(-\mu_{i}\right)_{i}^{y_{i}}}{y_{i} !} & \text { for } & y_{i}>0\end{array}\right.$

ZINB

$\operatorname{Pr}\left(Y_{i}=y_{i}\right)=\left\{\begin{array}{cc}\pi_{i}+\left(1-\pi_{i}\right)\left(\frac{\phi}{\mu_{i}+\phi}\right)^{\phi} & \text { for } \quad y_{i}=0 \\ \left(1-\pi_{i}\right) \frac{\Gamma\left(y_{i}+\phi\right)}{\Gamma(\phi) y_{i} !}\left(\frac{\phi}{\mu_{i}+\phi}\right)^{\phi}\left(\frac{\mu}{\mu_{i}+\phi}\right)^{y_{i}} & \text { for } \quad y_{i}>0\end{array}\right.$

where, $\mu_{\mathrm{i}}$ is again the expected value of the model $\left(\log \left(\mu_{i}\right)=x_{i}^{\prime} \beta\right)$, while $\pi_{\mathrm{i}}$ is also dependent on covariates determining the overrepresentation of 'zero/nonzero' values $\left(\operatorname{logit}\left(\pi_{i}\right)=z_{i}^{\prime} \psi\right)$. Similar control variables are used both for the 'inflation' and the outcome probability models as this helps in identifying the possible roles of variables explaining the earlier 'inflation' model. 


\section{D.4 Measures of fit between different count models}

Table D.5 Sum of predicted and actual mean count of the tested models for frequencies of all transfers

\begin{tabular}{l|cccc}
\hline & $\begin{array}{c}\text { Actual mean } \\
\text { count }\end{array}$ & $\begin{array}{c}\text { Predicted mean } \\
\text { count }\end{array}$ & Difference & Pearson \\
\hline PRM & 0.788 & 0.597 & 0.852 & 8959.342 \\
NBRM & 0.788 & 0.804 & 0.109 & 41.762 \\
ZIP & 0.788 & 0.614 & 0.234 & 4409.25 \\
ZINB & 0.788 & 0.801 & 0.105 & 41.056 \\
\hline
\end{tabular}

Note: PRM stands for Poisson regression, NBRM stands for Negative Binomial regression, ZIP stands for Zero-Inflated Poisson regression and ZINB stands for Zero-Inflated Negative Binomial regression.

Figure D.1 Residuals of the tested model for frequencies of all transfers

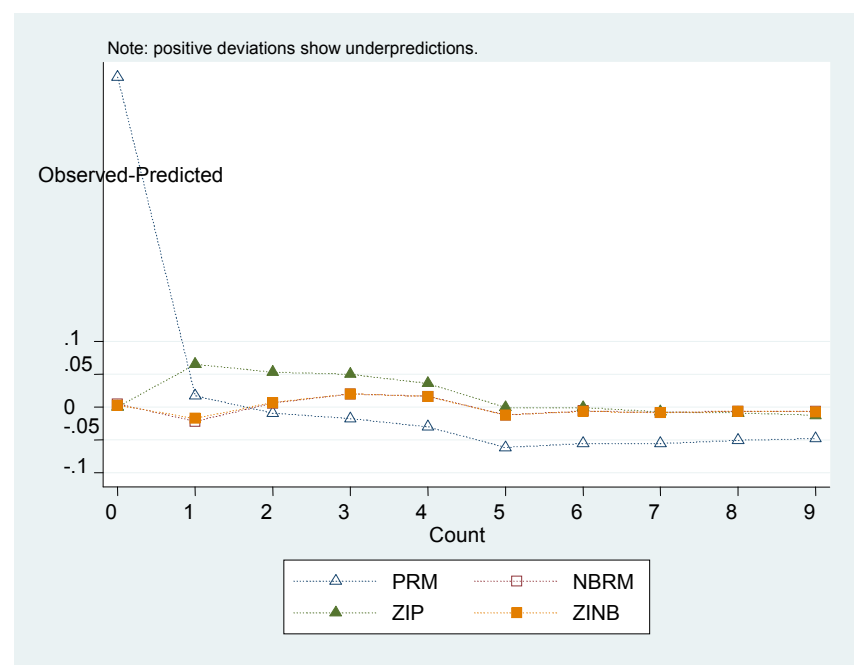

Note: PRM stands for Poisson regression, NBRM stands for Negative Binomial regression ZIP stands for Zero-Inflated Poisson regression, and ZINB stands for Zero-Inflated Negative Binomial regression. 


\section{D.5 Alternative specifications}

Table D.6 Results from NBRM including income: Frequency of receiving transfers

\begin{tabular}{|c|c|c|c|c|c|c|}
\hline & \multicolumn{2}{|c|}{ Financial transfers } & \multicolumn{2}{|c|}{ Good transfers } & \multicolumn{2}{|c|}{ Service transfers } \\
\hline & Coef. & st. error & Coef. & st. error & Coef. & st. error \\
\hline Main regression & & & & & & \\
\hline Transfer after migration & $0.97 * * *$ & 0.33 & $-1.28 * * *$ & 0.26 & $-1.04^{* * *}$ & 0.28 \\
\hline Relative parent & -0.05 & 0.62 & $1.35^{* *}$ & 0.55 & $-1.08^{*}$ & 0.6 \\
\hline Relative child & -0.39 & 0.87 & $1.80^{* * *}$ & 0.67 & 0.48 & 0.68 \\
\hline Relative sibling & 0.24 & 0.42 & $0.86^{* *}$ & 0.38 & $-0.79^{*}$ & 0.42 \\
\hline Relative other & -0.32 & 0.47 & 0.05 & 0.39 & $-1.87^{* * *}$ & 0.45 \\
\hline $\begin{array}{l}\text { Age hhh (now/ before } \\
\text { migration) }\end{array}$ & $-0.03^{* *}$ & 0.01 & $-0.03^{* *}$ & 0.01 & -0.01 & 0.01 \\
\hline Gender hh head & $1.30^{* *}$ & 0.64 & -0.97 & 0.64 & -0.35 & 0.81 \\
\hline Education years hhh & -0.04 & 0.06 & $0.07^{* *}$ & 0.03 & $0.08^{*}$ & 0.05 \\
\hline Income per capita- & -0.08 & 0.17 & $-0.32 *$ & 0.17 & -0.02 & 0.17 \\
\hline Hhh's religion Muslim & $1.04^{* *}$ & 0.52 & $0.78^{*}$ & 0.43 & 0.32 & 0.47 \\
\hline Hhh's origin Central & -0.64 & 0.54 & 0.17 & 0.44 & $1.00^{* *}$ & 0.49 \\
\hline Hhh's origin North-Central & -0.24 & 0.61 & -0.03 & 0.54 & 0.62 & 0.58 \\
\hline Hhh's origin Mountain & -0.7 & 0.57 & $-0.84^{*}$ & 0.5 & 0.36 & 0.52 \\
\hline $\begin{array}{l}\text { Hh extended family (now/ } \\
\text { before migration) }\end{array}$ & 0.31 & 0.29 & $-0.52 *$ & 0.27 & $-0.69 * *$ & 0.28 \\
\hline $\begin{array}{l}\text { Number of children hh } \\
\text { (now/ before migration) }\end{array}$ & -0.13 & 0.16 & -0.07 & 0.13 & $0.36^{* * *}$ & 0.14 \\
\hline Hh moved before 1997 & $-0.07^{*}$ & 0.04 & $0.08^{* * *}$ & 0.03 & -0.01 & 0.03 \\
\hline $\begin{array}{l}\text { Age relative/ friend (now/ } \\
\text { before migration) }\end{array}$ & 0.02 & 0.01 & 0 & 0.01 & -0.01 & 0.01 \\
\hline Gender relative/ friend & $-1.29 * * *$ & 0.3 & -0.18 & 0.26 & 0.39 & 0.27 \\
\hline $\begin{array}{l}\text { Education years relative/ } \\
\text { friend }\end{array}$ & 0.07 & 0.05 & 0.02 & 0.04 & $-0.09 * *$ & 0.04 \\
\hline $\begin{array}{l}\text { Hh \& relative/ friend same } \\
\text { religion }\end{array}$ & -0.61 & 0.6 & -0.03 & 0.54 & -0.33 & 0.65 \\
\hline $\begin{array}{l}\text { Hh \& relative/ friend live } \\
\text { in same district (now/ } \\
\text { before migration) }\end{array}$ & $1.18^{* * *}$ & 0.33 & 0.2 & 0.29 & $1.15^{* * *}$ & 0.29 \\
\hline Constant & -1.35 & 2.47 & 3.75 & 2.33 & 3.16 & 2.29 \\
\hline Ln alpha & $2.16^{* * *}$ & 0.13 & $2.12^{* * *}$ & 0.09 & $2.30^{* * *}$ & 0.08 \\
\hline Number of observations & 843 & & 843 & & 838 & \\
\hline Log pseudo likelihood & -602 & & --1073 & & -1539 & \\
\hline P- value Chi2 & 0.00 & & 0.00 & & 0.00 & \\
\hline Pseudo $\mathrm{R}^{2}$ & 0.0624 & & 0.0356 & & 0.0208 & \\
\hline
\end{tabular}

Note: Frequency of transfers refers to the number of times the transfer has been received in the past 12 months/ before migration

"Transfer after migration" is a dummy variable that is one for the observations for the period after migration

Income is current income per capita, logged. 
"Transfer after migration" is a dummy variable that is one for the observations for the period after migration

Base for relatives (friends), religion (catholic, orthodox and atheist), household origin (Coast)

${ }^{*}$ significant at $10 \%$; ${ }^{* *}$ significant at $5 \%$; ${ }^{* *}$ significant at $1 \%$ 
Table D.7 Results from NBRM and ZINB: Frequency of receiving all combined transfers

\begin{tabular}{|c|c|c|c|c|}
\hline & \multicolumn{2}{|c|}{ NBRM } & \multicolumn{2}{|c|}{ ZINB } \\
\hline & Coef. & st. error & Coef. & st. error \\
\hline \multicolumn{5}{|l|}{ Main regression } \\
\hline Transfer after migration & $-0.71^{* * *}$ & 0.2 & $-1.00^{* * *}$ & 0.21 \\
\hline Relative parent & -0.22 & 0.42 & 0 & 0.41 \\
\hline Relative child & 0.7 & 0.48 & $0.96^{* *}$ & 0.46 \\
\hline Relative sibling & -0.36 & 0.3 & -0.39 & 0.28 \\
\hline Relative other & $-1.23^{* * *}$ & 0.31 & $-0.89 * * *$ & 0.34 \\
\hline Age hhh (now/ before migration) & -0.01 & 0.01 & $-0.02^{*}$ & 0.01 \\
\hline Education years hhh & 0.18 & 0.51 & 0.44 & 0.5 \\
\hline Hh income/ per capita, in logs & $0.09^{* * *}$ & 0.03 & $0.09^{* * *}$ & 0.03 \\
\hline Hhh's religion Muslim & 0.53 & 0.33 & 0.47 & 0.31 \\
\hline Hhh's origin Central & $0.68^{*}$ & 0.35 & $0.91^{* * *}$ & 0.33 \\
\hline Hhh's origin North-Central & 0.43 & 0.41 & 0.59 & 0.39 \\
\hline Hhh's origin Mountain & 0.02 & 0.36 & 0.2 & 0.35 \\
\hline $\begin{array}{l}\text { Hh extended family (now/ before } \\
\text { migration) }\end{array}$ & $-0.46^{* *}$ & 0.2 & -0.18 & 0.2 \\
\hline $\begin{array}{l}\text { Number of children hh (now/ before } \\
\text { migration) }\end{array}$ & $0.21^{* *}$ & 0.1 & $0.26^{* * *}$ & 0.1 \\
\hline Hh moved before 1997 & 0 & 0.02 & -0.06 & 0.19 \\
\hline $\begin{array}{l}\text { Age relative/ friend (now/ before } \\
\text { migration) }\end{array}$ & -0.01 & 0.01 & $-0.02^{* *}$ & 0.01 \\
\hline Gender relative/ friend & 0.06 & 0.19 & -0.05 & 0.19 \\
\hline Education years relative/ friend & $-0.06^{* *}$ & 0.03 & $-0.05^{*}$ & 0.03 \\
\hline Hh \& relative/ friend same religion & -0.25 & 0.45 & -0.18 & 0.42 \\
\hline $\begin{array}{l}\text { Hh \& relative/ friend live in same } \\
\text { district (now/ before migration) }\end{array}$ & $0.88^{* * *}$ & 0.21 & $0.49^{* *}$ & 0.23 \\
\hline Constant & $2.21^{* *}$ & 1.03 & $2.53^{* *}$ & 1 \\
\hline \multicolumn{5}{|l|}{ inflate } \\
\hline Transfer after migration & & & -4.10 & 1.61 \\
\hline Relative parent & & & 1.44 & 2.01 \\
\hline Relative child & & & 0.43 & 2.60 \\
\hline Relative sibling & & & -0.95 & 1.43 \\
\hline Relative other & & & 2.67 & 1.79 \\
\hline Age hhh (now/ before migration) & & & 0.01 & 0.030 \\
\hline Education years hhh & & & -0.06 & 0.09 \\
\hline $\begin{array}{l}\text { Hh extended family (now/ before } \\
\text { migration) }\end{array}$ & & & 2.45 & 0.76 \\
\hline $\begin{array}{l}\text { Number of children hh (now/ before } \\
\text { migration) }\end{array}$ & & & 0.33 & 0.32 \\
\hline Hh moved before 1997 & & & 0.07 & 0.66 \\
\hline $\begin{array}{l}\text { Age relative/ friend (now/ before } \\
\text { migration) }\end{array}$ & & & -0.06 & 0.028 \\
\hline Gender relative/ friend & & & -0.61 & 0.68 \\
\hline Education years relative/ friend & & & 0.06 & 0.14 \\
\hline
\end{tabular}




\begin{tabular}{l|c|cc} 
Hh \& relative/ friend same religion & & 0.51 & 1.03 \\
$\begin{array}{l}\text { Hh \& relative/ friend live in same } \\
\text { district (now/ before migration) }\end{array}$ & & -3.95 & 1.29 \\
Constant & & 1.09 & 2.54 \\
\hline Number of observations & 860 & 860 & \\
Number of zero observations & & $455(53 \%)$ & \\
Log pseudo likelihood & -2074 & -2039 & \\
LR Chi2 & 86.79 & 86.06 & \\
P-value Chi2 & 0.00 & 0.00 & \\
McFadden's R & 0.020 & 0.037 & \\
\hline
\end{tabular}

Note: Frequency of transfers refers to the number of times the transfer has been received in the past 12 months/ before migration

Base for relatives (friends), religion (catholic, orthodox and atheist), household origin (coast) significant at $10 \%$; ${ }^{* *}$ significant at $5 \%$; ${ }^{* * *}$ significant at $1 \%$ 
Table D.8 Results from NBRM: Frequency of receiving before or after migration

\begin{tabular}{|c|c|c|c|c|c|c|}
\hline & \multicolumn{3}{|c|}{ Financial transfers } & \multicolumn{3}{|c|}{ Good transfers } \\
\hline & $\begin{array}{c}\text { Before } \\
\text { migration }\end{array}$ & $\begin{array}{c}\text { After } \\
\text { migration }\end{array}$ & $\begin{array}{c}\text { Difference } \\
\text { of coeff. }\end{array}$ & $\begin{array}{c}\text { Before } \\
\text { migration }\end{array}$ & $\begin{array}{c}\text { After } \\
\text { migration }\end{array}$ & $\begin{array}{c}\text { Difference } \\
\text { of coeff. }\end{array}$ \\
\hline \multicolumn{7}{|l|}{ NBRM regression } \\
\hline Relative Parent & 2.67 & 1.41 & -1.26 & 2.02 & 0.94 & -1.08 \\
\hline Relative Child & -15.15 & -0.6 & $14.55^{* * *}$ & 0.16 & 2.75 & $2.59 * *$ \\
\hline Relative Sibling & 3.29 & 0.52 & $-2.77^{* * *}$ & 1.15 & 0.25 & -0.9 \\
\hline Relative Other & 2.32 & -1.11 & $-3.43^{* * *}$ & -0.45 & -0.2 & 0.25 \\
\hline Constant & -1.03 & -8.41 & $-7.38^{* *}$ & -1.44 & 0.34 & 1.78 \\
\hline Ln alpha & $1.73^{* * *}$ & $1.92^{* * *}$ & & $2.28^{* * *}$ & $1.72^{* * *}$ & \\
\hline $\begin{array}{l}\text { Number of } \\
\text { observations }\end{array}$ & 340 & 542 & & 345 & 535 & \\
\hline Log-likelihood & --167 & -416 & & -484 & -610 & \\
\hline P-value Chi2 & 0.000 & 0.000 & & 0.000 & 0.000 & \\
\hline \multirow[t]{3}{*}{ Pseudo $\mathrm{R}^{2}$} & 0.1490 & 0.0863 & & 0.0352 & 0.0726 & \\
\hline & \multicolumn{3}{|c|}{ Service transfers } & \multicolumn{3}{|c|}{ All transfers combined } \\
\hline & $\begin{array}{c}\text { Before } \\
\text { migration }\end{array}$ & $\begin{array}{c}\text { After } \\
\text { migration }\end{array}$ & $\begin{array}{l}\text { Difference } \\
\text { of coeff. }\end{array}$ & $\begin{array}{c}\text { Before } \\
\text { migration }\end{array}$ & $\begin{array}{c}\text { After } \\
\text { migration }\end{array}$ & $\begin{array}{l}\text { Difference } \\
\text { of coeff. }\end{array}$ \\
\hline \multicolumn{7}{|l|}{ NBRM regression } \\
\hline Relative Parent & 1.02 & -1.23 & $-2.25^{* *}$ & 1.26 & -0.17 & -1.43 \\
\hline Relative Child & 1.25 & 1.13 & -0.12 & 1.24 & 1.23 & -0.01 \\
\hline Relative Sibling & 0.96 & -0.94 & $-1.9 * * *$ & 1.06 & -0.51 & $-1.57^{* * *}$ \\
\hline Relative Other & -0.56 & -2.13 & $-1.57 * *$ & -0.41 & -1.44 & -1.03 \\
\hline Constant & 3.37 & 1.3 & -2.07 & 2.91 & 0.92 & -1.99 \\
\hline Ln alpha & $2.21^{* * *}$ & $2.36^{* * *}$ & & $1.86^{* * *}$ & $1.52^{* * *}$ & \\
\hline $\begin{array}{l}\text { Number of } \\
\text { observations }\end{array}$ & 346 & 531 & & 356 & 524 & \\
\hline Log-likelihood & -731 & -820 & & -860 & -1188 & \\
\hline $\mathrm{P}$-value $\mathrm{Chi}^{2}$ & 0.000 & 0.000 & & 0.000 & 0.000 & \\
\hline Pseudo $\mathrm{R}^{2}$ & 0.0184 & 0.0316 & & 0.0208 & 0.0351 & \\
\hline
\end{tabular}

Note: Frequency of transfers refers to the number of times the transfer has been received in the past 12 months/ before migration.

All other control variables included are the same as in Table 6.4 ("Transfer after migration" does not apply here).

Difference coefficient is calculated as coefficient after migration - coefficient before migration.

${ }^{*}$ significant at $10 \%$; ${ }^{* *}$ significant at $5 \%$; ${ }^{* *}$ significant at $1 \%$ 


\section{Summary}

This dissertation has the objective to investigate the causes and effects of migration on migrant households in source countries. It discusses some of the reasons of why people migrate and send remittances. This thesis also analyses the consequences of migration on the wellbeing of migrant households and the relationship between family members.

This dissertation starts with the important question on why people migrate. The simple answer to this question is: People want to be better off. If migration makes people better off, why do not more people migrate? Current news coverage of migration issues is not proportional to current migration flows. Only 3\% of today's world population has migrated internationally (Koser, 2007). So in order to understand the current migration trends, the reasons why people do or indeed do not migrate need to be analysed thoroughly.

To answer the question on why people migrate I first reviewed the theoretical migration literature and the theories are linked in the Welfare Pentagon framework. This is followed by an econometric analysis of some aspects of these theories. So why do people migrate? They migrate because their assets, investments and opportunities in the source country are limited. They migrate because they are not able to support their families or use their skills efficiently. They migrate because they do not have access to public transfers. They migrate because they see others in their social network migrate and they realise that migration is another option to make a living.

This thesis argues that it is more valuable to consider migration theories in conjunction. Moreover, not all migration theories are applicable in all country contexts. This dissertation investigates two countries, Albania and Moldova, that seem similar on the surface: They are in transition from a central to market economy, very poor and European countries bordering the European Union. Nevertheless the motivations behind migration in these two countries and amongst different groups of migrants seem to diverge. Therefore it is impossible and undesirable to give a general answer to why people migrate and it is of utmost importance to consider the specific migration motives in different countries or amongst distinct groups of migrants.

For many politicians in poor source countries, remittances are seen as a major solution to domestic problems. Such large sums of money arouse interest not only of politicians but also researchers. The crucial question by all is: Who sends remittances under what circumstances? This is a particularly difficult question to answer and to draw general conclusions on, as the decision to remit is private and the personal considerations made in such a decision-making process are hard to measure. Consequently, the literature on the motivations to remit is still extremely dynamic. This thesis contributes to the discussion; it also analyses why and under what circumstances remittances are sent. 
The motivations of migrants to send remittances are explored by reviewing the literature and by looking at the specific cases of Albania and Moldova. While there is some "evidence" for some motivations, the aim to repay loans, self-insurance in Moldova and altruism in both countries, the analysis resulted in inconclusive results, very much in line with the literature. It is not possible to give a satisfying answer to this question on a general level, as the migration context, e.g. type of migration flows, the causes of migration, the family setting and specific norms and values, influences whether and how much remittances are sent (see also Carling, 2008).

Testing the motivations to remit remains an intricate area of research with much room for improvement. In this dissertation it is shown that the current methodology employed in the economic literature of testing several theories using multi-purpose household surveys does not lead to strong and meaningful results. Further research should focus on finding more innovative ways of measuring motives, but most importantly move towards measuring specific determinants and combining quantitative research with qualitative data to get a better impression of the motives of remitters.

After having reviewed why people migrate and more specifically why they send remittances back home, the question of why not more people migrate comes back up again. People migrate and send remittances to improve living standards for themselves and their families. It also appears that large shares of the global population would benefit from migration, but that they do not migrate. One might infer that the costs of migration are too high for many of the world's poor, but another reason could be that the impact of migration is not as positive as one would expect. Therefore the second part of this dissertation concentrates on the impact of migration.

The literature on the impact of international migration is still growing and the conclusions on whether migration is indeed a good strategy for migrants and their families are not clear-cut yet. Nevertheless, this thesis focuses on a bigger gap in the literature and investigates the impact of internal migration more closely. Internal migration is the movement of people from one region to another in the same country and is predominantly rural-urban, but not exclusively so. Internal migration is understudied despite the fact that the global number of internal migrants, 740 million people, is considerably higher than the number of international migrants, 200 million people (Bell \& Muhidin, 2009). This thesis concentrates on the impact of internal migration, looking at the specific case of internal migration to peri-urban areas in Albania's capital Tirana, as Albania experienced significant internal migration, besides the enormous international migration flows it is known for.

The question on the economic impact of internal migration on migrant households is rather unique in the literature. This question is answered in a detailed econometric study on internal migration to Tirana. While income increases, living conditions do not improve and the impact of internal migration is not as positive as one would expect. Unemployment is high and housing conditions are poor for internal migrant households.

An important question arises from the analysis: Why does internal migration continue, even though its impact on poverty is unclear? Migration may be a long- 
term investment. Households expect to have more opportunities in Tirana in the long-term in the shape of diversified employment opportunities, earning money to migrate internationally and having the opportunity to educate their children. My fieldwork in Tirana reveals that migrants expect improved conditions in the medium-term. Better long-term prospects are confirmed by the fact that longerterm residents and earlier migrants enjoy higher income and consumption than recent movers.

Since state support is low in Albania and poverty amongst internal migrants is high, family transfers could potentially play a vital role for these households. This dissertation consequently looks at how internal migration has affected family solidarity. It is based on a survey amongst internal migrant households in periurban Tirana. It investigates how migration and greater distance have affected the reliance on family and non-family members of kinship for support and on the patterns of transfers; a unique study in the literature. It is shown that migration has affected the mix between the transfers that households receive, towards more frequent financial transfers, but has also changed the composition of the family network to some extent with friends gaining importance compared to blood relatives.

In conclusion, this dissertation analyses the causes and effects of migration for a diverse range of migrant households, for example households receiving remittances from a migrant abroad or households that migrated together, with an exclusive focus on households living in source countries. Two broad conclusions can be drawn from all chapters. 1) Families influence the behaviour of migrants and continue being important. 2) Migration is a long-term investment that does not necessarily pay off right away.

Coming to the first conclusion, a (potential) migrant's family situation and needs influence the decision to migrate, and for those that did migrate, the decision to remit. Once people have migrated, families remain consequential and social networks remain strong. Families are so important that families or even entire clans may migrate together. The strength of family ties is highly beneficial in poor countries like Albania. Migrants (and also non-migrants of course) often live in poor circumstances, have high poverty rates and receive minimal support from a weak public sector. Financial and in-kind support from kin members that takes place instead is a kind of private social protection strategy.

The second broad conclusion is that migration is an investment for the future. It seems that migrants have modest expectations concerning the short-term. It takes time and money for households to finish building a house and to be solidly integrated into the labour market. Many migrant households that were interviewed even indicated that they migrated for the benefit of the next generation, their children. They want their children to have a good education and thus better future. Once again, it is valuable that family support is strong, because it helps households through the difficult investment period.

A policy maker in a developing country would be interested in the relationship between development and migration and vice versa. Development's impact on migration was discussed in this dissertation, whereas the effect of migration on development was not considered extensively. Briefly coming to internal migration's impact on development on a household level, migration has a positive 
impact on income in the short term and possibly positive and broader impact in the medium term. Individual improvement is beneficial to development. Continuous family transfers facilitate and make migration as an investment possible. Therefore inter-family transfers (i.e. internal and international remittances) should be facilitated. Strong family relationships should thus be encouraged (e.g. by allowing kin of already settled migrant families to join them). The more negative effects of migration were discussed in great detail, but it is not clear whether these would hinder development. In any case, improving the living conditions of internal migrants would be to the benefit of the wider population.

Furthermore I advocate the improvement of institutions in source areas of migrants. These general policies targeted at the whole population are to the benefit of non-migrants, migrants and potential migrants. This thesis has explained how failing labour and credit markets and public institutions entails individuals not being able to support their family or use their skills adequately. It was also shown that migrants respond to these policy gaps and failures through migration and family transfers. I certainly do not want to make a judgement on whether migration can or should be stopped, but the potential role for policy interventions in improving local and national institutions and thus creating more opportunities for varied livelihoods at home is great. Many potential policies come to mind, none easy to implement, like more employment possibilities, access to credit and social transfers. Such policy interventions do not exclude migration as a household strategy. However, the more options households can draw on, the better positioned they are to fight poverty.

The final policy recommendation, targeted particularly at migrant households, is based on improving living conditions of internal migrants. It was shown how the impact of internal migration can be rather negative. Inequality and mutual distrust is high between old residents and newly settled migrants and therefore not just migrants would benefit from improved circumstances for migrants. The policy recommendations here are evident: Create more local infrastructure (roads, more schools, access to health) and improve employment conditions (e.g. by clarifying legal status of migrants). Having better access to health, education, employment and living in better living conditions can make migration a better investment and at an earlier stage. 


\section{Samenvatting}

Dit proefschrift heeft als doelstelling de oorzaken en gevolgen van migratie op migrantenhuishoudens in het land van herkomst te onderzoeken. Het bespreekt verschillende redenen waarom mensen migreren en remittances versturen (geld overmaken naar het land van herkomst). Dit proefschrift geeft ook een analyse van de gevolgen van migratie op het welzijn van migrantenhuishouden en persoonlijke verhoudingen tussen familieleden.

Dit proefschrift opent met de belangrijke vraag waarom mensen migreren. Het eenvoudige antwoord lijkt: Om vooruit te komen. Maar, als migratie mensen vooruit zou helpen, waarom migreren er dan niet meer? De huidige aandacht van de nieuwsmedia voor migratiekwesties staat niet in verhouding tot de werkelijke migratiestromen. Slechts $3 \%$ van de wereldbevolking is internationaal gemigreerd (Koser, 2007). Om huidige migratietrends werkelijk te begrijpen, moeten we dieper onderzoeken waarom mensen migreren of juist niet.

Voor de vraag waarom mensen verhuizen heb ik eerst een literatuuronderzoek gedaan naar bestaande theorieën en deze volgens de welzijnsvijfhoek (Welfare Pentagon framework) met elkaar in verband gebracht. Daarna volgt een econometrisch onderzoek naar verschillende aspecten van de theorieën. Dus, waarom migreren mensen? Ze migreren omdat hun bezittingen, investeringen en mogelijkheden in het land van herkomst beperkt zijn. Ze migreren omdat ze niet in staat zijn hun familie te onderhouden of hun kennis en vaardigheden efficiënt te benutten. Ze migreren omdat anderen in hun sociale netwerk migreren en laten zien dat migratie een manier is meer te bereiken.

Dit proefschrift onderstreept dat theorieën over migratie het best in onderlinge samenhang worden beschouwd. Bovendien zijn niet alle theorieën van toepassing op de context van verschillende landen. Dit proefschrift onderzoekt twee landen, Albanië en Moldavië, die op het eerste gezicht veel op elkaar lijken: Ze maken beiden de overgang van een centraal geleide- naar een markteconomie, zijn zeer arme landen en zijn Europese landen die grenzen aan de Europese Unie. Niettemin, blijkt dat de motivaties die ten grondslag liggen aan migratie uiteenlopen tussen deze landen en hun specifieke groepen van migranten. Het is daardoor niet mogelijk of wenselijk een eenduidige motivatie voor migratie aan te wijzen en het is noodzakelijk de specifieke redenen voor migratie in verschillende landen en onder verschillende groepen te onderkennen.

Veel politici in arme landen zien remittances als een oplossing voor binnenlandse problemen. Zulke grote bedragen trekken niet alleen de aandacht van politici, maar ook van onderzoekers. Ze willen allemaal hetzelfde weten: Wie stuurt remittances en onder welke omstandigheden? Dit is zeer lastige vraag, aangezien de beslissing om remittances te sturen een persoonlijke is en de beweegredenen zijn moeilijk te meten. Daardoor is de literatuur over de motivering voor het versturen van remittances volop in ontwikkeling. Dit proefschrift draagt bij aan de discussie en geeft ook analyses waarom en onder welke omstandigheden remittances worden verstuurd. 
De beweegredenen voor het verzenden van remittances worden verkend door een literatuuronderzoek en door Albanië en Moldavië nader te beschouwen. Alhoewel we statistisch bewijs vinden voor specifieke beweegredenen: het aflossen van leningen, zelfverzekering in Moldavië en altruïsme in beide landen, leidt de analyse niet tot één eenduidige conclusie, zoals ook volgens de literatuur te verwachten is. Het blijkt niet mogelijk de vraag bevredigend en generaliserend te beantwoorden, aangezien de context van de migratie, zoals het type van migratie, de oorzaak van migratie, de familiesituatie en specifieke normen en waarden, bepaalt hoeveel remittances worden verstuurd (zie ook Carling, 2008)

Het statistisch toetsen van beweegredenen voor remitteren blijft een moeizaam onderzoeksonderwerp met veel ruimte voor verbetering. Dit proefschrift laat zien dat de gangbare methodologie in de economische literatuur, namelijk het testen van verschillende theorieën op basis van breed opgezette enquêtes voor huishoudens, niet leidt tot sprekende resultaten. Verder onderzoek zou zich kunnen richten op vernieuwende manieren om beweegredenen te meten, maar nog belangrijker zou een verschuiving zijn richting het meten van specifieke bepalende factoren en het combineren van kwantitatief onderzoek en kwalitatieve data om een betere indruk van de beweegredenen van remitters te krijgen.

$\mathrm{Na}$ onderzocht te hebben waarom mensen migreren en waarom ze remittances versturen, blijft de hardnekkige vraag waarom niet meer mensen migreren. Mensen migreren en versturen remittances om hun levensomstandigheden en die van hun familie te verbeteren. Het lijkt ook dat een groot deel van de wereldbevolking baat kan hebben bij migratie, maar het toch niet doet. Een mogelijke conclusie is dat de kosten voor migratie te hoog zijn voor de armen op de wereld, maar het zou ook kunnen dat de gevolgen van migratie niet zo positief zijn als verwacht. Daarom gaat het tweede deel van dit proefschrift over de gevolgen van migratie.

De wetenschappelijke literatuur naar de gevolgen van internationale migratie blijft groeien en er is nog geen eenduidige conclusies of migratie een goede strategie is voor migranten en hun families. Toch richt dit proefschrift zich op een grotere lacune in de literatuur, namelijk de impact van interne migratie. Interne migratie is de verhuizing binnen een land van één regio naar een andere en is hoofdzakelijk van landelijk naar stedelijk gebied. Interne migratie is weinig bestudeerd ondanks dat het aantal interne migranten wereldwijd met 740 miljoen mensen aanzienlijk hoger is dan het aantal van 200 miljoen internationale migranten (Bell \& Muhidin, 2009). Dit proefschrift richt zich op interne migratie en gaat specifiek in op de casus van interne migratie naar peri-urbane wijken in Tirana, in de hoofdstad van Albanië, aangezien in Albanië sterke interne migratie heeft plaatsgevonden, naast de enorme internationale migratie waar het om bekend staat.

De vraag naar de economische impact van interne migratie is tamelijk uniek in de literatuur. De vraag wordt beantwoord aan de hand van een gedetailleerde econometrische studie naar interne migratie naar Tirana. Hoewel het inkomen toeneemt na migratie blijkt het totaalplaatje minder positief. Werkloosheid onder migrantenhuishoudens is hoog en hun woonomstandigheden zijn slecht. 
De analyse roept een verdere vraag op: Waarom blijft men intern migreren zolang de mogelijke impact op armoede onduidelijk is. Mogelijk vormt migratie een langetermijn investering. Huishoudens verwachten meer mogelijkheden in Tirana op lange termijn, door: meer diversiteit in de arbeidsmarkt, geld te verdienen voor internationale migratie, en opleidingsmogelijkheden voor hun kinderen. Mijn veldwerk in Tirana laat zien dat migranten verbeteringen verwachten op de middellange termijn. Betere verwachtingen op de lange termijn worden bevestigd door het gegeven dat de langwonende en vroege migranten een hoger inkomen hebben en meer consumeren dan nieuwkomers.

Aangezien sociale voorzieningen in Albanië zeer beperkt zijn en interne migranten vaak arm zijn, kunnen financiële transfers binnen families van vitaal belang zijn voor migrerende huishoudens. Hoofdstuk 6 onderzoekt hoe interne migratie familiesolidariteit beïnvloedt. Het is gebaseerd op een enquête onder huishoudens van interne migranten en onderzoekt hoe migratie en de grotere afstand de afhankelijkheid van familie en ander verwanten verandert evenals de patronen die de transfers volgen. Het blijkt dat na migratie de mix van transfers verandert en voor een groter deel uit regelmatig terugkerende financiële transfers bestaat. Ook blijkt dat het netwerk van verwantschap verandert en dat de rol van vrienden belangrijker wordt ten opzichte van die van bloedverwanten.

Concluderend, dit proefschrift analyseert de oorzaken en effecten van migratie voor een verscheidenheid van migrantenhuishoudens, bijvoorbeeld huishoudens die remittances ontvangen van een gemigreerd lid of huishoudens die als geheel gemigreerd zijn, met een exclusieve focus op huishoudens in het land van herkomst. Twee algemene conclusies zijn te trekken: 1) Families beïnvloeden het gedrag van migranten en blijven ook na migratie belangrijk. 2) Migratie is een lange-termijn investering die zich niet noodzakelijkerwijs direct terugverdient.

Met betrekking tot de eerste conclusie zien we dat de familiesituatie en behoeften de beslissing tot al dan niet migreren beïnvloeden en voor migranten ook de beslissing om remittances te sturen. Ook na migratie blijven families van belang en blijven sociale netwerken sterk. Familie is zo belangrijk dat niet zelden hele families en zelfs hele clans gemeenschappelijk migreren. De kracht van familiebanden is tot voordeel van arme landen als Albanië. Migranten (net als nonmigranten) leven vaak in armoedige omstandigheden, zijn zelf arm en krijgen minimale ondersteuning van de zwakke publieke sector. Ondersteuning door verwanten, financieel of in goederen vervangt de publieke sector en is een vorm van private sociale verzekeringsstrategie.

De tweede brede conclusie is dat migratie een investering voor de toekomst is. We zien dat migranten bescheiden verwachtingen voor de korte termijn hebben. Het kost tijd en geld voor huishoudens om een huis te bouwen en om stevig verankerd te raken in de arbeidsmarkt. Veel van de gemigreerde huishoudens lieten blijken dat ze migreerden met het oog op de volgende generatie, hun kinderen. Ze willen hun kinderen goede scholing bieden en daarmee een betere toekomst. Weer blijkt de waarde van familieondersteuning om door een moeilijke investeringsperiode te raken.

Beleidsmakers in ontwikkelingslanden zullen geïnteresseerd zijn in de relatie tussen ontwikkeling en migratie en vice versa. De invloed van ontwikkeling op migratie is besproken zonder uitgebreid aandacht te besteden aan de wederkerige 
relatie. Persoonlijke ontwikkeling is goed voor de nationale ontwikkeling. Voortdurende familie transfers faciliteren migratie en maken migratie een investeringsmogelijkheid en inter-familiaire overmakingen (in andere woorden interne en internationale remittances) dienen ondersteund te worden. Sterke familiebanden dienen aangemoedigd te worden (bijvoorbeeld door het recht op gezinshereniging voor migranten). De schaduwkanten van migratie zijn in detail besproken, maar het is niet duidelijk of deze economische ontwikkeling in de weg staan. In ieder geval is het tot algemeen nut om de leefomstandigheden van interne migranten te verbeteren.

Verder pleit ik voor institutionele verbetering in de herkomstgebieden van migranten. Deze algemene maatregelen, gericht op de gehele bevolking zijn tot nut van migranten, niet-migranten en potentiële migranten Dit proefschrift licht toe hoe het falen van arbeids- en kredietmarkten en publieke instituten er toe leidt dat individuen niet in staat zijn hun families te onderhouden en hun kennis en vaardigheden volop te benutten. Het laat ook zien dat families op deze beleidslacunes reageren door te migreren en door transfers te maken.

De laatste beleidsaanbeveling is gebaseerd op het verbeteren van leefomstandigheden van interne migranten. Het is aangetoond dat de gevolgen van migratie tamelijk negatief kunnen zijn. Ongelijkheid en wederzijds wantrouwen zijn hevig tussen nieuwkomers en langzittende bewoners en daardoor zullen niet alleen migranten profiteren van verbeterde omstandigheden voor migranten. De aanbevelingen zijn helder: Creëer betere locale infrastructuur (wegen, scholen, gezondheidszorg). zorg voor betere werkomstandigheden (bijvoorbeeld door de juridische status van migranten helder te maken). Betere toegang tot zorg, scholing en werk en betere leefomstandigheden maken migratie al in een vroeger stadium een renderende investering. 


\section{Biography}

Jessica Hagen-Zanker, born in 1981 in Tübingen, Germany, grew up in Germany, the UK and Australia. Prior to her study in International Economics at Maastricht University started in September 2000, she completed a marketing internship at DaimlerChrysler in Germany.

Jessica specialised in "Global Development and Technology" and wrote her master thesis on the theoretical relations between population and economic growth. During her studies she did a research internship at the Social Security department of the International Labour Organisation in Geneva and also worked as a student assistant for the Social Protection master programme at the Maastricht Graduate School of Governance (MGSoG). Upon graduation in August 2004 Jessica continued working for this master programme, as a researcher and coordinator.

In addition to her other work, Jessica started her $\mathrm{PhD}$ in the European Social Protection Programme at the MGSoG in September 2005. Her PhD research has focused on migration and remittances. She wrote and co-authored a number of papers that were also presented at numerous workshops and international conferences. While most of the chapters of her dissertation are based on existing data, Jessica also did fieldwork in peri-urban Tirana, Albania, in April 2008.

Jessica now lives in Cambridge, UK. She has started working at the Overseas Development Institute in London in the Social Protection team in January 2010. 